\title{
Response of TLD-Albedo and Nuclear Track Dosimeters Exposed to Plutonium Sources
}

\author{
L. W. Brackenbush \\ W. V. Baumgartner \\ J. J. Fix
}

December 1991

Prepared for the U.S. Department of Energy under Contract DE-AC06-76RLO 1830

Pacific Northwest Laboratory

Operated for the U.S. Department of Energy

by Battelle Memorial Institute 


\title{
DISCLAIMER
}

This report was prepared as an account of work sponsored by an agency of the United States Government. Neither the United States Government nor any agency thereof, nor Battelle Memorial Institute, nor any of their employees, makes any warranty, expressed or implied, or assumes any legal liability or responsibility for the accuracy, completeness, or usefulness of any information, apparatus, product, or process disclosed, or represents that its use would not infringe privately owned rights. Reference herein to any specific commercial product, process, or service by trade name, trademark, manufacturer, or otherwise does not necessarily constitute or imply its endorsement, recommendation, or favoring by the United States Government or any agency thereof, or Battelle Memorial institute. The views and opinions of authors expressed herein do not necessarily state cr reflect those of the United States Government or any agency thereof.

\author{
PACIFIC NORTHWEST LABORATORY \\ operated by \\ BATTELLE MEMORIAL INSTITUTE \\ for the \\ UNITED STATES DEPARTMENT OF ENERGY \\ under Contract DE-ACO6-76RLO 1830
}

Printed in the United States of America

Available to DOE and DOE contractors from the

Office of Scientific and Technical Information, P.O. Box 62, Oak Ridge, TN 37831; prices available from (615) 576-8401. FTS 626-8401.

Available to the public from the National Technical Information Service, U.S. Department of Commerce, 5285 Port Royal Rd., Springfield, VA 22161. 
PNL--7881

DE92 006875

RESPONSE OF TLD-ALBEDO AND

NUCLEAR TRACK DOSIMETERS

EXPOSED TO PLUTONIUM SOURCES

L. W. Brackenbush

W. V. Baumgartner

J. J. Fix

December 1991

Prepared for

the U.S. Department of Energy

under Contract DE-ACO6-76RLO 1830

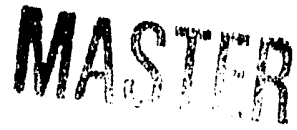

Pacific Northwest Laboratory

Richland, Washington 99352

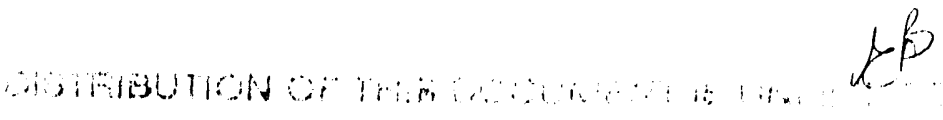




\section{EXECUTIVE SUMMARY}

Neutron dosimetry has been extensively studied at Hanford since the inception of operations in the mid-1940s (Wilson et a1. 1990). At the present time, Hanford contractors use thermoluminescent dosimeter (TLD)-albedo dosimeters to record the neutron dose equivalent received by workers. The energy dependence of the TLD-albedo dosimeter has been recognized and documented since introduced at Hanford in 1964, and numerous studies have been performed to help assure the accuracy of dosimeters used in the work place.

Historically, the largest personnel neutron exposures occurred at the fluorinator glove boxes used for processing plutonium. In the past, the Hanford Multipurpose Dosimeter was calibrated to accurately record doses from this source. This has resulted in conservative assessments for many other neutron sources.

With the recent change in Hanford's mission, there has been a significant decrease in the handling of plutonium tetrafluoride, and an increase in the handling of plutonium metal and plutonium oxide sources. Also, the introduction of U.S. Department of Energy Laboratory Accreditation Program (DOELAP) requires the dosimeter to accurately assess the dose equivalent from ${ }^{252} \mathrm{Cf}$ sources under the low scatter conditions of the calibration laboratory.

This study was initiated to document the performance of the current Hanford TLD-albedo dosimeter under the low scatter conditions of the calibration laboratory and under the high scatter conditions in the work place under carefully controlled conditions at the Plutonium Finishing Plant (PFP). The neutron fields at the PFP facility were measured using a variety of instruments, including a multisphere spectrometer, tissue equivalent proportional counters, and specially calibrated rem meters. The dose equivalent rates from plutonium fluoride, plutonium oxide, and plutonium metal sources were determined using these instruments. The plutonium tetrafluoride source is of importance because it is the same source that was used to calibrate instruments and neutron dosimeters at Hantord from 1964 to 1981. The dosimeter results from the plutonium tetrafluoride exposures may be useful in interpreting past dosimeter records. A variety of neutron dosimeters were 
exposed on an acrylic plastic phantom (the same phantoms used in DOELAP accreditation) in these measured fields. Measurements were also performed with selected thickness of acrylic plastic positioned between the neutron source and the detectors to simulate glove boxes and neutron shielding windows.

Various algorithms were used to evaluate the TLD-albedo dosimeters, and the results are given in Section 7 of this report. Using current algorithms, the dose equivalents evaluated for bare sources and sources with less than $2.5 \mathrm{~cm}$ ( 1 in.) of acrylic plastic shielding in high scatter conditions typical of glove box operations are reasonably accurate, as expected. But the TLDalbedo dosimeters significantly overestimate the dose equivalent when exposed to moderated neutrons from sources with $5 \mathrm{~cm}$ to $15 \mathrm{~cm}(2$ in. to 6 in.) of acrylic plastic shielding. The results confirm the traditional practice of requiring that any errors result in overestimation of the dose equivalent.

Recently developed CR-39 track etch dosimeters (TEDs) were also exposed in the calibration laboratory and at the PFP. The results indicate that the TED dosimeters are quite accurate for both bare and moderated neutron sources. However, the accuracy of the TEDs decreases with increasing moderator thickness, because an increasingiy large fraction of the neutrons reaching the dosimeters have energies below the $100 \mathrm{keV}$ threshold for detection of fast neutrons by the CR-39.

Until a personnel dosimeter is available that incorporates a direct measure of the neutron dose to a person, technical uncertainties in the accuracy of the recorded data will continue. This study is intended to help document the accuracy of the existing Hanford dosimetry system, and to provide information that could be used to help interpret various past and present dosimeter algorithms. At Hanford, studies are continuing to evaluate methods for reducing the uncertainty. Strong reliance is placed on parallel dosimeter and instrument measurements in the work environment. Field measurements have been and continue to be a critical element to insure the credibility of routine dosimeter results. 
The following recommendations are made on the basis of this study:

- Continuing instrument measurements and dosimeter exposures on phantoms in characterized fields are essential to ensure the credibility of routine dosimetry results, especially if any changes are made to the system.

- Consideration should be given to implementing the CR-39 TED in combination with the TLD-albedo dosimeter to provide greater analytical capability in determining personnel neutron dose.

- The Hanford Project has a long-standing policy (Wilson et al. 1990) that, if there are any inaccuracies, the personnel doses recorded shali err so that the recorded doses will always overestimate the actual dose; efforts should be made to increase the accuracy and reduce the degree of conservatism in neutron dosimetry.

- As part of the effort to increase the accuracy of TLD-albedo dosimeters, it may be possible to develop improved algorithms based on site-specific calibration factors or TLD chip ratios using the data contained in this report. 


\section{CONTENTS}

EXECUTIVE SUMMARY .................... i i

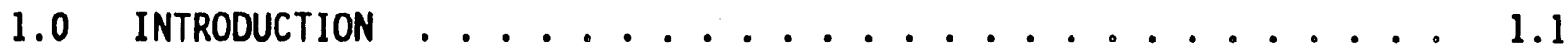

1.1 NIST-TRACEABLE SOURCES . . . . . . . . . . 1.1

1.2 HANFORD SITE CALIBRATION FACTORS .......... 1.2

1.3 POTENTIAL CHANGES IN RADIATION PROTECTION STANDARDS . . . 1.3

1.4 NEUTRON MEASUREMENTS . . . . . . . . . . . 1.5

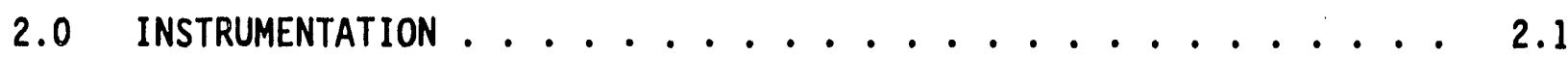

2.1 TISSUE EQUIVALENT PROPORTIONAL COUNTERS $\ldots \ldots \ldots$

2.2 MULTISPHERE SPECTROMETER $\ldots \ldots \ldots \ldots$

$2.3{ }^{3}$ He SPECTROMETER ....................... 2.7

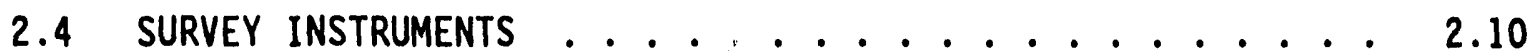

2.5 PERSONNEL NEUTRON DOSIMETERS ............ 2.11

2.5.1 CR-39 Nuclear Track Detectors . . . . . . 2.11

2.5.2 TLD-Albedo Dosimeters . . . . . . . 2.12

3.0 MEASUREMENT FACILITIES . . . . . . . . . . . 3.1

3.1 DESCRIPTION OF THE FACILITIES ........... 3.1

3.1.1 Calibration Laboratory ........... 3.1

3.1.2 Plutonium Finishing Plant ......... 3.2

3.2 NEUTRON SOURCES ..................... 3.4

3.2.1 Calibrated Neutron Sources .......... 3.4

3.2.2 Plutonium Sources ............ 3.9

4.0 QUALITY ASSURANCE MEASUREMENTS ................ 4.1

4.1 VERIFICATION MEASUREMENTS MADE PRIOR TO FIELD

MEASUREMENTS ................... 4.2

4.2 VERIFICATION MEASUREMENTS MADE AFTER COMPLETION
OF THE FIELD MEASUREMENTS $\ldots \ldots \ldots 4.3$ 
5.0 MEASUREMENTS AND RESULTS . . . . . . . . . . . . . . 5.1

5.1 PLUTONIUM FLUORIDE MEASUREMENTS ............ 5.2

5.1.1 Dose Equivalent Determinations from

Plutonium Fluoride Source ......... 5.2

5.1.2 Long Counter Measurements with the

Plutonium Fluoride Source ......... 5.3

5.1.3 Multisphere Spectrometer Measurements with the

Plutonium Fluoride Source ....... 5.6

5.2 PLUTONIUM DIOXIDE MEASUREMENTS ........... . . 5.16

5.2.1 Dose Equivalent Determinations from

Plutonium Dioxide Source .......... 5.16

5.2.2 Multisphere Spectrometer Measurements with the

Plutonium Dioxide Source . . . . . . . 5.17

5.3 PLUTONIUM METAL MEASUREMENTS ............ 5.20

5.3.1 Dose Equivalent Determinations from the

Plutonium Metal Source ........... 5.21

5.3.2 Multisphere Spectrometer Measurements with the

Plutonium Metal Source ........... 5.21

6.0 ATTENUATION BY ACRYLIC PLASTIC SHIELDING . . . . . . . . . 6.1

7.0 MEASURED RESPONSE OF THE HANFORD DOSIMETERS . . . . . . . 7.1

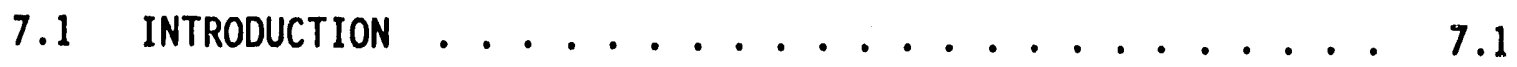

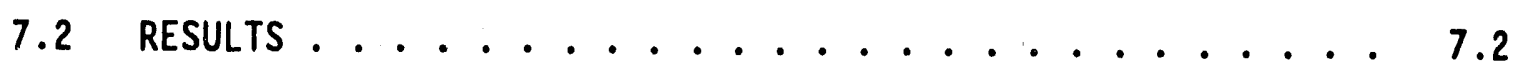

7.3 DISCUSSION .......................... 7.5

7.4 MEASUREMENTS WITH CR-39 DOSIMETERS . . . . . . . . 7.7

8.0 CONCLUSIONS AND RECOMMENDATIONS .............. 8.1

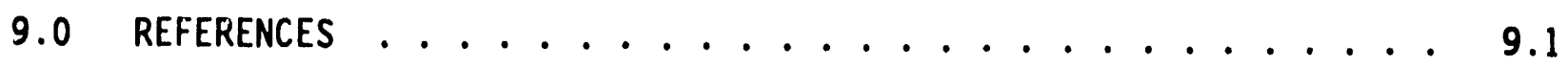

APPENDIX A - TISSUE EQUIVALENT PROPORTIONAL COUNTER

APPENDIX B - MULTISPHERE SPECTROMETER

APPENDIX C - RAW DATA FROM TLD-ALBEDO DOSIMETERS 


\section{EIGURES}

1.1 Neutron Energy Spectra for Plutonium Tetrafluoride,

Plutonium Dioxide, and Plutonium Matal Sources . . . . . . 1.6

2.1 Variation in the Response as a Function of Neutron

Energy for Electrochemically Etched CR-39 . . . . . . . . 2.13

2.2 Directional Response of CR-39 Dosimeters on a

Phantom Exposed to a ${ }^{252} \mathrm{Cf}$ Source ............ 2.13

2.3 Energy Dependence of Various TLD-Albedo Dosimeters . . . . . . 2.15

2.4 View of Dosimeter Card Containing the TLDs

and the Dosimeter Holder with Various Filters . . . . . . . 2.17

3.1 Plan View of Room $179 \mathrm{C}$ Where the

Plutonium Measurements Were Performed . . . . . . . . . 3.3

3.2 Neutron Energy Spectrum from the Bare ${ }^{252} \mathrm{Cf}$ Source

Inside the Aluminum Transfer Capsule . . . . . . . . . 3.8

3.3 Neutron Energy Spectrum from the Bare ${ }^{252} \mathrm{Cf}$ Source

Inside a $30-\mathrm{cm}$ Diameter Sphere of Deuterium Oxide . . . . . 3.8

3.4 Details for the Construction of the Hanford PuF 4

Neutron Source ..................... 3.11

5.1 Inverse Square Plot of Long Counter Data to Determine

the Neutron Emission Rate and Room Return from

the Puf ${ }_{4}$ Source .................... . 5.6

5.2 Neutron Flux per Unit Lethargy at $50 \mathrm{~cm}$ from the

PuF $_{4}$ Source Measured by the Multisphere Spectrometer . . . . . 5.8

5.3 Neutron Flux per Unit Lethargy at $100 \mathrm{~cm}$ from the

$\mathrm{PuF}_{4}$ Source Measured by the Multisphere Spectrometer . . . . . 5.9

5.4 Neutron Flux per Unit Lethargy at $100 \mathrm{~cm}$ from the

$\mathrm{PuO}_{2}$ Source Measured by the Multisphere Spectrometer . . . . . 5.20

5.5 Neutron Flux per Unit Lethargy at $50 \mathrm{~cm}$ from the

Pu Metal Source Measured by the Multisphere Spectrometer . . . 5.24

6.1 Reduction in Dose Equivalent Rate from Acrylic

Piastic Shielding.................... 6.3

A.1 Representation of a Short Segment of the Track

of a Recoil Proton Produced by a 1 MeV Neutron 


\section{A.2 Simplified Cross-Sectional View of a Spherical}

Tissue Equivalent Proportional Counter ............

A.3 A Typical Spectrum Recorded by a TEPC Operated with a $1-\mu \mathrm{m}$ Equivalent Diameter.............

A.4 Simultaneous Measurement of Absorbed Dose from Neutrons and Photons by a Tissue Equivalent Proportional Counter . . . . .

A.5 Ratio of Neutron Dose Measured by TEPCs to the Kerma Calculated from Fluence Measurements .........

A.6 Relation Between Quality Factor and the Mean Chord Length in a Cylinder as a Function of the Length/Diameter Ratio .................

A.7 Neutron Quality Factors Empirically Derived from the First Moment of the Absorbed Dose Distribution Measured by the Tissue Equivalent Proportional Counter . . . . . . . .

A.8 Quality Factor Redefined as a Function of Lineal

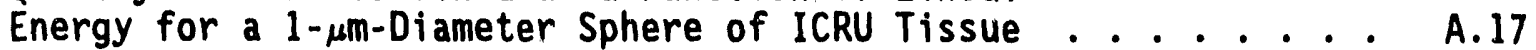

A.9 Dose-Weighted Effective Quality Factor Calculated as a Function of Neutron Energy for Monoenergetic Neutrons ...

B.1 Typical Spectrum Measured by the ${ }^{6} \mathrm{LiI}(\mathrm{EU})$ Scintillator Showing the Slow Neutron Peak and Gamma Continuum .......

B.2 Diagram of the Scintillator Detector ........... 


\section{IABLES}

2.1 The Dependence of Quality Factor, $Q(L)$, on Linear Energy Transfer, $L_{\infty} \ldots \ldots . . \ldots 2$

2.2 Quality Factors and Fluence-to-Dose Equivalent Conversion Factors ................ 2.3

2.3 Description of the Filters Used at Each Position in the Hanford Multipurpose Dosimeter. ............

3.1 Neutron Dose Equivalent Rates from the NISTCal ibrated ${ }^{252}$ Cf Neutron Sources at PNL .......... 3.7

3.2 Neutron Fluence-to-Dose Equivalent Conversion Factors from the $D, 0$-Moderated ${ }^{252} \mathrm{Cf}$ Neutron Sources at PNL and Other Calibration Facilities ............. 3.7

3.3 Plutonium Sources Used for Field Measurements . . . . . . . 3.10

3.4 Isotopic Composition of Plutonium Sources .......... 3.10

4.1 Summary of Verification Measurements at the PNL Calibration Laboratory ................

4.2 Summary of Verification Measurements at the PNL Calibration Laboratory Made after the Field Measurements Were Completed

4.3 Summary of Verification Measurements at the PNL Calibration Laboratory with the TEPCs Refilled with Tissue Equivalent Gas ............. 4.6

5.1 Results of Neutron Measurements Performed on the 764-Gram $\mathrm{PuF}_{4}$ Source at the Plutonium Finishing Plant ....... 5.3

5.2 Summary of the Multisphere Spectrometer Measurements with the Plutonium Tetrafluoride Source . . . . . . . . . 5.7

5.3 Neutron Flux, Absorbed Dose, and Dose Equivalent Distributions Determined from Multisphere Spectrometer Measurements at $50 \mathrm{~cm}$ from the Bare $\mathrm{PuF}_{4}$ Source ... . . . . 5.10

5.4 Neutron Flux, Absorbed Dose, and Dose Equivalent Distributions Determined from Multisphere Spectrometer Measursments at $50 \mathrm{~cm}$ from the $\mathrm{PuF}_{4}$ Source with l-in. Acrylic Plastic Shield 
5.5 Neutron Flux, Absorbed Dose, and Dose Equivalent

Distributions Determined from Multisphere Spectrometer

Measurements at $50 \mathrm{~cm}$ from the PuF 4 Source with

2. in. Acrylic Plastic Shield ...............

5.6 Neutron Flux, Absorbed Dose, and Dose Equivalent

Distributions Determined from Multisphere Spectrometer

Measurements at $100 \mathrm{~cm}$ from the Bare PuF 4 Source . . . . . . .

5.7 Neutron Flux, Absorbed Dose, and Dose Equivalent

Distributions Determined from Multisphere Spectrometer

Measurements at $100 \mathrm{~cm}$ from the PuF ${ }_{4}$ Source with

1 in. Acrylic Plastic Shield

5.8 Neutron Flux, Absorbed Dose, and Dose Equivalent

Distributions Determined from Multisphere Spectrometer

Measurements at $100 \mathrm{~cm}$ from the PuF Source with

2-in. Acrylic Plastic Shield

5.9 Results of Neutron Measurements Performed on the

$\mathrm{PuO}_{2}$ Source at the Plutonium Finishing Plant . . . . . . . .

5.10 Summary of the Multisphere Spectrometer Measurements

with the $\mathrm{PuO}_{2}$ Source

5.11 Neutron Flux, Absorbed Dose, and Dose Equivalent

Distributions Determined from Mult isphere Spectrometer

Measurements at $100 \mathrm{~cm}$ from the $\mathrm{Bare}^{\mathrm{PuO}_{2}}$ Source

5.12 Results of Neutron Measurements Performed on the

1508-Gram Plutonium Metal Source ..............

5.13 Summary of the Multisphere Spectrometer Measurements

with the Plutonium Metal Source .................

5.14 Neutron Flux, Absorbed Dose, and Dose Equivalent

Distributions Determined from Multisphere Spectrometer

Measurements at $50 \mathrm{~cm}$ from the Bare Plutonium

Metal Source

6.1 Attenuation of Neutron Dose Equivalent Provided by Slabs of Acrylic Plastic for Californium and Plutonium Tetrafluoride Neutron Sources .............

7.1 Summary of TLD-Albedo Dosimeter Results for the

Hanford Multipurpose Dosimetor Exposed to Calibration

and Plutonium s

7.2 Thermoluminescent Dosimeter Chip Responses for Hanford

Multipurpose Dosimeters Exposed to ${ }^{252} \mathrm{Cf}$ Calibration

Sources and Plutonium Sources. 
7.3 Summary of CR-39 Dosimeter Expcsures . . . . . . . . 7.8

8.1 Summary of Dosimeter Measurements . . . . . . . . . . 8 8.2

A.1 Compositions of Tissue Equivalent Materials Used in Tissue Equivalent Proportional Counters ......... A.5

A.2 Relationship Between the Proton Drop Point Used for Energy Calibration and the Site Size in a Spherical Tissue Equivalent Proportional Counter . . . . . A.7

A.3 Relationship Between Quality Factor and Linear Energy Transfer, LET ............. A.12

A.4 Dose and Dose Equivalent Calculated on the Surface and at the Maximum Values in a Cylindrical Phantom ...... A.22

B.1 Dimensions of the PNL Bonner Sphere Set . . . . . . . B.11

B.2 NIM Bin Electronic Components Used to Provide Signals

from the Multisphere Detector to the Spectrometer . . . . . . B.14 


\subsection{INTRODUCTION}

The Hanford External Dosimetry Program is a multifaceted program involving routine interaction between numerous operational organizations within each site contractor and with the Richland Operations Office (RL) of the U.S. Department of Energy (DOE). The program provides for the measurement and recording of the official external occupational radiation doses for all employees/visitors during their employment/visit ai Hanford Site, and is conducted for DOE by Pacific Northwest Laboratory $(P N L)^{(a)}$ in compliance with the requirements of DOE 5480.11 and DOE 5480.15 (DOE 1988; 1987).

The Hanford External Dosimetry Program is technical in nature and involves significant quality control (QC) for the dosimeters and equipment used. The thermoluminescent dosimeter (TLD) reader is the instrument that processes the TLD inserts by measuring the light photons released from the TL chips in the inserts, thereby determining any radiation dose received by the individual dosimeter wearers.

The complete TLD system must meet the performance criteria described in the DOE Laboratory Accreditation Program (DOELAP) handbook (DOE/EH-0026 1986a) and standard (DOE/EH-0027 1986b). The individual system parts must be integrated so that maximum automation is achieved. As designed and modified by PNL, Hanford readers and inserts have provided such capability in full compliance with the performance criteria since 1970 .

The Hanford multipurpose dosimeters are calibrated based on exposure(s) to specific radiation sources, including on-phantom calibrations. Hanfordspecific calibration factors and environmental dose correction formulas are applied. The dosimeters are processed to assess dose using an automated reader system.

\subsection{NIST-TR.ACEABLE SOURCES}

The radiation sources used as a basis for calibrating Hanford personnel dosimeters are traceable to National Institute of Standards and Technology

(a) Pacific Northwest Laboratory is operated for the U.S. Department of Energy by Battelle Memorial Institute under Contract DE-AC06-76RLO 1830. 
(NIST) standards. For the multipurpose dosimeter, primary calibration is based on

- 16-keV K-fluorescent on-phantom exposure for the shallow-dose photon component

- on-phantom ${ }^{137} \mathrm{Cs}$ exposure for the deep-dose photon component

- on-phantom ${ }^{252} \mathrm{Cf}$ exposure for the fast-neutron component.

Additional exposures are made using selected $K$-fluorescant, filtered $x$-ray techniques, beta sources, and neutron energies to determine ihe response of the dosimeters to other radiation environments. Information pertaining to the calibration of the exposure and/or dose received from these sources is available in the respective source documentation maintained at the 318 Building Calibration Facility.

\subsection{HANFORD SITE CALIBRATION FACTORS}

Calibration factors determined from the NIST calibration sources are used directly without any modification for field conditions, with the exception of the fast-neutron calibration. When a TLD-albedo dosimeter is exposed to bare ${ }^{252} \mathrm{Cf}$ in the field, its response per rem-dose-equival in is considered to be 1.73 times higher than its response to bare ${ }^{252} \mathrm{Cf}$ in the calibration laboratory. (The factor is based on historical measurements from the field using survey instruments and other dosimetric devices.) Therefore, the dose responses in the laboratory are multiplied by 1.73 to approximate actual field dose responses at Hanford. This calibration results in a calculated dose approximately a factor of 5 greater than the actual dose for a 15 -cm $\mathrm{D}_{2} \mathrm{O}$-moderated ${ }^{252} \mathrm{Cf}$-source exposure.

A11 neutron dosimeters and survey instruments exhibit energy dependence; i.e., the response per unit dose equivalent varies with energy. For this reason, it is necessary to know the response in the field in which the dosimeter is to be used. Typically, dosimeters are calibrated in low scatter calibration laboratories under precisely controlled conditions. The response of the dosimeter under these conditions is generally different than the response when the dosimeter is exposed under the high scatter conditions typical of work place exposures. The purpose of this study was to make 
measurements of dosimeter responses to various plutonium sources under the high scatter condition found at a typical Hanford facility, the Plutonium Finishing Plant (PFP). This information would provide the data for determining new algorithms for more accurate determination of neutron dose equivalent from Hanford Multipurpose Dosimeters in a typical work place situation. In addition, the encapsulated plutonium tetrafluoride source used for these measurements was previously used as a calibration source for previous Hanford neutron dosimeters. Thus, the measurements would provide historical data for evaluating previous dosimeter algorithms.

\subsection{POTENTIAL CHANGES IN RADIATION PROTECTION STANDARDS}

These measurements also provide data of interest for proper evaluation of neutron dosimeters if radiation protection standards are changed in the future. Various national and international advisory bodies have recommended that the quality factors for fast neutrons be increased, and it is expected that the U.S. Department of Energy may implement these changes in the future. The National Council on Radiation Protection and Measurements (NCRP) has recommended increasing neutron quality factors in Report No. 91, Recommendations on Limits for Exposure to Ionizing Radiation (NCRP 1987). Unless the neutron energy spectrum is knowi, the NCRP recommends applying a quality factor of 20 for neutrons; this would result in doubling dose equivalents. Determination of neutron energy spectra in the work place allows the use of inore accurate neutron quality factors and reduces unnecessary conservatism in assigning dose equivalent from dosimeter responses.

In ICRU Report 40, The Quality Factor in Radiation Protection (ICRU and ICRP 1986), a joint task force of the International Coinmission on Radiation Units and Measurements (ICRU) and the International Commission on Radiological Protection (ICRP) proposed changing the basis for the definition of quality factors. At present, quality factors for all radiations are defined on the basis of linear energy transfer (LET), the average rate of energy loss per unit path length of charged particles in water. ICRU Report 40 proposes defining quality factors in terms of lineal energy, which is the quotient of the energy imparted by a single energy deposition event to matter in a volume divided by the mean chord length of that volume. Linear energy transfer is a 
macroscopic quantity that must be determined by the average of many observations (or calculated mathematically); lineal energy is a stochastic quantity that can be measured by devices such as the tissue equivalent proportional counter as outlined in Section 2 of this report.

Also, in Federal Radiation Protection Guidance to Federal Agencies for Occupational Exposure (52 FR 2822-2834), the President has accepted the Environmental Protection Agency (EPA) guidance that federal agencies adopt the methodology of the ICRP Publication 26 (ICRP 1977) for determining effective dose equivalent. This guidance provides a mechanism for adding internal and external exposures, but does not explicitly deal with determination of effective dose equivalent from external sources. ICRP Publication 51, Data for Use in Protection Against External Radiation (ICRP 1987), gives some guidance on how to determine effective dose equivalent for external radiations.

DOE has traditionally followed the recommendations of the NCRP. If radiation protection standards are changed, either by increasing quality factors or implementation of effective dose equivalent, some knowledge of the neutron energy spectra in the work place will be mandatory. This information is beneficial for the following reasons:

- Increased accuracy can be achieved by field calibration of personnel dosimeters and instruments. Neutron dosimeters are typically calibrated in the laboratory under carefully contrclled conditions. But the neutron energy spectrum and irradiation geometry in the work place are usually quite different than those in the calibration laboratory. A correction factor is applied to account for these differences. Correction factors specific to actual work locations can be determined by exposing dosimeters on a phantom at locations where the dose equivalent has been determined from spectral measurements.

- Spectral information will allow calculation of quality factors and dose equivalent conversion factors. If the energy spectra at work locations have been measured, the effects of proposed changes in radiation protection standards can be determined.

- Effective dose equivalent can be calculated from neutron energy spectra and irradiation geometry using the data published in ICRP Publication 51 (1987). Because effective dose equivalent accounts for attenuation and degradation of the energy of neutrons penetrating the body, adopting effective dose equivalent methodology can mitigate the effects of increases in neutron quality factors. 
- Effective dose equivalent can be calculated from neutron energy spectra and irradiation geometry using the data published in ICRP Publication 51 (1987). Because effective dose equivalent accounts for attenuation and degradation of the energy of neutrons penetrating the body, adopting effective dose equivalent methodology can mitigate the effects of increases in neutron quality factors.

\subsection{NEUTRON MEASUREMENTS}

The most significant source of neutron exposure at Hanford historically involved the processing and handling of plutonium. Several different plutonium sources were h..ed for these measurements, including a sealed plutonium tetrafluoride $\left(\mathrm{PuF}_{4}\right)$ source, a plutonium oxide $\left(\mathrm{PuO}_{2}\right)$ source, and a plutonium metal source. These sources are typical of the plutonium handled at Hanford. The sources are described in more detail in Section 3.3 of this report.

The plutonium tetrafluoride source is of special interest. It was previously used as the calibration source for Hanford neutron dosimeters from December 1964 until August 14, 1981, when it was replaced by a californium-252 fission source. In the 1960s much of the neutron exposure was the result of processing plutonium fluoride, which is an intermediate step in the separation of plutonium. Alpha particles from plutonium interact with fluorine to produce neutrons, thus increasing the neutron yield by a factor of 100 or more.

Measurements of the neutron energy spectra have been made on similar plutonium sources in the laboratory, as discussed in BNWL-1262, Neutron Spectra of Plutonium Compounds, Part 1: ${ }^{3} \mathrm{He}$ and ${ }^{6} \mathrm{Li}$ Spectrometer Measurements (Brackenbush and Faust 1970). The results of these measurements are shown in Figure 1.1, which gives the fast neutron energy spectrum for plutonium tetrafluoride (average energy $1.4 \mathrm{MeV}$ ), plutonium dioxide (average energy 2.0 MeV), and plutonium metal (average energy $2.0 \mathrm{MeV}$ ) sources. These measurements were made under carefully controlled conditions in the laboratory and provide the energy spectra from the source itself; no room scatter component was measured.

These spectra are not typical of neutron energy spectra in the work $\mathrm{place}$, where the plutonium is processed in glove boxes. The hydrogenous snielding provided by glove boxes, concrete walls and floors, and process 
equipment results in a significant fraction of neutrons at low energies. A TLD-albedo neutron dosimeter is 100 times more sensitive to these low energy neutrons than to $1 \mathrm{MeV}$ neutrons, so these low energy scattered neutrons are very important to the dosimeter response. Although these low energy scattered neutrons contribute very little to dose equivalent, they often dominate the response of the TLD-albedo dosimeter.

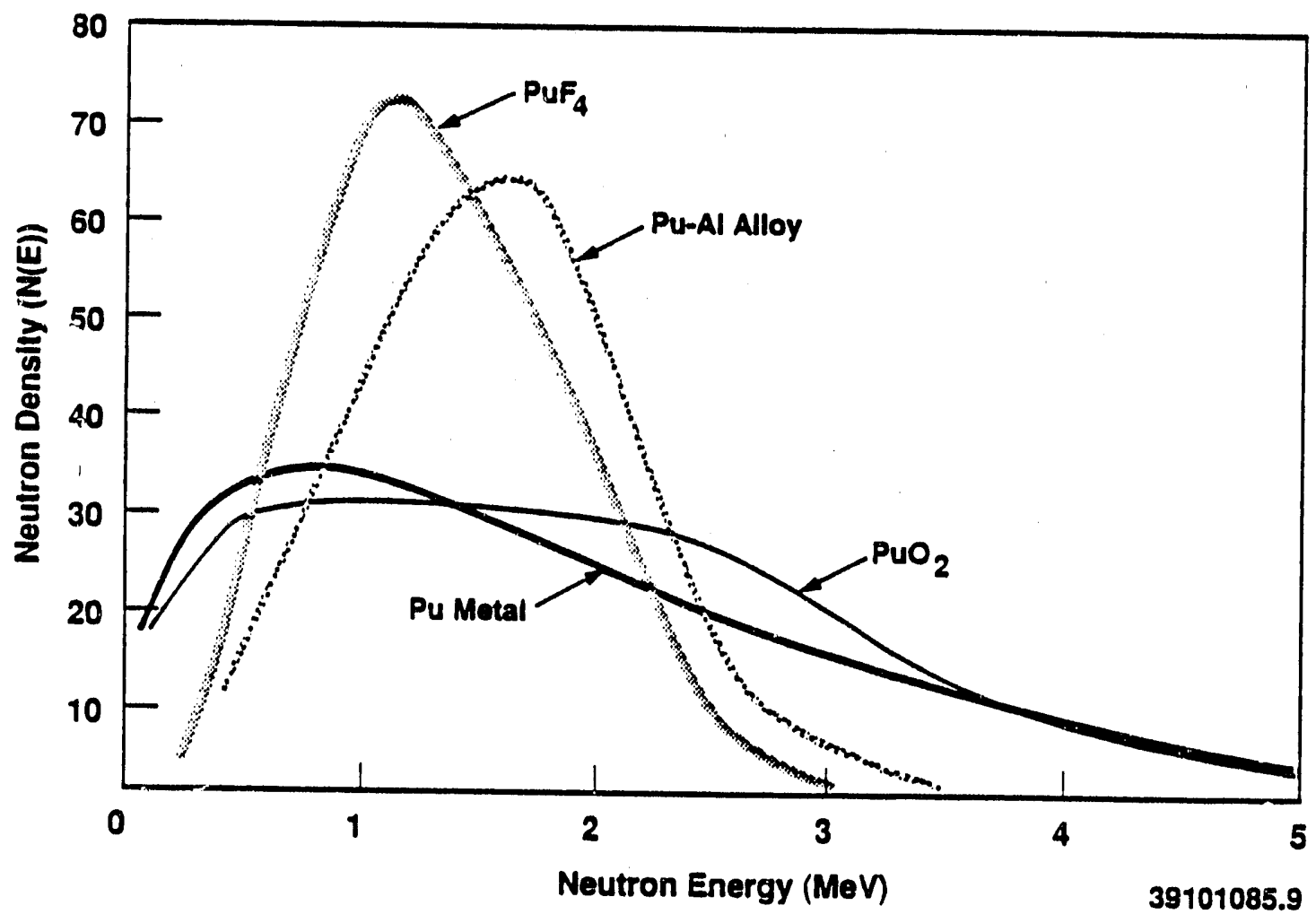

FIGURE 1.1. Neutron Energy Spectra for Plutonium Tetrafluoride, Plutonium Dioxide, and Plutonium Metal Sources

(Source: Brackenbush and Faust 1970) 


\subsection{INSTRUMENTATION}

This section discusses the instruments used to perform the spectral measurements. Most of the information presented here is contained in other documents, but is included so that the reader will have one document with all the necessary information. The instruments covered include

- tissue equivalent proportional counters (TEPCS) to measure the lineal energy distribution or LET, so that quality factors and dose equivalent can be calculated from their definitions

- multisphere or Bonner sphere spectrometers, which provide low resolution neutron energy spectra covering an energy range of thermal to $20 \mathrm{MeV}$

- ${ }^{3}$ He proportional counter spectrometers, to provide high-resolution energy spectra over an energy range of $200 \mathrm{keV}$ to $3 \mathrm{MeV}$

- survey instruments, including the Snoopy, the Hanford standard neutron survey instrument, and a micro rem meter to measure low-level gamma dose rates

- personnel dosimeters, including the Hanford multipurpose dosimeter and CR-39 track etch dosimeters.

Information is provided on the principles of operation, the energy response of the device, the operating range, and sensitivity to neutrons and possible interfering radiations. Detailed information about TEPCs is presented in Appendix $A$ of this report, and a description of the multisphere spectrometer is given in Appendix B. If the reader is unfamiliar with the terminology used in microdosimetry (e.g., lineal energy versus linear energy transfer), an introduction to these concepts is provided in Appendix $A$.

With these instruments, there are theoretically at least three generic methods to determine dose equivalent. The first is to use an instrument that has a response per unit dose equivalent that mimics the fluence-to-dose equivalent conversion factor as a function of incident neutron energy. Unfortunately, no single such instrument exists for the wide range of neutron energies found in DOE facilities. Moderator-based instruments such as the Snoopy or remball can be used over limited energy ranges and are reasonably accurate if calibrated properly for the energy range in which they are used. 
A second method is to measure the incident neutron energy spectrum and apply fluence-to-dose-equivalent conversion factors, which are published in DOE Order 5480.11 (DOE 1988) or NCRP Report 38 (NCKR 1971). The existing published conversion factors are based on Monte Carlo computer code calculations performed over 20 years ago by scientists at Oak Ridge National Laboratory (Auxier et al. 1968) using a parallel beam of neutrons normally incident on a cylindrical phantom $30 \mathrm{~cm}$ in diameter and $60 \mathrm{~cm}$ high. The dose equivalent for a given energy was calculated by finding the highest neutron dose at some depth in the phantom. The charged particle spectrum was calculated; then the average quality factor was determined by looking at the LET distribution and applying the definition of quality factor as a function of LET (see Table 2.1). The dose equivalent at this energy was then calculated from the product of the absorbed dose times the average quality factor determined from the LET distribution. The resulting quality factors are shown in Table 2.2 as a function of incident neutron energy.

The determination of neutron energy spectra does have distinct advantages. If neutron quality factors are changed in the future, it will be possible to calculate the effect of the changes from the neutron energy spectrum and revised fluence-to-dose equivalent conversion factors. Also, if the incident neutron energy spectrum is determined as a function of direction, it is possible to determine effective dose equivalent and mitigate the effects of increases in neutron quality factors.

TABLE 2.1. The Dependence of Quality Factor, $Q(L)$, on Linear Energy Transfer, $b_{\infty}$

$L_{\infty}$ in Water

$<3.5$

7.0

23.

53.

175.
Quality Factor

1

2

10

20

Source: ICRU Report 20 (1971), page 4. 
TABLE 2.2. Quality Factors and Fluence-to-Dose Equivalent Conversion Factors

$\begin{gathered}\text { Neutron Energy } \\ (\text { MeV })\end{gathered}$
$2.5 \times 10^{-8}$
$1 \times 10^{-7}$
$1 \times 10^{-6}$
$1 \times 10^{-5}$
$1 \times 10^{-4}$
$1 \times 10^{-3}$
$1 \times 10^{-2}$
$1 \times 10^{-1}$
$5 \times 10^{-1}$
1
2.5
5
7
10
14
20
40
60
$1 \times 10^{2}$
$2 \times 10^{2}$
$3 \times 10^{2}$
$4 \times 10^{2}$

Source: NCRP Report 38 (1971), page 16.

However, this procedure results in conservative or upper 1 imit values for the dose equivalent for a variety of reasons. First, the highest dose equivalent rate found at any depth in the phantom is applied to the entire phantom. The model assumes a parallel beam of neutrons normally incident (i.e., at $90^{\circ}$ to the axis of the cylinder), but neutrons usually arrive from all angles; thus, the parallel beam model yields maximal values for the dose equivalent. The calculated dose equivalent represents maximum values in the phantom, which occur at different depths for different neutron energies; however, for polyenergetic neutron energy spectra, the conversion factors are added together as if the maxima occurred at the same depth. Finally, there is the problem of activation gamma rays. For slow and intermediate energy neutrons, recoil protons from neutron scatter with hydrogen results in very 
little energy transfer. At these energies the principal mechanism for energy transfer is the absorption of a slow neutron by hydrogen and the subsequent emission of a $2.2 \mathrm{MeV}$ gamma ray from deuterium. In the Monte Carlo computer code calculations, activation gamma rays are included as part of the neutron dose. However, a gamma dosimeter will record some of these gamma rays, resulting in an overly conservative estimation of the dose equivalent. These problems are discussed in greater detail in Appendix $A$.

A third method of determining dose equivalent is to measure the absorbed dose as a function of LET and apply the definition of quality factors as a function of LET, as shown in Table 2.1. In principle, this can be accomplished using instruments such as the TEPC.

\subsection{IISSUE EQUIVALENT PROPORTIONAL COUNTERS}

The TEPC consists of a hollow sphere of tissue equivalent (TE) plastic filled with TE gas. An electrode is placed in the counter to collect the charge produced by interactions with ionizing radiations. In commercially available proportional counters, the tissue equivalent plastic walls are composed of Shonka A150 plastic (ICRU 1983, page 75) and are typically 1/8-in. thick. The inside diameter of the sphere varies between $1 / 4 \mathrm{in}$. and $5 \mathrm{in}$. $A$ 5-in. diameter single-wire TEPC was found to be the most useful for field measurements.

From Bragg-Gray cavity theory, the absorbed dose measured by the tissue equivalent gas cavity is the same as that measured in the center of a sphere of tissue equivalent gas, if the compositions of the plastic walls and gas cavity are identical. Thus, the TEPC measures the absorbed dose in a sphere of tissue-1ike material with a radius of $1 / 8$ in. If the composition of TE plastic is sufficiently close to that of tissue, this provides a direct measure of absorbed dose in tissue. For neutrons with fission energies, the energy deposition in TE plastic is very close to that in soft tissue.

It is relatively easy to determine the absorbed dose with a tissue equivalent proportional counter; the problem is how to determine quality factors from the distribution of events in the TEPC. Unlike ordinary proportional counters, the TEPC is operated at very low gas pressures, so that 
the gas cavity has the same stopping power as a 1- or 2- $\mu \mathrm{m}$ sphere of tissue of unit density. As a crude approximation, the energy deposited in the TEPC is the product of the path length times the LET. However, the concept of linear energy transfer breaks down at these microscopic levels. Particles with the same energy traversing the same path will produce a distribution of event sizes in the counter because of the statistical nature of microscopic interactions. However, there are approximate methods to convert the lineal energy distributions measured by the TEPC to LET distributions, as explained in Appendix $B$. Within the errors of the approximations and algorithms used, it is possible to determine LET distributions and hence quality factors from their definition.

The dose equivalent can be determined from the TEPC measurement of absorbed dose multiplied by the quality factor determined from the definition based on LET. However, this dose equivalent is not exactly the same as that obtained from neutron energy spectra measurements. The TEPC measures the absorbed neutron dose and the energy deposition spectra at a fixed depth of $1 / 8$ in. in a sphere of tissue-equivalent plastic. This is not the same as the maximum absorbed neutron dose calculated at any depth in a $30-\mathrm{cm}$ diameter cylindrical phantom.

Neutron and gamma events in the TEPC can be separated on the basis of the size of the event produced in the TEPC. Although there is some overlap in the size of the events, gamma rays produce events with lineal energies below about $15 \mathrm{keV} / \mu \mathrm{m}$. Thus, it is possible to determine neutron quality factors by analyzing only those events with lineal energies above about $15 \mathrm{keV} / \mu \mathrm{m}$. For fission energy neutrons, the average quality factors $(\bar{Q})$ calculated from TEPC measurements are remarkably close to the average neutron quality factors determined by weighting neutron quality factors by measured neutron energy spectra, as in Equation (2.1):

$$
\bar{Q}=\frac{\sum Q(E) \phi(E)}{\Sigma \phi(E)}
$$

At neutron energies above $20 \mathrm{MeV}$, the maximum in the absorbed dose occurs at a depth greater than $1 / 8$ in., and the dose equivalent determined from TEPC 
measurements are lower than those calculated from neutron energy spectrum measurements. Also, for intermediate energy neutrons, the primary mechanism for energy transfer is the production of $2.2-\mathrm{MeV}$ gamma rays produced by the absorption of slow neutrons by hydrogen. The TEPC cannot distinguish between an external gamma ray and one produced by neutron activation. Thus, the absorbed neutron dose and the quality factors determined by TEPC measurement.s are different than those calculated from neutron-energy spectra measurements for intermediate energies. The importance of these effects is shown in Table A.5 in Appendix A. For fission spectra or lightly moderated fission spectra, the dose equivalents determined by TEPC measurements are almost identical to those calculated from neutron-energy spectrum measurements. This is because most of the dose is delivered by hydrogen recoils (rather than activation gamma rays), and the maximum absorbed dose occurs near the surface of the phantom (which is closely approximated by the TEPC measurement at a depth of $1 / 8$ in.).

\subsection{MULTISPHERE SPECTROMETER}

The multisphere spectrometer consists of a set of five polyethylene spheres with different diameters, a cadmium shield, and a ${ }^{6} \mathrm{LII}(E \mathrm{E})$ scintillator crystal attached to a light pipe and photomultiplier, so that the scintillator can be positioned at the center of the polyethylene spheres. Seven different detector/moderator configurations are possible: a bare detector, a cadmium-covered detector, and the detector positioned at the center of 3-, 5-, 8-, 10-, and 12-in. polyethylene spheres.

The scintillator responds to slow neutrons to produce a distinct peak in the spectrum produced by the light emitted by the scintillator. The number of counts in the neutron-induced peak varies with the incident neutron enorgy and detector/moderator configuration. Low energy neutrons are easily thermalized by small amounts of moderator, so the small spheres have a large response per incident neutron. Thermal neutrons are absorbed before they reach the center of the largest spheres, so the response of the largest spheres is quite low. At high neutron energies, there is not sufficient moderator in the smaller spheres, so the response per incident neutron is low. However, the largest spheres contain sufficient moderator to thermalize a significant fraction of 
the incident fast neutrons, and the response is high. Thus, from the count rates in the various detectors, it is possible to determine an approximate energy spectrum over a wide range of neutron energies.

As explained in Appendix B, the slow neutron count rate is determined from the seven different detector/moderator configurations. These data are used as input to the computer code SPUNIT (Brackenbush and Scherpelz 1983). The computer code determines the neutron flux in 26 energy bins from the seven measurements. Mathematically, this is an underdefined problem, and there are an infinite number of mathematically correct solutions. The SPUNIT computer code chooses the most probable physically correct solution, based on an initial guess of a fission spectrum for the shape of the spectrum. The code determines an approximate energy spectrum over a range of neutrun energies from thermal to $20 \mathrm{MeV}$. The shape of the spectrum for intermediate energy neutrons is only an approximation, because there is no detector in the set of spheres that gives a unique response to intermediate energy neutrons. Large variations in the intermediate neutron flux produce very little change in the response of the spheres used in the multisphere set. Thus, the intermediate energy neutrons are not always determined with sufficient accuracy to allow one to directly calculate the response of TLD-albedo dosimeters.

The dose equivalents calculated from a multisphere spectrometer are reasonably accurate for fission sources and moderated fission sources, such as the $\mathrm{D}_{2} \mathrm{O}$-moderated ${ }^{252} \mathrm{Cf}$ source (see Section 4.0 of this report). The response of TLC-albedo dosimeters can be determined by exposing them in the neutron fields where the dose equivalent rate has been determined from multisphere spectrometer measurements.

\section{$2.3{ }^{3} \mathrm{He}$ SPECTROMETER}

The ${ }^{3} \mathrm{He}$ spectrometer provides better energy resolution than the multisphere spectrometer and is useful over a shorter energy range. The ${ }^{3} \mathrm{He}$ proportional counter spectrometer used in these measurements provided neutron energy spectra over a range of about $200 \mathrm{keV}$ to $3 \mathrm{MeV}$. This section provides information on the theory of operation, how the neutron energy spectrum is derived, and the limitations and advantages of the ${ }^{3} \mathrm{He}$ spectrometer. 
The basis for the use of ${ }^{3} \mathrm{He}$ proportional counters as neutron-enargy spectrometers is the nuclear reaction:

$$
{ }^{3} \mathrm{He}+\mathrm{n} \longrightarrow{ }^{1} \mathrm{H}+{ }^{3} \mathrm{H}+764 \mathrm{keV}
$$

Neutrons interact with ${ }^{3} \mathrm{He}$ gas in the counter to form a proton and a triton with the release of $764 \mathrm{keV}$ of energy from the nuclear reaction. Because the proton and triton are charged particles, they interact with the gas in the counter, and the output pulse is proportional to the energy deposited in the proportional counter gas.

If the proton and triton are stopped within the counter, the total energy deposited is the initial energy of the neutron plus the $764 \mathrm{keV}$, the Q value of the reaction. A thermal neutron produces a single peak at $764 \mathrm{keV}$ of energy, which is convenient for energy calibration. In addition, the positive $Q$ value of the reaction is often sufficiently high that gamma rays will deposit significantly less energy in the counter. Thus, neutrons and gamma rays can easily be separated by pulse height discrimination.

The probability of a ${ }^{3} \mathrm{He}(n, p) T$ reaction depends on the amount of ${ }^{3} \mathrm{He}$ gas present and the energy of the incident neutrons. Helium-3 has a cross-section that is proportional to the inverse of the velocity of the neutron at low energies; for thermal neutrons, the cross-section is 5327 barn. Because of the high cross-section for low energies, the ${ }^{3} \mathrm{He}$ proportional counter must be encased in a slow neutron absorber such as cadmium or boron to prevent pulse pile-up from distorting the recorded spectrum.

There are several problems that limit the usefulness of ${ }^{3} \mathrm{H}$. proportional counters for spectrometric applications:

- Pulse pile-up can occur if the count rate exceeds about 100 counts/second. Uniess special precautions are taken to reduce the count rate from thermal neutrons, the lower energy portion of the spectrum will be distorted by chance coincidences between neutron events and gamma events. [See page 14 of NUREG/CR-3610 (Brackenbush et al. 1984) for methods to estimate the amount of pulse pile-up and how it affects the analyzed data.]

- The lowest detectable energy is determined by the resolution of the proportional counter and by the peak produced by thermal neutrons, which overlaps very low-energy neutron events. Currently available ${ }^{3}$ He proportional counters have a resolution of about $2.5 \%$, so that the practical lower energy limit is about $30 \mathrm{keV}$. However, tubes 
with higher pressures above about 1 atmosphere have problems with gamma events being mistaken for low-energy neutron events. Also, great care must be taken in selection of tubes with good resolution. Some tubes have non-linear gains, such that thermal neutrons produce a few higher energy pulses that can be mistaken for lowenergy neutrons.

- At energies above $1.02 \mathrm{MeV}$ there are competing nuclear reactions that produce pulses that can be confused with the desired ${ }^{3} \mathrm{He}(n, p) \mathrm{T}$ reaction and complicate the proper interpretation of spectral data. Some of these competing reactions can be eliminated by rise time or pulse shape analysis, but this complicates the measurement apparatus.

- Some neutron-induced events occur near the wall or end of the counter. Charged particles striking the wall will not deposit all of their energy in the sensitive volume of the counter, and the resulting pulse will be confused with lower energy neutron events. The computer analysis code used to unfold the spectrum must correct for the wall events.

In spite of these apparent limitations, the ${ }^{3} \mathrm{He}$ proportional spectrometer offers some distinct advantages:

- The ${ }^{3} \mathrm{He}$ detectors are reasonably sensitive for neutrons with energies below about $1 \mathrm{MeV}$. Few other spectrometers operate well in this energy region.

- The data analysis of the ${ }^{3}$ He proportional counter is straightforward if the energy range is restricted. If many neutrons with energies above about $5 \mathrm{MeV}$ are present, the data analysis becomes quite complicated. Higher pressure tubes (with fillings above about 1 atmosphere) are more sensitive to higher-energy neutrons, but gamma rays can deposit sufficient energy to be confused with neutron events. Thus, the useful energy range is somewhat restricted. PuF emits neutrons in the proper energy range for the ${ }^{3} \mathrm{He}$ counter to be useful.

- The components necessary to construct a ${ }^{3} \mathrm{He}$ proportional counter are commercially available, moderately expensive, and perhaps more rugged than those of other types of spectrometers.

- The ${ }^{3} \mathrm{He}$ spectrometer is self-calibrating by using the $764 \mathrm{keV}$ peak produced by slow neutrons.

A computer code called HESTRIP was written to analyze the data from ${ }^{3} \mathrm{He}$ proportional counters. A Monte Carlo code was used to generate the response function for the proportional counter as a function of energy. The code uses the response function to remove wall events from the pulse height spectrum, 
then corrects for the ${ }^{3} \mathrm{He}$ cross-section to determine the incident neutron flux over an energy range of $100 \mathrm{keV}$ to about $3 \mathrm{MeV}$. A more detailed description is given in Section 3 of PNL-6620, Vol. 2 (Brackenbush et al. 1988) and in NUREG/CR-3610, PNL-4943 (Brackenbush et al. 1984).

\subsection{SURVEY INSTRUMENTS}

Neutron survey instruments, such as the Snoopy or Eberline PNR-4 "remball," are traditionally used to determine dose equivalent rates. These devices consist of a 9-in.-diameter cylinder or sphere of polyethylene. A boron trifluoride or ${ }^{3} \mathrm{He}$ proportional counter is positioned at the center of the moderator to detect slow neutrons. Over a range of neutron energies, the count rate measured at the center of the moderator follows the curve of the neutron fluence-to-dose-equivalent conversion factor curve as a function of incident neutron energy.

Some instrument manufacturers claim an accuracy of $15 \%$ over an energy range of thermal to $20 \mathrm{MeV}$. But measurements at the Physikalish Technische Bundesanstalt in Braunschweig, Germany, have shown that the response of commercially available neutron survey meters is far from ideal (Lesikecki and Cosack 1984). The data of Lesiecki and Cosack demonstrate that a typical survey meter underestimates the dose equivalent by a factor of 2 at $14 \mathrm{MeV}$ and overestimates the dose equivalent by factors of 2 to 3 at $20 \mathrm{keV}$. Survey instruments also exhibit changes in response with the direction of incidence of the neutrons due to absorption and scattering of neutrons by the electronics packages attached to the moderator/detector. This can also result in $40 \%$ variation in response, depending upon the direction of incidence.

For plutonium and plutonium compounds, most of the neutrons that contribute significantly to dose equivalent have energies between $100 \mathrm{keV}$ and about $5 \mathrm{MeV}$. In this energy range, commercially available neutron survey instruments function quite well, particularly if they are carefully calibrated with ${ }^{252} \mathrm{Cf}$ neutron sources. Moderate amounts of shielding (less than 6 in. of acrylic plastic or other moderator) do not alter the spectrum sufficiently to introduce large errors in the survey meter measurements. 


\subsection{PERSONNEL NEUTRON DOSIMETERS}

This section describes two types of personnel dosimeters, electrochemically etched CR-39 foils and TLD-albedo dosimeters, and the energy ranges over which these dosimeters can be used.

\subsubsection{CR-39 Nuclear Track Dosimeters}

Nuclear track detectors were discovered by R. L. Fleischer, B. Price, and R. M. Walker at the General Electric Research Laboratories in Schenectady, New York, in the early 1960s. The book Nuclear Tracks in Solids (Fleischer 1975) contains an excellent review of the subject. One of the first neutron dosimeters using track etch material in contact with fissionable material was developed at Hanford in 1964-1966 (Baumgartner and Brackenbush 1966). More recently, L. Tomassino discovered that electrochemically etched CR-39 plastic (diallyl diglycol carbonate) offered superior energy response for neutron dosimetry (Tommasino 1970). Work has progressed at PIL and at Lawrence Livermore Laboratories to develop a fast neutron dosimetry system using improved CR-39 plastic. Neutron dosimetry using CR-39 became practical with the development of "dosimetry grade" CR-39 and detailed studies of the etching parameters, stability, energy response, and angular response of improved materials.

When heavy charged particles pass through solid materials, they produce a damaged volume that is susceptible to chemical attack. The CR-39 plastic is especially useful, because proton recoils from films on the surface of the CR-39 or the CR-39 itself produces damaged sites that are easily etched by exposing the foil to an alternating electric field in a caustic potassium hydroxide solution. The electrochemically etched tracks are readily visible under a low-power microscope. The number of tracks per unit area is directly proportional to the neutron dose over a fairly wide range of energies above about $100 \mathrm{keV}$. The number of tracks per unit area is determined by an automated optical reader, and the track density is converted into a fast neutron dose equivalent (Hankins et a1. 1987).

Laboratories use materials from various sources, and the reader is cautioned that some materials may not have the same etching parameters and energy responses as the material used in this study. The CR-39 foils are 
nominally $25-\mathrm{mil}(0.635-\mathrm{mm})$ thick with $5-\mathrm{mil}(0.127-\mathrm{mm})$ polyethylene films on both sides to protect the surface. For the exposures in the field, two foils were inserted side by side in a plastic badge holder taped to the surface of the acrylic plastic phantom.

After exposure, the CR-39 dosimeters were electrochemically etched at $2500 \mathrm{~V}$ using Homann-type etch chambers and the etching procedure described by D. E. Hankins in UCRL-53833, Rev. 1 (Hankins et al. 1989). This procedure results in a more uniform sensitivity (tracks per neutron) for neutrons with energies between $200 \mathrm{keV}$ and about $5 \mathrm{MeV}$, a range which encompasses most of the neutrons emitted by plutonium and plutonium compounds. The energy dependence of electrochemically etched CR-39 dosimeters using this procedure is given in Figure 2.1. Note that the etched surface is the surface towards the source and away from the phantom in these studies. (This results in slightly higher sensitivity, because the polyethylene covering has a higher hydrogen density than CR-39 itself.)

Like TLD-albedo dosimeters, CR-39 exhibits a strong angular dependence, as shown in Figure 2.2 (Hankins et al. 1989). This is a serious problem for personnel dosimetry at present, but may be of benefit if CR-39 dosimeters are used to estimate effective dose equivalent in which the direction of incidence of the neutrons must be evaluated for determining the proper conversion factors. In this study, the dosimeters were placed on the surface of acrylic plastic phantoms, dimensions $40 \mathrm{~cm}$ by $40 \mathrm{~cm}$ by $25 \mathrm{~cm}$, which were positioned at right angles to the neutron sources (the 00 position shown in Figure 2.2).

\subsubsection{ILD-Albedo Dosimeters}

The TLD-albedo dosimeter is the most widely used personnel neutron dosimeter in DOE facilities. This dosimeter employs a slow neutron detector worn on the surface of the body. Fast neutrons strike the body and are moderated and reflected, and then return to the surface where they are detected by the TLDs. Because the neutrons are reflected back from the body, the dosimeter is also called "albedo." At Hanford TLDs are used in pairs; one type (such as TLD-600) is sensitive to both slow neutrons and gamma rays, and a second (such as TLD-700) is sensitive only to gamma rays. The neutron response is determined from the difference in response of the paired TLDs. 


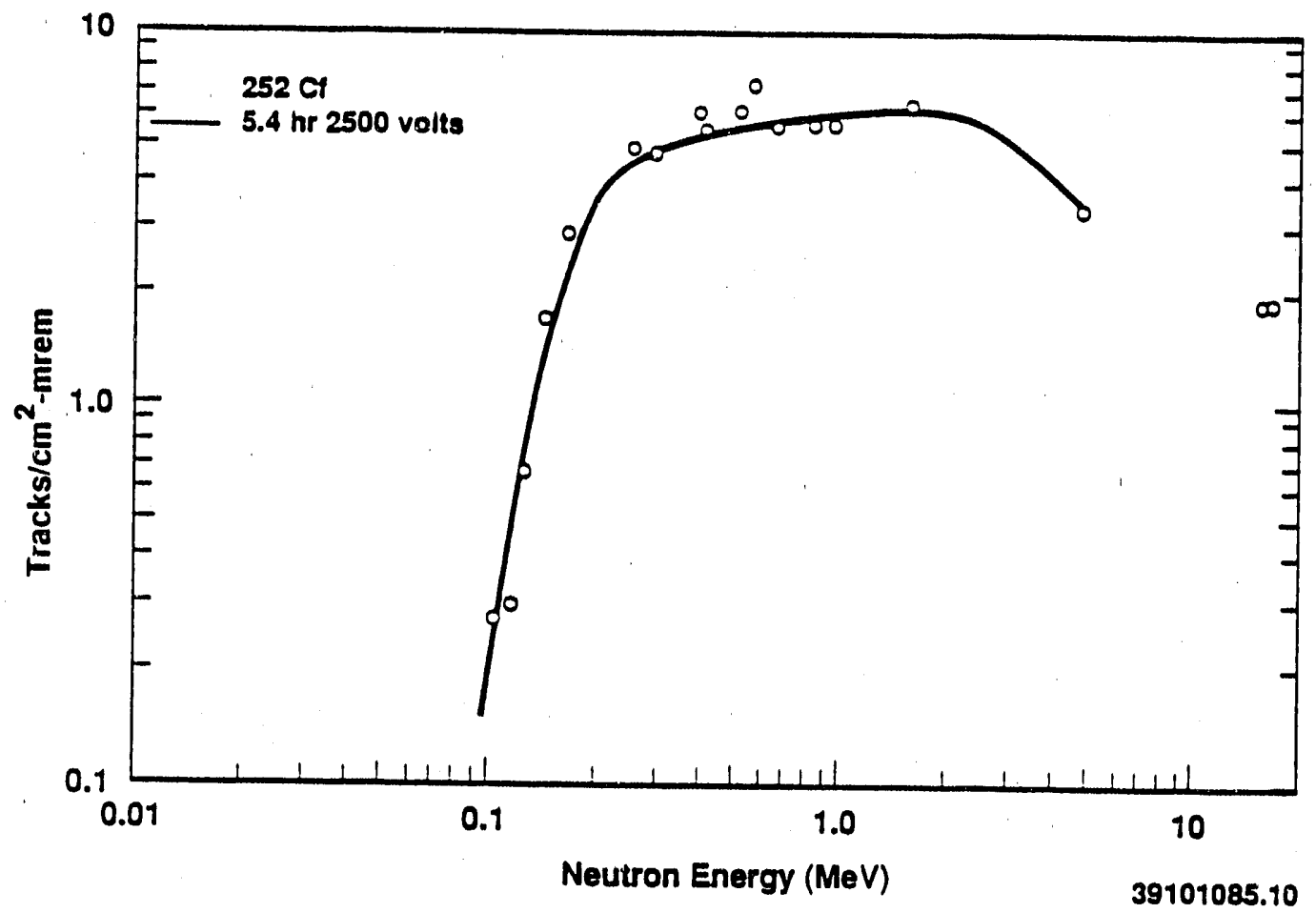

EIGURE 2.1. Variation in the Response (Tracks per Neutron) as a Function of Neutron Energy for Electrochemically Etched CR-39

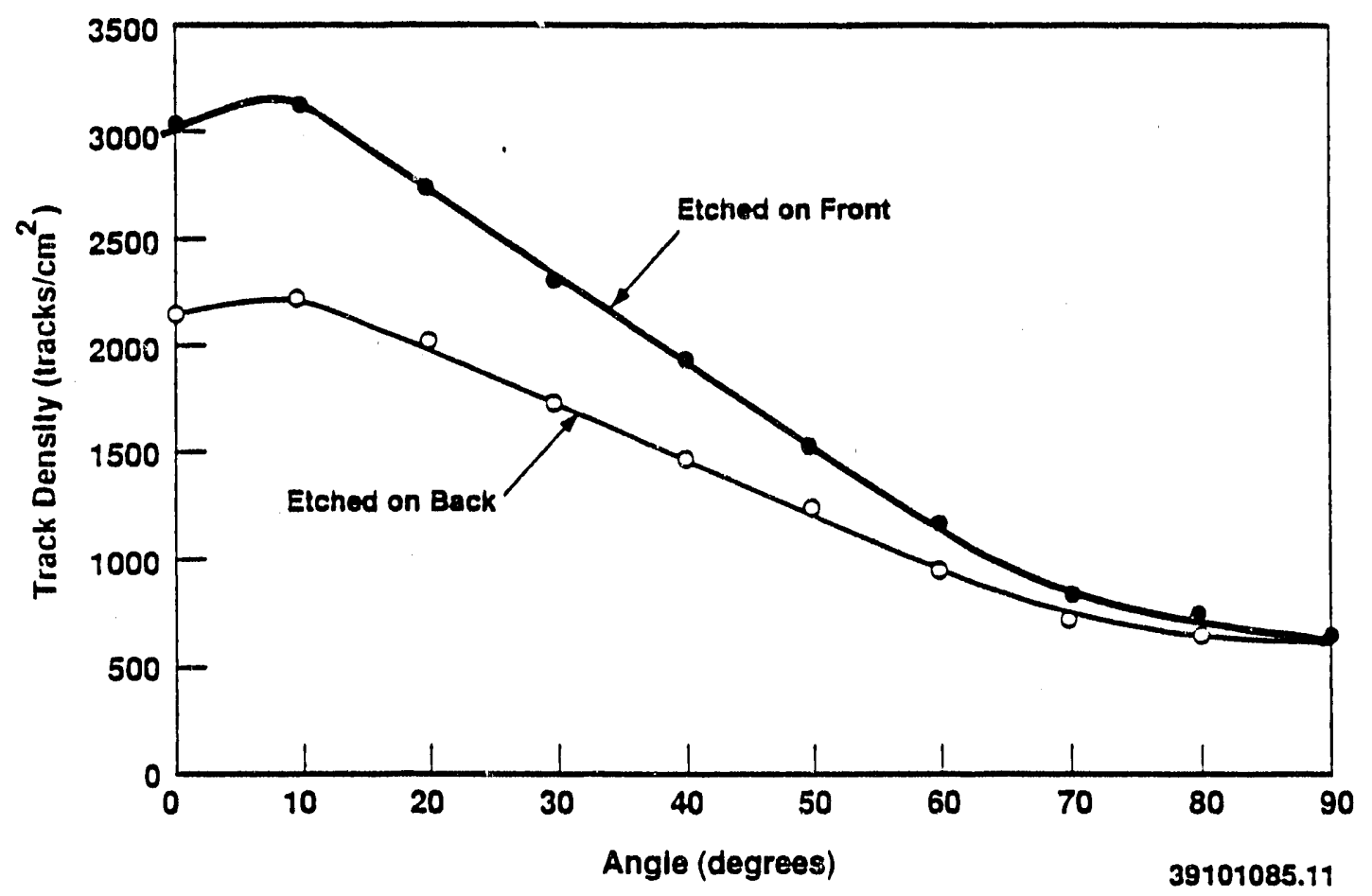

FIGURE 2.2. Directional Response of CR-39 Dosimeters on a Phantom Exposed to a ${ }^{252} \mathrm{Cf}$ Source 
Thermoluminescent dosimeters consist of crystals doped with certain impurities to create energy traps in the crystalline lattice. When these materials are heated, they emit visible light that is proportional to the amount of energy stored in the traps. At Hanford TLDs are used for neutron dosimetry; the crystals contain ${ }^{6} \mathrm{~L} i$ that absorbs slow neutrons and emits alpha particles. These alpha particles deposit energy in the crystal lattice, which is stored until the TLD crystal is heated in a suitable reader with a photomultiplier to measure the amount of light emitted.

The TLD-albedo dosimeters have several advantages over other types of passive personnel neutron dosimeters:

- TLD-albedo dosimeters always give some indication when exposed to a significant neutron dose.

- They are relatively inexpensive and can be reused many times.

- They are simple to fabricate, lightweight, and easy to wear.

- They are insensitive to humidity and moderate mechanical shock.

- Readout is relatively simple, covers a wide dosimeter response range, and automated readers are available to process thousands of dosimeters.

There are also several disadvantages in using TLD-albedo dosimeters:

- The most important disadvantage is that the response of the TLD-albedo dosimeter is highly energy-dependent. Errors of a factor of 10 are possible if the dosimeter is not properly calibrated.

- TLDs are also sensitive to mixed radiations, and significant errors can occur if the dosimeter is not properly designed to correct for the effects of gamma and beta radiations.

- Many TLD-albedo dosimeters, including the Hanford multipurpose dosimeter, must be worn flat against the body for the dosimeter to function properly. They cannot be worn dangling from a necklace or lanyard.

- TLDs do not provide a permanent record that can be reread at a later time; if the reader malfunctions during operation, the dosimeter reading can be lost. 
- TLDs must be carefully annealed to preserve the accuracy of their calibration.

- Some TLDs may exhibit fading problems with time, especially at elevated temperatures, such as being stored on the dashboard of automobiles.

The severe energy response problem of TLD-albedo dosimeters is demonstrated in Figure 2.3. A simplistic explanation of the variation in response with energy is that high energy neutrons must penetrate further into the body before they are thermalized. The deeper into to body the neutron penetrates before being thermalized, the greater the probability of being absorbed before the slow neutron can return to the surface of the body where the TLD-albedo dosimeter is worn.

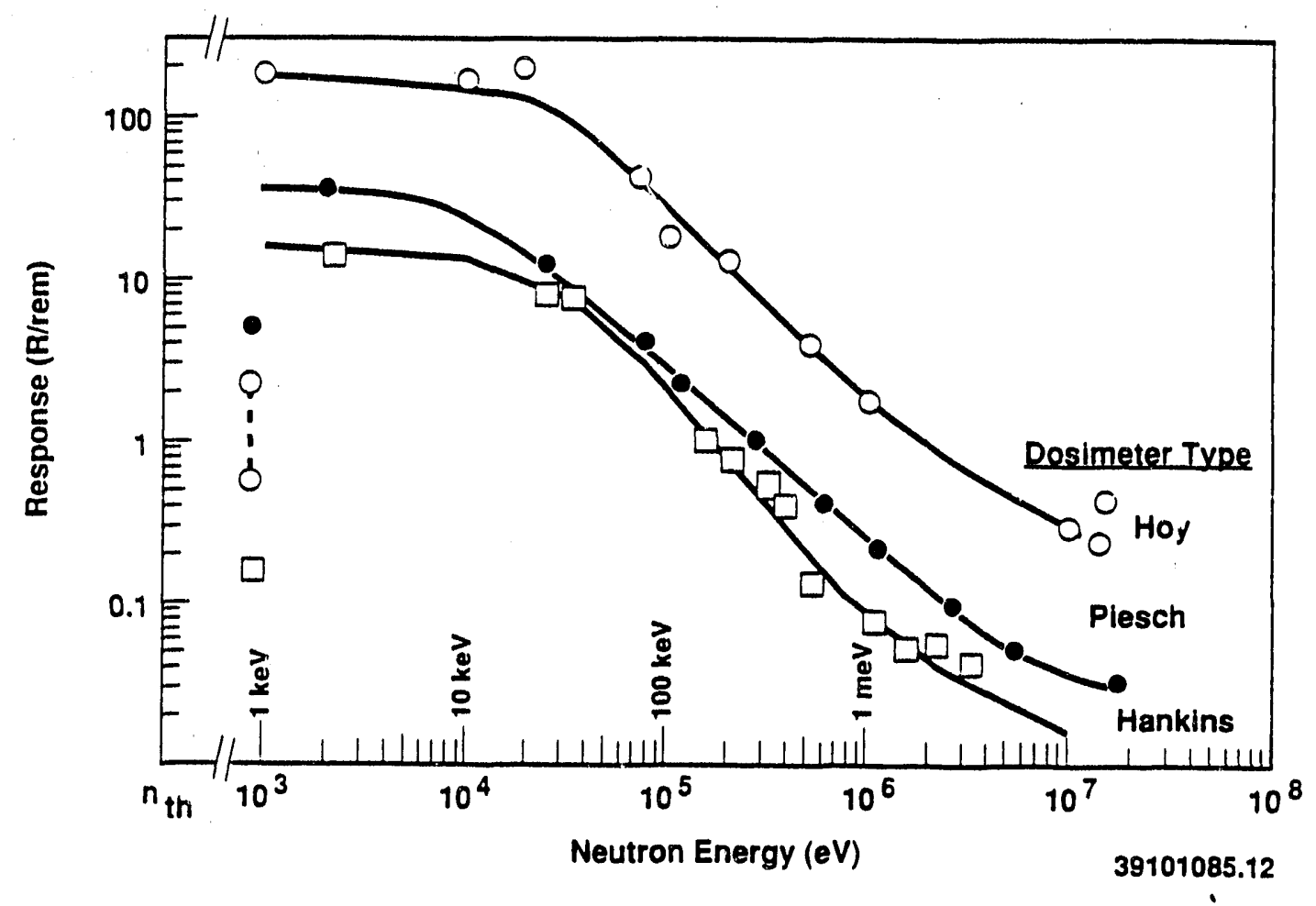

FIGURE 2.3. Energy Dependence of Various TLD-Albedo Dosimeters (Source: Piesch and Bergkhardt 1978) 
Details of the construction, calibration, and methods of dose interpretation of the Hanford multipurpose dosimeter have been published el sewhere (Kocher et al. 1971; Fix et al. 1981). The neutron dosimetry portion of the multipurpose badge consists of three LiF "chips" corresponding to positions 3, 4 , and 5 in Figures 2.4. Two of the chips (positions 3 and 4) are isotopically enriched to a maximum of $95 \%{ }^{6} \mathrm{~L} i$ to respond to neutrons, and the remaining chip (position 5) is enriched to $99.993 \%{ }^{7} \mathrm{Li}$ to respond primarily to gamma rays. Figure 2.4 shows the position of the thermoluminescent (TL) chips in the plastic dosimeter card, and the front and back views of the dosimeter holder which also holds a security credential. Table 2.3 provides details of the filter materials and dimensions.

The ${ }^{6} \operatorname{Li}(n, \alpha)$ cross-section is about 1000 barn for thermal neutrons and about 0.3 barn for $1.0-\mathrm{MeV}$ neutrons; therefore, we can assume that the ${ }^{6} \mathrm{LiF}$ chip responds only to slow neutrons, which originate from the source or are produced by fast neutrons moderated and reflected from the body. The "bare" ${ }^{6}$ LiF chip at position 3 responds to the backscattered neutrons from the body as well as to incident neutrons. The ${ }^{6} \mathrm{Li}$ chip in position 4 is shielded from incident slow neutrons by placing $0.51 \mathrm{~mm}$ of cadmium in front of $i t$. However, a small correction must be made for neutrons that diffuse around the cadmium filter.

Traditionally, the Hanford multipurpose dosimeter was evaluated by the following method. The response of the chip is proportional to the neutronreaction rate in the chip, which is the number of ${ }^{6} \mathrm{Li}$ atoms multiplied by the ${ }^{6} L i(n, \alpha)$ cross-section and the slow neutron flux reaching the TLD chip. The slow neutron flux reaching the chip originates from 1) slow neutrons from the source $\left(\phi_{s}\right), 2$ ) backscattered slow neutrons that diffuse around the cadmium filter $\left(\phi_{s}{ }^{\prime}\right)$, and 3 ) fast neutrons from the source that are moderated and return to the TLD as slow neutrons $\left(\phi_{f}{ }^{\prime}\right)$. If we ignore photon response, the response of chip 3 is the sum of the direct slow neutron response and the backscattered slow neutrons that diffuse around the cadmium and the backscattered fast neutrons:

$$
R_{3}=c\left[\phi_{s}+\phi_{s}^{\prime}+\phi_{f}^{\prime}\right]
$$




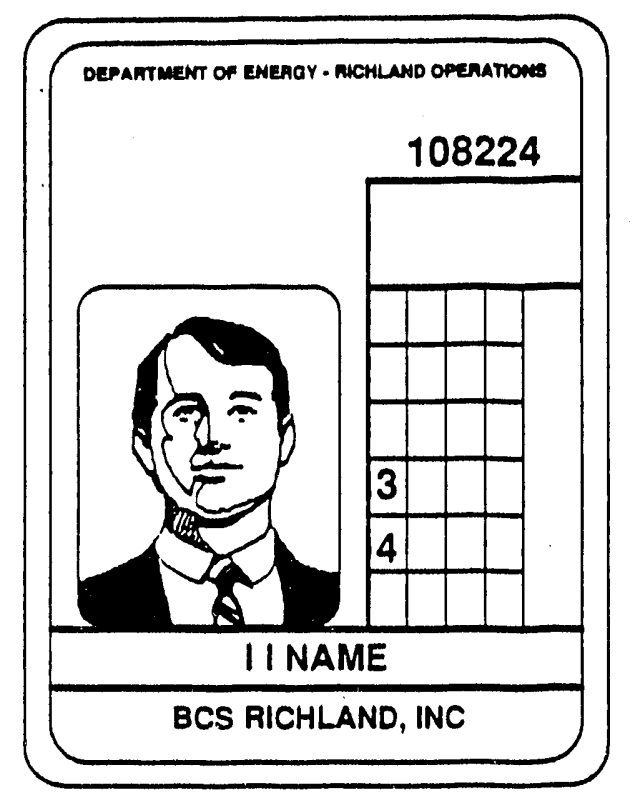

Security Credential

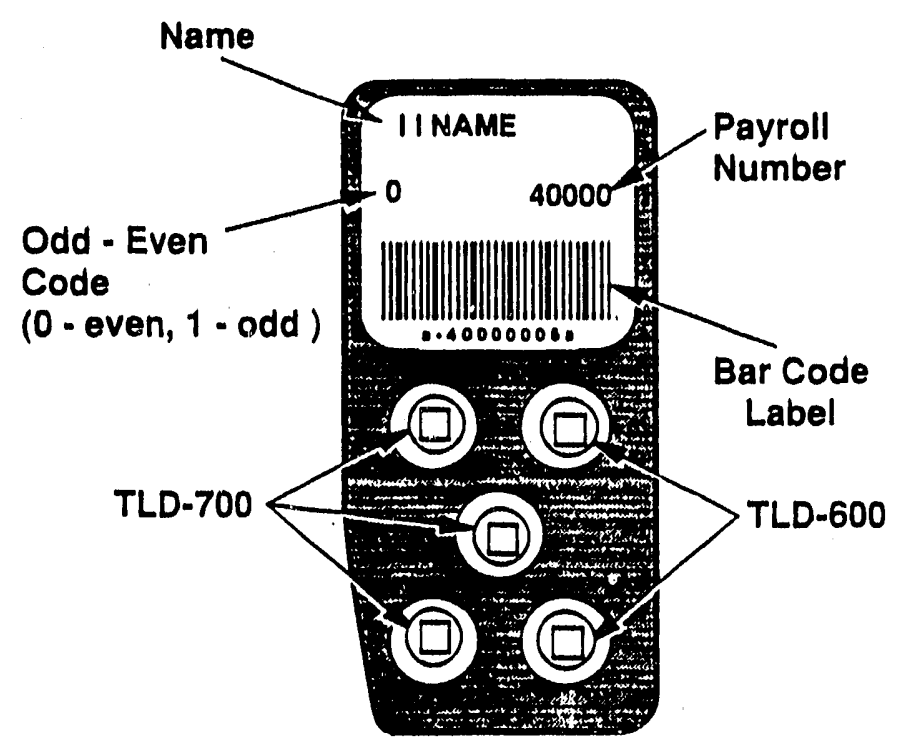

Desimeter

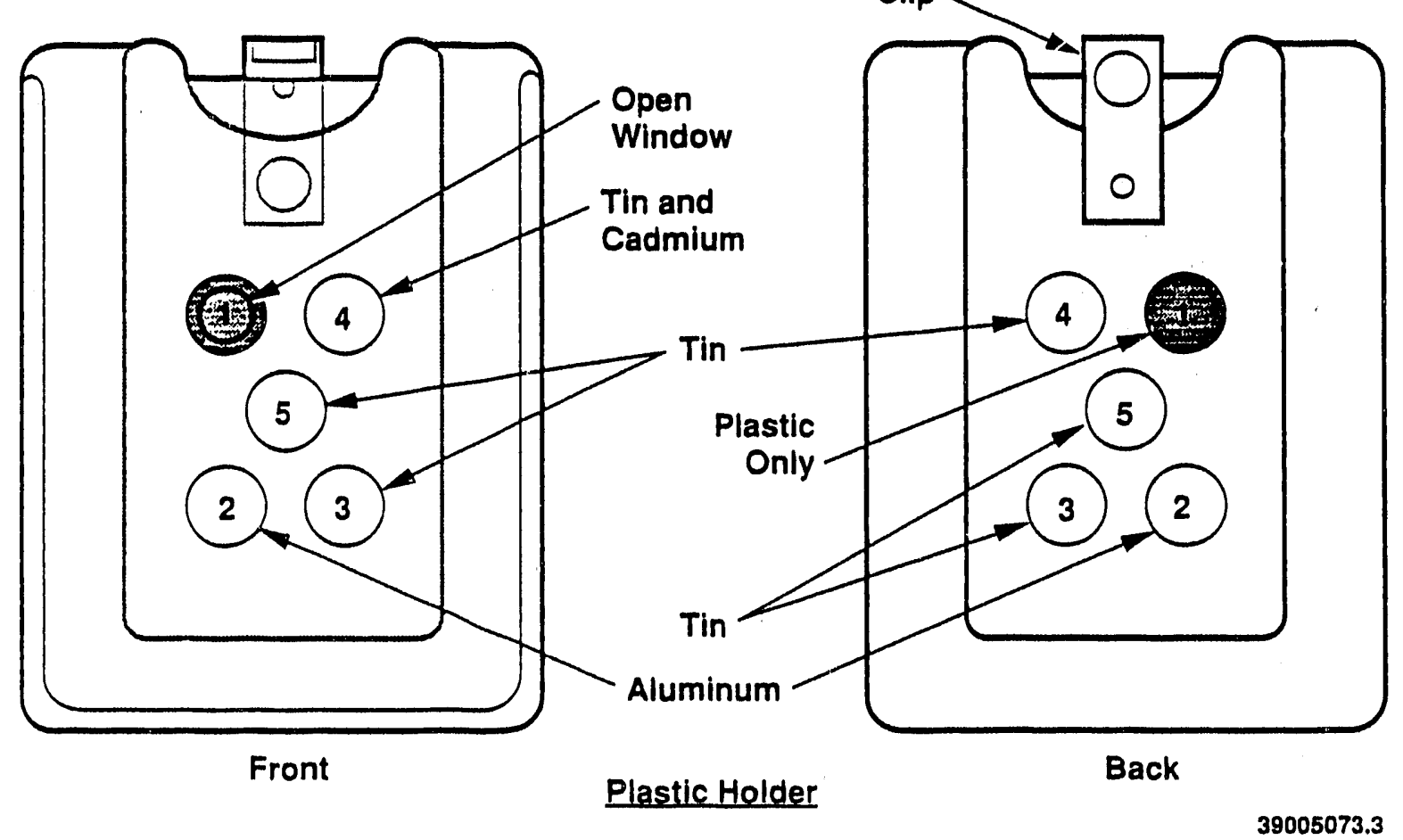

FIGURE 2.4. View of Dosimeter Card Containing the TLDs and the Dosimeter Holder with Various Filters 
TABLE 2.3. Description of the Filters Used at Each Position in the Hanford Multipurpose Dosimeter

Position

1. Front

Back

2. Front

Aluminum filter
Dosimeter card Tefion
Total

Back

Badge holder Aluminum filter Dosimeter card Tefion Total

Security credential Dosimeter card Tefion Total

Badge holder

Dosimeter card Tefion Total

Security credential Badge holder Dosimeter card Tefion Total

3. Front Security credential Badge holder Tin filter Dosimeter card Tefion Total

Thickness (mi1) $\left(\mathrm{mg} / \mathrm{cm}^{2}\right)$

32.6

2.0 83 $\frac{5}{88}$

7.1

2.0 56 $\frac{6}{61}$

33.0

41.0

26.6

2.0 84 84 182 $\frac{5}{356}$

40.6

27.3

2.0 85 187 $\frac{5}{277}$

33.0 25.6

41.0 84 53 760 Total

Back

Badge holder

Tin filter

Dosimeter card Teflon

4. Front Security credential

Badge holder

Cadmium filter

Tin filter

Dosimeter card Tefion Total

Back

Badge holder

Tinfilter

Dosimeter card Tefion Total
2.0

28.5

41.3

2.0

$\frac{5}{902}$

33.0

25.8

20.8

21.1

2.0

59

766

$\frac{5}{830}$

84

54

457

391

$\frac{5}{991}$

$25.8 \quad 54$

41.0

2.0

760

$\frac{5}{819}$ 
IABLE 2.3. (continued)

\begin{tabular}{clc} 
Position & \multicolumn{1}{c}{ Description } & $\begin{array}{c}\text { Thickness } \\
\text { (mil) }\end{array}$ \\
\hline \multirow{2}{*}{ 5. Front } & Security credential & 33.0 \\
& Badge holder & 25.8 \\
& Tin filter & 40.9 \\
& Dosimeter card Teflon & 2.0 \\
& Total & \\
Back & Badge holder & 25.0 \\
& Tin filter & 41.1 \\
& Dosimeter card Teflon & 2.0 \\
& & \\
Densities & used for calculations: & \\
& Teflon & $1.0 \mathrm{~g} / \mathrm{cm}^{2}$ \\
& ABS plastic in holder & 0.82 \\
& Aluminum filter & 2.70 \\
& Cadmium filter & 8.65 \\
& Tin filter & 7.30
\end{tabular}

Ignoring the photon response, the response of chip 4 is just the slow neutrons that diffuse around the cadmium filter and the backscattered fast neutrons that are moderated by the body:

$$
R_{4}=c\left[\phi_{s}^{\prime}+\phi_{f}^{\prime}\right]
$$

where $R_{3}$ and $R_{4}$ are the thermoluminescent responses of chips 3 and 4 , respectively, and $c$ is an arbitrary constant of proportionality. The difference between $R_{3}$ and $R_{4}$ can be related to the incident thermal neutron dose by subtracting Equation (2.4) from Equation (2.3):

incident slow neutron dose $=\left(R_{3}-R_{4}\right) / k_{4}$ mrem

where $k_{4}$ is a calibration constant. By exposing the badge to a source of pure thermal neutrons, $\phi_{f}$ and $\phi_{f}{ }^{\prime}$ are zero, so that Equations (2.3) and (2.4) become:

$$
\begin{aligned}
& R_{3}=c\left[\phi_{s}+\phi_{s}{ }^{\prime}\right] \\
& R_{4}=c\left[\phi_{s}\right]
\end{aligned}
$$

Using Equations (2.6) and (2.7), the ratio of backscattered thermal to incident thermal neutrons can be defined as a constant:

$$
k_{5}=\phi_{s}{ }^{\prime} / \phi_{s}=R_{4} /\left(R_{3}-R_{4}\right)
$$


Equation (2.8) can be rewritten to give the response of chip 4 to backscattered slow neutrons:

$$
R_{4}=k_{5}\left(R_{3}-R_{4}\right)
$$

Equation (2.9) is needed in the determination of the fast neutron dose. Subtracting that portion of the backscattered neutrons due to slow neutrons $\left(k_{5} \phi_{s}\right)$ from the bracketed term in Equation $(2.4)$, yields a response of $R_{4}$ that is proportional to $\phi_{f}$. This can then be related to the fast neutron dose.

The ${ }^{6}$ Lif chips are a'iso sensitive to photons, so a chip of ' $L i F$ material is placed in position 5 and shielded front and back by $1.02 \mathrm{~mm}$ of tin to prevent beta particles and low-energy photons from interacting and possibly causing statistical problems in low neutron dose interpretations in mixed radiation fields. The TL chip in position 3 is similarly shielded and the chip in position 4 has $1.02 \mathrm{~mm}$ of tin on the back and $0.51 \mathrm{~mm}$ on the front between the cadmium and the chip. This arrangement is designed to make all three shields photon-equivalent and helps reduce the photon contribution from the activated cadmium in position 4.

The fast neutron dose is proportional to the response of chip 4 minus both a correction for gamma rays and a correction for slow neutrons that diffuse around the cadmium filter. The correction for gamma rays is given by the response of chip 5 multiplied by a constant to take into account the differences in chip sensitivity between TLD-600s and TLD-700s. The correction for slow neutrons that diffuse around the cadmium filter is given by Equation (2.9). The fast neutron dose is then interpreted using the equation:

fast neutron dose $=\left[R_{4}-k_{6} R_{5}-k_{5}\left(R_{3}-R_{4}\right)\right] / k_{7}$ mrem where $k_{6}$ is a correction factor for the differences in photon sensitivity between the ${ }^{6} \mathrm{LiF}$ and ${ }^{7} \mathrm{LiF}$ chips, and $k_{7}$ is a calibration constant. The various constants can be evaluated by making exposures to fast and thermal neutron sources. This formulation is quite simplistic and only functions for a single fast-neutron energy spectrum. Additional correction factors must be applied to correct for differences in the response to different spectra in the work place. One of the goals of this study is to derive these correction factors and obtain data to derive improved dosimeter evaluation algorithms. 


\subsection{MEASUREMENT FACILITIES}

This section describes the neutron sources used and the facilities in which the measurements were performed. Verification measurements were performed at the PNL Calibration Laboratory in the 318 Building on the Hanford Site to verify the accuracy of the detectors used. These verification measurements were performed using bare and $D_{2} 0$-moderated ${ }^{252} \mathrm{Cf}$ sources callibrated by NIST. Field measurements were performed at the Plutonium Finishing Plant (PFP) in the 234-5 Building, using plutonium metal, plutonium fluoride, and plutonium oxide sources. Dosimeters were exposed to bare sources and to sources shielded by acrylic plastic slabs. Details of the facilities and the sources used are presented in this section.

\subsection{DESCRIPTION OF FACILITIES}

The detector verification measurements were performed in the PNL Calibration Laboratory in the 318 Building. The field measurements with plutonium sources were conducted at the PFP in the 234-5 Building.

\subsubsection{Calibration Laboratory}

The Calibration Laboratory was specifically designed for calibration measurements under very low-scatter conditions. The low-scatter room for neutron calibrations was constructed with massive concrete walls, $10 \mathrm{~m}$ by $14 \mathrm{~m}$ by $9 \mathrm{~m}$ ( $30 \mathrm{ft}$ by $42 \mathrm{ft}$ by $27 \mathrm{ft}$ ), with the neutron sources positioned in the approximate center of the room at $4 \mathrm{~m}(12 \mathrm{ft})$ above the floor. The sources are moved to the irradiation position on a tower using a pneumatic transfer system. An aluminum grating platform surrounding the tower helps to minimize neutron scatter. A more detailed description of the facility is given in the paper by J. C. McDonald (1988) in Operation of a Proficiency Testing Laboratory for Radiation Dosimeters, PNL-SA-15532, presented at the National Conference of Standards Laboratories 1988 Workshop and Symposium, pages 19-1 to $19-11$.

Two dosimetry accreditation programs use this facility: the DOELAP, based on the DOE standard Department of Energy Standard for Performance Iesting of Personnel Dosimetry Systems (DOE 1986a); and the National Voluntary 
Laboratory Accreditation Program (NVLAP), operated by NIST and based on ANSI Standard N13.11, American National Standard for Dosimetry. Personnel Dosimetry Performance - Criteria for Testing (ANSI 1983).

To verify the consistency (or traceability) of the PNL measurements with national standards, the PNL Calibration Laboratory uses a hierarchial system of calibrations standards. In order to achieve measurements of national standards quality, the PNL Calibration Laboratory is participating in a measurements quality assurance (MQA) program in conjunction with NIST. In addition, the ${ }^{252} \mathrm{Cf}$ neutron sources used in the laboratory are periodically calibrated at NIST. The standards that form the basis for the dosimeter proficiency testing programs require that the overall uncertainty in the irradiation not exceed 5\%; the overall uncertainty in the neutron irradiations from the ${ }^{252} \mathrm{Cf}$ sources is estimated at $4.2 \%$ (see data from Table 2 of PNL-SA-155is, McDonald 1988).

\subsubsection{Plutonium Finishing Plant}

Measurements with plutonium sources were performed at the PFP in room 179C of the 234-5 Building. This location was selected for a variety of reasons. Room $179 \mathrm{C}$ has the necessary handling procedures, criticality safety specifications, physical security, and trained technicians to allow kilogram quantities of plutonium to be left unattended for the several days required to perform the necessary measurements. A plan view of the physical layout of Room $179 \mathrm{C}$ is given in Figure 3.1. The room is large enough that nearby equipment will not cause significant neutron scatter when the plutonium source is positioned in the middle of the room. However, the glove boxes at a distance of $295 \mathrm{~cm}$ ( $9 \mathrm{ft}, 8 \mathrm{in.}$ ) from the source contained some plutonium, and a definite increase in the neutron background was observed near the glove boxes. In retrospect, it may have been better to locate the sources farther away froin the glove boxes to reduce the neutron background.

The plutonium sources were positioned at the approximate center of the room on an aluminum table (a slide projector support stand), which was $100 \mathrm{~cm}$ ( $3 \mathrm{ft}, 4 \mathrm{in.}$ ) above the floor. Various detectors were positioned around the 


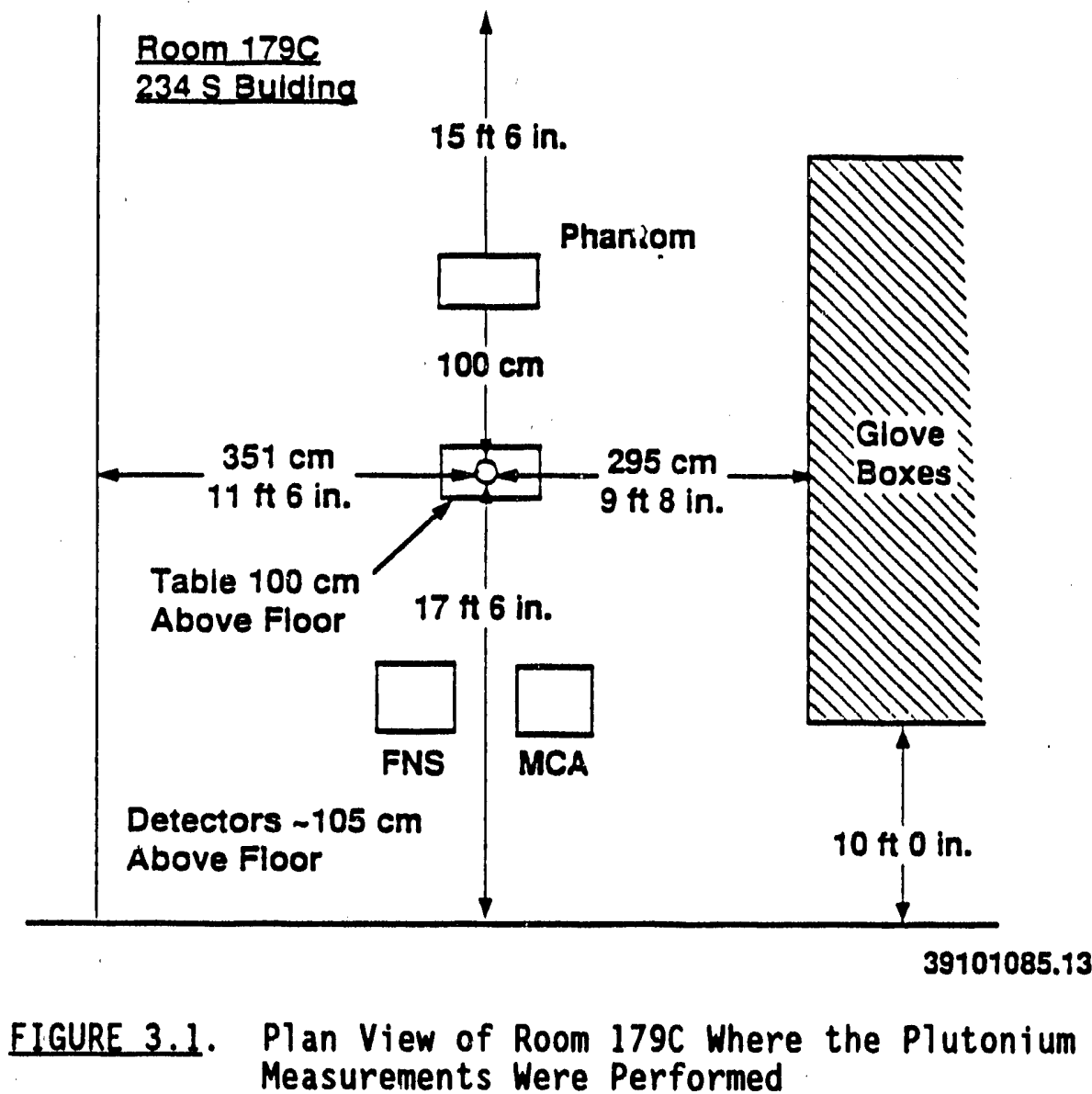

sources at a height of about $105 \mathrm{~cm}(3 \mathrm{ft}, 6 \mathrm{in}$.) above the concrete floor. The TEPC and multisphere detectors were positioned on tripods, which produced minimal scatter of neutrons. The acrylic plastic phantoms were placed on aluminum tables to support the heavy weight, and the center of the phantom was positioned at about $105 \mathrm{~cm}(3 \mathrm{ft}, 6 \mathrm{in}$.) above the floor to match the center of the plutonium sources. For the measurements made behind acrylic plastic shielding, the $40-\mathrm{cm}-b y-40-\mathrm{cm}(16-i n .-b y-16-i n$.$) slabs of plastic were$ supported on another aluminum table positioned near the source.

For the measurements made with the plutonium metal and plutonium oxide sources, the acrylic plastic phantoms for the personnel dosimeters werc positioned as shown in Figure 3.1 to minimize the influence from neutrons from the glove boxes. At the position nearest the glove box, the $10.2-\mathrm{cm}(4-\mathrm{in}$. thick phantom provided shialding to greatly reduce the background. A second phantom was positioned at $90^{\circ}$ to the glove box. The sensitivity of TLD-albedo 
and CR-39 dosimeters is significantly reduced for neutrons striking the dosimeters from the side. With this arrangement, the neutron dose equivalent corrected for room background should be applicable for the dosimeter exposures.

\subsection{NEUTRON SOURCES}

This section describes the neutron sources used for the measurements. Two calibrated ${ }^{252} \mathrm{Cf}$ neutron sources were used for the verification measurements in the 318 Building, as described in Section 3.2.1. The field measurements were performed with plutonium metal, plutonium oxide, and plutonium fluoride sources, as described in Section 3.2.2.

\subsubsection{Calibrated Neutron Sources}

Two different ${ }^{252} \mathrm{Cf}$ neutron sources, labelled source $318-38$ and source 318-167, were used for the verification measurements in the PNL Calibration Laboratory. Both of these sources have neutron emission rates and dose equivalent rates determined by NIST, as shown in Table 3.1. Following the protocol of ANSI N13.11 (ANSI 1983), the reutron dose equivalent rates are evaluated at a centerline distance of $50 \mathrm{~cm}(20 \mathrm{in}$.$) from the source; the$ dose equivalent rate at other distances up to $1 \mathrm{~m}(3.3 \mathrm{ft})$ is calculated using simple inverse square attenuation. This neglects the effects of room scatter, which is acceptable for distances of less than $1 \mathrm{~m}(3.3 \mathrm{ft})$. Corrections for the decay of the ${ }^{252} \mathrm{Cf}$ sources are made by assuming a halflife of 2.645 years. Two different irradiation geometries were used for the calibration measurements: a bare geometry, in which the ${ }^{252} \mathrm{Cf}$ source was contained in the "rabbit" capsule used for the pneumatic transfer system and a moderated geometry, in which the ${ }^{252} \mathrm{Cf}$ source is enclosed in a $30-\mathrm{cm}(12-\mathrm{in}$. diameter sphere of deuterium oxide, that considerably softens the spectra.

The ${ }^{252} \mathrm{Cf}$ material is in the form of an oxide, which is contained in a SR-Cf-100 capsule. This capsule is cylindrical with porous platinum plugs on each side of the ${ }^{252} \mathrm{Cf}$ to allow venting of the helium and fission gases to prevent the build-up of high-pressure gases inside the source capsule. The source is doubly encapsulated. The primary encapsulation is with a $90 \%$ platinum-10\% rhodium alloy cylinder positioned inside a secondary 
encapsulation consisting of Zircalloy-2. The SR-Cf-100 capsule is contained inside an aluminum capsule used for the pneumatic transfer system.

As a result of the encapsulation, the spectrum from the ${ }^{252} \mathrm{Cf}$ source is softened (i.e., lowered in energy) due to scatter within the source encapsulation. The neutron energy spectrum from the bare ${ }^{252} \mathrm{Cf}$ source inside the aluminum transfer capsule is shown in Figure 3.2, along with calculated spectra presented in the International Organization for Standardization (ISO), Standard 8529 (ISO 1986). The average energy of the encapsulated neutron source is calculated to be $2.01 \mathrm{MeV}$, based on the calculations of Hertel and McDonald (1990). The fluence-to-dose-equivalent conversion factor for this source is calculated to be $3.32 \times 10^{-5} \mathrm{mrem}-\mathrm{cm}^{2}$ (Hertel and McDonald 1990).

Because there is more material at the ends of the cylindrical capsules, neutrons are preferentially scattered out the sides of the cylinder. As a result, the neutron flux at $90^{\circ}$ to the axis of the cylinder is calculated to be $7.1 \%$ higher than expected from isotropic emission (Hertel and McDonald 1990). Dosimeters and instruments are usually irradiated at the $90^{\circ}$ position, so the dose equivalent rate must be corrected by the anisotropy factor to account for the increase in fluence due to scatter within the source encapsulation.

To provide a lower-energy neutron energy spectrum, it is possible to mount a $30-\mathrm{cm}(12-\mathrm{in}$.$) diameter sphere of \mathrm{D}_{2} \mathrm{O}$ around the ${ }^{252} \mathrm{Cf}$ sources. The $\mathrm{D}_{2} \mathrm{O}$-moderated sphere represents one extreme of moderated fission spectra, while the bare ${ }^{252} \mathrm{Cf}$ source represents the other. The low-energy $\mathrm{D}_{2} \mathrm{O}$-moderated spectrum is used to simulate the much softer neutron energy spectrum found in commercial nuclear power plants, and is recommended for performance testing of personnel neutron dosimeters by the ANSI Standard N-13.11 (1983). However, it should be noted that the $\mathrm{D}_{2} \mathrm{O}$-moderated ${ }^{252} \mathrm{Cf}$ source does not yield a neutron energy spectrum similar to that of commercial nuclear reactors, but the response per unit dose equivalent of a typical TLD-albedo dosimeter is similar to that from a dosimeter exposed to the lower energy spectrum found in nuclear reactors (Brackenbush et a1. 1984).

Calculations by Hertel and McDonald (1990) demonstrate that the moderated spectrum is highly dependent on the amount of hydrogen oxide present in 
the deuterium oxide. In the PNL sphere, the $D_{2} \mathrm{O}$ is considered to be $99.7 \%$ pure; the amount of hydrogen oxide is inconsequential for altering the neutron energy spectrum.

The PNL sphere is $30 \mathrm{~cm}$ (12 in.) in diameter to the inner surface of a steel sphere containing the $D_{2} 0$, and the outer surface is covered with $0.5 \mathrm{~mm}$ (0.02 in.) of cadmium metal to eliminate thermal neutrons. Because the PNL sphere is mounted on a pneumatic source transfer system, it has a $4-\mathrm{cm}$ (1.6-in.) diameter hole to allow the encapsulated ${ }^{252} \mathrm{Cf}$ source to be positioned at the geometric center of the sphere. This hole has a larger diameter than the holes in similar moderators used at other facilities.

Monte Carlo calculations by Hertel and McDonald (1990) indicate that the neutron energy from the $\mathrm{D}_{2} \mathrm{O}$-moderated ${ }^{252} \mathrm{Cf}$ source is somewhat harder due to a larger void in the sphere. As shown in Table 3.2, the average energy of the PNL sphere was $0.615 \mathrm{MeV}$. Calculated fluences were converted to dose equivalent using the ICRP Report 21 (ICRP 1973) conversion factors evaluated at the logarithmic midpoints of the energy bins. The average fluence-to-doseequivalent conversion factor for the PNL sphere is $1.04 \times 10^{-5} \mathrm{mrem}-\mathrm{cm}^{2}$, based on the MCNP calculations that the ENDF/B-V cross-section set. The neutron energy spectra calculated from the MCNP calculations (Hertel and McDonald 1990) are shown in Figures 3.2 and 3.3. The sharp dips in the spectrum correspond to absorption resonances in the oxygen cross-section.

In conclusion, the bare and $\mathrm{D}_{2} \mathrm{O}$-moderated ${ }^{252} \mathrm{Cf}$ sources are used to represent the two extremes in neutron energy spectra found at Hanford. The bare source in the low scatter conditions is expected to simulate the "hardest" spectrum likely to be encountered in the processing of plutonium. The $D_{2} 0$-moderated source is expected to simulate the lowest energy spectrum that may be encountered behind massive shields. Both the bare and $D_{2} O$ moderated ${ }^{252} \mathrm{Cf}$ sources are recommended for use in the DOELAP standard (DOE 1986a) for testing personnel neutron dosimeter performance. 
TABLE 3.1. Neutron Dose Equivalent Rates from NIST-Calibrated ${ }^{252}$ Cf Neutron Sources

\begin{tabular}{|c|c|c|c|c|}
\hline $\begin{array}{l}\text { Source } \\
\text { Number }\end{array}$ & $\begin{array}{c}\text { Calibration } \\
\text { Configuration }\end{array}$ & $\begin{array}{l}\text { Initial } \\
\text { Size } \\
\text { Date } \\
\end{array}$ & $\begin{array}{c}\text { Initial } \\
\text { Source } \\
\text { Rate } \\
\text { (mg) } \\
\end{array}$ & $\begin{array}{c}\text { Initial Dose } \\
\text { Equivalent } \\
\text { at } 50 \mathrm{~cm} \\
(\mathrm{mrem} / \mathrm{h}) \\
\end{array}$ \\
\hline $318-38$ & Bare & $5 / 2 / 83$ & 0.795 & 9654.5 \\
\hline $318-38$ & $\mathrm{D}_{2} \mathrm{O}$-moderated & $5 / 2 / 83$ & 0.795 & 2343.6 \\
\hline $318-167$ & Bare & $9 / 7 / 89$ & 1.47 & 13089. \\
\hline $318-167$ & $\mathrm{D}_{2} \mathrm{O}$-moderated & $9 / 7 / 89$ & 1.47 & 3158.5 \\
\hline
\end{tabular}

TABLE 3.2. Neutron Fluence-to-Dose Equivalent Conversion Factors from the $\mathrm{D}, 0$-Moderated ${ }^{252} \mathrm{Cf}$ Neutron Sources at PNL and Other Calibration Facilities

Source

ISO 8529

LLNL sphere

NIST sphere (MCNP)

PNL sphere (MCNP)

Fluence-to-Dose Equivalent Factor (mrem- $\left.\mathrm{cm}^{2}\right)$

$$
0.916 \times 10^{-5}
$$$$
0.985 \times 10^{-5}
$$$$
0.929 \times 10^{-5}
$$$$
1.04 \times 10^{-5}
$$

Average Energy (MeV)

$$
0.541
$$

0.557

0.548

0.615

$\overline{\text { Source: Hertel }}$ and McDonald 1990. 


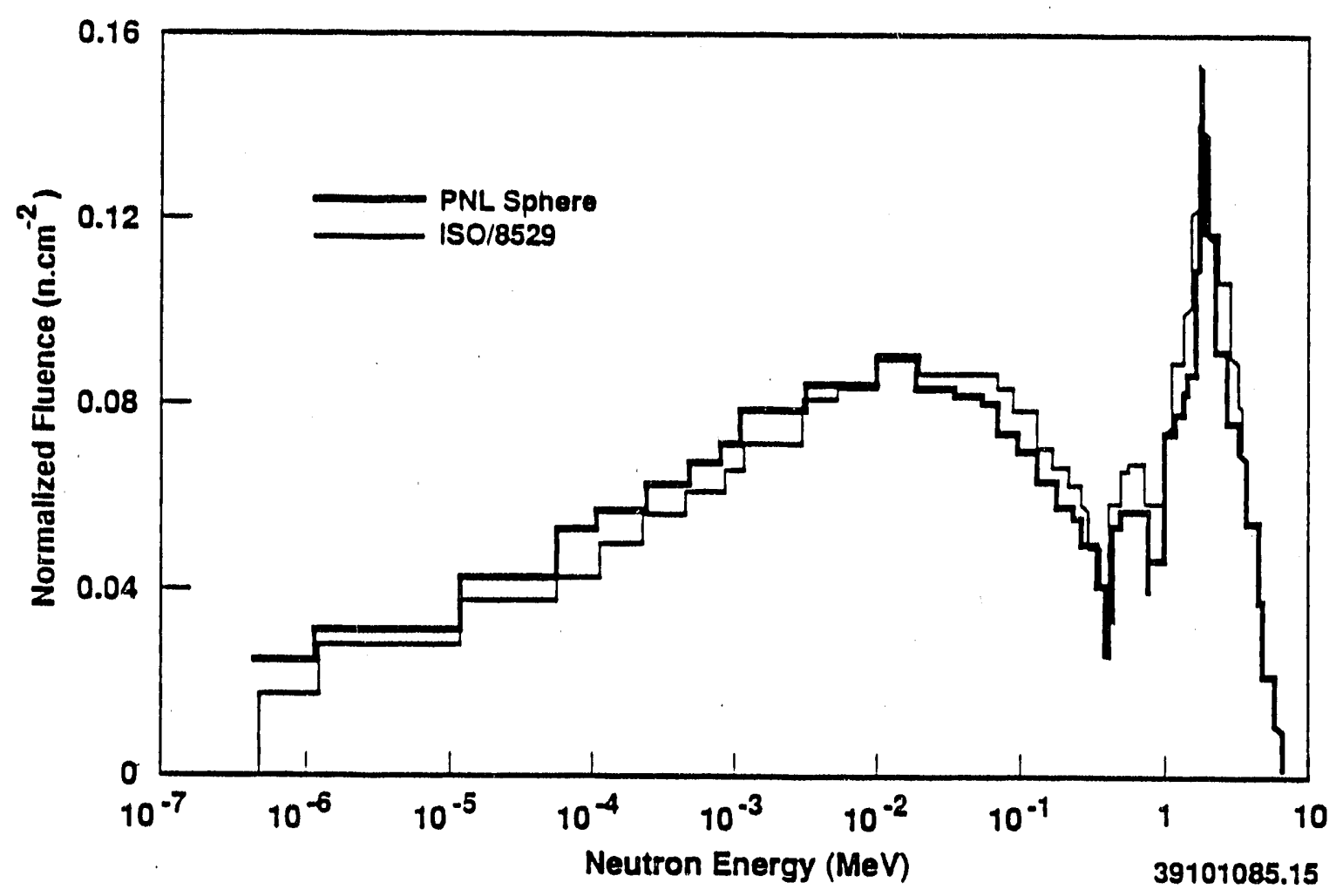

EIGURE 3.2. Neutron Energy Spectrum from the Bare ${ }^{252} \mathrm{Cf}$ Source Inside the Aluminum Transfer Capsule

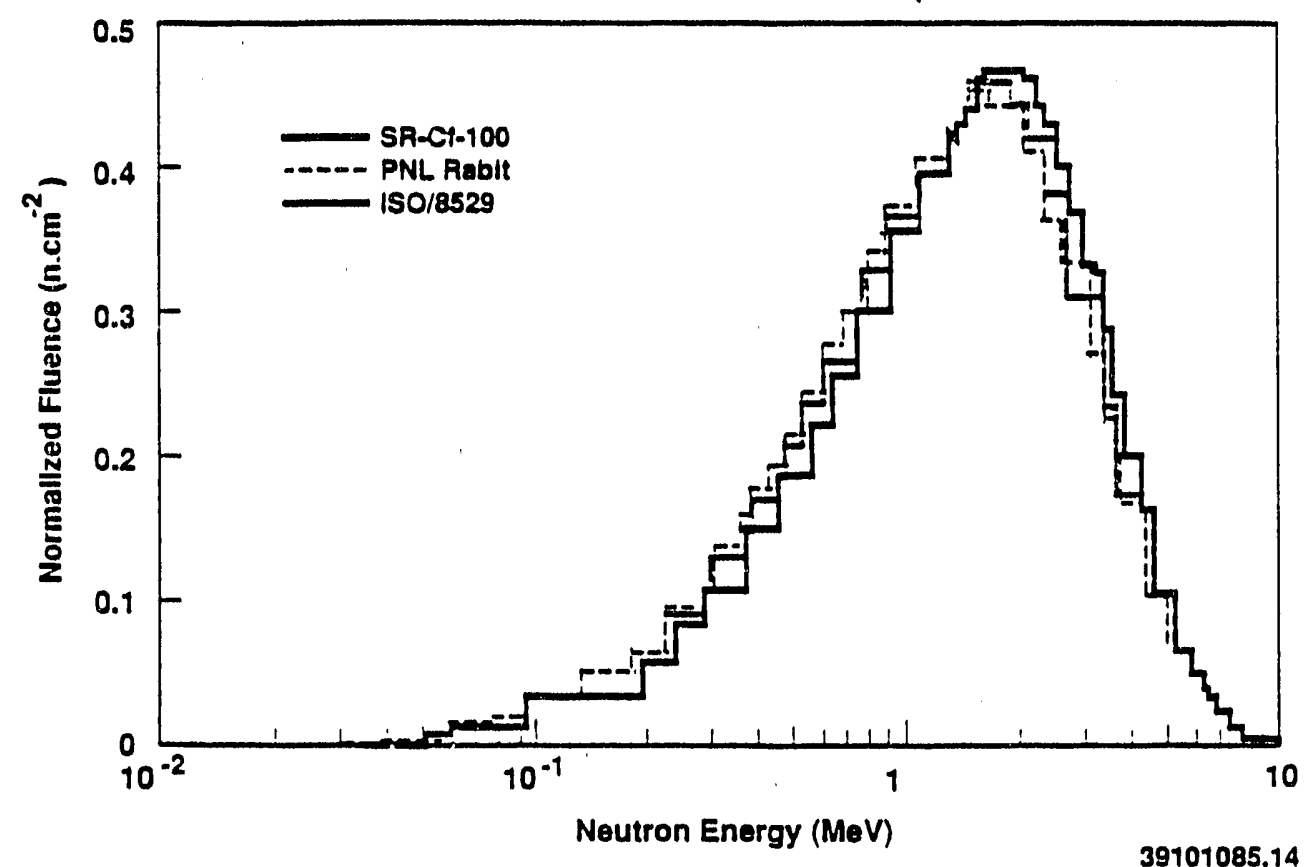

FIGURE 3.3. Neutron Energy Spectrum from the ${ }^{252} \mathrm{Cf}$ Source Inside a $30-\mathrm{cm}$ Diameter Sphere of Deuterium Oxide 


\subsubsection{Plutonium Sources}

Three different plutonium sources were used to represent the major sources of neutron exposure to workers at Hanford. These included a plutonium metal source, a plutonium oxide source, and a plutonium fluoride source; the characteristics of these sources are summarized in Table 3.3. The isotopic compositions for the plutonium are shown in Table 3.4.

In the early days of Hanford, $\mathrm{PuF}_{4}$ was perhaps the most significant source of exposure to neutrons, because it is an important intermediate step in the production of plutonium. The neutron emission rate from plutonium fluoride is over 100 times higher than that from pure plutonium metal. The high neutron emission is caused by alpha particles from plutonium (and its daughter, americium) reacting with fluorine to produce neutrons. As explained in Section 1 of this report, the neutrons from $F(\alpha, n)$ reactions have a lower average energy, about $1.4 \mathrm{MeV}$, than the fission neutrons from plutonium metal. These lower energy neutrons are easier to shield with hydrogenous shielding, such as acrylic plastic placed over the windows of glove boxes. More importantly, the lower energy neutrons from $F(\alpha, n)$ reactions are more readily thermalized, and hence produce a greater response per unit dose equivalent in TLD-albedo dosimeters. For this reason, plutonium fluoride sources have been traditionally used for calibrating TLD-albedo dosimeters at Hanford and at Savannah River, the two main chemical processing plants for plutonium production in the United States.

The first set of measurements were made with the $\mathrm{PuF}_{4}$ source positioned on the center of an aluminum projector stand at $100 \mathrm{~cm}(3.3 \mathrm{ft})$ above the concrete floor. This particular source is unique in that it was once used for calibrating film and TLD-albedo dosimeters at Hanford from December 1964 unit? August 1981. Use of the source was discontinued due to physical security reasons. The irradiation geometry in the PFP is very close to that used in the 3745 Building calibration laboratory when this source was used for calibrating Hanford neutron dosimeters.

The PuF $_{4}$ source contains some 765 grams of plutonium doubly encased in hermetically welded containers, as shown in Figure 3.4. The inner container is a monel metal cylinder (chosen for its resistance to chemical attack by 
fluorides) $8.9 \mathrm{~cm}(3.5 \mathrm{in.})$ in diameter and $10.8-\mathrm{cm}(4.25-\mathrm{in}$.$) high. The \mathrm{PuF}_{4}$ was packed to within $0.32 \mathrm{~cm}(0.125 \mathrm{in}$.) from the top, and a monel metal lid was welded in position. This container was placed inside a second aluminum container with an outside diameter of $10.5 \mathrm{~cm}(4.125 \mathrm{in.})$ and $12.7-\mathrm{cm}$ (5.0-in.) high. A small bail was attached to the end of the cylinder, so that it could be easily hondled remotely. For these measurements, the PuF 4 source was sealed in a steel food can with an outside diameter of $10.8-\mathrm{cm}(4.25-\mathrm{in}$. by $17.8-\mathrm{cm}(7-\mathrm{in.})$ high. To assure that the detectors were equidistant from the center of the source, the center of gravity was determined by placing the steel can on its side and marking the end of the cylinder.

TABLE 3.3. Plutonium Sources Used for Field Measurements

\begin{tabular}{|c|c|c|c|c|}
\hline $\begin{array}{l}\text { Source } \\
\text { Material }\end{array}$ & $\begin{array}{c}\text { Source } \\
\text { Identification }\end{array}$ & $\begin{array}{l}\text { Container } \\
\text { Plutonium } \\
\text { Mass (g) }\end{array}$ & $\begin{array}{c}\text { Average } \\
\text { Size } \\
\text { (in.) } \\
\end{array}$ & $\begin{array}{c}\text { Neutron } \\
\text { Energy (MeV) }\end{array}$ \\
\hline $\mathrm{PuF}_{4}$ & $\begin{array}{l}\text { PuF }_{4} \text { sealed } \\
\text { source }(500 \mathrm{MWD} / \mathrm{T})\end{array}$ & 764 & $\begin{array}{l}3.5 \text { dia. } \\
4.25 \text { high }\end{array}$ & 1.4 \\
\hline $\mathrm{PuO}_{2}$ & ARF $-102-90-01$ & 846.6 & $\begin{array}{l}3.5 \text { dia. } \\
3.5 \text { high }\end{array}$ & 2.1 \\
\hline Pu metal & $\begin{array}{l}\text { Anode heel } 49 \mathrm{~B} \\
\text { I-6-22-89-5-10-90 } \\
C-6-30-89-5-11-90\end{array}$ & 1508 & $\begin{array}{l}4 \text { dia. } \\
6.75 \text { high }\end{array}$ & 2.0 \\
\hline
\end{tabular}

TABLE 3.4. Isotopic Composition of Plutonium Sources

\begin{tabular}{|c|c|c|c|c|c|c|}
\hline \multirow[b]{2}{*}{ Source Material } & \multicolumn{6}{|c|}{ Weight Percent Isotope } \\
\hline & $P u-238$ & Pu-239 & Pu-240 & Pu-241 & $P_{u-242}$ & Am-241 \\
\hline $\begin{array}{l}\text { PuF }_{\text {f }} \\
\text { (50ठ MWD/MTU) }\end{array}$ & 99. & $<1$. & & & & \\
\hline $\begin{array}{l}\mathrm{PuO}_{2}{ }^{(\mathrm{a})} \\
\text { (measured 12/6/89) }\end{array}$ & 0.0104 & 93.699 & 6.059 & 0.2076 & 0.0231 & 0.0036 \\
\hline $\begin{array}{l}\text { Pu metal(a) } \\
\text { (measured } 6 / 22 / 89 \text { ) }\end{array}$ & 0.0112 & 94.448 & 5.3525 & 0.1721 & 0.0157 & 0.0448 \\
\hline
\end{tabular}

(a) Plutonium isotopes add up to $99.9995 \%$ of total Plutonium. The ${ }^{241} \mathrm{Am}$ is in addition to the total plutonium. Isotopic compositions provided by Westinghouse Hanford Company. 


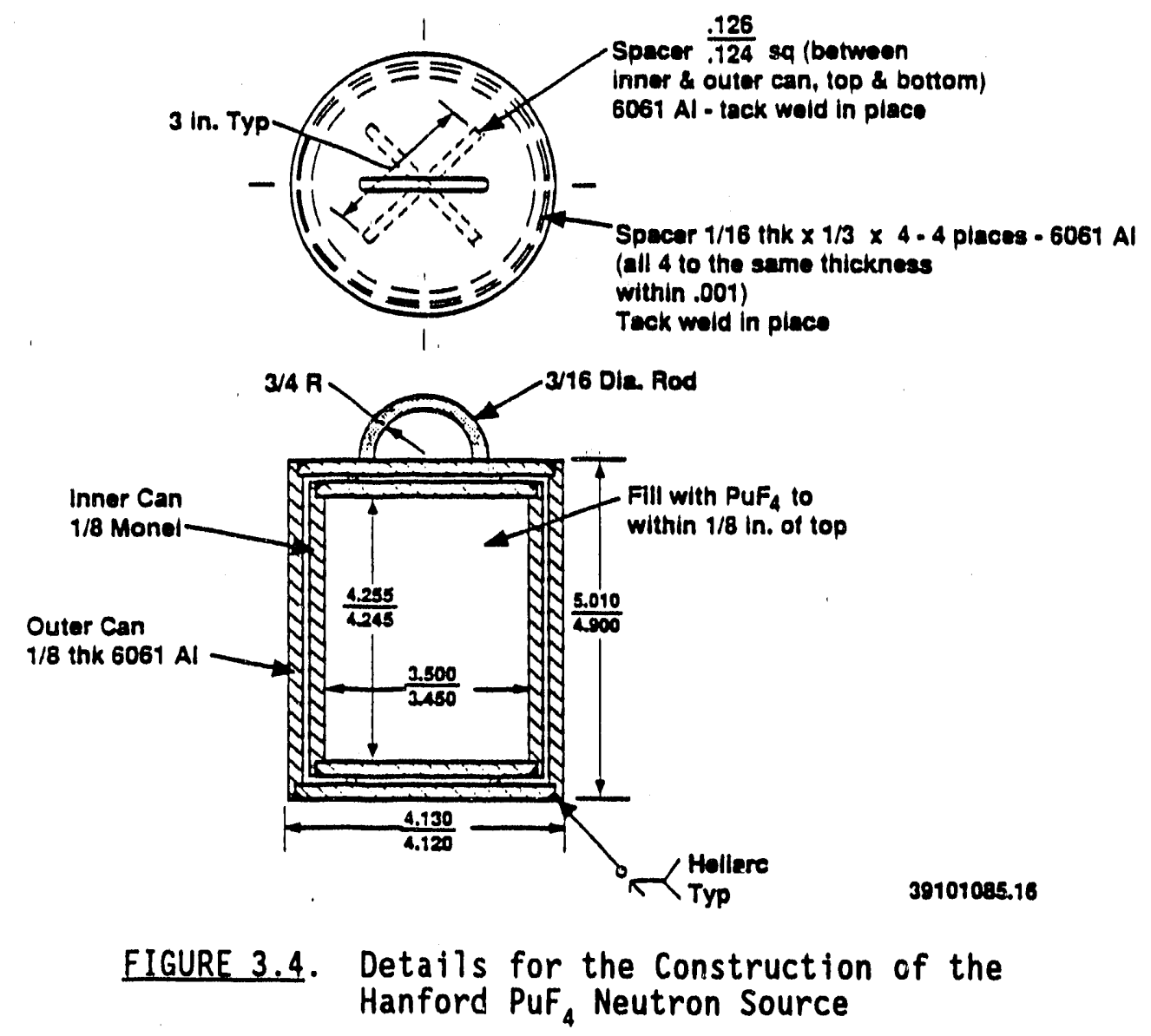

Because of its chemical stability, $\mathrm{PuO}_{2}$ is the preferred form for handling, shipping, and storing plutonium. At the present time, most of the neutron exposure at Hanford originates from the handling and storage of $\mathrm{PuO}_{2}$.

The $\mathrm{PuO}_{2}$ source contained 846.6 grams of plutonium in the form of oxide from lot H-GE-0221-065. The loose powder was contained in an inner slip lid steel can, $8.9 \mathrm{~cm}$ (3.5 in.) in diameter by $8.9-\mathrm{cm}(35-\mathrm{in}$.$) high. This can$ was sealed inside a second steel food can, $10.2 \mathrm{~cm}(4 \mathrm{in.})$ in diameter and $11.8-\mathrm{cm}(4.625-\mathrm{in.})$ high. This was sealed inside a plastic bag, and the assembly placed in a third steel food can $10.8 \mathrm{~cm}$ (4.25 in.) in diameter and $17.8 \mathrm{~cm}(7-\mathrm{in}$.$) high. As before, measurements were performed with the can$ positioned at the center of an aluminum projector stand, with the bottom of the can at $100 \mathrm{~cm}(3 \mathrm{ft}, 4 \mathrm{in.})$ above the concrete floor in room $179 \mathrm{C}$. 
The final product is the production of plutonium metal. However, plutonium metal is unstable and readily oxidizes. Under certain conditions, it is even pyrophoric (Faust et al. 1988). Therefore, plutonium metai is usually processed rapidiy, and it is difficult to obtain massive quantities for measurements. We were able to obtain a sample of plutonium metal identified as anode heel $49 \mathrm{~B}$ weighing some 1508 grams. The metal sample is composed of scrap from two different lots of plutonium: I-6-22-89-5-10-90 and C-6-30-89-5-11-90. The metal pieces were contained in a sealed steel food can $10.5 \mathrm{~cm}(4.125 \mathrm{in.})$ in diameter by $17.8-\mathrm{cm}\left(7-\mathrm{in}_{\mathrm{n}}\right)$ high. This sample has an unusually high neutron emission rate, and it is suspected that this is due to alpha-neutron $(\alpha, n)$ reactions from high concentrations of impurities of low atomic number in the metal. Unfortunately, the neutrons produced by the $\alpha, n$ reactions have different energies than those of pure plutonium, so the neutron energy spectrum may not be typical of pure plutonium metal.

The steel food can containing the plutonium metal samples was also placed on an aluminum projector stand at $100 \mathrm{~cm}(3 \mathrm{ft}, 4 \mathrm{in}$.) above the floor. However, because of the low neutron emission rates from the metal source, most of the measurements were made with the detectors positioned near the multichannel analyzers, where the neutron background was lower and more nearly uniform. 


\subsection{QUALITY ASSURANCE MEASUREMENTS}

As described in Section 2 of this report, the TEPCs deteriorate due to out-gassing of volatile impurities in the tissue equivalent plastic walls. For this reason, it is a good idea to check the accuracy of the TEPC by measuring the dose rate from a calibrated neutron source before the field measurements are performed to assure that the TEPC is operating properly. Measurements were also made with the multisphere spectrometer and with the ${ }^{3} \mathrm{He}$ spectrometer to verify the accuracy of their operation. In addition, a $25.4-\mathrm{cm}\left(10-i n_{.}\right)$diameter polyethylene sphere with a $1.3-\mathrm{cm}(0.5-i n$.$) diameter$ ${ }^{6} \mathrm{LII}(E \mathrm{E})$ scintillation detector was calibrated to correlate the delivered dose equivalent rate with the observed count rate in the slow neutron peak. The net peak area was determined using the logarithmic background subtraction technique described in Appendix $B$ of this report. This section describes these quality assurance measurements.

PNL is the primary testing laboratory for personnel dosimeter testing under the direction of the NIST, as part of the NVLAP. So, PNL maintains sets of calibrated ${ }^{252} \mathrm{Cf}$ neutron sources that are periodically calibrated for neutron yield and certified for accuracy by NIST. The procedures for calibration and testing are described in the document ANSI 13.11, American National Standard for Dosimetry. Personnel Dosimetry Performance - Criteria for Testing (ANSI 1983). These calibrated neutron sources were used to test the accuracy of the field neutron spectrometer.

Two different neutron sources were used for the measurements in the 318 Building Calibration Laboratory because the dose rate from one source was too high for the multisphere spectrometer to function properly. The dose equivalent rate at $50 \mathrm{~cm}(20 \mathrm{~cm})$ from the largest source $(318-167)$ was $11.08 \mathrm{rem} / \mathrm{h}$, which produces significant pulse pile-up in the ${ }^{6} \mathrm{LiI}(\mathrm{Eu})$ scintillator detector. (Three distinct slow neutron peaks were observed.) Therefore, tests were also made with a smaller source (318-38) having a dose equivalent rate of $1.55 \mathrm{rem} / \mathrm{h}$ at $50 \mathrm{~cm}(20 \mathrm{in}$.) from the source.

Measurements were made with two different types of detectors: TEPCs and the multisphere detectors. The NIST-calibrated neutron sources are much too intense for the ${ }^{3} \mathrm{He}$ spectrometer to operate properly; the high pressure tubes 
have too much pulse pile-up to give meaningful results. The ${ }^{3} \mathrm{He}$ spectrometer was tested separately in the Engineering Support But?ding (ESB) using a neutron source with a much lower neutron emission rate.

These devices are absolute dosimeters in the sense that they do not require calibration in neutron fields with known dose equivalent rates. The TEPCS use an internal energy calibration (the proton edge or an internal alpha source). Because the TEPC measures the energy deposited in a known mass of tissue-1ike material, it directly determines absorbed neutron dose. With appropriate mathematical algorithms, it is also possible to determine quality factor and hence dose equivalent directly from first principles. The multisphere spectrometer also does not require a calibrated neutron source. The calibration of the multisphere is built into the response function, which is included in the spectrum-unfolding code SPUNIT for the $1.3-\mathrm{cm}(0.5-\mathrm{in.})$ diameter by $1.3-\mathrm{cm}(0.5-\mathrm{in.})$ long ${ }^{6} \mathrm{LiI}(E u)$ scintillation crystal. Thus, measurements with these detectors expo: ed to the NIST-calibrated sources are used only to verify the accuracy of the technique and computer codes used.

\subsection{VERIFICATION MEASUREMENTS MADE PRIOR TO FIELD MEASUREMENTS}

Before any measurements were made in the field, the accuracy of the detectors was checked using the NIST-calibrated sources in the 318 Building Calibration Laboratory. The TEPCs were placed on tripods at the centerline distances indicated and positioned at the same height as the source on the tower in the low-scatter room. The results of these measurements are shown in Table 4.1 for different TEPCs (5-in. diameter spherical counters manufactured by Far West Technology TEPC, serial numbers 501 and 184) and one multisphere detector $\left(1 / 2-i n\right.$. diameter ${ }^{6} \mathrm{LiI}[\mathrm{Eu}]$ detector manufactured by Harshaw Chemical Co., serial number PE648).

TEPC 501 was filled with methane-based TE gas at 11.3-torr pressure, which simulates a $2-\mu \mathrm{m}$ diameter deposition site in tissue of unit density. However, TEPC 184 was filled with pure methane gas in an attempt to eliminate the gain shift problems that are inherent in the TE gas filling. It is believed that the gas gain of TE gas changes with temperature due to the ibsorption of carbon dioxide gas in the TE plastic. By using pure methane 
IABLE 4.1. Summary of Verification Measurements

at the PNL Calibration Laboratory

\begin{tabular}{|c|c|c|c|c|c|}
\hline \multirow[b]{2}{*}{ Source } & \multirow{2}{*}{$\begin{array}{l}\text { Distance } \\
(\mathrm{cm})\end{array}$} & \multirow{2}{*}{$\begin{array}{l}\text { Delivered Dose } \\
\text { Equivalent Rate } \\
\text { (rem } / \mathrm{h}) \\
\end{array}$} & \multicolumn{3}{|c|}{$\begin{array}{c}\text { Measured Dose Equivalent Rate } \\
(\text { rem } / \mathrm{h})\end{array}$} \\
\hline & & & TEPC 501 & TEPC 184 & Mult t sphere \\
\hline $318-167$ & 50 & 11.08 & $\begin{array}{l}11.7 \\
(+5.6 \%)\end{array}$ & -- & -- \\
\hline $318-167$ & 100 & 2.77 & $\begin{array}{c}3.06 \\
(+10.4 \%)\end{array}$ & $\begin{array}{c}3.06 \\
(+10.4 \%)\end{array}$ & -. \\
\hline $318-38$ & 100 & 0.387 & $\begin{array}{r}0.447 \\
(+15.5 \%)\end{array}$ & $\begin{array}{r}0.438 \\
(+13.2 \%)\end{array}$ & $\begin{array}{r}0.370 \\
(-4.4 \%)\end{array}$ \\
\hline
\end{tabular}

gas, gain shifts with temperature should be eliminated. But the rate of energy deposition in methane is not the same as TE gas, so the calibration factor used in the data analysis is different. In this case, we analyzed the data as if the counter were filled with TE gas and corrected the results later.

The results given in Table 4.1 demonstrate that all of the detectors are accurate within $15 \%$ when exposed to the spontaneous fission energy spectrum from the ${ }^{252} \mathrm{Cf}$ neutron sources. In Table 4.1 , the numbers in parentheses give the percent deviation from the delivered dose equivalent rate. TEPC 184 contained the built-in electronics described in Section 7.4.2 of PNL-6620, Vol. 2 (Brackenbush et al. 1988) and is used with the field neutron spectrometer with automatic data analysis. TEPC 501 used conventional NIM Bin electronics with a Canberra Series 40 multichannel analyzer. The data from TEPC 501 were analyzed manually using an analysis code almost identical to that used in the field neutron spectrometer code. The results from either TEPC detector or analysis code agree within a few percent.

\subsection{VERIFICATION MEASUREMENTS MADE AFTER COMPLETION OF THE FIELD MEASUREMENTS}

Because of scheduling difficulties, the measurements at the PFP were completed almost 4 months after the TEPC detectors were filled. During this time, impurities out-gassed from the TE plastic walls, and the resolution of the detectors deteriorated. It was decided that another set of measurements 
should be performed to determine how the counter deterioration would affect the accuracy of the TEPC measurements. Also, because of concerns about the possible deterioration of the detectors, another TEPC detector was used for the field measurements. This detector, TEPC serial number 504 , had a built-in alpha source that could be used for a secondary calibration in the field. Thus, this detector could provide more accurate results in low dose-rate areas where there were insufficient data to accurately determine the proton edge.

These verification measurements were performed with the three TEPC detectors (Far West Technology 5-in. diameter single wire counters, serial numbers 184, 501, and 504). These measurements were made with the same NIST-certified sources as before, except that measurements were made with bare californium sources and with the sources inside $30-\mathrm{cm}$ diameter spheres filled with $D_{2} O$. The $D_{2} 0$-moderated ${ }^{252} \mathrm{Cf}$ sources have a neutron energy spectrum of considerably lower energy than the bare ${ }^{252} \mathrm{Cf}$ sources, as explained in Section 3.2 .

The results of these measurements are shown in Table 4.2. The numbers in parentheses are the percent deviation of the measured from the delivered dose equivalent rate. It is evident from these measurements that the counters have deteriorated over the 4 months since they were filled, and that they are not as accurate. This is especially true of TEPC 184, which was filled with methane gas. All of the detectors overestimate the delivered dose equivalent, but TEPC 184 overestimates the delivered " stron dose equivalent by over $30 \%$ when exposed to the bare ${ }^{252} \mathrm{Cf}$ neutron source. The situation is even worse for the detectors exposed to the $\mathrm{D}_{2} \mathrm{O}$-moderated sources. In this case. TEPC 184 over-estimates the delivered neutron dose by about $50 \%$ if we use the energy calibration for methane-based TE gas. (The methane fil?ing requires a correction for differences in the stopping power and hence a different calibration factor must be applied.)

Table 4.2 also contains the results of multisphere measurements using the $D_{2} 0$-moderated ${ }^{252} \mathrm{Cf}$ neutron source. The dose rates from source 318-167 were so high that the computer code analysis did not determine the correct area of the neutron peak, so the measured dose equivalent rate from the multisphere spectrometer was too low. This problem did not occur at the lower 
IABLE 4.2. Summary of Verification Measurements at the PNL Calibration Laboratory Made after the Field Measurements Were Completed

\begin{tabular}{|c|c|c|c|c|c|c|}
\hline & & & & sured $D$ & $\begin{array}{l}\text { se Equi } \\
(\mathrm{rem} / \mathrm{h})\end{array}$ & alent Rate \\
\hline & $\begin{array}{c}\text { Distance } \\
(\mathrm{cm}) \\
\end{array}$ & $\begin{array}{c}\text { Rate } \\
(\mathrm{rem} / \mathrm{h}) \\
\end{array}$ & $\begin{array}{l}\text { TEPC } \\
501 \\
\end{array}$ & $\begin{array}{l}\text { TEPC } \\
184 \\
\end{array}$ & $\begin{array}{l}\text { TEPC } \\
184 \\
\end{array}$ & Mult isphere \\
\hline $\begin{array}{l}318-167 \\
\text { (bare) }\end{array}$ & 100 & 2556.5 & $\begin{array}{l}2770 \\
(+8 \%)\end{array}$ & $\begin{array}{l}2660 \\
(+4 \%)\end{array}$ & $\begin{array}{l}3420 \\
(+34 \%)\end{array}$ & -- \\
\hline $\begin{array}{l}318-167 \\
\left(D_{2} 0-\text { moderated }\right)\end{array}$ & 100 & 616.9 & $\begin{array}{c}789 \\
(+28 \%)\end{array}$ & $\begin{array}{c}722 \\
(+17 \%)\end{array}$ & $\begin{array}{c}926 \\
(+50 \%)\end{array}$ & $\begin{array}{l}470 \\
(-24 \%)\end{array}$ \\
\hline $\begin{array}{l}318-38 \\
\left(D_{2} 0 \text {-moderated }\right)\end{array}$ & 100 & 86.7 & -- & -- & -- & $\begin{array}{c}95.0 \\
(+10 \%)\end{array}$ \\
\hline
\end{tabular}

dose rates from source 318-38, when the dose equivalent rate determined by the multisphere spectrometer is within $10 \%$ of the delivered dose equivalent (see Table 4.2).

To confirm that changes in accuracy after 4 months were due to deterioration of the counter gas, additional measurements were made one day after the TEPC detectors had been refilled. The TEPCs were exposed to the same NIST-certified sources in the 318 Building Calibration Laboratory, and the results are summarized in Table 4.3. As before, the numbers in parentheses indicate the percent deviation of the measured value from the delivered dose equivalent rate. As shown in the table, TEPCs 501 and 504 determined the delivered dose equivalent rate within about $5 \%$ when exposed to bare ${ }^{252} \mathrm{Cf}$ sources, and within about $13 \%$ when exposed to the $\mathrm{D}_{2} 0$-moderated ${ }^{252} \mathrm{Cf}$ sources. For all the measurements with TEPCs 501 and 504, the average dose equivalent was $3.7 \%$ higher than the delivered dose equivalent rate, with a standard deviation of $5.6 \%$. However, TEPC 184, filled with pure methane for 4 months, showed a dose equivalent about $33 \%$ higher than the delivered dose equivalent rate. Because the methane filling requires a different calibration than the TE gas fillings, it is recommended that the dose equivalent values measured by TEPC 184 be reduced by $33 \%$ to indicate the correct dose equivalent. 
IABLE 4.3. Summary of Verification Measurements at the PNL Calibration Laboratory with the TEPCs Refilled with Tissue Equivalent Gas

Delivered Dose

\begin{tabular}{|c|c|c|c|c|c|}
\hline \multirow[b]{2}{*}{ Source } & \multirow{2}{*}{$\begin{array}{c}\text { Distance } \\
(\mathrm{cm}) \\
\end{array}$} & \multirow{2}{*}{$\begin{array}{c}\text { Equivalent } \\
\text { Rate } \\
\text { (mrem } / \mathrm{h} \text { ) }\end{array}$} & Measured & \multicolumn{2}{|c|}{ Dose Equivalent Rate } \\
\hline & & & IEPC 501 & TEPC 504 & TEPC 184 \\
\hline $\begin{array}{l}318-38 \\
\text { (bare) }\end{array}$ & 50 & 1423.6 & $\begin{array}{r}1450 \\
(+1.9 \%)\end{array}$ & $\begin{array}{c}1390 \\
(-2.4 \%)\end{array}$ & $\begin{array}{c}1910 \\
(+34 \%)\end{array}$ \\
\hline $\begin{array}{l}318-38 \\
\text { (bare) }\end{array}$ & 100 & 355.9 & $\begin{array}{c}376 \\
(+5.6 \%)\end{array}$ & $\begin{array}{c}369 \\
(+3.6 \%)\end{array}$ & $\begin{array}{c}492 \\
(+38 \%)\end{array}$ \\
\hline $\begin{array}{l}318-167 \\
\text { (bare) }\end{array}$ & 50 & 10189. & $\begin{array}{l}10400 \\
(\div 2.1 \%)\end{array}$ & $\begin{array}{l}10000 \\
(-1.9 \%)\end{array}$ & $\begin{array}{l}13100 \\
(+29 \%)\end{array}$ \\
\hline $\begin{array}{l}318-167 \\
\text { (bare) }\end{array}$ & 80 & 3980. & -- & $\begin{array}{c}4150 \\
(+4.3 \%)\end{array}$ & $\begin{array}{c}5290 \\
(+33 \%)\end{array}$ \\
\hline $\begin{array}{l}318-167 \\
\text { (bare) }\end{array}$ & 100 & 2547. & $\begin{array}{l}2560 \\
(+0.5 \%)\end{array}$ & $\begin{array}{r}2650 \\
(+4.0 \%)\end{array}$ & $\begin{array}{c}3440 \\
(+35 \%)\end{array}$ \\
\hline $\begin{array}{l}318-38 \\
\left(D_{2} 0-\text { moderated }\right)\end{array}$ & 100 & 86.4 & $\begin{array}{r}97.8 \\
(+13.2 \%)\end{array}$ & $\begin{array}{r}83.1 \\
(-3.8 \%)\end{array}$ & $\begin{array}{c}95.6 \\
(+10.6 \%)\end{array}$ \\
\hline $\begin{array}{l}318-167 \\
\left(D_{2} 0-\text { moderated }\right)\end{array}$ & 100 & 614.7 & $\begin{array}{c}687 \\
(+11.7 \%)\end{array}$ & $\begin{array}{c}677 \\
(+10.1 \%)\end{array}$ & $\begin{array}{c}929 \\
(+51 \%)\end{array}$ \\
\hline
\end{tabular}




\subsection{MEASUREMENTS AND RESULTS}

This section of the report discusses the field measurements made with plutonium sources in the PFP under conditions typical of work places. As described in Section 3 of this report, the measurements were performed in a room with concrete floors, walls, and ceiling representative of processing facilities at Hanford. Under these conditions, about half of the neutrons siriking the floors will be scattered back into the room; this is typical of the "high-scatter" conditions found in the work place. Because of their higher response to low-energy neutrons, TLD-albedo dosimeters will have a higher response per unit dose equivalent than under the low-scatter conditions found in calibration laboratories and, consequently, will overestimate dose equivalent. By exposing neutron dosimeters at locations where the dose equivalent has been determined using other devices (such as TEPCs, multisphere spectrometers, ${ }^{3} \mathrm{He}$ spectrometers, or carefully calibrated survey instruments), it is possible to determine the dosimeter response under these high-scatter conditions. This information allows field correction factors that account for spectral differences between the work place and the calibration laboratory.

Note that the shielding and scatter conditions are sometimes of greater importance than the initial energy spectrum of neutrons emitted from the source. To be conservative, the TLD-albedo dosimeters were exposed to bare plutonium sources in air, which gives relatively low dosimeter responses per unit of dose equivalent. Measurements were also performed with small amounts of acrylic plastic shielding between the dosimeters and the source. The plastic shielding generates intermediate and low-energy neutrons that contribute little to the dose equivalent, but which increase the dosimeter response per unit of dose equivalent. The acrylic plastic is typical of the materials that have been used in the past. Presently, glove boxes are constructed from stainless steel with glass windows, and fewer intermediate energy neutrons are present. Hydrogenous shielding does increase the number of low-energy neutrons and increase the response of TLD-albedo dosimeters.

Information is presented here about each of the sources used for the measurements. Additional information about the plutonium sources can be found in Section 3.2 of this document. 


\subsection{PLUTONIUM FLUORIDE MEASUREMENTS}

Dose equivalent rate measurements and dosimeter measurements were performed on the 764-gram plutonium tetrafluoride source in Room 179 of the PFP. This source is of historical significance, because it was used as the calibration source for neutron dosimeters at Hanford from December 1964 unti1 August 1981. The encapsulated source was contained in a steel food can, so it was not possible to make exact distance measurements. However, the approximate center of gravity was determined, and distances were measured relative to this reference point.

\subsubsection{Dose Equivalent Determinations from Plutonium Fluoride Source}

Measurements were performed using two TEPCS (TEPC 501 and TEPC 184); the multisphere spectrometer using a Harshaw ${ }^{6}$ LiI(EU) $1 / 2$-in. diameter scintillation crystal, number PE648, operated at +700 volts; a 10 -in.-diameter polyethylene sphere using a Harshaw ${ }^{6} \mathrm{LiI}(\mathrm{EU})$ detector, number PE648, assuming a sensitivity of 11.12 counts $/ \mathrm{s}$ per $\mathrm{mrem} / \mathrm{h}$; a Precision Long Counter, using $\mathrm{BF}_{3}$ tube G14123; and a Bicron micro rem meter, serial number A514M or Hanford instrument number 4981. The results of the neutron measurements are shown in Table 5.1 for measurements taken at $50 \mathrm{~cm}$ and $100 \mathrm{~cm}$ from the center of gravity of the source for the bare $\mathrm{PuF}_{4}$ source and for the source shielded by 40-cm-by-40-cm (15.75-in.-by-15.75-in.) slab shields of acrylic plastic. The results from TEPC 184 were not included in the averages because of uncertainties in the correction factor that must be applied for the methane gas filling. For the measurements on the bare $\mathrm{PuF}_{4}$ source, averages were also calculated excluding long-counter data. The uncertainties given in the table are for one standard deviation in the measured values. 
IABLE 5.1. Results of Neutron Measurements Performed on the 764-Gram $\mathrm{PuF}_{4}$ Source at the Plutonium Finishing Plant

\begin{tabular}{|c|c|c|c|}
\hline & & Neutron Dose Equivalent & ate $(\mathrm{mrem} / \mathrm{h})^{(\mathrm{a})}$ \\
\hline Shielding_ & Detector & at $50 \mathrm{~cm}$ & at $100 \mathrm{~cm}$ \\
\hline Bare $\mathrm{PuF}_{4}$ & $\begin{array}{l}\text { Mult isphere } \\
\text { TEPC 501 }\end{array}$ & $\begin{array}{l}21.5 \\
22.9\end{array}$ & $\begin{array}{l}5.73 \\
6.26\end{array}$ \\
\hline & $\begin{array}{l}\text { TEPC } 184 \\
10-\text { in. bal1 } \\
\text { Long counter }\end{array}$ & $\begin{array}{l}(29.1) \\
22.0 \\
18.6 \\
\end{array}$ & $\begin{array}{l}(7.92) \\
5.89 \\
4.65 \\
\end{array}$ \\
\hline Average & cluding TEPC 184 & $21.25 \pm 1.85$ & $5.87 \pm 0.79$ \\
\hline $\begin{array}{l}\text { Average } \\
\text { and long }\end{array}$ & $\begin{array}{l}\text { cluding TEPC } 184 \\
\text { ounter }\end{array}$ & $22.13 \pm 0.71^{(b)}$ & $6.18 \pm 0.46^{(b)}$ \\
\hline $\begin{array}{l}\text { l-in. acrylic } \\
\text { plastic }\end{array}$ & $\begin{array}{l}\text { Multisphere } \\
\text { TEPC 501 } \\
\text { TEPC 184 } \\
10 \text {-in. ball }\end{array}$ & $\begin{array}{c}14.5 \\
15.9 \\
(20.2) \\
15.4 \\
\end{array}$ & $\begin{array}{c}4.01 \\
- \\
- \\
4.14 \\
\end{array}$ \\
\hline Average & cluding TEPC 184 & $15.3 \pm 0.709$ & 4.10 \\
\hline $\begin{array}{l}2 \text {-in. acrylic } \\
\text { plastic }\end{array}$ & $\begin{array}{l}\text { Multisphere } \\
\text { TEPC } 501 \\
\text { TEPC 184 } \\
\text { lo-in. ball }\end{array}$ & $\begin{array}{c}8.82 \\
10.6 \\
(14.2) \\
10.25 \\
\end{array}$ & $\begin{array}{c}2.59 \\
- \\
- \\
2.84 \\
\end{array}$ \\
\hline Average & cluding TEPC 184 & $9.89 \pm 0.94$ & 2.72 \\
\hline
\end{tabular}

(a) Uncertainties given for one standard deviation in the average of the measured values.

(b) Assumed to be the most accurate value excluding values in parentheses for TEPC 184, which was filled with methane.

\subsubsection{Long Counter Measurements with the Plutonium Fluoride Source}

Measurements of the neutron emission rate perpendicular to the axis of the source were made using the precision long counter. The methodoiogy used for these measurements is outlined on page 46 of Laboratory Record Book BNW-49 and in A Precision Long Counter for Measuring Fast Neutron Flux Density, BNWL-260 (DePangher and Nichols 1966). Basically, the analysis assumes that the response of the long counter can be described by a direct component, which 
follows an inverse square relation from the source, and a room-scatter component, which is assumed to be a constant background in a large room:

$$
\text { Count rate }=k \frac{s_{0}}{4 \pi r^{2}}+b
$$

Adopting the nomenclature of DePangher and Nichols (1966), c, the distance in centimeters from the effective center of the long counter to the front face of the long counter, is given by:

$$
c=1.1 E_{n}+7.8(\mathrm{~cm})
$$

where $E_{n}$ is the average energy of the neutrons incident on the face of the long counter. The inverse square distance in Equation (5.1) is replaced by the distance from the source to the front face $(x)$ plus $c$, the distance to the effective center of the long counter. The constant of proportionality between the incident flux and the count rate is the product of $\epsilon$, the energy correction factor (L), a factor to account for differences between different long counters, and the $\mathrm{BF}_{3}$ tube sensitivity factor (B). For these measurements, the tube sensitivity factor for tube number 614123 was 3.864 counts per $\mathrm{n} / \mathrm{s}-\mathrm{cm}^{2}$ incident on the long counter. If we substitute these expressions into Equation (5.1), we obtain:

$$
4 \pi R(x+c)^{2}=S_{0}\left[1+b(x+c)^{2}\right] \in L B
$$

If the source does not emit isotopically, we can substitute the product of $S \alpha$ for the source strength and rearrange Equation (5.3) to give:

$$
S \alpha=4 \pi(x+c)^{2} /\left[\epsilon L B\left(1+b(x+c)^{2}\right)\right]
$$

where $\alpha$ is the source anisotropy factor.

Now let us consider the case in which we let the distance $(x+c)$ approach zero. In this case the term $b(x+c)^{2}$ approaches zero and the term $R(x+c)^{2}$ approaches a constant. Then, Equation (5.4) reduces to: 


$$
S \alpha=\frac{4 \pi R(x+c)^{2}}{\epsilon L B}
$$

We can evaluate Equation (5.5) from a plot of $R(x+c)^{2}$ versus $(x+c)^{2}$, i.e., a plot of the square of the distance from the source to the effective center of the long counter times the count rate versus the square of the distance. This plot is shown in Figure 5.1 for the count rates measured at a distance of $80 \mathrm{~cm}$ to $171 \mathrm{~cm}$ to the front of the long counter. The intercept at $(x+c)^{2}=0$ allows us to evaluate the term $R(x+c)^{2}=$ 206.1 counts $/ \mathrm{sec}-\mathrm{m}^{2}$.

Assuming a tube sensitivity factor of $3.864 \mathrm{c} / \mathrm{s}$ per $\mathrm{n} / \mathrm{s}-\mathrm{cm}^{2}$, and an energy correction factor of 1.02 to account for the differences in sensitivity between the energy of $1.3 \mathrm{MeV}$ and $2 \mathrm{MeV}$, the source intensity is calculated to be $6.57 \times 10^{6} \mathrm{n} / \mathrm{s}$. Assuming inverse square attenuation, the dose equivalent rate at $50 \mathrm{~cm}$ is calculated to be $18.6 \mathrm{mrem} / \mathrm{h}$. This is calculated using a conversion factor of $2.4 \times 10^{-8}$ rem per $n / \mathrm{cm}^{2}$ from page 29 of BNWL-1262 (Brackenbush and Faust 1970) and the neutron source strength measured by the long counter.

The plot shown in Figure 5.1 can indicate the influence of room scatter on the long-counter count rate. The difference between the intercept and the value of $R(x+c)^{2}$ at a given distance gives the amount of room scatter. For instance, at $50 \mathrm{~cm}$, room scatter is $1.1 \%$; at $100 \mathrm{crn}$, room scatter is $4.3 \%$ and at $200 \mathrm{~cm}$, room scatter is $17 \%$ of the measured count rate. This method of plotting can determine the amount of room scatter for other detectors. For instance, in NBS Special Publication 633, Procedures for Calibrating Neutron Personnel Dosimeters, Schwartz and Eisenhauer (1982) have used the inverse square plots to calculate the effects of room return for measured TLD-albedo dosimeter responses in calibration laboratories. 


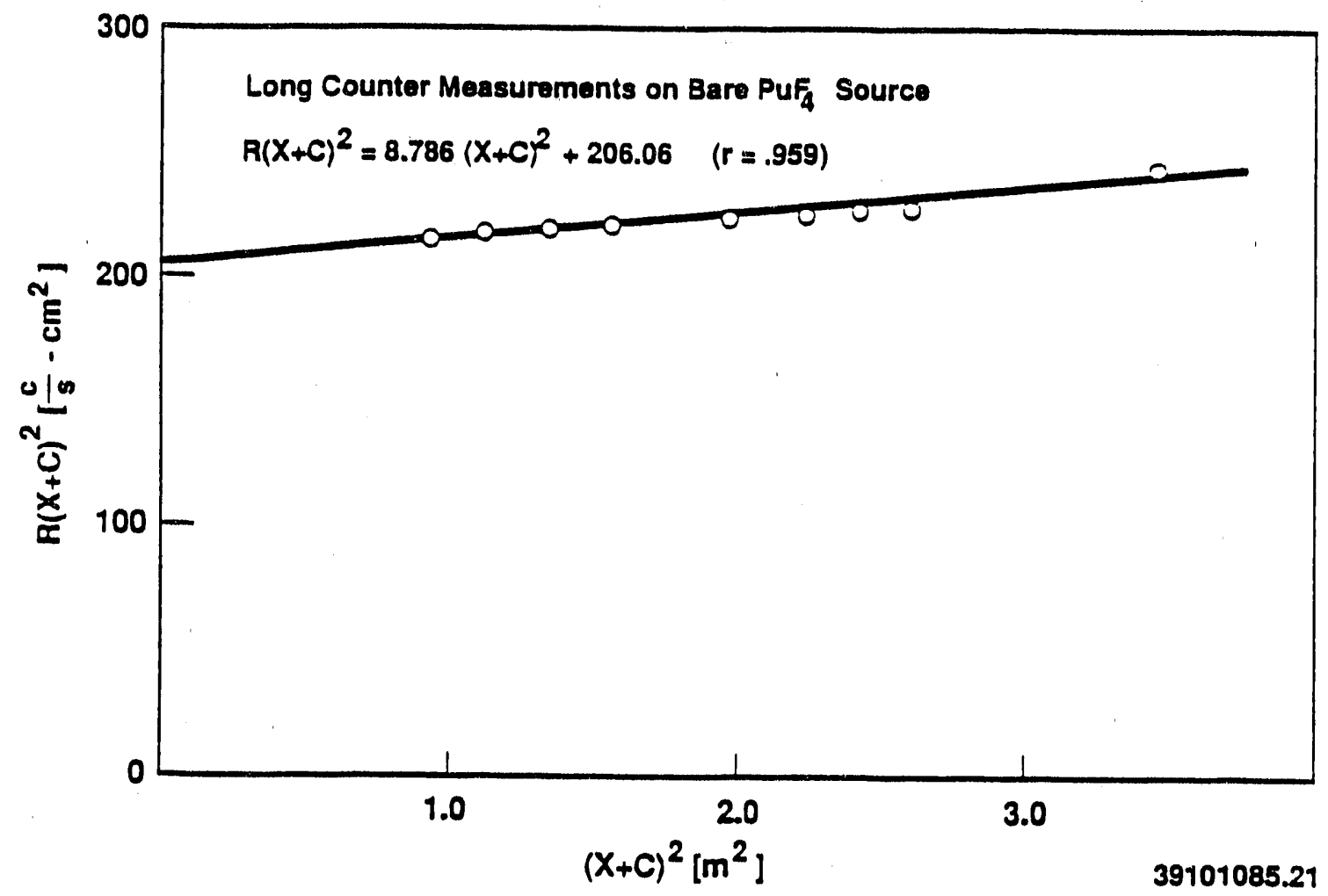

FIGURE 5.1. Inverse Square Plot of Long Counter Data to Determine the Neutron Emission Rate and Room Return from the PuF 4 Source

\subsubsection{Multisphere Spectrometer Measurements with the Plutonium Fluoride Source}

A series of measurements were also performed using the multisphere spectrometer to determine the approximate energy spectra using the bare PuF $_{4}$ source and the source shielded with acrylic plastic slabs 1-in. and 2-in. thick. Although these measured spectra lack the resolution of other spectrometers, such as the ${ }^{3} \mathrm{He}$ spectrometer, these measurements cover the entire range of neutron energies from thermal to $20 \mathrm{MeV}$. The spectra presented have sufficient resolution to allow qualitative analysis of TLD-albedo dosimeter responses. Details of how the spectra are derived are contained in Appendix $B$ and summarized in Section 2.2 of this report.

A summary of the multisphere spectrometer measurements with the PuF $_{4}$ source is given in Table 5.2. The effects of the acrylic plastic shielding 
IABLE 5.2. Summary of Multisphere Spectrometer Measurements with the Plutonium Tetrafluoride Source

\begin{tabular}{lcccccc} 
Shielding & $\begin{array}{c}\text { Neutron } \\
\text { Distance } \\
(\mathrm{cm})\end{array}$ & $\begin{array}{c}\text { Dose } \\
\begin{array}{c}\text { Flux } \\
\left(\mathrm{n} / \mathrm{s}-\mathrm{cm}^{2}\right)\end{array}\end{array}$ & $\begin{array}{c}\text { Average } \\
\begin{array}{c}\text { Equivalent } \\
\text { Rate (mrem/h) }\end{array}\end{array}$ & $\begin{array}{c}\text { Average } \\
\text { Quality } \\
\text { Factor }\end{array}$ & $\begin{array}{c}\text { Energy } \\
(\text { MeV })\end{array}$ \\
\cline { 1 - 1 } Bare PuF & 50 & 208 & 21.5 & 9.7 & 1.29 \\
1-in. acrylic & 50 & 196 & 14.5 & 9.8 & 0.86 \\
2-in. acrylic & 50 & 173 & 8.65 & 8.9 & 0.69 \\
Bare PuF & 100 & 63.8 & 5.72 & 9.7 & 1.12 \\
1-in. acrylic & 100 & 53.1 & 3.97 & 9.8 & 0.86 \\
2-in. acrylic & 100 & 46.6 & 2.56 & 9.4 & 0.66
\end{tabular}

are apparent from examining the table. Although the total neutron flux is not greatly reduced, the neutrons that penetrate the shield are lower in energy, and there is a significant reduction in the dose equivalent rate. The table also demonstrates that there is a significant room scatter component at $100 \mathrm{~cm}$ from the source. This may be caused by significant scatter around the shield caused by the tables necessary to support the source and slab shields. For these measurements, the slab shields were placed as close to the source as possible.

The neutron flux per logarithmic energy bin determined from the multisphere measurements is given in Figure 5.2 for measurements at $50 \mathrm{~cm}$ from the PuF $_{4}$ source and in Figure 5.3 for measurements at $100 \mathrm{~cm}$ from the PuF 4 source. At $50 \mathrm{~cm}$ from the $\mathrm{PuF}_{4}$ source, there are very few room-scattered neutrons in the measured spectrum from the bare source. The effect of the acrylic plastic shielding is apparent in these figures; the peaks in the PuF ${ }_{4}$ spectrum shift to slightly lower energies with increasing amounts of shielding, and the number of low-energy neutrons is significantly increased. The shape of the measured spectra from the multisphere measurements is quite similar to the results of Monte Carlo calculations found in Compendium of Neutron Spectra in Criticality Accident Dosimetry (Ing and Makra 1978).

The measured neutron energy spectra at $100 \mathrm{~cm}$ show a significant number of lower energy neutrons, presumably from room scatter. The spectrum from the bare PuF $_{4}$ source at $100 \mathrm{~cm}$ has essentially the same shape as the spectrum 


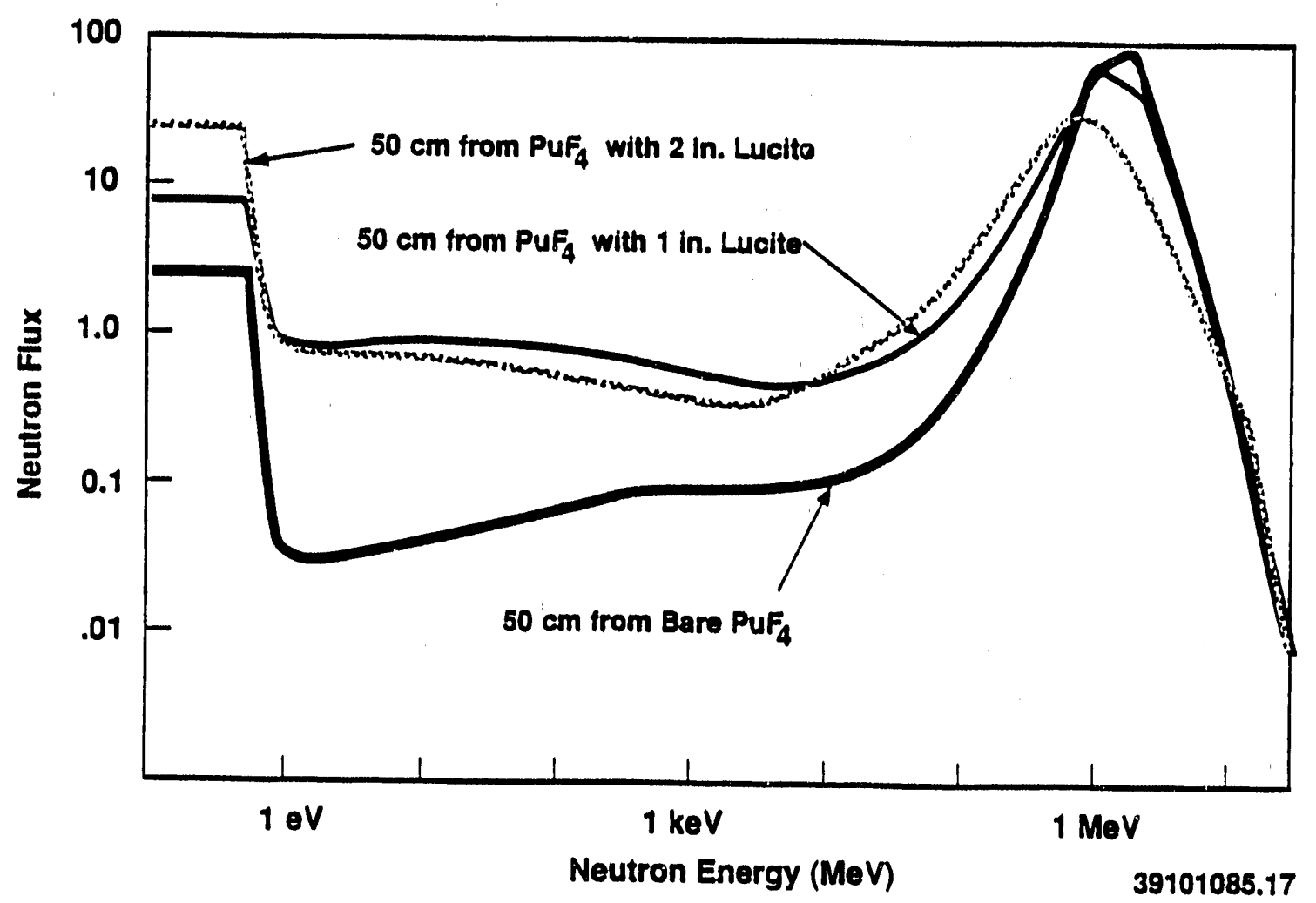

EIGURE 5.2. Neutron Flux per Unit Lethargy at $50 \mathrm{~cm}$ from the PuF $_{4}$ Source Measured by the Multisphere Spectrometer

at $50 \mathrm{~cm}$ for energies above $1 \mathrm{keV}$. Below $1 \mathrm{keV}$, there are significantly more neutrons, presumably from room scatter. The intermediate neutron energy spectra presented here are consistent with what one would expect. However, the reader should be cautioned that the multisphere spectrometer is not highly accurate in the intermediate energy region. The calculated fluxes in this region are dominated by measurements with the cadmium-covered detector and the cadmium covered 3 -in. diameter and 5-in. diameter spheres. The responses of these detectors change very little with significant changes in neutron energy. More selective detectors are needed for increased energy resolution for these neutron energies. 


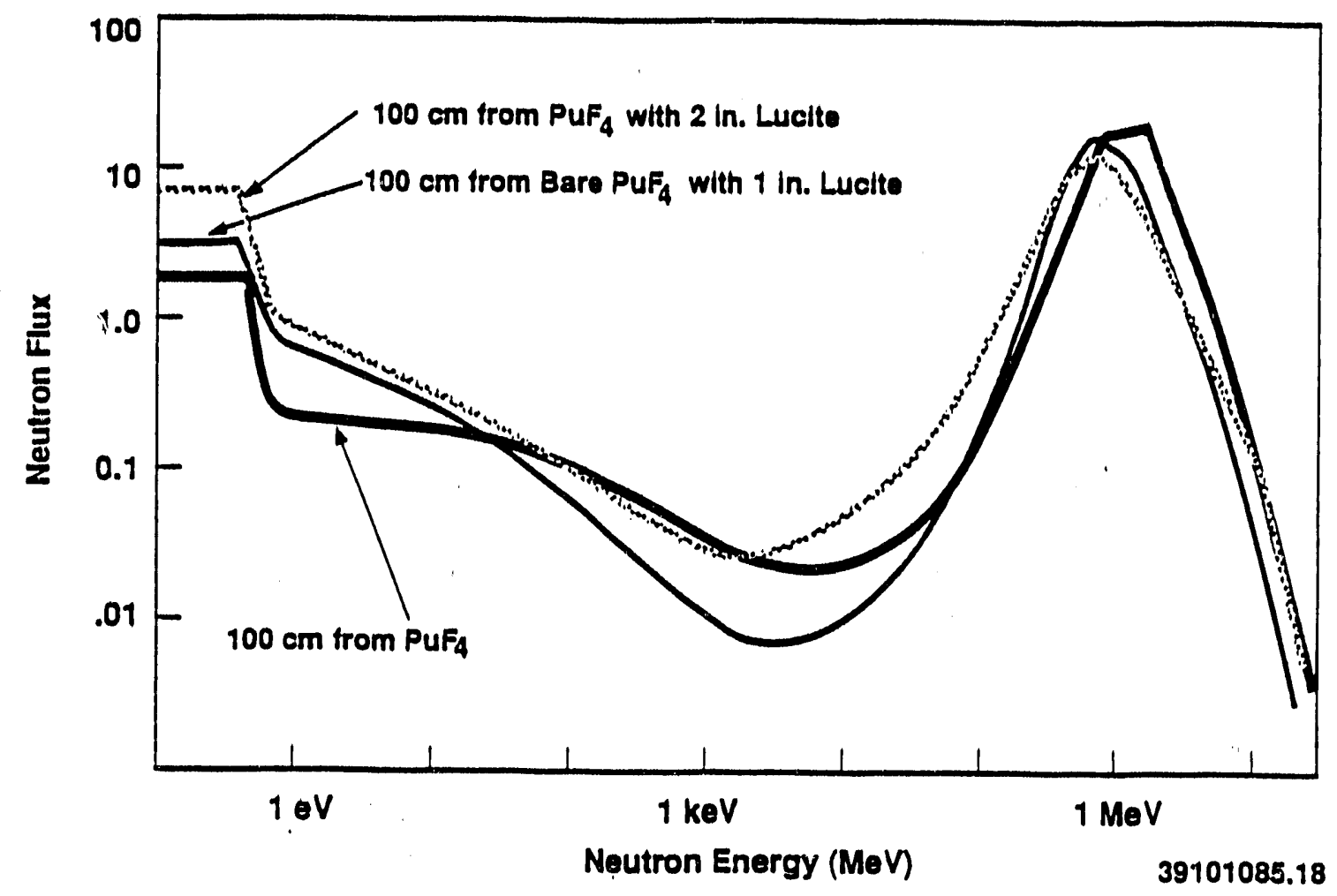

EIGURE 5.3. Neutron Flux per Unit Lethargy at $100 \mathrm{~cm}$ from the $\mathrm{PuF}_{4}$ Source Measured by the Multisphere Spectrometer

Detafled neutron energy spectra are presented in Tables 5.3 to 5.8. In these tables, the differential neutron flux is the flux per energy bin. The energy bins are in logarithmic energy increments, so the fluxes are listed per unit lethargy, with dimensions of neutrons $/ \mathrm{s}-\mathrm{cm}^{2}$ per energy bin. The tables also include the cumulative dose equivalent distribution, which gives the dose equivalent summed from the energy listed in the first column of the tables to $20 \mathrm{MeV}$. The absorbed dose distributions are also listed, so that the effects of any future changes in quality factors can be evaluated. 
IABLE 5.3. Neutron Flux, Absorbed Dose, and Dose Equivalent Distributions Determined from Multisphere Spectrometer Measurements at $50 \mathrm{~cm}$ from the Bare $\mathrm{PuF}_{4}$ Source

\begin{tabular}{|c|c|c|c|c|c|c|}
\hline \multirow[b]{2}{*}{$\begin{array}{l}\text { Bin } \\
\text { No. }\end{array}$} & \multirow[b]{2}{*}{$\begin{array}{l}\text { Energy } \\
(\mathrm{MeV})\end{array}$} & \multirow[b]{2}{*}{$\begin{array}{c}\text { Flux } \\
\left(\mathrm{N} / \mathrm{S}-\mathrm{cm}^{2}\right) \\
\end{array}$} & \multicolumn{2}{|c|}{ Ditferential } & \multicolumn{2}{|c|}{ Cumulative } \\
\hline & & & $\begin{array}{c}\text { Dose } \\
\text { (rad/hr) }\end{array}$ & $\begin{array}{l}\text { 'Dose } \\
\text { Equiv. } \\
\text { (rem/hr) }\end{array}$ & $\begin{array}{c}\text { Dose } \\
\text { Dist. } \\
\text { (rad/hr) }\end{array}$ & $\begin{array}{c}\text { Dose Eq. } \\
\text { Dist. } \\
\text { (rem/hr) }\end{array}$ \\
\hline 1 & 2.57E-07 & $2.61 E+00$ & 4.93E-06 & $1.15 \mathrm{E}-05$ & 2.21E-03 & $2.15 \mathrm{E}-02$ \\
\hline 2 & 5.48E-07 & 3.67E-02 & 8.05E-08 & $1.68 \mathrm{E}-07$ & 2.20E-03 & $2.15 E-02$ \\
\hline 3 & 1.06E-06 & 2.85E-02 & 6.33E08 & 1.33E=07 & 2.20E-03 & 2.15E-02 \\
\hline 4 & 2.25E-06 & $3.38 \mathrm{E}-02$ & 7.47E-08 & $1.58 \mathrm{E}-07$ & $2.20 \mathrm{E}-03$ & $2.15 \mathrm{E}-02$ \\
\hline 5 & 4.77E-06 & 4.02E-02 & 8.78E-08 & $1.88 E-07$ & 2.20E-03 & 2.15E-02 \\
\hline 6 & 1.01E-05 & 4.72E-02 & 1.02E-07 & 2.20E-07 & $2.20 \mathrm{E}-03$ & 2.15E-02 \\
\hline 7 & 2.14E-05 & 5.51E-02 & 1.19E-07 & 2.52E-07 & $2.20 \mathrm{E}-03$ & $2.15 E-02$ \\
\hline 8 & 4.52E-05 & $6.17 E-02$ & 1.32E-07 & 2.75E-07 & 2.20E-03 & 2.15E-02 \\
\hline 9 & 9.58E-05 & 7.04E-02 & 1.49E-07 & 3.05E-07 & 2.20E-03 & $2.15 E-02$ \\
\hline 10 & 2.03E-04 & 8.12E-02 & 1.67E-07 & $3.38 \mathrm{E}-07$ & $2.20 \mathrm{E}-03$ & 2.15E-02 \\
\hline 11 & 4.34E-04 & 8.93E-02 & $1.76 E-07$ & 3.56E-07 & 2.20E-03 & 2.15E-02 \\
\hline 12 & $9.13 E-04$ & 8.69E-02 & 1.64E-07 & 3.32E-07 & 2.20E-03 & $2.15 E-02$ \\
\hline 13 & $1.92 E-03$ & 8.74E-02 & $1.62 E-07$ & 3.26E-07 & 2.20E-03 & 2.15E-02 \\
\hline 14 & 4.07E-03 & $1.03 E-01$ & 1.89E-07 & 3.79E-07 & 2.20E-03 & 2.15E-02 \\
\hline 15 & 8.62E-03 & $1.18 E-01$ & 2.14E-07 & 4.32E-07 & 2.20E-03 & 2.15E-02 \\
\hline 16 & $1.82 E-02$ & 1.58E-01 & 3.19E-07 & 8.81E-07 & $2.20 \mathrm{E}-03$ & 2.15E-02 \\
\hline 17 & 3.86E-02 & 2.52E-01 & $6.02 E-07$ & 2.57E-06 & $2.20 \mathrm{E}-03$ & $2.15 \mathrm{E}-02$ \\
\hline 18 & 8.18E-02 & 6.01E-01 & $1.70 E-06$ & 1.11E-05 & 2.20E-03 & $2.15 E-02$ \\
\hline 19 & 1.67E-01 & $2.18 E+00$ & 8.14E-06 & $6.92 E-05$ & 2.20E-03 & 2.15E-02 \\
\hline 20 & 3.37E-01 & $7.27 E+00$ & 3.80E-06 & $3.82 E-05$ & 2.19E-03 & $2.14 \mathrm{E}-02$ \\
\hline 21 & $6.79 \mathrm{E}-01$ & $6.70 E+01$ & 5.41E-04 & $5.89 \mathrm{E}-03$ & $2.19 \mathrm{E}-03$ & 2.14E-02 \\
\hline 22 & $1.39 E+00$ & $1.01 E+02$ & $1.24 E-03$ & $1.22 E-02$ & 1.65E-03 & 1.55E-02 \\
\hline 23 & $2.78 E+00$ & $2.34 E+01$ & 3.55E-04 & 2.90E-03 & 4.06E-04 & $3.25 E-03$ \\
\hline 24 & $5.54 E+00$ & $2.19 E+00$ & 4.55E-05 & $3.19 \mathrm{E}-04$ & $5.06 \mathrm{E}-05$ & 3.53E-04 \\
\hline 25 & $1.12 E+01$ & $1.97 E-01$ & 4.70E-06 & $3.25 E-05$ & 5.01E-06 & 3.46E-05 \\
\hline 26 & $2.04 E+01$ & 9.34E-03 & 3.06E-07 & 2.12E-06 & 3.05E-07 & 2.12E-06 \\
\hline \multicolumn{2}{|c|}{ Total } & $2.08 E+02$ & $2.21 E-03$ & $2.15 E-02$ & & \\
\hline
\end{tabular}


IABLE 5.4. Neutron Fiux, Absorbed Dose, and Dose Equivalent

Distributions Determined from Multisphere

Spectrometer Measurements at $50 \mathrm{~cm}$ from the

$\mathrm{PuF}_{4}$ Source with l-in. Acrylic Plastic Shield

\begin{tabular}{|c|c|c|c|c|c|c|}
\hline \multirow[b]{2}{*}{$\begin{array}{l}\text { Bin } \\
\text { No. }\end{array}$} & \multirow[b]{2}{*}{$\begin{array}{l}\text { Energy } \\
\text { (MeV) }\end{array}$} & \multirow[b]{2}{*}{$\begin{array}{c}\text { Flux } \\
\left(\mathrm{N} / \mathrm{S}-\mathrm{cm}^{2}\right) \\
\end{array}$} & \multicolumn{2}{|c|}{ Differential } & \multicolumn{2}{|c|}{ Cumulative } \\
\hline & & & $\begin{array}{c}\text { Dose } \\
(\mathrm{rad} / \mathrm{hr})\end{array}$ & $\begin{array}{c}\text { Dose } \\
\text { Equiv. } \\
\text { (rem } / \mathrm{hr} \text { ) }\end{array}$ & $\begin{array}{c}\text { Dose } \\
\text { Dist. } \\
\text { (rad/hr) }\end{array}$ & $\begin{array}{c}\text { Dose Eq. } \\
\text { Dist. } \\
\text { (rem/hr) }\end{array}$ \\
\hline 1 & 2.57E-07 & 7.87E+00 & 1.49E-05 & 3.46E-05 & $1.48 E-03$ & $1.45 E-02$ \\
\hline 2 & $5.48 \mathrm{E}-07$ & $9.26 \mathrm{E}-01$ & 2.03E-06 & $4.24 \mathrm{E}-06$ & $1.47 \mathrm{E}-03$ & $1.45 E-02$ \\
\hline 3 & $1.06 E-06$ & 8.29E-01 & 1.84E-06 & 3.87E-06 & 1.47E-03 & $1.45 E-02$ \\
\hline 4 & $2.25 \mathrm{E}-06$ & 9.07E-01 & $2.00 \mathrm{E}-06$ & 4.25E-06 & $1.47 \mathrm{E}-03$ & $1.44 \mathrm{E}-02$ \\
\hline 5 & 4.17E-06 & $9.71 E-01$ & 2.12E-06 & 4.54E-06 & $1.46 \mathrm{E}-03$ & $1.44 E-02$ \\
\hline 6 & $1.01 E-0.5$ & $1.01 E+00$ & 2.19E-06 & 4.73E-06 & $1.46 \mathrm{E}-03$ & $1.44 E-02$ \\
\hline 7 & $2.14 \mathrm{E}-05$ & $1.02 E+00$ & $2.18 \mathrm{E}-06$ & $4.64 \mathrm{E}-06$ & $1.46 \mathrm{E}-03$ & $1.44 \mathrm{E}-02$ \\
\hline 8 & $4.52 \mathrm{E}-05$ & $9.67 \mathrm{E}-01$ & 2.07E-06 & 4.31E-06 & $1.46 \mathrm{E}-03$ & 1.44E-02 \\
\hline 9 & $9.58 E-05$ & 8.70E-01 & $1.84 E-06$ & 3.77E-06 & 1.45E-03 & $1.44 E-02$ \\
\hline 10 & 2.03E-04 & $8.01 E-01$ & $1.64 \mathrm{E}-06$ & 3.34E-06 & $1.45 \mathrm{E}-03$ & $1.44 \mathrm{E}-02$ \\
\hline 11 & $4.34 \mathrm{E}-04$ & $7.06 \mathrm{E}-01$ & $1.39 \mathrm{E}-06$ & 2.81E-06 & $1.45 \mathrm{E}-03$ & $1.44 \mathrm{E}-02$ \\
\hline 12 & $9.13 E-04$ & 5.62E-01 & 1.06E-06 & 2.15E-06 & 1.45E-03 & $1.44 E-02$ \\
\hline 13 & 1.92E-03 & 4.88E-01 & 9.05E-07 & 1.82E-06 & $1.45 E-03$ & $1.44 \mathrm{E}-02$ \\
\hline 14 & 4.07E-03 & 5.33E-01 & 9.76E-07 & 1.96E-06 & 1.45E-03 & $1.44 E-02$ \\
\hline 15 & 8.62E-03 & 5.86E-01 & $1.06 E-06$ & 2.15E-06 & 1.45E-03 & $1.44 E-02$ \\
\hline 10 & $1.82 E-02$ & 7.60E-01 & $1.54 E-06$ & 4.25E-06 & $1.45 E-03$ & $1.44 E-02$ \\
\hline 17 & 3.86E-02 & $1.15 E+00$ & 2.76E-06 & $1.18 E-05$ & 1.44E-03 & 1.44E-02 \\
\hline 18 & 8.18E-02 & $2.43 E+00$ & $6.86 E-06$ & $4.50 E-05$ & 1.44E-03 & $1.44 \mathrm{E}-02$ \\
\hline 19 & $1.67 E-01$ & $7.79 E+00$ & 2.91E-05 & $2.48 \mathrm{E}-04$ & $1.43 \mathrm{E}-03$ & 1.43E-02 \\
\hline 20 & 3.37E-01 & $2.99 E+01$ & 1.57E-05 & 1.57E-04 & $1.41 \mathrm{E}-03$ & 1.41E-02 \\
\hline 21 & 6.79E-01 & $7.33 E+01$ & 5.92E-04 & $6.45 E-03$ & $1.39 E-03$ & $1.39 E-02$ \\
\hline 22 & $1.39 E+00$ & 4.95E+01 & $6.07 E-04$ & $5.98 \mathrm{E}-03$ & 7.98E-04 & 7.49E-03 \\
\hline 23 & $2.78 E+00$ & $1.04 E+01$ & $1.58 E-04$ & $1.29 E-03$ & $1.90 E-04$ & 1.51E-03 \\
\hline 24 & 5.54E +00 & $1.33 E+00$ & 2.77E-05 & $1.94 E-04$ & $3.23 E-05$ & 2.25E-04 \\
\hline 25 & $1.12 E+01$ & $1.78 \mathrm{E}-01$ & 4.25E-06 & 2.94E-05 & 4.57E-06 & 3.15E-05 \\
\hline 26 & $2.04 E+01$ & $9.59 E-03$ & $3.14 \mathrm{E}-07$ & 2.18E-06 & $3.14 E-07$ & 2.17E-06 \\
\hline & & $1.96 E+02$ & $1.48 E-03$ & $1.45 E-02$ & & \\
\hline
\end{tabular}


TABLE 5.5. Neutron Flux, Absorbed Dose, and Dose Equivalent Distributions Determined from Multisphere Spectrometer Measurements at $50 \mathrm{~cm}$ from the PuF $_{4}$ Source with 2-in. Acrylic Plastic Shield

\begin{tabular}{|c|c|c|c|c|c|c|}
\hline \multirow[b]{2}{*}{$\begin{array}{l}\text { Bin } \\
\text { No. }\end{array}$} & \multirow[b]{2}{*}{$\begin{array}{c}\text { Energy } \\
\text { (MeV) } \\
\end{array}$} & \multirow[b]{2}{*}{$\begin{array}{c}\text { Flux } \\
\left(N / S-\mathrm{cm}^{2}\right)\end{array}$} & \multicolumn{2}{|c|}{ Differential } & \multicolumn{2}{|c|}{ Cumulative } \\
\hline & & & $\begin{array}{c}\text { Dose } \\
\text { (rad/hr) } \\
\end{array}$ & $\begin{array}{c}\text { Dose } \\
\text { Equiv. } \\
\text { (rem/hr) }\end{array}$ & $\begin{array}{c}\text { Dose } \\
\text { Dist. } \\
\text { irad/hr) }\end{array}$ & $\begin{array}{c}\text { Dose Eq. } \\
\text { Dist. } \\
\text { (rem/hr) }\end{array}$ \\
\hline 1 & 2.57E-07 & $2.61 E+01$ & $4.94 E-05$ & 1.15E-04 & 9.77E-04 & 8.65E-03 \\
\hline 2 & 5.48E-07 & $1.91 E+00$ & 4.19E-06 & 8.76E-06 & 9.27E-04 & $8.53 E-03$ \\
\hline 3 & 1.06E-06 & $1.64 E+00$ & 3.64E-06 & 7.64E-06 & 9.23E-04 & 8.53E-03 \\
\hline 4 & 2.25E-06 & $1.67 E+00$ & 3.69E-06 & 7.83E-06 & $9.20 E-04$ & 8.52E-03 \\
\hline 5 & 4.77E-06 & $1.67 E+00$ & 3.65E-06 & 7.81E-06 & $9.16 E-04$ & 8.51E-03 \\
\hline 6 & $1.01 E-05$ & $1.62 E+00$ & $3.51 E-06$ & 7.58E-06 & $9.12 E-04$ & 8.50E-03 \\
\hline 7 & 2.14E-05 & $1.52 E+00$ & $3.27 E-06$ & 6.95E-06 & $9.09 E-04$ & 8.50E-03 \\
\hline 8 & 4.52E-05 & $1.35 E+00$ & 2.83E-06 & 6.02E-06 & 9.05E-04 & 8.49E-03 \\
\hline 9 & $9.58 E-05$ & $1.19 E+00$ & 2.52E-06 & 5.15E-06 & 9.03E-04 & 8.48E-03 \\
\hline 10 & 2.03E-04 & $1.11 E+00$ & 2.27E-06 & 4.61E-06 & $9.00 E-04$ & 8.48E-03 \\
\hline 11 & 4.34E-04 & $1.03 E+00$ & $2.04 E-06$ & 4.12E-06 & 8.98E-04 & 8.47E-03 \\
\hline 12 & $9.13 E-04$ & 9.16E-01 & $1.73 E-06$ & 3.50E-06 & 8.96E-04 & 8.47E-03 \\
\hline 13 & $1.92 E-03$ & $9.14 E-01$ & $1.69 E-06$ & 3.41E-06 & 8.94E-04 & 8.46E-03 \\
\hline 14 & 4.07E-03 & $1.14 E+00$ & 2.09E-06 & 4.21E-06 & 8.92E-04 & 8.46E-03 \\
\hline 15 & 8.62E-03 & $1.39 E+00$ & 2.51E-016 & 5.08E-06 & 8.90E-04 & 8.46E-03 \\
\hline 16 & $1.82 E-02$ & $1.92 E+00$ & 3.89E-06 & $1.07 E-05$ & 8.88E-04 & $8.45 \vdots-03$ \\
\hline 17 & 3.86E-02 & $2.93 E+00$ & 7.00E-06 & 2.99E-05 & 8.84E-04 & 8.44E-03 \\
\hline 18 & 8.18E-02 & $5.56 E+00$ & $1.57 E-015$ & $1.03 E-04$ & 8.77E-04 & $8.41 E=03$ \\
\hline 19 & 1.67E-01 & $1.28 E+01$ & $4.78 E-015$ & 4.06E-04 & 8.61E-04 & 8.31E-03 \\
\hline 20 & 3.37E-01 & $3.06 E+01$ & 1.60E-015 & 1.61E-04 & 8.13E-04 & 7.90E-03 \\
\hline 21 & $6.79 E-01$ & $3.87 E+01$ & $3.13 E-(1) 4$ & $3.41 E-03$ & 7.97E-04 & 7.74E-03 \\
\hline 22 & $1.39 E+00$ & $2.29 E+01$ & $2.80 E-104$ & 2.76E-03 & 4.84E-04 & 4.33E-03 \\
\hline 23 & $2.78 E+00$ & $8.43 E+00$ & $1.28 E-D 4$ & $1.04 E-03$ & 2.04E-04 & 1.57E-03 \\
\hline 24 & $5.54 E+00$ & $2.65 E+00$ & 5.52E-05 & $3.86 E-04$ & $7.60 \mathrm{E}-05$ & 5.30E-04 \\
\hline 25 & $1.12 E+01$ & 8.01E-01 & 1.91E-05 & $1.32 E-04$ & 2.08E-05 & $1.44 E-04$ \\
\hline 26 & $2.04 E+01$ & 5.32E-02 & 1.74E-06 & $1.21 E-05$ & $1.74 E-06$ & 1.2YE-05 \\
\hline & & $1.73 E+0 ?$ & $9.77 E .04$ & 8.65E-03 & & \\
\hline
\end{tabular}


TABLE 5.6. Neutron Flux, Absorbed Dose, and Dose Equivalent Distributions Determined from Multisphere Spectrometer Measurements at $100^{\circ} \mathrm{cm}$ from the Bare $\mathrm{PuF}_{4}$ Source

\begin{tabular}{|c|c|c|c|c|c|c|}
\hline \multirow[b]{2}{*}{$\begin{array}{l}\text { Bin } \\
\text { No. }\end{array}$} & \multirow[b]{2}{*}{$\begin{array}{c}\text { Energy } \\
\text { (MeV) }\end{array}$} & \multirow[b]{2}{*}{$\begin{array}{c}\begin{array}{c}\text { Flux } \\
\left(\mathrm{N} / \mathrm{S}-\mathrm{cm}^{2}\right)\end{array} \\
\end{array}$} & \multicolumn{2}{|c|}{ Differential } & \multicolumn{2}{|c|}{ Cumulative } \\
\hline & & & $\begin{array}{c}\text { Dose } \\
\text { (rad/hr) } \\
\end{array}$ & $\begin{array}{c}\text { Dose } \\
\text { Equiv. } \\
\text { (rem/hr) }\end{array}$ & $\begin{array}{c}\text { Dose } \\
\text { Dist. } \\
\text { (rad/hr) } \\
\end{array}$ & $\begin{array}{c}\text { Dose Eq. } \\
\text { Dist. } \\
\text { (rem/hr) }\end{array}$ \\
\hline 1 & 2.:7E-07 & 2.24E+00 & 4.24E-06 & 9.85E-06 & 5.90E-04 & 5.72E-03 \\
\hline 2 & 5.48E-07 & 3.08E-01 & 6.76E-07 & 1.41E-06 & 5.86E-04 & 5.71E-03 \\
\hline 3 & 1.06E-06 & 2.66E-01 & 5.91E-07 & 1.24E-06 & 5.85E-04 & 5.70E-03 \\
\hline 4 & 2.25E-06 & 2.68E-01 & 5.92E-07 & 1.25E-06 & 5.85E-04 & 5.70E-03 \\
\hline 5 & 4.77E-06 & 2.61E-01 & 5.70E-07 & $1.22 E-06$ & 5.84E-04 & 5.70E-03 \\
\hline 6 & $1.01 E-05$ & 2.44E-01 & 5.27E-07 & $1.14 E-06$ & 5.83E-04 & 5.70E-03 \\
\hline 7 & 2.14E-05 & 2.13E-01 & 4.58E-07 & 9.74E-07 & 5.83E-04 & 5.70E-03 \\
\hline 8 & 4.52E-05 & 1.66E-01 & 3.55E-07 & 7.41E-07 & 5.82E-04 & 5.70E-03 \\
\hline 9 & 9.58E-05 & 1.25E-01 & 2.65E-07 & 5.42E-07 & 5.82E-04 & 5.70E-03 \\
\hline 10 & 2.03E-04 & 9.22E-02 & 1.89E-07 & 3.84E-07 & $5.82 E_{-04}$ & 5.70E-03 \\
\hline 11 & $4.34 E-04$ & $6.41 E-02$ & $1.26 E-07$ & 2.55E-07 & 5.82E-04 & 5.70E-03 \\
\hline 12 & $9.13 E-04$ & $3.94 E-02$ & $7.45 E-08$ & $1.51 E-07$ & 5.31E-04 & 5.70E-03 \\
\hline 13 & 1.92E-03 & 2.74E-02 & 5.07E-08 & 1.02E-07 & 5.81E-04 & 5.70E-03 \\
\hline 14 & 4.07E-03 & 2.53E-02 & 4.63E-08 & 9.29E-08 & 5.8/E-04 & 5.70E-03 \\
\hline 15 & 8.62E-03 & $2.66 E-02$ & 4.82E-08 & 9.75E-08 & 5.81E-04 & 5.70E-03 \\
\hline 16 & 1.82E-0\% & $3.52 E-02$ & 7.13E-08 & 1.97E-07 & 5.81E-04 & 5.70E-03 \\
\hline 17 & $3.86 E-c 2$ & 5.99E-02 & $1.43 E-07$ & $6.11 E-07$ & 5.81E-04 & 5.70E-03 \\
\hline 18 & 8.18E-02 & $1.63 E-01$ & 4.60 E-07 & 3.02E-06 & 5.81E-04 & 5.70E-03 \\
\hline 19 & 1.67E-01 & y.02E-01 & 3.37E-06 & 2.87E-05 & 5.81E-04 & 5.69E-03 \\
\hline 20 & 3.37E-01 & $6.10 E+00$ & 3.20E-06 & $3.21 E-05$ & 5.77E-04 & 5.66E-03 \\
\hline 21 & 6.79E-01 & $2.16 E+01$ & 1.75E-04 & $1.90 E-03$ & 5.74E-04 & 5.63E-03 \\
\hline 22 & $1.39 E+00$ & $2.38 E+01$ & 2.91E-04 & $2.87 E-03$ & 3.99E-04 & 3.73E-03 \\
\hline 23 & $2.78 E+00$ & $5.92 E \rightarrow 00$ & $9.00 E-05$ & 7.33E-04 & 1.08E-04 & 8.57E-04 \\
\hline 24 & $5.54 E+00$ & 7.40 E-01 & $1.54 E-05$ & $1.08 E-04$ & 1.78E-05 & $1.24 E-04$ \\
\hline 25 & $1.12 E+01$ & 9.37E-02 & 2.23E-06 & 1.54E-05 & 2.39E-06 & 1.65E-05 \\
\hline 26 & $2.04 E+01$ & 4.79E-03 & 1.57E-07 & 1.09E-06 & 1.57E-07 & $1.09 E-06$ \\
\hline & & $6.38 E+01$ & 5.90E-04 & 5.72E-03 & & \\
\hline
\end{tabular}


IABLE 5.7. Neutron Flux, Absorbed Dose, and Dose Equivalent Distributions Determined from Multisphere Spectrometer Measurements at $100 \mathrm{~cm}$ from the $\mathrm{PuF}_{4}$ Source with l-in. Acrylic Plastic Shield

\begin{tabular}{|c|c|c|c|c|c|c|}
\hline \multirow[b]{2}{*}{$\begin{array}{l}\text { Bin } \\
\text { No. }\end{array}$} & \multirow[b]{2}{*}{$\begin{array}{l}\text { Energy } \\
(\mathrm{MeV})\end{array}$} & \multirow[b]{2}{*}{$\begin{array}{c}\begin{array}{c}\text { Flux } \\
\left(\mathrm{N} / \mathrm{S}-\mathrm{cm}^{2}\right)\end{array} \\
\end{array}$} & \multicolumn{2}{|c|}{ Differential } & \multicolumn{2}{|c|}{ Cumulative } \\
\hline & & & $\begin{array}{c}\text { Dose } \\
\text { (rad/hr) }\end{array}$ & $\begin{array}{c}\text { Dose } \\
\text { Equiv. } \\
\text { (rem/hr) }\end{array}$ & $\begin{array}{l}\text { Dose } \\
\text { Dist. } \\
\text { (rad/hr) }\end{array}$ & $\begin{array}{c}\text { Dose Eq. } \\
\text { Dist. } \\
\text { (rem } / \mathrm{hr} \text { ) }\end{array}$ \\
\hline 1 & 2.57E-07 & $3.31 \varepsilon+00$ & 6.26E-06 & $1.45 E-05$ & 4.05E-04 & $3.97 \mathrm{E}-03$ \\
\hline 2 & 5.48E-07 & 7.87E-01 & $1.72 E-06$ & 3.60E-06 & 3.99E-04 & 3.96E-03 \\
\hline 3 & $1.06 E-06$ & $6.09 E-01$ & 1.35E-06 & 2.84E-06 & 3.97E-04 & 3.96E-03 \\
\hline 4 & 2.25E-05 & 4.90E-01 & $1.08 E-06$ & 2.29E-06 & 3.96E-04 & 3.95E-03 \\
\hline 5 & 4.77E-06 & $3.74 E-01$ & 8.17E-07 & $1.75 E-06$ & 3.95E-04 & 3.95E-03 \\
\hline 6 & 1.01E-05 & $2.68 E-01$ & 5.79E-07 & $1.25 E-06$ & 3.94E-04 & 3.95E-03 \\
\hline 7 & 2.14E-05 & $1.72 E-01$ & 3.70E-07 & Z.85E-07 & 3.93E-04 & 3.95E-03 \\
\hline 8 & 4.52E-05 & 9.28E-02 & $1.98 \mathrm{E}-07$ & 4.13E-07 & 3.93E-04 & 3.95E-03 \\
\hline 9 & $9.58 E-05$ & 5.14E-02 & $1.09 E-07$ & 2.23E-07 & 3.93E-04 & 3.95E-03 \\
\hline 10 & 2.03E-04 & $2.86 E-02$ & 5.87E-08 & 1.19E-07 & $3.93 E-04$ & $3.95 E-03$ \\
\hline 11 & 4.34E-04 & $1.63 E-02$ & $3.20 E-08$ & $6.48 E-08$ & 3.93E-04 & 3.95E-03 \\
\hline 12 & $9.13 E-04$ & 8.99E-03 & $1.70 E-08$ & 3.43E-08 & 3.93E-04 & 3.95E-03 \\
\hline 13 & 1.92E-03 & $6.41 E-03$ & 1.19E-08 & 2.39E-08 & $3.93 E-04$ & 3.95E-03 \\
\hline 14 & 4.07E-03 & 6.76E-03 & $1.24 E-08$ & 2.49E-08 & 3.93E-04 & 3.95E-03 \\
\hline 15 & 8.62E-03 & 8.79E-03 & $1.59 E-08$ & 3.22E-08 & 3.93E-04 & 3.95E-03 \\
\hline 16 & 1.82E-02 & $1.51 E=02$ & 3.06E-08 & $8.45 E-08$ & $3.93 E-04$ & 3.95E-03 \\
\hline 17 & $3.86 E-02$ & 3.47E-02 & 8.30E-08 & 3.54E-07 & 3.93E-04 & $3.95 E-03$ \\
\hline 18 & 8.18E-02 & $1.32 E-01$ & $3.74 E-07$ & $2.46 E-06$ & 3.92E-04 & $3.95 E-03$ \\
\hline 19 & 1.67E-01 & $9.82 E-01$ & 3.67E-06 & 3.12E-05 & 3.92E-04 & $3.94 E-03$ \\
\hline 20 & 3.37E-01 & $8.05 E+00$ & 4.21E-06 & 4.23E-05 & $3.88 E-04$ & 3.91E-03 \\
\hline 21 & 6.79E-01 & $2.12 E+01$ & 1.71E-04 & 1.87E-03 & 3.84E-04 & 3.87E-03 \\
\hline 22 & $1.39 E+00$ & $1.34 E+01$ & $1.64 E-04$ & $1.62 E-03$ & 2.13E-04 & 2.00E-03 \\
\hline 23 & $2.78 E+C O$ & $2.62 E+00$ & $3.98 E-05$ & $3.24 E-04$ & 4.84E-05 & 3.85E-04 \\
\hline 24 & $5.54 E+00$ & $3.50 E-01$ & $7.29 E-06$ & 5.10E-05 & 8.66E-06 & 6.04E-05 \\
\hline 25 & $1.12 E+01$ & 5.32E-02 & $1.27 E-06$ & 8.76E-06 & 1.37E-06 & 9.44E-06 \\
\hline 26 & $2.04 E+01$ & $3.00 E-03$ & $9.82 E-08$ & $6.80 E-07$ & $9.82 E-08$ & 6.80E-07 \\
\hline & & $5.31 E+01$ & 4.05E-04 & 3.97E-03 & & \\
\hline
\end{tabular}


TABLE 5.8. Neutron Flux, Absorbed Dose, and Dose Equivalent Distributions Determined from Multisphere Spectrometer Measurements at $100 \mathrm{~cm}$ from the $\mathrm{PuF}_{4}$ Source with 2-in. Acrylic Plastic Shield

\begin{tabular}{|c|c|c|c|c|c|c|}
\hline \multirow[b]{2}{*}{$\begin{array}{l}\text { Bin } \\
\text { No. }\end{array}$} & \multirow[b]{2}{*}{$\begin{array}{l}\text { Energy } \\
\text { (MeV) }\end{array}$} & \multirow[b]{2}{*}{$\begin{array}{c}\text { Fiux } \\
\left(\mathrm{N} / \mathrm{S}-\mathrm{cm}^{2}\right)\end{array}$} & \multicolumn{2}{|c|}{ Differential } & \multicolumn{2}{|c|}{ Eumulative } \\
\hline & & & $\begin{array}{c}\text { Dose } \\
\text { (rad/hr) } \\
\end{array}$ & $\begin{array}{c}\text { Dose } \\
\text { Equiv. } \\
\text { (rem/hr) }\end{array}$ & $\begin{array}{c}\text { Dose } \\
\text { Dist. } \\
\text { (rad/hr) } \\
\end{array}$ & $\begin{array}{l}\text { Dose Eq. } \\
\text { Dist. } \\
\text { (rem/hr) }\end{array}$ \\
\hline 1 & 2.57E-07 & $7.08 E+00$ & 1.34E-05 & 3.12E-05 & 2.73E-04 & 2.56E-03 \\
\hline 2 & 5.48E-07 & $1.06 E+00$ & 2.33E-06 & 4.87E-06 & 2.59E-04 & 2.52E-03 \\
\hline 3 & 1.06E-06 & 7.73こ-01 & 1.72E-06 & 3.61E-06 & 2.57E-04 & 2.52E-03 \\
\hline 4 & 2.25E-06 & 5.91E-01 & 1.30E-06 & 2.76E-06 & 2.55E-04 & 2.52E-03 \\
\hline 5 & 4.77E-06 & 4.33E-0: & $9.46 E-07$ & 2.03E-06 & 2.54E-04 & 2.51E-03 \\
\hline 6 & $1.01 E-05$ & $3.04 E-01$ & 6.57E-07 & $1.42 E-06$ & 2.53E-04 & 2.51E-03 \\
\hline 7 & $2.14 E-05$ & $1.96 E-01$ & 4.22E-07 & 8.98E-07 & 2.52E-04 & 2.51E-03 \\
\hline 8 & $4.52 E-05$ & $1.12 E-01$ & 2.39E-07 & $4.98 E-07$ & 2.52E-04 & 2.51E-03 \\
\hline 9 & S.58E-05 & 6.95E-02 & $1.48 E-07$ & 3.01E-07 & 2.52E-04 & 2.51E-03 \\
\hline 10 & 2.03E-04 & 4.63E-02 & 9.49E-08 & $1.93 E-07$ & 2.51E-04 & 2.51E-03 \\
\hline 11 & $4.34 E-04$ & $3.32 E=02$ & 6.53E-08 & $1.32 E=07$ & 2.51E-04 & 2.51E-03 \\
\hline 12 & $9.13 E=04$ & 2.42E-02 & 4.57E-08 & $9.23 E-08$ & 2.51E-04 & 2.51E.03 \\
\hline 13 & 1.92E-03 & 2.24E-02 & $4.15 E-08$ & 8.35E-08 & 2.51E-04 & 2.51E-03 \\
\hline 14 & 4.07E-03 & 2.90E-02 & 5.30E-08 & $1.06 E-07$ & $2.51 E-04$ & 2.51E-03 \\
\hline 15 & 8.62E-03 & 4.12E-02 & 7.48E-08 & 1.51E-07 & 2.51E-04 & 2.51E-03 \\
\hline 16 & 1.82E-02 & 7.24E-02 & 1.47E-07 & 4.05E-07 & 2.51E-04 & 2.51E-03 \\
\hline 17 & $3.86 E-02$ & $1.55 E-01$ & $3.70 E-07$ & 1.58E:06 & $2.51 E-04$ & 2.51E-03 \\
\hline 18 & $8.18 E-02$ & 4.73E-01 & $1.34 E-06$ & 8.77E-06 & 2.51E-04 & 2.51E-03 \\
\hline 19 & 1.67E-01 & $2.12 E+00$ & 7.91E-06 & $6.73 E-05$ & 2.49E-04 & 2.50E-03 \\
\hline 20 & 3.37E-01 & 9.47E+00 & 4.95E-06 & 4.97E-05 & 2.41E-04 & 2.43E-03 \\
\hline 21 & $6.79 E-01$ & $1.45 E+01$ & 1.17E-04 & $1.27 E-03$ & 2.36E-04 & 2.38E-03 \\
\hline 22 & $1.39 E+00$ & $6.91 E+00$ & 8.47E-05 & 8.34E-04. & 1.20E-04 & 1.11E-03 \\
\hline 23 & $2.78 E+00$ & $1.68 E+00$ & 2.55E-05 & $2.08 E-04$ & $3.49 E-05$ & 2.74E-04 \\
\hline 24 & $5.54 E+00$ & $3.52 E-01$ & 7.33E-06 & 5.12E-05 & 9.39E-06 & $6.55 E-05$ \\
\hline 25 & $1.12 E+01$ & 7.97E-02 & $1.90 E-06$ & 1.31E-05 & 2.06E-06 & 1.43E-05 \\
\hline 26 & $2.04 E+01$ & $5.04 E-03$ & 1.65E-07 & 1.14E-06 & 1.65E-07 & 1.14E-0̈6 \\
\hline & & $4.66 E+01$ & 2.73E-04 & 2.56E-03 & & \\
\hline
\end{tabular}




\subsection{PLUTONIUM DIOXIDE MEASUREMENTS}

Measurements were performed on a 962 -gram $\mathrm{PuO}_{2}$ source containing 846.6 grams of plutonium. The loose $\mathrm{PuO}_{2}$ powder was $\mathrm{placed}$ in a 3.5-in.-diameter by 3.5-in. high steel can, which was in turn sealed inside a steel food can 4-1.8 in. in diameter by 7-in. high. As reported in Section 2 of this report, the plutonium was recently separated low-exposure plutonium containing only $6.0 \%{ }^{240} \mathrm{Pu}$ and $0.21 \%{ }^{241} \mathrm{Pu}$, so that there was $11 \mathrm{ttl}$ le ingrowth of ${ }^{241} \mathrm{Am}$.

The can containing the $\mathrm{PuO}_{2}$ was $\mathrm{placed}$ on an aluminum projector support stand at a height of $1 \mathrm{~m}(3.3 \mathrm{feet})$ from the floor to the bottom of the can. The center of gravity of the can was determined, and distances were measured relative to this point. The dose rates from this source were so low that all of the measured dose rates had to be corrected for room background, which was about $0.07 \mathrm{mrem} / \mathrm{h}$ near the source. To minimize the effects of material in the glove box, the phantoms for the dosimeter exposures were positioned so that the dosimeters were shielded by the phantom or so that the dosimeters were at right angles to the glove box to minimize their response to room background.

\subsubsection{Dose Equivalent Determinations from the Plutonium Dioxide Source}

The results of the neutron measurements are summarized in Table 5.9 below using the various detectors indicated in the table. The dose equivalent rates, corrected for room background of about $0.07 \mathrm{mrem} / \mathrm{h}$, follow an inverse square relationship with distance. The measured dose equivalent rates are so low that there is considerable variation in the measurements made with the various detectors. The numbers in parentheses in the table are the percent standard deviations of the measured values. In general, the results have a $17 \%$ deviation from the averages reported at the one standard deviation level. 
IABLE 5.9. Results of Neutron Measurements Performed on the $\mathrm{PuO}_{2}$ Source at the Plutonium Finishing Plant

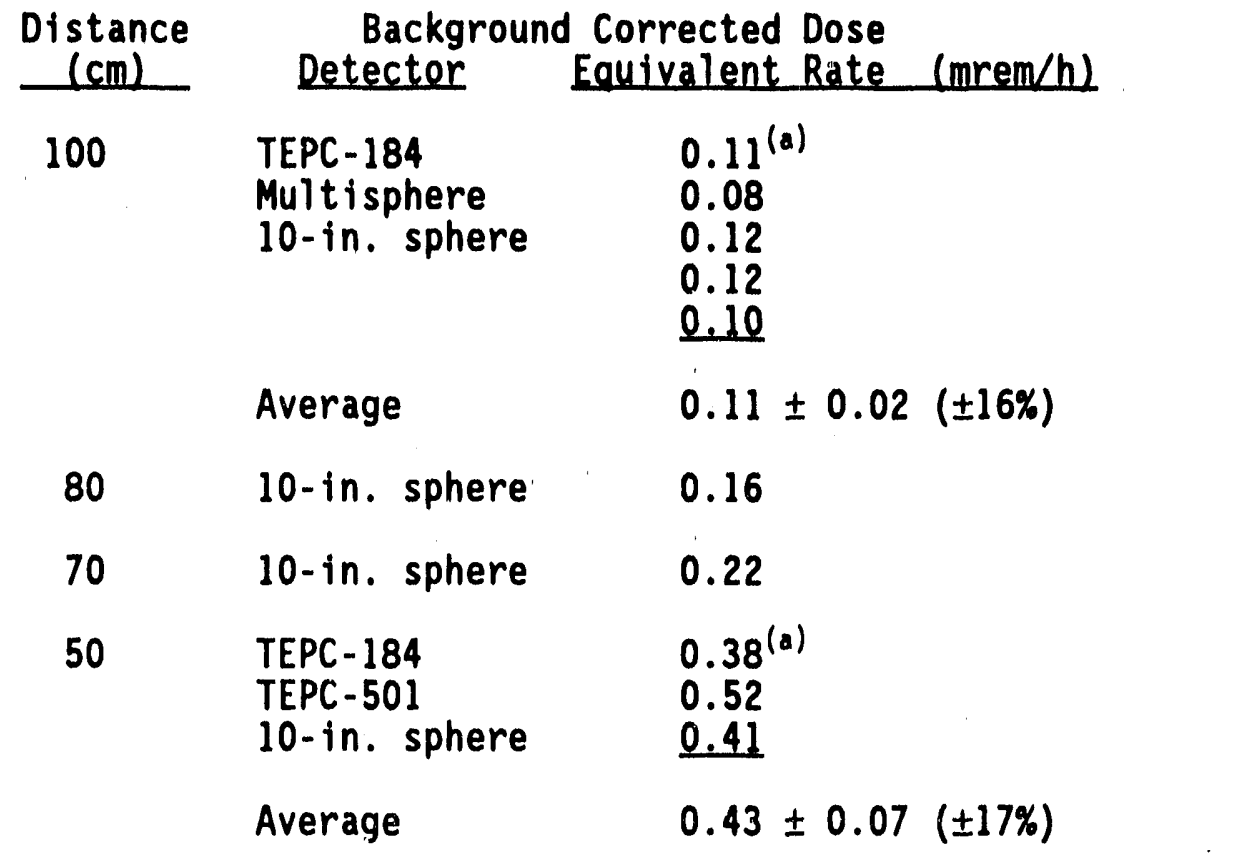

(a) TEPC-184 corrected for methane gas filling.

\subsubsection{Multisphere Spectrometer Measurements with the Plutonium Dioxide Source}

A multisphere spectrometer measurement was made at $100 \mathrm{~cm}$ from the $\mathrm{PuO}_{2}$ source with the spectrometer positioned on the side of the source closest to the glove boxes. A summary of the results from the multisphere spectrometer measurements is presented in Table 5.10, and details of the differential flux per logarithmic energy bin and dose equivalent distributions as a function of energy are presented in Table 5.11. A plot of the differential flux, i.e., the neutron flux per logarithmic energy bin or flux per unit lethargy, is presented in Figure 5.4 .

The measurement was made at $100 \mathrm{~cm}$ from the source to minimize positioning errors, which can influence the results. In retrospect, this was a poor choice. The background dose rate was almost as high as the dose rate from the $\mathrm{PuO}_{2}$ source. The results shown in Table 5.10 show that the average energy from the $\mathrm{PuO}_{2}$ measurement is about $0.9 \mathrm{MeV}$; previous measurements made by the authors indicate that the average energy from a bare $\mathrm{PuO}_{2}$ source should 
be about $2 \mathrm{MeV}$. An examination of the plot of the neutron flux as a function of energy shows that room background is influencing the measured results. It is thought that properly positioning the phantoms for the dosimeter exposures may reduce the influence of the room background by shielding the dosimeters from the glove box material.

TABLE 5.10. Summary of Multisphere Spectrometer Measurements with the $\mathrm{PuO}_{2}$ Source

\begin{tabular}{|c|c|c|c|c|c|}
\hline Shielding & $\begin{array}{c}\text { Distance } \\
(\mathrm{cm}) \\
\end{array}$ & $\begin{array}{l}\text { Neutron } \\
\text { Flux } \\
\left(\mathrm{n} / \mathrm{s}-\mathrm{cm}^{2}\right)\end{array}$ & $\begin{array}{l}\text { Dose } \\
\text { Equiv. Rate } \\
\text { (mrem } / \mathrm{h} \text { ) }\end{array}$ & $\begin{array}{l}\text { Average } \\
\text { Quality } \\
\text { actor } \\
\end{array}$ & $\begin{array}{l}\text { Average } \\
\text { Energy } \\
(\mathrm{MeV}) \\
\end{array}$ \\
\hline Bare $\mathrm{PuO}_{2}$ & 100 & 3.21 & 0.18 & 8.6 & 0.90 \\
\hline
\end{tabular}


TABLE 5.11. Neutron Flux, Absorbed Dose, and Dose Equivalent Distributions Determined from Multisphere Spectrometer

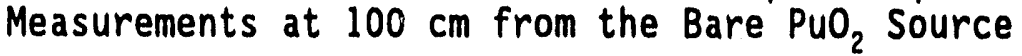

\begin{tabular}{|c|c|c|c|c|c|c|}
\hline \multirow[b]{2}{*}{$\begin{array}{l}\text { Bin } \\
\text { No. }\end{array}$} & \multirow[b]{2}{*}{$\begin{array}{c}\text { Energy } \\
\text { (MeV) }\end{array}$} & \multirow[b]{2}{*}{$\begin{array}{c}\text { Filux } \\
\left(\mathrm{N} / \mathrm{S}-\mathrm{cm}^{2}\right) \\
\end{array}$} & \multicolumn{2}{|c|}{ Differential } & \multicolumn{2}{|c|}{ Cumulative } \\
\hline & & & $\begin{array}{c}\text { Dose } \\
\text { (rad/hr) }\end{array}$ & $\begin{array}{c}\text { Dose } \\
\text { Equiv. } \\
\text { (rem/hr) }\end{array}$ & $\begin{array}{c}\text { Dose } \\
\text { Dist. } \\
\text { (rad/hr) } \\
\end{array}$ & $\begin{array}{c}\text { Dose Eq. } \\
\text { Dist. } \\
\text { (rem/hr) }\end{array}$ \\
\hline 1 & 2.57E-07 & 6.07E-01 & $1.15 E-06$ & 2.67E-06 & 2.10E-05 & $1.81 E-04$ \\
\hline 2 & 5.48E-07 & 9.37E-02 & 2.05E-07 & 4.29E-07 & $1.99 \mathrm{E}-05$ & $1.79 E-04$ \\
\hline 3 & 1.06E-06 & 7.19E-02 & 1.60E-07 & 3.35E-07 & 1.97E-05 & $1.78 E-04$ \\
\hline 4 & 2.25E-06 & 5.69E-02 & 1.26E-07 & 2.66E-07 & 1.95E-05 & $1.78 E-04$ \\
\hline 5 & 4.77E-06 & 4.44E-02 & 9.70E-08 & 2.08E-07 & 1.94E-05 & 1.77E-04 \\
\hline 6 & 1.01E-05 & 3.40E-02 & 7.35E-08 & 1.59E-07 & 1.93E-05 & 1.77E-04 \\
\hline 7 & 2.14E-05 & 2.50E-02 & 5.36E-08 & 1.14E-07 & $1.92 E-05$ & 1.77E-04 \\
\hline 8 & $4.52 E-05$ & 1.71E-02 & $3.66 E-08$ & 7.62E-08 & 1.92E-05 & 1.77E-04 \\
\hline 9 & 9.58E-05 & 1.26E-02 & 2.68E-08 & 5.47E-08 & 1.91E-05 & 1.77E-04 \\
\hline 10 & 2.03E-04 & $1.01 E-02$ & 2.07E-08 & 4.21E:08 & $1.91 E-05$ & $1.77 E-04$ \\
\hline 11 & 4.34E-04 & 8.54E-03 & 1.68E-08 & 3.40E-08 & 1.91E-05 & 1.77E-04 \\
\hline 12 & $9.13 E-04$ & 7.11E-03 & 1.34E-08 & 2.71E-08 & $1.91 E-05$ & 1.77E-04 \\
\hline 13 & $1.92 E-03$ & $6.98 E-03$ & 1.29E-08 & 2.61E-08 & 1.91E-05 & 1.77E-04 \\
\hline 14 & 4.07E-03 & 8.88E-03 & $1.62 E-08$ & 3.26E-08 & 1.90E-05 & 1.77E-04 \\
\hline 15 & 8.62E-03 & 1.12E-02 & 2.04E-08 & 4.12E-08 & 1.90E-05 & 1.77E-04 \\
\hline 16 & 1.82E-02 & 1.64E-02 & 3.33E-08 & $9.18 E-08$ & 1.90E-05 & 1.77E-04 \\
\hline 17 & 3.86E-02 & 2.68E-02 & 6.40E-08 & 2.73E-07 & 1.90E-05 & 1.77E-04 \\
\hline 18 & 8.18E-02 & 5.53E-02 & 1.56E-07 & 1.03E-06 & $1.89 E-05$ & 1.76E-04 \\
\hline 19 & 1.67E-01 & $1.45 E-01$ & 5.44E-07 & 4.62E-06 & 1.87E-05 & 1.75E-04 \\
\hline 20 & 3.37E-01 & 4.23E-01 & 2.21E-07 & 2.22E-06 & $1.82 E-05$ & $1.71 E-04$ \\
\hline 21 & 6.79E-01 & 6.28E-01 & 5.07E-06 & 5.52E-05 & $1.80 E-05$ & $1.68 E-04$ \\
\hline 22 & $1.39 E+00$ & 5.30E-01 & 6.50E-06 & 6.40E-05 & 1.29E-05 & $1.13 E-04$ \\
\hline 23 & $2.78 E+00$ & 2.51E-01 & 3.81E-06 & 3.11E-05 & 6.41E-06 & 4.92E-05 \\
\hline 24 & $5.54 E+00$ & 8.85E-02 & 1.84E-0j & 1.29E-05 & 2.60E-06 & 1.81E-05 \\
\hline 25 & $1.12 E+01$ & 2.94E-02 & 7.00E-07 & 4.83E-06 & $7.60 \mathrm{E}-07$ & $5.25 E-06$ \\
\hline 26 & $2.04 E+01$ & 1.83E-03 & 5.99E-08 & 4.15E-07 & 5.99E-08 & 4.15E-07 \\
\hline & & $3.21 E+00$ & 2.10E-05 & 1.81E-04 & & \\
\hline
\end{tabular}




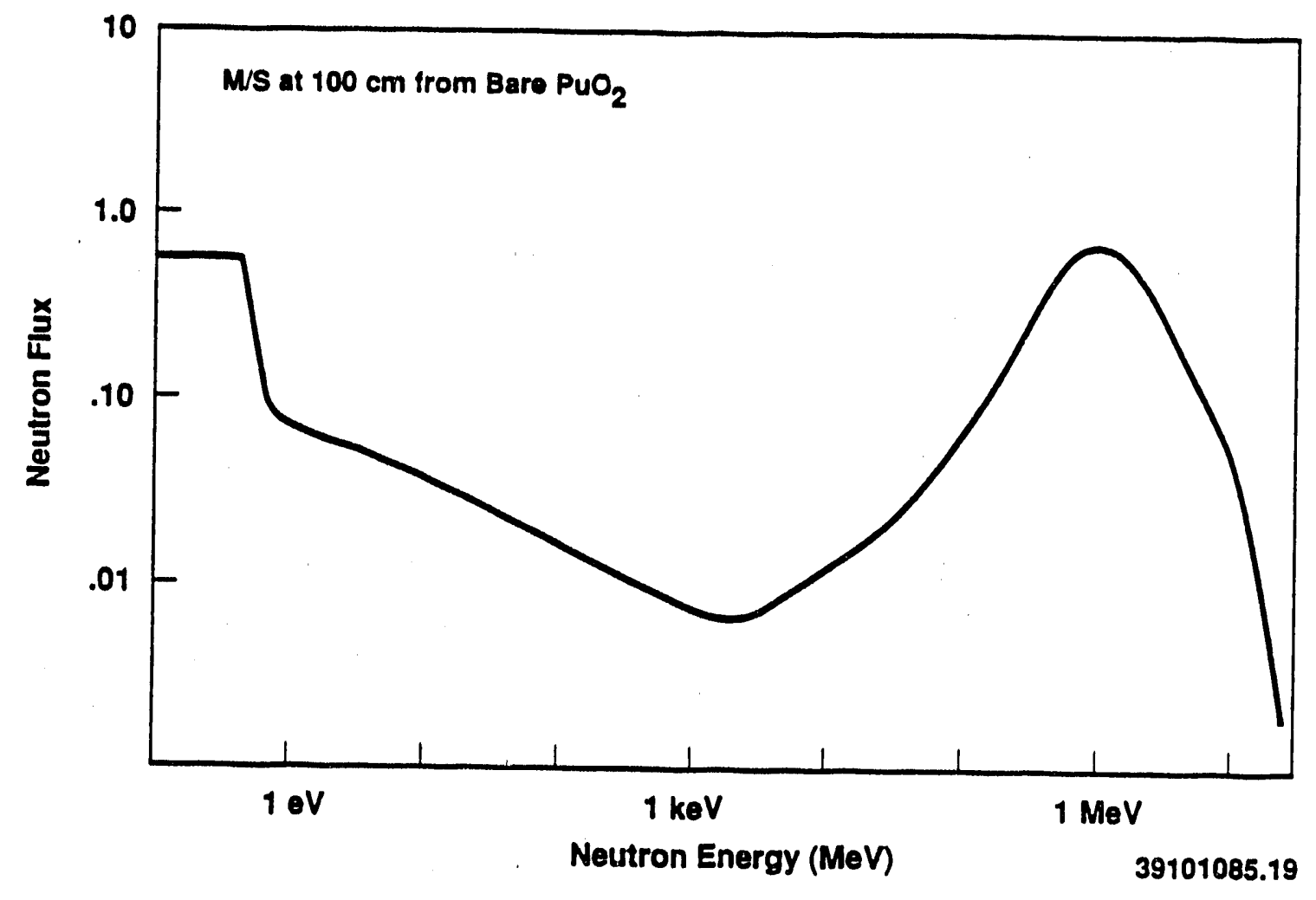

EIGURE 5.4. Neutron Flux per Unit Lethargy at $100 \mathrm{~cm}$ from the $\mathrm{PuO}_{2}$ Source Measured by the Multisphere Spectrometer

\subsection{PLUTONIUM METAL MEASUREMENTS}

Measurements were performed on a plutonium metal source containing 1508 grams of plutonium. Two anode heel samples were placed inside cans and sealed inside a steel food can 4-1.8 in. in diameter by 7-in. high. As reported in Section 2.0 of this report, the plutionium was recently separated low-exposure plutonium containing only $5.4 \%^{240} \mathrm{Pu}$ and $0.17 \%{ }^{241} \mathrm{Pu}$, so that ingrowth of ${ }^{241} \mathrm{Am}$ was not a problem.

The can containing the plutonium metal was placed on an aluminum projector support stand at a height of $1 \mathrm{~m}(3.3 \mathrm{ft})$ to the bottom of the can. The center of gravity of the can was determined, and distances were measured relative to this point. As before, the dose rates from this source were so low that all of the measured dose rates had to be corrected for room background. 


\subsubsection{Dose Equivalent Determinations from the Plutonium Metal Source}

A summary of the measured dose equivalent rates from tissue equivalent proportional counters, the multisphere spectrometer, and a 10-in. diameter sphere calibrated as a rem meter are presented in Table 5.12. The uncertainties in the average for the measured values are given for one standard deviation. The numbers in parentheses are the percent standard deviation in the measured values. The dose rate measured for this source is somewhat higher than expected, so it is suspected that the neutron emission rate may be enhanced by impurities of low atomic number present in the anode heel samples. The measured dose equivalent rates follow an inverse square relationship when corrected for room background, which is about $0.07 \mathrm{mrem} / \mathrm{h}$ at the source location.

TABLE 5.12. Results of Neutron Measurements Performed on the 1508-Gram Plutonium Metal Source

\begin{tabular}{|c|c|c|}
\hline $\begin{array}{l}\text { Distance } \\
(\mathrm{cm}) \\
\end{array}$ & Detector & $\begin{array}{l}\text { Background Corrected Dose } \\
\text { Equivalent Rate (mrem/h) }\end{array}$ \\
\hline 100 & $\begin{array}{l}\text { TEPC } 184 \\
\text { TEPC } 501 \\
10-\text { in. sphere }\end{array}$ & $\begin{array}{l}0.18 \\
0.20 \\
0.16 \\
0.16 \\
\end{array}$ \\
\hline & Average for $100 \mathrm{~cm}$ & $0.17 \pm 0.017( \pm 10 \%)$ \\
\hline 80 & 10-in. sphere & 0.26 \\
\hline 50 & $\begin{array}{l}\text { TEPC } 184 \\
\text { TEPC } 501 \\
\text { Multisphere } \\
10-\text { in. sphere }\end{array}$ & $\begin{array}{l}0.70 \\
0.74 \\
0.64 \\
0.54 \\
0.58 \\
0.56 \\
0.59 \\
\end{array}$ \\
\hline & Average for $50 \mathrm{~cm}$ & $0.62 \pm 0.075( \pm 12 \%)$ \\
\hline
\end{tabular}

\subsubsection{Multisphere Spectrometer Measurements with the Plutonium Metal Source}

A summary of the results from the multisphere spectrometer measurements is presented in Table 5.13, and detailed neutron flux and dose equivalent distributions for logarithmic energy intervals are presented in Table 5.14. 
The multisphere measurements were performed at $50 \mathrm{~cm}$ for the metal measurements, so that the background would not present as much a problem as in the previous measurement. The measured dose equivalent rates are almost an order of magnitude higher than the general room background. Table 5.13 shows that the average energy is about $1.4 \mathrm{MeV}$, which is only slightly higher than the $\mathrm{PuF}_{4}$ results. Previous measurements have demonstrated that the average neutron energy is actually about $2 \mathrm{MeV}$ for a bare plutonium metal source. Part of the difference in measured average energy may be ascribed to the fact that the multisphere energy bins are so wide that average energies in the MeV region are not very accurate. Also, the average depends on whether arithmetic averages or logarithmic averages are used for the midpoint energies of the bias.

The neutron flux density per logarithmic interval or the flux per unit lethargy is plotted as a function of the logarithm of the neutron energy in Figure 5.5. This plot clearly indicates that the plutoniun metal spectrum is harder than the $\mathrm{PuO}_{2}$ spectrum, but that there is still a significant lowenergy component. It is believed that this low-energy component is due to room background, and this is lowering the overall average energy. Comparing the spectrum above $1 \mathrm{keV}$ with previous measurements, one can see that the metal spectrum is much harder (i.e., higher energy), as expected. These results indicate the difficulty of finding a location where the room background is low enough to allow proper measurements of plutonium metal and $\mathrm{PuO}_{2}$ sources. In many instances, it may be more accurate to substitute a ${ }^{252} \mathrm{Cf}$ spontaneous fission source, which has a much higher neutron emission rate, so that room background will be insignificant. 
IABLE 5.13. Summary of Multisphere Spectrometer Measurements with the Plutonium Metal Source

\begin{tabular}{|c|c|c|c|c|c|}
\hline Shielding & $\begin{array}{l}\text { Distance } \\
(\mathrm{cm}) \\
\end{array}$ & $\begin{array}{l}\text { Neutron } \\
\text { Flux } \\
\left(\mathrm{n} / \mathrm{s}-\mathrm{cm}^{2}\right) \\
\end{array}$ & $\begin{array}{l}\text { Dose } \\
\text { Equiv. Rate } \\
\text { (mrem } / h \text { ) }\end{array}$ & $\begin{array}{l}\text { Average } \\
\text { Quality } \\
\text { Factor } \\
\end{array}$ & $\begin{array}{l}\text { Average } \\
\text { Energy } \\
(\mathrm{MeV}) \\
\end{array}$ \\
\hline Bare Pu Metal & 50 & 6.80 & 0.607 & 9.2 & 1.36 \\
\hline
\end{tabular}

IABLE 5.14. Neutron Flux, Absorbed Dose, and Dose Equivalent Distributions Distributions Determined from Multisphere Spectrometer Measurements at $50 \mathrm{~cm}$ from the Bare Plutonium Metal Source

\begin{tabular}{|c|c|c|c|c|c|c|}
\hline \multirow[b]{2}{*}{$\begin{array}{l}\text { Bin } \\
\text { No. }\end{array}$} & \multirow[b]{2}{*}{$\begin{array}{l}\text { Energy } \\
(\mathrm{MeV}) \\
\end{array}$} & \multirow[b]{2}{*}{$\begin{array}{c}\text { Fiux } \\
\left(\mathrm{N} / \mathrm{S}-\mathrm{cm}^{2}\right) \\
\end{array}$} & \multicolumn{2}{|c|}{ Differential } & \multicolumn{2}{|c|}{ Cumulative } \\
\hline & & & $\begin{array}{c}\text { Dose } \\
(\mathrm{rad} / \mathrm{hr})\end{array}$ & $\begin{array}{c}\text { Dose } \\
\text { Equiv. } \\
\text { (rem/hr) }\end{array}$ & $\begin{array}{c}\text { Dose } \\
\text { Dist. } \\
\text { (rad/hr) }\end{array}$ & $\begin{array}{c}\text { Dose Eq. } \\
\text { Dist. } \\
\text { (rem/hr) }\end{array}$ \\
\hline 1 & 2.57E-07 & 4.46E-01 & 8.45E-07 & 1.96E-06 & 6.63E-05 & 6.07E-04 \\
\hline 2 & 5.48E-07 & 3.09E-01 & 6.76E-07 & 1.41E-06 & 6.54E-05 & 6.05E-04 \\
\hline 3 & $1.06 E-06$ & $1.74 E-01$ & 3.87E-07 & 8.12E-07 & $6.47 E-05$ & 6.04E-04 \\
\hline 4 & $2.25 E_{-06}$ & $7.80 E-02$ & 1.72E-07 & 3.65E-07 & $6.44 E-05$ & 6.03E-04 \\
\hline 5 & 4.77E-06 & $3.27 E-02$ & 7.14E-08 & 1.53E-07 & 6.42E-05 & 6.03E-04 \\
\hline 6 & $1.01 E-05$ & $4.26 E-02$ & 2.73E-08 & 5.89E-08 & $6.41 E-05$ & 6.03E-04 \\
\hline 7 & $2.14 E-05$ & 4.15E-03 & 8.93E-09 & 1.90E-08 & $6.41 E-05$ & $6.03 E-0.4$ \\
\hline 8 & 4.52E-05 & $1.04 E-03$ & 2.23E-09 & 4.64E-09 & 6.41E-05 & 6.03E-04 \\
\hline 9 & $9.58 E-05$ & $3.31 E-04$ & 7.02E-10 & 1.43E-09 & 6.41E-05 & 6.03E-04 \\
\hline 90 & 2.03E-04 & $1.12 E-04$ & 2.30E-10 & 4.67E-10 & 6.41E-05 & 6.03E-04 \\
\hline 11 & 4.34E-04 & 4.50E-05 & $8.86 E-11$ & $1.79 E-10$ & $6.41 E-05$ & $6.03 E-04$ \\
\hline 12 & $9.13 E-04$ & 2.02E-05 & 3.81E-11 & $7.70 E-11$ & 6.41E-05 & 6.03E-04 \\
\hline 13 & $1.92 E-03$ & 1.39E-05 & 2.57E-11 & 5.17E-11 & $6.41 E-05$ & 6.03E-04 \\
\hline 14 & 4.07E-03 & 1.61E-05 & 2.94E-11 & 5.91E-11 & $6.41 E-05$ & $6.03 E-04$ \\
\hline 15 & $8.625-03$ & $2.60 E-05$ & 4.73E-11 & $9.56 E-11$ & 6.41E-05 & 6.03E-04 \\
\hline 16 & $1.82 E-02$ & $6.00 E-05$ & $1.22 E-10$ & 3.36E-10 & 6.41E-05 & 6.03E-04 \\
\hline 17 & 3.86E-02 & $2.01 E-04$ & 4.80E-10 & 2.04E-09 & 6.41E-05 & 6.03E-04 \\
\hline 18 & 8.18E-02 & $1.27 E-03$ & 3.60E-09 & 2.36E-08 & 6.41E-05 & 6.03E-04 \\
\hline 19 & 1.67E-01 & 1.99E-02 & 7.43E-08 & 6.32E-07 & 6.41E-05 & $6.02 E-04$ \\
\hline 20 & 3.37E-01 & 3.91E-01 & 2.05E-07 & 2.05E-06 & $6.40 E-05$ & $6.02 E-04$ \\
\hline 21 & 6.79E-01 & $1.71 E+00$ & 1.38E-05 & $1.50 \mathrm{E}-04$ & 6.38E-05 & $6.00 E-04$ \\
\hline 22 & $1.39 E+00$ & $2.40 E+00$ & 2.94E-05 & 2.89E-04 & 5.00E-05 & 4.50E-04 \\
\hline 23 & $2.78 E+00$ & $9.28 E-01$ & 1.41E-05 & $1.15 E-04$ & 2.06E-05 & $1.60 E-04$ \\
\hline 24 & $5.54 E+00$ & 2.39E-01 & 4.97E-06 & 3.47E-05 & 6.53E-06 & 4.55E-05 \\
\hline 25 & $1.12 E+01$ & $6.00 \mathrm{E}-02$ & 1.43E-06 & 9.87E-06 & 1.56E-06 & 1.08E-05 \\
\hline 26 & $2.04 E+01$ & $3.98 E-03$ & 1.30E-07 & 9.03E-07 & 1.30E-07 & 9.02E-07 \\
\hline & & $6.80 E+00$ & 6.63E-05 & 6.07E-04 & & \\
\hline
\end{tabular}




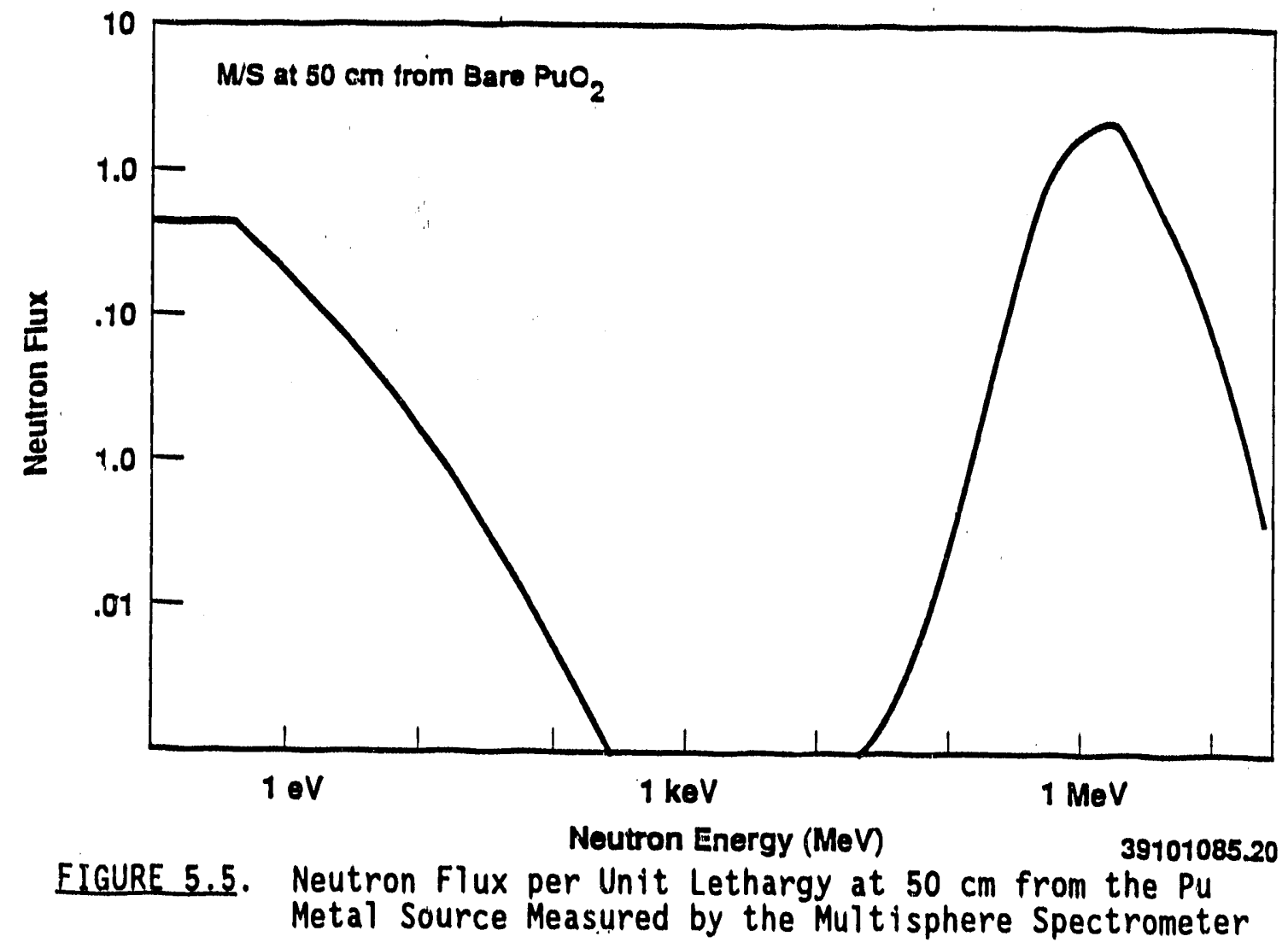




\subsection{ATTENUATION BY ACRYLIC PLASTIC SHIELDING}

In the early days of Hanford, plutonium was processed in glove boxes constructed from acrylic plastic or constructed with acrylic plastic windows. More recentiy, slabs of acrylic plastic have been added to glove boxes to reduce the neutron exposure to workers. A series of measurements was performed to determine the amount of attenuation of the dose equivalent rate provided by acrylic plastic slab shields. Measurements were performed at the PNL Calibration Laboratory using bare ${ }^{252} \mathrm{Cf}$ sources, and in the PFP, using PuF and $\mathrm{PuO}_{2}$ sources.

In the PNL Calibration Laboratory, $40 \mathrm{~cm}$ by $40 \mathrm{~cm}$ by $2.54 \mathrm{~cm}$ thick slabs of acrylic plastic were positioned between the TEPC detector and the ${ }^{252} \mathrm{Cf}$ source on the support stand normally used to hold the acrylic plastic phantoms. These measurements included the effects of room scatter and scatter around the shield by the support stand. The attenuation was calculated by dividing the dose equivalent rate measured behind the shield by the dose equivalent rate without the shield in place. The results of these measurements are inc?uded in Table 6.1 and are plotted in Figure 6.1. The results of earlier measurements made with TEPCS are also included. In these earlier measurements, the effects of room scatter were eliminated by placing a thick shadow shield between the source and the TEPC. The room scatter around the shadow shield was mared, and the dose equivalent rate was subtracted from the result measured with the slab shield in position. This was done to provide data to compare with computer code calculations for the slab shields; for simplicity, the computer code calculations did not model room scatter. In general, room scatter reduces the shield effectiveness.

In the PFP, $40-\mathrm{cm}-\mathrm{by}-40-\mathrm{cm}$ slab shields of acrylic plastic were placed on an aluminum support stand positioned between the plutonium source and the TEPC detector. As before, the attenuation in dose equivalent rate was determined from the ratio of the dose equivalent rates measured with and without a shield in position. For these measurements, the room background from nearby glove boxes was subtracted from the measured dose rates. But no correction was made for room scatter. The results of these measurements 
TABLE 6.1. Attenuation of Neutron üose Equivalent Provided by Slabs of Acrylic Plastic for Californium and Plutorium Tetrafluoride Neutron Sources

\begin{tabular}{|c|c|c|c|c|}
\hline Source & Shield & $\begin{array}{l}\text { Distance } \\
(\mathrm{cm})\end{array}$ & $\begin{array}{l}\text { Dose Equivalent } \\
\text { Rate (mrem/h) }\end{array}$ & Attenuation \\
\hline \multirow[t]{2}{*}{${ }^{252} \mathrm{Cf}$} & $\begin{array}{l}\text { None } \\
1 / 2-\text { in. plastic } \\
1-\text { in. plastic }\end{array}$ & $\begin{array}{l}100 \\
100 \\
100\end{array}$ & $\begin{array}{l}2770 \\
2500 \\
2210\end{array}$ & $\begin{array}{l}1.00 \\
0.90 \\
0.80\end{array}$ \\
\hline & $\begin{array}{l}\text { None } \\
2-i n \text {. plastic } \\
4-i n \text {. plastic }\end{array}$ & $\begin{array}{l}50 \\
50 \\
50\end{array}$ & $\begin{array}{r}11700 \\
6970 \\
3610\end{array}$ & $\begin{array}{l}1.00 \\
0.60 \\
0.31\end{array}$ \\
\hline $\mathrm{PuF}_{4}$ & $\begin{array}{l}\text { None } \\
1-i n \text {. plastic } \\
2 \text {-in. plastic }\end{array}$ & $\begin{array}{l}50 \\
50 \\
50\end{array}$ & $\begin{array}{c}27.13 \pm 0.71^{(a)} \\
15.3 \pm 0.71 \\
9.89 \pm 0.94\end{array}$ & $\begin{array}{l}1.00 \pm 0.026^{(\mathrm{d})} \\
0.56 \pm 0.030 \\
0.36 \pm 0.036\end{array}$ \\
\hline $\mathrm{PuO}_{2}$ & $\begin{array}{l}\text { None } \\
\text { l-in. plastic } \\
2 \text {-in. plastic }\end{array}$ & $\begin{array}{l}50 \\
50 \\
50\end{array}$ & $\begin{array}{l}0.48 \\
0.41 \\
0.31\end{array}$ & $\begin{array}{l}1.00 \\
0.85 \\
0.65\end{array}$ \\
\hline
\end{tabular}

(a) Uncertainties given for one standard deviation in the measured results.

are also included in Table 6.1. Beca'se the dose rates were low, several measurements were sace. The uncertainties shown in the table are for one standard deviation in the measured results.

In general, the lower energy neutrons from $\mathrm{PuF}_{4}$ are easier to shie?d. A factor-of-2 reduction in dose equivalent rate requires about 1-1/2 to $2 \mathrm{in}$. of acrylic plastic shielding for $\mathrm{PuF}_{4}$ and about 2-1/2 in. of acrylic plastic shielding for ${ }^{252} \mathrm{Cf}$, plutonium oxide, or plutonium metal, which have about the same average neutron energy. Note that the reduction in dose equivalent rate is highly dependent on the measurement situation. Earlier measurements published in BNW-2086, A Guide to Good Practices at Plutonium Facilities (Faust et a1. 1977, page 4-52) and in HEDL-TME 80-50, Personnel Dosimetry and Shielding Program Progress Report: July-December 1979 (Smith 1980) give slightly different transmission factors for the acrylic shields because of differences in the measurements. In the previous documents, the effects of scatter around the shield were corrected for by making shadow shield measurements and subtracting the room scatter from the results. In the PFP 


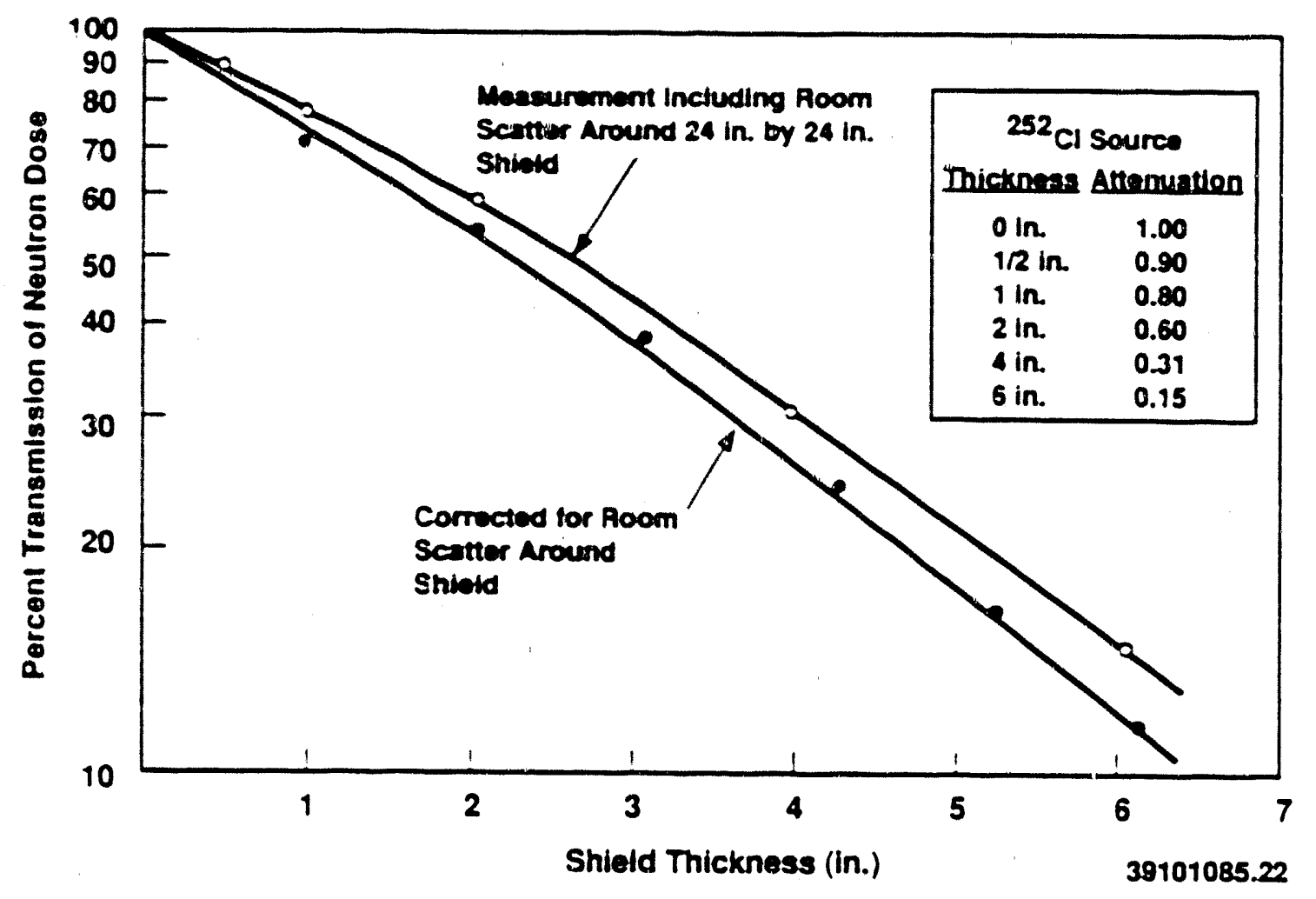

FIGURE 6.1. Reduction in Dose Equivalent Rate from Acrylic Plastic Shielding

measurements presented here, the effects of scatter from the floor and support stands for the source and shields are not corrected for, because these scattered neutrons will influence the albedo dosimeter measurements, and these high-scatter conditions are typical of the workplace conditions.

\section{3}




\subsection{MEASURED RESPONSE OF THE HANFORD DOSIMETERS}

\subsection{INTRODUCTION}

The response of TLD-albedo personnel neutron dosimeters to neutron radiation is significantly dependent on energy (Brackenbush et al. 1980). For routine calibration, Hanford TLDs are exposed to a bare ${ }^{252} \mathrm{Cf}$ source. The exposure time is increased by a factor of 1.73 so that the TLD response is similar between the "field" and calibration source. At Hanford, the "fluorinator hood" at the Hanford PFP was selected as the "field" work environment. This work environment has been characterized on numerous occasions in the past to ensure that the personnel doses determined with the Hanford TLD-albedo dosimeter correctly determined the actual neutron dose equivalent.

With the recent change in Hanford's mission, there has been a significant decrease in $\mathrm{PuF}_{4}$ handling, and an increase in plutonium metal and $\mathrm{PuO}_{2}$ handling. This has resulted in a larger spread in the neutron response variation in the Hanford TLD-albedo dosimeter, i.e., the ratio of

\section{Chip 3 adjusted reading (R3) - Chip 5 adjusted reading (R5)} Chip 4 adjusted reading (R4) - Chip 5 adjusted reading (R5).

This ratio has been an indicator of the type and constancy of neutron exposures being received by personnel in the field.

It is extremely difficult and manpower-intensive to administer a neutron-monitoring program in which a large number of correction factors is necessary for different locations in the same facility because the same employees would, in all probability, work in more than one location during a badge period. It was felt that a measurement study using selected neutron sources could lead to an alternate method in evaiuating personnel neutron dose. These new measurements should complement the measurements conducted in the work environment during the past several years.

Measurements were taken with NIST-traceable neutron sources to calibrate the multisphere spectrometer, TEPCS, Depangher long counter, TLD-albedo dosimeters, and CR-39 TEDs. The responses of the Hanford TLD, CR-39 TED, and Mound Design TLD dosimeters to moderated neutrons were determined by covering the 
${ }^{252} \mathrm{Cf}$ sources with selective thicknesses of acrylic plastic. Measurements were then made at PFP from three plutonium neutron sources: a $\mathrm{PuF}_{4}$, a plutonium metal anode, and $\mathrm{PuO}_{2}$ powder, which were described in Section 3.0 . Several thicknesses of acrylic plastic shielding to simulate glove-box shielding were used with the $\mathrm{PuF}_{4}$. The dose rates from plutonium metal and $\mathrm{PuO}_{2}$ were too low to do any studies using plastic shielding. The TLD insert.s for these special dosimeters were processed in the routine fashion as are personnel TLD inserts. Electrochemically etched TEDs were processed, read, and evaluated by Mary Ann Parkhurst of PNL.

\subsection{RESULTS}

Detailed results for each type of measurement are presented in Appendix $C$. The data include the standard Hanford Multipurpose TL Dosimeter results, a modified multipurpose TL dosimeter to resemble the Mound Laboratory dosimeter configuration (chip 3 has a cadmium filter between the body and the chip), and the CR-39 TED results. The data from the modified multipurpose TL dosimeter will not be discussed, but is included in Appendix C. Table 7.1 is a summary of the exposure data; Table 7.2 presents the standard errors associated with the results.

The data listed in Table 7.1 represent average values of nine measurements for each configuration. The first column in Table 7.1 describes the source and moderator; the second and third columns give the TLD counts corrected for gamma response for chips 3 and 4 , respectively; the fourth column gives the ratio of the responses of TLD chip 3 to TLD chip 4 . Chip 3 is designed to respond to both incident slow neutrons and albedo neutrons; chip 4 is designed to respond primarily to albedo neutrons reflected from the body. The ratio is used as an indicator of the incident neutron spectrum; higher ratios indicate moderated neutron spectra. The fifth column of Table 7.1 gives the TLD calibration for chip 4 in terms of chip counts per mrem delivered to the dosimeter. The sixth column lists the dose equivalent delivered to the dosimeters irom the calibrated sources. The seventh and eighth give the dose equivalent evaluated using the 1990 algorithm, and they 
TABLE 7.1. Summary of TLD-AIbedo Dosimeter Results for the Hanford Multipurpose Dosimeter Exposed to Calibration and Plutonium Sources

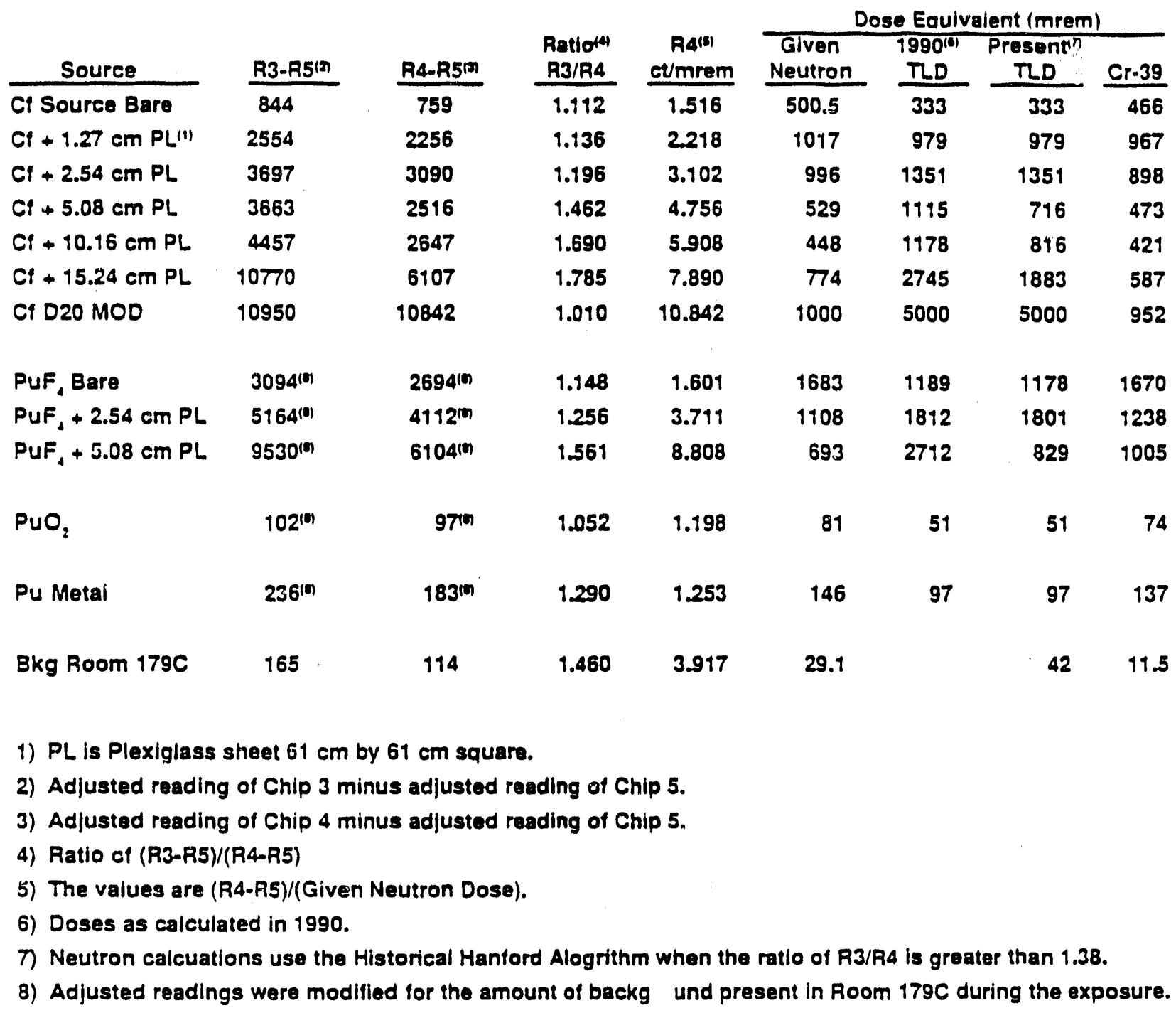




\section{IABLE 7.2. Thermoluminescent Dosimeter Chip Responses for Hanford Multipurpose Dosimeters Exposed to ${ }^{252} \mathrm{Cf}$ Calibration Sources and Plutonium Sources}

\begin{tabular}{|c|c|c|c|c|c|c|c|}
\hline \multirow[b]{2}{*}{ Souree } & \multicolumn{2}{|c|}{ R4-R5(") } & \multicolumn{3}{|c|}{ Ratlo R3-R412 } & \multirow{2}{*}{$\begin{array}{c}R 4^{(3)} \\
\text { ct/mrem } \\
\end{array}$} & \multirow{2}{*}{$\begin{array}{c}\text { mrern } \\
\text { Given } \\
\text { Neutron }\end{array}$} \\
\hline & $x^{(01)}$ & CVin & $\overline{\bar{x}+2 g^{(4)}}$ & $\bar{X}^{(1)}$ & $\bar{X}-2 g^{\prime n}$ & & \\
\hline Cf Souren Bare & 759 & 5.67 & 1.27 & 1,112 & 0.954 & 1.416 & 500.5 \\
\hline $\mathrm{Cf}+1.27 \mathrm{~cm} \mathrm{PLim}$ & 2256 & 7.36 & 128 & 1.8956 & 1.044 & 2.218 & 1017 \\
\hline $\mathrm{Cl}+2.54 \mathrm{~cm}$ PLim & 3090 & 8.64 & 29 & 1.157 & 1.105 & 3.102 & 996 \\
\hline$C P+5.08 \mathrm{~cm} \mathrm{PLim}$ & 2516 & 10.33 & $1.7 \%$ & $1,4 \% 2$ & 1.164 & 4.756 & 529 \\
\hline $\mathrm{Cf}+10.16 \mathrm{~cm}$ PLm & 2647 & 9.08 & 1.92 & 1.690 & 1.458 & 5.908 & 448 \\
\hline $\mathrm{Cf}+15.24 \mathrm{~cm}$ PLim & 6107 & 12.77 & 2.17 & 1.785 & 1.397 & 7.89 & $\pi 4$ \\
\hline Cf 020 MOD & 10842 & 0.75 & 1.02 & 1.010 & 1.003 & 10.842 & 1000 \\
\hline PuF, Bare & 2720 & 14.19 & 1.26 & 1.148 & 1.036 & 1.601 & 1683 \\
\hline$P_{U F}+2.54 \mathrm{~cm} \mathrm{PLin}$ & 4136 & 7.13 & 1.47 & 1.256 & 1.042 & 3.711 & 1108 \\
\hline PuF $+5.08 \mathrm{~cm}$ PL'm & 6128 & 10.82 & 1.80 & 1.561 & 1.321 & 8.808 & 693 \\
\hline $\mathrm{PuO}_{2}$ & 164 & 11.18 & 1.27 & 1.050 & 0.830 & 1.012 & 81.0 \\
\hline Pu Metal & 263 & 14.45 & 1.71 & 1.290 & 0.870 & 1.260 & 145.6 \\
\hline Bkg Room $179 \mathrm{C}$ & 114 & 16.31 & 1.68 & 1.460 & 1.240 & 1.360 & 29.1 \\
\hline
\end{tabular}

1) Adjusted reading for Chip 4 minus the adjusted reading for Chip 3.

2) Ratlo of (R3-P.5)/(R4-R5).

3) The values are (R4-R5)/(Given Neutron Dose).

4) Average.

5) Coefficient of variance - standard deviation in percent.

6. Represents the upper value of the $95 \%$ confidence interval.

7) Represents the lower value of the $95 \%$ confidence interval.

8; PL is Plexiglass sheet $61 \mathrm{~cm}$ by $61 \mathrm{~cm}$ square. 
give the dose equivalent evaluated using the current algorithm, respectively. Finally, the ninth column gives the results of the electrochemically etched CR-39 TEDS.

Table 7.2 shows the uncertainties associated with the averages listed in the previous table. These are described as follows. The first column describes the source and thickness of acrylic plastic moderator placed between the source and the dosimeters. The second column gives the TL chip counts from chip 4, which responds primarily to albedo neutrons reflected from the body and chip 5, which is used to subtract out the gamma response of chip 4 . The third column gives the coefficient of variation or the percent standard deviation in the average listed in the second column. The fifth column gives the ratio of chip counts from position 3 divided by the chip counts from position 4. This is an indicator of the "softness" of the spectrum. The fourth and sixth columns give the upper and lower values in the range of the $95 \%$ confidence interval for this ratio. The seventh column gives the cali. bration constant for TL chip 4; this value is the TL chip counts from chip 4 minus the chip counts from chip 5 (used to account for the gamma response of chip 4) divided by the delivered neutron dose equivalent. Finally, the last column gives the dose equivalent in mrem delivered to the dosimeter.

\subsection{DISCUSSION}

The dose ratio from the ${ }^{252} \mathrm{Cf}$ neutron source was three urders of magnitude higher than that measured from the $\mathrm{PuO}_{2}$. These differences are important since the time it took to obtain the exposure varied from several minutes to several weeks. During the $\mathrm{PuO}_{2}$ measurement, one of the two acrylic plastic plates containing the Mound design TL dosimeter and half of the CR-39 TED dropped off the phantom, and the results were lost.

The measurements with the spectrometers and dosimeters were performed over an extended time period. The background measurement was made almost eight months after the previous exposure had been made when the activity of the operation was again comparable to those where the original exposures were made. The background measurements using the 10-in. rem meter and TEPCS indicate the background remained constant within the counting uncertainties of the measurements. 
There are some questions whether this background subtraction is correct because the adjusted ratio of the $\mathrm{PuO}_{2}$ appears to be too close to 1.00 . The large correction (194-102 for chip 3) for $\mathrm{PuO}_{2}$, the relatively small original observed counts, and the large standard error in the observed values are all major factors in influencing the final outcome. The increase in the observed dose rate of the plutonium metal and the slightly larger-than-expected ratio of the R3/R4 are the direct results of the impurities in the plutorium metal anocie. The impurities were in excess of $5 \%$ of the total weight and some of the impurities appear to have had a higher yield for the alpha-neutron reaction.

In 1990, the routine Hanford External Dosimetry Program used an algorithm that was based on the value of R4-R5 and multiplied by constants that were derived from ${ }^{252} \mathrm{Cf}$ exposure data and previously determined factor of filed measurements:

$$
T N=C 8 \times(R 4-R 5) 1.73
$$

where $C 8$ is about 0.75 . This equation was used to pass the DOELAP certification.

The present calculation is a hybrid of the historical Hanford algorithm (Wilson et al. 1990) and the equation used in 1990. When the ratio of $(R 3-R 4) / R 4-R 5)$ is less than 1.38, then the calculation is as in 1990:

$$
\begin{aligned}
& \text { TN }=C 8 \times(R 4-R 5) / 1.73 \\
& \text { if }(R 3-R 4 /(R 4-R 5) \geq 1.38
\end{aligned}
$$

Then calculate as the Historical Hanford Algorithm

$$
\begin{aligned}
& F N=(C 4 \times R 4)-(C 6 \times R 5)-[C 7 \times(R 3-R 4) / 1.73] \\
& C S N=C 4 \times(R 3-R 4) \\
& T N=F N+S N
\end{aligned}
$$

where $\mathrm{C} 4, \mathrm{C5}, 36$, and $\mathrm{C7}$ are coefficients derived from measurements of the ${ }^{252} \mathrm{Cf}$ source and sigma pile. 
From the data in Table 7.1, one can see that there is significant improvement in the results when the ratio $R 3 / R 4$ is equal to or greater. than 1.38. The ratio of chip 3 to chip 4 data indicates that the TLD is very sensitive to small changes in the spectra and results in a significant increase in the counts/mrem.

One anomaly of the change in ratio is for the ${ }^{252} \mathrm{Cf} \mathrm{D}_{2} \mathrm{O}$-moderated source in a cadmium shield, which removes all of the thermal neutrons from the source spectra. The moderated $D_{2} 0$ source spectrum is not representative of any neutron spectrum at Hanford. As such, the TL dosimeter only sees the albedo neutrons from the phantom. It is very interesting that the standard error in the moderated spectra measurements is a factor of 7 to 19 smaller than for the other sources. One can infer that imperfections in the dosimeters, TL chips, phantom, and spacing of dosimeters result in considerably less impact on the final result. Therefore, the use of this source maybe of value in a quality control program through sensitive recognition of dosimetry processing changes.

The notable change in the ratio R3/R4 is accompanied by a large $95 \%$ confidence intorval, indicating that the ratio would have to move considerably before one could be assured that spectra had changed significantly. The ratio R3/R4 would have to be greater than 1.3 to be assured that the result ratio was not caused by a bare ${ }^{252} \mathrm{Cf}$ source.

\subsection{MEASUREMENTS WITH CR-39 DOSIMETERS}

While the TLD-albedo dosimeters were exposed, sets of CR-39 dosimeters were also exposed to the calibrated neutron sources in the PNL Calibrations Laboratory and to the plutonium sources in the PFP. The results of these exposures are summarized in Table 7.3. The first column describes the neutron source and the amount of acrylic plastic shielding $p l$ aced between the source and the CR-39 TEDs. In the table, $x$ designates the mean value of the measured values, and $\sigma$ designates one standard deviation in the measured values. The precision of the CR-39 measurements is indicated by the one standard deviation uncertainty in the average of 12 CR-39 dosimeters used for each measurement listed in the third column of Table 7.3. The coefficient of variation of the CR-39 TEDs is better than $\pm 10 \%$. 
For the measurements in the PFP, the delivered dose was estimated from the average of measurements from the multisphere spectrometer, TEPCs, and 10in. diameter rem meter. One standard deviation uncertainity in the dose equivalent calculated from spectrometric measurement is included for the delivered dose shown in the fifth column in Table 7.3. The sixth column in Table 7.3 lists the ratio of the dose equivalent measured by the CR-39 dosimeters divided by the delivered dose. The uncertainty listed in the last column includes one standard deviation uncertainty in the doses estimated by 12 CR-39 dosimeters and in the dose equivalent calculated from spectrometric measurements.

For lightly moderated fission sources and plutonium sources, the CR-39 dosimeters are reasonably accurate. On the average, the dose equivalent determined with the CR-39 dosimeters was only $2 \%$ lower than the dose equivalent delivered by calibrated californium sources or from the plutonium sources; the coefficient of variation was $\pm 17 \%$. However, this close agreement

IABLE 7.3. Summary of CR-39 Dosimeter Exposures

\begin{tabular}{|c|c|c|c|c|c|c|}
\hline \multirow[b]{2}{*}{ Source } & \multicolumn{4}{|c|}{ Dose Equivalent (mrem) } & \multicolumn{2}{|c|}{$\begin{array}{l}\text { Ratio } \\
\text { Meas./Deliv. }\end{array}$} \\
\hline & \multicolumn{2}{|c|}{$\begin{array}{l}\text { CR-39 Meas. } \\
x \quad \frac{\sigma}{x} \\
\end{array}$} & $x$ & $\theta$ & $x$ & $\sigma$ \\
\hline $\begin{array}{l}\text { CF with no shield } \\
\text { Cf }+1.27 \mathrm{~cm} \text { plastic } \\
\text { Cf }+2.54 \mathrm{~cm} \text { plastic } \\
\mathrm{Cf}+5.08 \mathrm{~cm} \text { plastic } \\
\mathrm{Cf}+10.2 \mathrm{~cm} \text { plastic } \\
\mathrm{Cf}+15.2 \mathrm{~cm} \text { plastic }\end{array}$ & $\begin{array}{l}466 \\
966 \\
898 \\
473 \\
421 \\
587\end{array}$ & $\begin{array}{l}46 \\
64 \\
58 \\
32 \\
37 \\
54\end{array}$ & $\begin{array}{l}500.5 \\
1017 \\
996 \\
529 \\
448 \\
774\end{array}$ & & $\begin{array}{l}0.93 \\
0.95 \\
0.90 \\
0.89 \\
0.94 \\
0.76\end{array}$ & \\
\hline $\mathrm{Cf}+\mathrm{D}_{2} \mathrm{O}$ moderator & 952 & 62 & 1000 & & 0.95 & \\
\hline $\begin{array}{l}\text { PuF }_{4} \text { with no shield } \\
\text { PuF }_{4}+2.54 \mathrm{~cm} \text { plastic } \\
\text { PuF }_{4}+5.08 \mathrm{~cm} \text { plastic }\end{array}$ & $\begin{array}{l}1670 \\
1238 \\
1006\end{array}$ & $\begin{array}{l}82 \\
58 \\
91\end{array}$ & $\begin{array}{r}1683 \\
1108 \\
693\end{array}$ & $\begin{array}{l}54 \\
51 \\
66\end{array}$ & $\begin{array}{l}0.99 \\
1.12 \\
1.45\end{array}$ & $\begin{array}{l}0.059 \\
0.067 \\
0.191\end{array}$ \\
\hline $\mathrm{PuO}_{2}$ with no shield & 74 & 6.6 & 81 & 13 & 0.92 & 0.17 \\
\hline Pu Metal with no shield & 137 & 16 & 146 & 18 & 0.94 & 0.16 \\
\hline Room Background & 11.5 & 3.7 & 29 & 2.5 & 0.40 & 0.13 \\
\hline & Average & exclud & ng back & round & 0.98 & 0.17 \\
\hline
\end{tabular}


is somewhat deceptive. There were two measurements in which there was poor agreement between the delivered values and the CR-39 measured values; the CR-39 overestimated the delivered dose by $45 \%$ when exposed to the PuF 4 source moderated with $5 \mathrm{~cm}$ of acrylic plastic. This was offset by the CR-39 indicating a dose equivalent some $24 \%$ lower than the delivered dose when exposed to the californium source moderated by $15 \mathrm{~cm}$ of acrylic plastic. Ignoring these two extremes, the CR-39 dosimeter averaged about 5\% 1ower than the delivered dose, with a coefficient of variation of $\pm 6.5 \%$. Note that this good agreement is obtained by expcsing the CR-39 dosimeters to fairly high doses to obtain good counting statistics for the number of tracks $/ \mathrm{cm}^{2}$. At dose values greater than $50 \mathrm{mrem}$, CR-39 dose results are superior to the TLD results. Three lots of CR-39 plastic were used in the measurements, and all lots resulted in about the same variation in the results.

The CR-39 dosimeters function quite well when exposed to fission sources or isotopic sources, such as $\mathrm{PuF}_{4}$. For the unmoderated sources, the majority of neutrons have energies above the threshold for track registration. However, the CR-39 dosimeters start to miss part of the dose for highly moderated sources, in which neutrons have energies below the 100-keV threshold for track registration in the electrochemicily etched CR-39. 


\subsection{CONCLUSIONS AND RECOMMENDATIONS}

Currently available neutron dosimeters and survey instruments exhibit a well known significant dependent with energy; i.e., their response per unit of dose equivalent varies with energy. The TLD-albedo neutron dosimeters used at Hanford are no exception, as demonstrated by the data presented in Sections 5 , 6 , and 7 of this report. Typically, TLD-albedo dosimeters are calibrated under low-scatter conditions in the laboratory under carefully controlled, reproducible conditions similar to those used in DOELAP accreditation. When exposed in the work place, the response of the TLD-albedo dosimeter may be quite different per unit of dose equivalent. Traditionally, a field calibration factor or other mechanism has been used to determine the appropriate factor to correctly interpret the dosimeter response in the field.

This study was initiated to document the response of the Hanford TLDalbedo dosimeter and CR-39 TED under carefully controlled conditions in the calibration laboratory and in the workplace. The measurements included the PNL calibration bare and heavy-water-moderated californium sources, whose calibrations are directly traceable to the NIST. Various neutron spectrometers and dose measuring devices, including multisphere spectrometers, TEPCs, and $10-i n$. diameter rem meters, were also exposed to the calibrated sources to verify their accuracy.

These instruments were then used in the PFP to determine the neutron dose equivalent rates and responses from various plutonium sources, including $\mathrm{PuF}_{4}, \mathrm{PuO}_{2}$, and plutonium metal. The results of these measurements are summarized in Table 8.1. The PuF ${ }_{4}$ source is of special interest; it is the same source that had previously been used to calibrate Hanford neutron dosimeters from December 1964 to August 1981. The TLD-albedo dosimeters and CR-39 TED were exposed to these plutonium sources under the high-scatter conditions typically found in the work environment. The data from the PuF 4 source provide historical documentation of dosimeter response and help evaluate the accuracy of dose equivalent algorithms that were used in the past.

The results summarized in Table 8.1 indicate that the dosimeter response per unit dose equivalent increases in the high-scatter conditions found in the 
IABLE 8.1. Summary of Dosimeter Measurements

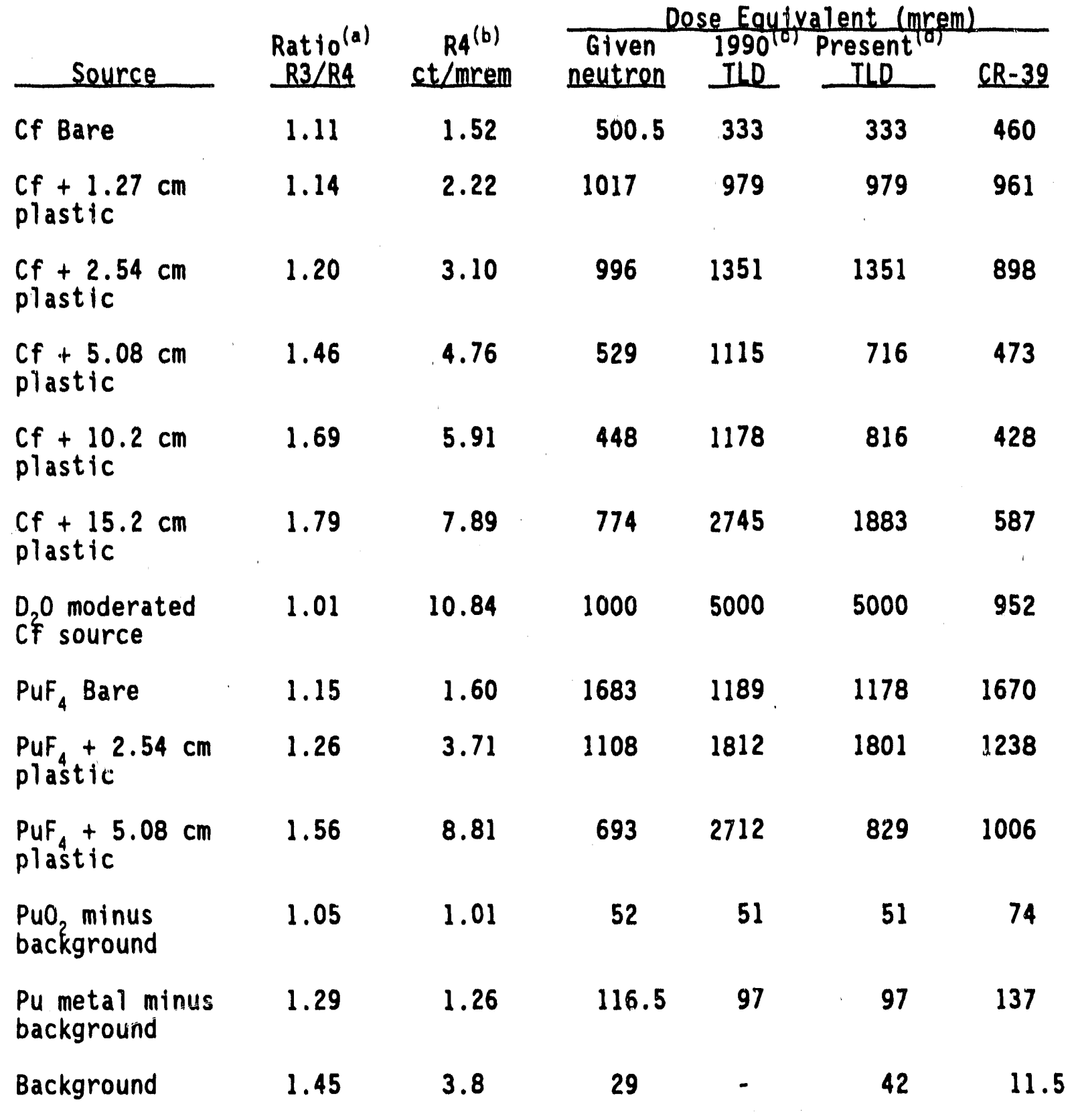
(a) TLD 600 chips corrected for gamma response.
(b) The values are TLD chip 4 - TLD chip 5 response/delivered neutron dose.
(c) Doses calculated using the 1990 algorithm.
(d) Doses calculated using the Historical Hanford Algorithm when R3/R4>1.38. 
work place. The dosimeter response is a complex function of the initial neutron energy spectrum, the orientation of the dosimeter, the amount $0 \%$ intervening moderator, and the scatter conditions in the vicinity of the dosimeter during exposures.

The $\mathrm{PuF}_{4}$ source was strong enough that the major contributor to dosimeter response was the source itself. However, the neutron emission rates from the $\mathrm{PuO}_{2}$ and plutonium metal sources were so small that room background from the adjacent plutonium glove boxes in the room contributed to almost half of the dosimeter response. To correct for this background, sets of control dosimeters were exposed under identical conditions to allow corrections to be applied to the dosimeter response for the "background." This is generally true of sperations in glove boxes; the general background from material stored in the box and distributed on the surface is a significant contribution to TLD-albedo dosimeter response. The increased response to the lower energy scattered neutrons from backgrounds is demonstrated in Table 8.1. Here, the scattered background neutrons create about the same effect as adding $3 / 4 \mathrm{in}$. to 1 in. of acrylic plastic moderator to the glove box.

As shown in Table 8.1, the response of the TLD-albedo dosimeter varied from a low value of about 1 count/mrem for an unmoderated source to a high value of 10 for a heavy-water-moderated source. From the data presented, one might conclude that the response of the TLD-albedo dosimeter is controlled by the intervening moderator between the source and the dosimeter. This is not always the case; room-scattered neutrons can be a significant factor in determining the dosimeter response and can alter the ratios of the responses of TLD chips behind various filters. For this reason, it is recommended that field exposures be performed to verify the accuracy of the system.

It may be possible to develop improved algorithms to properly interpret dosimeter response correction factors based on the TLD chip ratios. In the case of the Hantord TLD-albedo dosimeter, it appears that the ratio of TLDs in position 3 to position 4 may indicate what calibration factor should be used. This approach is used at Hanford in the existing dosimetry systems and is extensively used at other sites, such as Karlsruhe, where the dosimeters are actually caliurated on phantoms in the work place. The variability in the counts/mrem factors and the position 3/position 4 TLD ratios points out the 
need for careful calibration and field exposure if accuracy is to be improved. Traditionally, TLD calibration factors have been based on field measurements at Hanford work locations. This was especially true when the plutonium fluoride source was used to simulate the primary contribution to occupational neutron exposure during plutonium separation work at Hanford. It is especially important to perform additional measurements in the workplace if new dosimetry systems or evaluation algorithms are implemented.

The data presented in Table 8.1 show that the dose equivalents evaluated from the CR-39 TEDs are remarkably accurate. The dosimeter results are in excellent agreement with the delivered dose equivalent determined from the average of measurements performed with the multisphere spectrometer, TEPCs, and a 10-in. diameter spherical rem meter. Excluding the measurament of the room background, the CR-39 dosimeter results agree within about 5\% of the delivered dose equivalents, with a standard deviation of about $21 \%$ in the measurements. Excluding the measurement of the room background is justified because the CR-39 dosimeters were exposed on the side of the acrylic plastic phantom positioned away from the glove boxes to minimize the effect of room background. Fast neutrons from the glove box must pass through the phantom or be scattered from the room to reach the CR-39 TED.

Although the CR-39 dosimeters give superior results, we caution that the results were obtained with exposures well over 100 mrem for statistical accuracy. With low doses (about 10 to $50 \mathrm{mrem}$ ), the CR-39 dosimeters are not very accurate due to lack of sensitivity and interference from background tracks. This background track problem cannot be avoided; it may be caused by interactions with alpha particles from radon and cosmic rays during storage of the material.

From the data presented in Table 8.1, we can draw the following conclusioirs. Neutron doses estimated for personnel are generally high based on the simplified Hanford dose algorithm. The simplified algorithm can significantly over-estimate personnel neutron dose equivalent if the dosimeter is not calibrated to the neutron field in which it is used. With care, it may be possible to arrive at spectral correction factors based on TLD chip ratios, but additional studies must be performed to substantiate this assertion. 
The following recommendations are made based on these preliminary studies :

- To obtain more accurate estimates of neutron dose to personnel, it is necessary to utilize location-dependent calibration factors or calibration factors based on TLD chip ratios.

- Continual instrument measurements and dosimeter exposures on phantoms in measured neutron fields are essential to ensure the credibility of routine dosimeter results.

- Consideration should be given to implementing the CR-39 nuclear track detector in combination with the TLD-aibedo dosimeter. The CR-39 dosimeter appears to give acceptable results for neutron exposures over about 100 mrem from plutonium sources, even if placed behind thick shields.

- Although the TLD-albedo dosimeter may over-estimate the dose, this type of dosimeter is more sensitive and gives more accurate results at low doses, below about 50 mrem.

- Algorithms to compensate for energy effects should be developed.

- Energy-compensation algorithms, along with continued improvements in the External Dosimetry Program, may provide a means to improve the accuracy of occupational dose estimations and still meet DOELAP test criteria.

- As in the past, field measurements and dosimeter exposures in the work environment muet be continued to test new algorithms or implement new dosimetry systems. The External Dosimetry Program should acquire the expertise to perform these field measurements.

It must be recognized that Hanford has had a longstanding policy (Wilson et al. 1990) that if there are any inaccuracies or confusing responses, the personnel doses recorded shall err conservatively, that is, by reporting too much dose. The field neutron measurements of the 234-5 Building confirm that this is still the case. Measurements obtained indicate that personnel neutron doses are, on the average, being over-estimated using the existing TLD-albedo calibration and dose algorithm methodology. This over-estimation was observed for all algorithms used for the TLD-albedo dosimeter. It is hoped that, based on these measurements, a method can be developed that reduces still further the amount of over-evaluation of neutron doses reported to personnel. A combination TLD and CR-39 TED is just such a dosimeter that can accomplish this narrowing of the error response.

\section{5}




\subsection{REFERENCES}

52 FR 2822-2834. January 27, 1987. "Federal Radiation Protection Guidance to Federal Agencies for Occupational Exposure; Approval of the Environmental Protection Agency Recommendations." Federal Register.

American National Standards Institute (ANSI). 1983. American National Standard for Dosimetry. Personnel Dosimetry Performance - Criteria for Iesting. ANSI N13.11, New York, New York.

Auxier, J. A., W. S. Snyder, and T. D. Jones. 1968. "Neutron Interactions and Penetration in Tissue." In Radiation Dosimetry, Vol. 1, eds. F. W. Attix and W. C. Roesch, pp. 289-312. Academic Press, New York.

Baumgartner, W. V., and L. W. Brackenbush. 1966. "Neutron Dosimetry Using the Fission Fragment Damage Principle." BNWL-SA-516, Pacific Northwest Laboratory, Richland, Washington.

Brackenbush, L. W., W. D. Reece, and J. E. Tanner. 1984. Neutron Dosimetry at Commercial Nuclear P'ants, Final Report of Subtask $C$ : 'He Neutron Spectrometer. NUREG/CR-3610 (PNL-4943), U.S. Nuclear Regulatory Commission, Washington, D.C.

Brackenbush, L. W., G. W. R. Endres, J. M. Selby, and E. J. Vallario. 1980. Personnel Neutron Dosimetry at Department of Energy Facilities. PNL-3213, Pacific Northwest Laboratory, Richland, Washington.

Brackenbush, L. W. and L. G. Faust. 1970. Neutron Spectra of Plutonium Compounds, Part 1: ${ }^{3} \mathrm{He}$ and ${ }^{6} \mathrm{Li}$ Spectrometer Measurements. BNW-1262, Pacific Northwest Laboratory, Richland, Washington.

Brackenbush, L. W., W. D. Reece, S. D. Miller, G. W. R. Endres, J. S. Durham, R. I. Scherpelz, and P. L. Tomeraasen. 1988. Personnel Neutron Dose Assessment Upgrade Volume 2: Field Neutron Spectrometer for Health Physics Applications. PNL-6620, Vo1. 2, Pacific Northwest Laboratory, Richland, Washington.

Brackenbush, L. W., and R. I. Scherpe1z. 1983. SPUNIT, A Computer Code for Multisphere Unfolding. PNL-SA-11645, Pacific Northwest Laboratory, Richland, Washington.

DePangher, J., and L. L. Nichols. 1966. A Precjsion and Long Counter for Measuring Fast Neutron Flux Density. BNWL-260, Pacific Northwest Laboratory, Richland, Washington.

Doroshenko, J. J., S. N. Kraitor, T. V. Kuznetsova, K. K. Kushnereva, and E. S. Lonov. 1977. "New Methods for Measuring Neutron Sectra with Energy from $0.4 \mathrm{eV}$ to $10 \mathrm{MeV}$ by Track and Activation Detectors." Nuclear Technology $33: 296-304$. 
Faust, L. G., L. W. Brackenbush, K. R. Heid, W. N. Herrington, J. L. Kenoyer, L. F. Munson, L. H. Munson, J. M. Selby, K. L. Soldat, G. A. Stoetzel, R. J. Traub, and E. J. Vallario. 1988. Health Physics Manual of Good Practices for Plutonium Facilities. PNL-6534, Pacific Northwest Laboratory, Richland, Washington.

Faust, L. G., L. W. Brackenbush, L. A. Carter, G. W. R. Endres, R. D. Glenn, J. J. Jech, J. M. Selby, R. C. Smith, D. A. Waite, and W. P. Walsh. 1977. A Guide to Good Practices at Plutonium Facilities. BNWL-2086, Pacific Northwest Laboratory, Richland, Washington.

Fix, J. J., et al. 1981. Hanford Personnel Dosimeter Supporting Studies FY-1980. PNL-3536, Pacific Northwest Laboratory, Richland, Washington.

Fleischer, R. L. 1975. Nuclear Tracks in Solids: Principles and Applications. University of California Press, Berkeley, California.

Hankins, D. E., S. G. Homann, and J. Westermark. 1989. Personnel Neutron Dosimetry Using Electrochemically Etched CR-39 Foils. UCRL-53833, Rev. 1, Lawrence Livermore National Laboratory, Livermore, Cal ifornia.

Herte1, N. E., and J. C. McDonald. 1990. Calculations of Ani sotropy Factors and Dose Equivalents for Unmoderated ${ }^{252}$ Cf Sources. PNL.SA-17524, Pacific Northwest Laboratory, Richland, Washington.

Ing, H., and S. Makra. 1978. Compendium of Neutron Spectra in Criticality Accident Dosimetry. Technical Report Series No. 180, International Atomic Energy Agency, Vienna.

International Organization for Standardization (ISO). 1986. Neutron Reference Radiations for Calibrating Neutron Measuring Devices Used for Radiation Protection Purooses and for Determining Their Response as a Function of Neutron Energy. ISO/DIS 8529.

International Commission on Radiological Protection (ICRP). 1973. Data for Protection Against Ionizing Radiation from External Sources: Supplement to ICRP Publication 16. ICRP Publication 21, Pergamon Press, 0xford, England.

International Commission on Radiological Protection (ICRP). 1987. Data for Use in Protection Against External Radiation. ICRP Publication 5i, Pergamon Press, Oxford, England.

International Commission on Radiological Protection (ICRP). 1977. Recommendations of the International Commission on Radiological Protection. ICRP Publication 26, Pergamon Press, 0xford, England.

International Commission on Radiation Units and Measurements (ICRU). 1971. Radiation Protection Instrumentation and Its Application. ICRU Report No. 20, ICRU Publications, Bethesda, Maryland. 
International Commission on Radiation Units and Measurements (ICRU). 1983. Microdosimetry. ICRU Report No. 36, ICRU Publications, Bethesda, Maryland.

Joint Task Group of ICRU and ICRP. 1986. The Quality Factor in Radiation Protection. ICRU Report No. 40, International Commission on Radiation Units and Measurements Publications, Bethesda, Maryland.

Kocher, L. F., G. W. R. Endres, L. L. Nichols, D. B. Shipler and A. J. Haverfield. 1971. "The Hanford Thermoluminescent Multipurpose Dosimeter." BNWL-SA-3955, Pacific Northwest Laboratory, Richland, Washington.

Lesiecki, L., and M. Cosack. 1984. "Responses of Neutron Dose Equivalent Survey Meters." In Proceedings of the 1st Symposium on Personnel Radiation Dosimetry, Knoxville, Tennessee, October 15-18, 1984.

McDonald, J. C. 1988. Operation of a Proficiency Testing Laboratory for Radiation Dosimeters. PNL-SA-15532, Pacific Northwest Laboratory, Richland, Washington.

National Council on Radiation Protection and Measurements (NCRP). 1971. Protection Against Neutron Radiation. NCRP Report No. 38, Bethesda, Maryl and.

National Council on Radiation Protection and Measurements (NCRP). 1987. Recommendations on limits for Exposure to Ionizing Radiation. NCRP Report No. 91, Bethesda, Maryland.

Piesch, E., and B. Burgkhardt. 1978. "The Role of an Analyzer Type Albedo Dosimeter in Routine Monitoring and the Current Situation for the Calibration Technique." In Seventh DOE Workshop on Personnel Neutron Dosimetry.

PNL-2807, Pacific Northwest Laboratory, Richland, Washington.

Schwartz, R. B., and C. M. Eisenhauer. 1982. Procedures for Calibrating Neutron Personnel Dosimeters. NBS Special Publication 633, U.S. Department of Commerce/National Bureau of Standards, Washington, D.C.

Smith, R. C. 1980. Personnel Dosimetry and Shielding Program Progress Report: July-December 1979. HEDL-TME 80-50, Hanford Engineering Development Laboratory, Richland, Washington.

Tommasino, L. 1970. Electrochemical Etching of Damaged Track Detectors by HV Pulse and Sinusoided Waveforms. RT/PRUT(II) 1970, Comitato Nazionale Energia Nucleare, Rome, Italy.

U.S. Department of Energy (DOE). 1986a. Handbook for the Department of Energy Laboratory Accreditation Program for Personnel Dosimetry Systems. DOE/EH-0026, Washington, D.C.

U.S. Department of Energy (DOE). 1986b. Department of Energy Standard for the Performance Testing of Personnel Dosimetry Systems. DOE/EH-0027, Washington, D.C. 
U.S. Department of Energy (DOE). 1987. Environmental Protection, Safety, and Health Protection Information Reporting Requirements. DOE 5480.15, Washington, D.C.

U.S. Department of Energy (DOE). 1988. Radiation Protection for Occupational Workers. DOE 5480.11, Washington, D.C.

Wilson, R. H., W. V. Baumgarnter, J. J. Fix, and L. L. Nichols. 1990. Description and Evaluation of the Hanford Personnel Dosimeter Program from 1944 Through 1989. PNL-7447, Pacific Northwest Laboratory, Richland, Washington. 
APPENDIX A

IISSUE EQUIVALENT PROPORTIONAL COUNTERS 
APPENDIX A

\section{IISSUE EQUIVALENT PROPORTIONAL COUNTERS}

In principle, a single tissue equivalent (TE) proportional counter (TEPC) can detect any penetrating ionizing radiation. Tissue equivalent proportional counters provide an absolute measure of absorbed dose in a tissue-like material. With appropriate algorithms, they also provide an estimate of neutron quality factors. Algorithms developed for fast neutrons are reasonably accurate for fission energies and many of the neutron exposure situations found in DOE facilities. This section provides a review of the terminology used in microdosimetry, and delineates how dose and dose equivalent are determined using TEPCs.

\section{A.1 TERMINOLOGY}

Many persons are not familiar with the specialized terminology and microdosimetric concepts used in the analysis of data from TEPCs. Therefore, the following explanation of terms may be appropriate to prepare the reader for detailed discussions of the theory of radiation interactions in TEPCs. A more complete explanation of the terminology is given in ICRU Report 36, Microdosimetry (ICRU 1983).

Energy deposit, $e_{1}$ - The energy deposit is the energy deposited in a site by a single radiation interaction. It is the difference between the energy of the incident ionizing particle (exclusive of rest mass energy) minus the sum of energies of all ionizing particles, leaving the interaction (exclusive of rest mass energy) plus the changes in rest mass of all atoms and particles involved (the $Q$ value of the reaction). The energy deposit is a stochastic quantity that has units of joule $(\mathrm{J})$ or electron volts $(\mathrm{eV})$.

Energy imparted, e - The energy imparted to the mass in a volume of interest is simply the sum of energy deposits within that volume. The energy imparted is also a stochastic quantity having units of joule $(\mathrm{J})$ or electron volts (eV). Note that the energy imparted may result from one or more stochastically independent particle tracks.

Lineal energy, $y$ - The lineal energy $(y)$ is the energy imparted by a single energy deposition event to matter in a volume (e) divided by the mean chord length (1) in that volume. Lineal energy is a stochastic quantity with units of joules per meter $(\mathrm{J} / \mathrm{m})$ or kiloelectron volts per micrometer $(\mathrm{keV} / \mu \mathrm{m})$. The

$$
\text { A. } 1
$$


mean chord length in a volume is the average or mean of all randomly oriented chords within the volume. For convex bodies, the mean chord length (1) is the quotient of 4 times the volume (V) divided by the surface area (S) of the body. It is important to note that $y$ is defined only for single energydeposition events. Energy-deposition events occur with a distribution of lineal energies. The value of the distribution function, $F(y)$, is the probability that the lineal energy is equal to or less than $y$. The lineal energy distribution or probability density, $f(y)$, is the derivative of $F(y)$ with respect to $y$. The lineal energy distribution, $f(y)$, is independent of the absorbed dose or dose rate.

Linear energy transfer (LET), L - The linear energy transfer is the amount of energy transferred per unit path length of an ionizing particle. It has the units of joule per meter $(\mathrm{J} / \mathrm{m})$ or kiloeiectron volts per micrometer $(\mathrm{keV} / \mathrm{\mu m})$.

Event size, $Y$ - The event size is a concept closely related to lineal energy. The event size for a sphere is the energy imparted to the spherical volume divided by the diameter of a sphere. For a sphere, the event size $(Y)$ is two-thirds of the lineal energy $(\mathrm{J})$ "

Lineal energy $(y)$ and linear energy transfer (LET) are closely related. Consider the path of a recoil proton produced by a $1 \mathrm{MeV}$ neutron, as shown in Figure A.1. The dots in the figure represent ionizing events produced by the passage of the proton and its delta rays. The value of LET is constant over the short segment of the particle paths shown in the figure. However, as can be readily seen, the value of lineal energy depends upon which microscopic volume is chosen. This is observed experimentally; i.e., particles with a constant LET traversing a proportional counter operated at very low gas pressures produce a distribution of event sizes. Lineal energy is a microscopic quantity that represents the actual amount of energy deposited in a microscopic site; it is the microdosimetric analog of LET. Lineal energy can be physically measured by a device such as a TEPC. Linear energy transfer is a macroscopic quantity that cannot be easily measured. The value for LET represents the average value for the energy loss per unit path length, and thousands of paths must be considered to obtain an accuate average. Under the assumptions that particles travel in straight lines and LET is nearly constant over a small segment of the path, it is possible to mathematically convert from either quantity to the other, as illustrated in Appendix $B$ of ICRU Report 40 (ICRU 1986). 


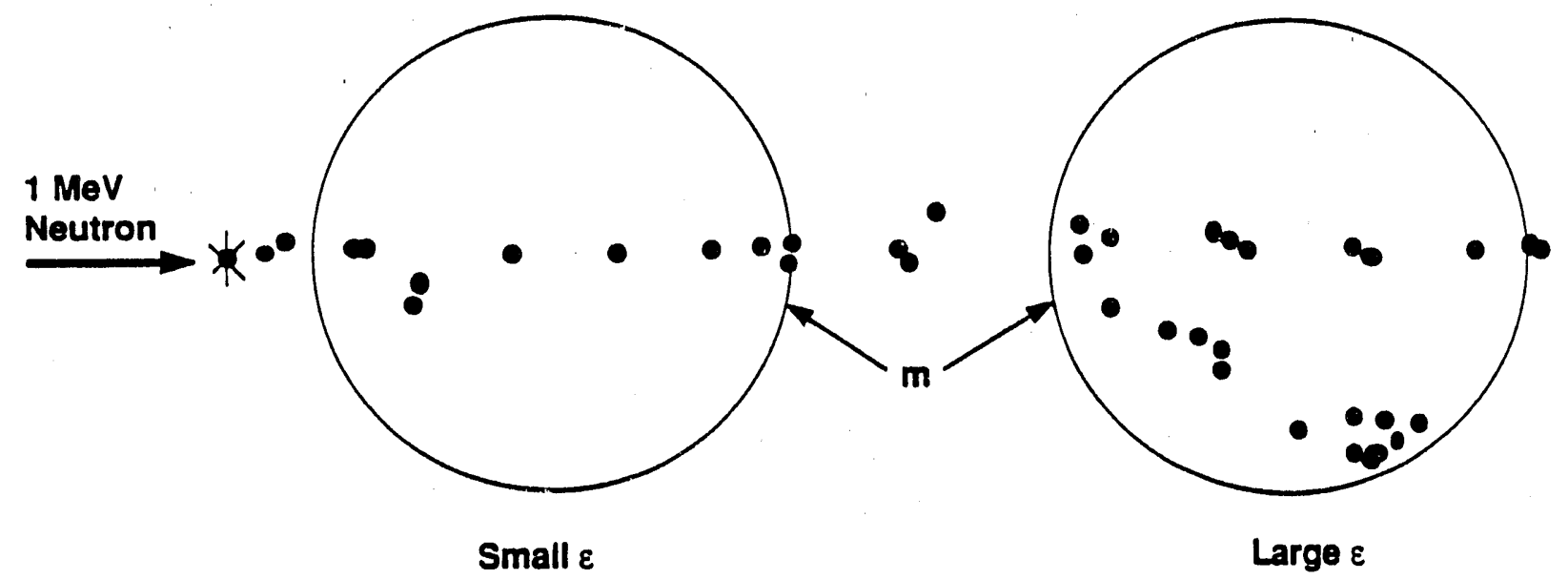

39101085.23

FIGURE A.1. Representation of a Short Segment of the Track of a Recoil Proton Produced by a $1-\mathrm{MeV}$ Neutron

\section{A.2 CONSTRUCTION OF TISSUE EQUIVALENT PROPORTIONAL COUNTERS}

The basic concept of a TEPC is shown in Figure A.2. Typically, the TEPC consists of a hollow sphere of TE plastic filled with TE gas. The cavity inside the TE plastic walls is the sensitive volume of a proportional counter. Several configurations are possible. In one version, a single wire is used as the anode of the proportional counter inside a spherical counter. In another version, called the Rossi counter, a fine helix operated at an intermediate potential surrounds the anode wire to make the electric field more nearly constant, thus giving more uniform gain along the anode. Unfortunately, the helix makes the counters more sensitive to vibration, so these counters are better suited to laboratory measurements. Spherical counters with internal diameters ranging from $1 / 2$ in. to 5 in. are commercially available. Single wire counters are more rugged and are usually used for measurements in the workplace. Cylindrical counters are much less expensive to build than spherical counters, but the algorithms used to derive quality factors are more difficult to utilize, as will be explained later. 


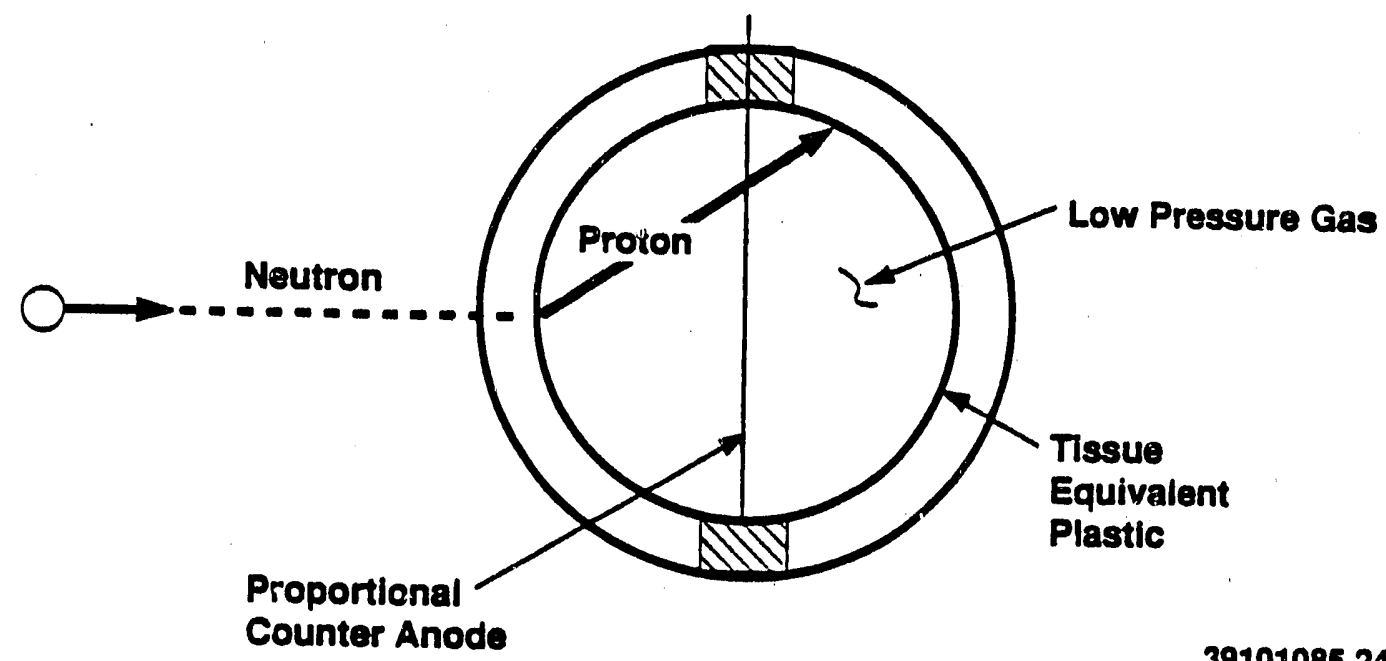

39101085.24

EIGURE A.2. Simplified Cross-Sectional View of a Spherical Tissuiz Equivalent Proportional Counter

Unlike the typical proportional counter, the gas pressure in the TEPC is very low, usually a few torr, so that the mass of gas in the hollow sphere has

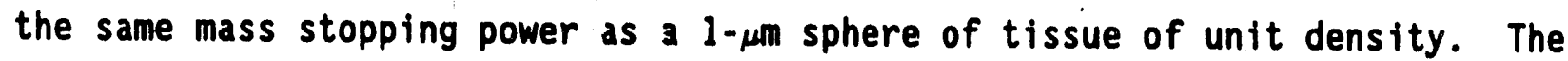
equivalent diameter of a gas-filled TEPC is the diameter of a unit-density sphere that has the same mass as the gas inside the TEPC. The gas pressure is usually adjusted to give equivalent diameters of $0.5 \mu \mathrm{m}$ to $10 \mu \mathrm{m}$ in tissue.

The compositions of TE gases and Shonka A-150 TE plastic used in construction of TEPCs are given in Table A.1. It is evident that the compositions of these materials are not exactly equivalent to tissue, which is mostly water. In these materials, the amounts of oxygen (from water) and carbon (from plastics) are reversed. This is of little consequence because of similar cross-sections for carbon and oxygen, except for resonances in charged particle production that occur at about $4.5 \mathrm{MeV}$ and it 16 to $17 \mathrm{MeV}$.

Neutrons or other types of fonizing radiation interact with the Shonka A-150 TE plastic to produce charged particles, which then traverse the gas cavity. The gas pressure is so low that most heavy charged particles have a nearly constant LET in traversing the cavity. If Bragg-Gray conditions are satisfied (i.e., if electronic equilibrium exists, if the wall thickness is greater than the range of the secondary particles, and if the walls and gas

$$
\text { A. } 4
$$


TABLE A.1. Compositions of Tissue Equivalent Materials Used in Tissue Equivalent Proportional Counters $(a)$

\begin{tabular}{|c|c|c|c|c|c|c|c|c|c|c|c|}
\hline \multirow[b]{2}{*}{ Material } & \multicolumn{11}{|c|}{ Proportion of Element (\%) } \\
\hline & $\mathrm{H}$ & $c$ & $N$ & 0 & $F$ & $\mathrm{Na}$ & $\mathrm{Mg}$ & $\frac{P}{p}$ & $S$ & $\underline{K}$ & Ca \\
\hline $\begin{array}{l}\text { ICRU Muscle } \\
\text { Tissue }\end{array}$ & 10.2 & 12.3 & 3.5 & 72.9 & - & 0.08 & 0.02 & 0.2 & 0.5 & 0.3 & 0.007 \\
\hline $\begin{array}{l}\text { A-150 Muscle } \\
\text { Equivalent } \\
\text { Plastic }\end{array}$ & 10.1 & 77.6 & 3.5 & 5.2 & 1.7 & - & - & - & - & - & - \\
\hline $\begin{array}{l}\text { Methane } \\
\text { TE Gas }\end{array}$ & 10.2 & 45.6 & 3.5 & 40.7 & - & - & - & - & - & - & - \\
\hline $\begin{array}{l}\text { Propane } \\
\text { TE Gas }\end{array}$ & 10.3 & 56.9 & 3.5 & 29.3 & - & - & - & - & - & - & - \\
\hline
\end{tabular}

(a) Data from Appendix C of ICRU Report 36, Microdosimetry (ICRU 1983).

have very nearly the same composition), then the dose in the cavity is a very close approximation to that in solid TE material. If it is assumed that the number of ionizations produced in the detector is proportional to the energy deposited in the gas cavity, the ionizations produced and the pulse height from the proportional counter show the energy deposition. This value of energy deposition divided by the mass of the gas in the cavity gives a direct measure of absorbed dose (energy absorbed per unit mass, by definition). Although the gas compositions may not always be TE, most of the charged particles originate in the walls, and this material does closely approximate tissue. In fact, almost any counting gas such as propane or methane can be used withou: changing the measured dose.

\section{A.3 ENERGY CALIBRATION}

The energy calibration of a TEPC relates the pulse height distribution from the proportional counter to energy deposition in the counter. At least two methods will accomplish this.

The first method is to bombard the gas cavity with particles of known energy. Some of the commercially available TEPCS have built-in ${ }^{244} \mathrm{Cm}$ alpha calibration sources operated by a simple shutter mechanism. When the shutter

$$
\text { A.5 }
$$


is open, alpha particies pass through a small hole in the TE plastic wall and traverse the diameter of the counter. Because the initial energy of the alpha particles, the path length, and the path length are known, the energy loss in the gas cavity per unit path length can be calculated. For example, energy loss or stopping power data can be found in Ziegler (1977) for individual elements, and the Bragg-Kleyman rule or similar methods can be used to determine the stopping power in mixtures of gases. This energy loss value can then be related to the centroid of the peak produced by alpha pulses, as recorded by a multichanilel analyzer (MCA). This result is the energy deposition per unit path lenjth per MCA channel.

The second method relies on built-in calibration using the so-called "proton edge" or "proton drop point." Consider the case of a TEPC irradiated by fast neutrons. The reutrons produce recoils with a continuum of energies and LET vaiues. Protons with the higliest LET value that traverse the diameter of the counter will deposit the maximum possible energy in a spherical counter. This results in the so-called proton edge. These energy deposition values have been measured experimentally for methane-based TE gas by Glass and Samsky (1967). In this experiment, monoenergetic protons produced by a Van de Graaff accelerator irradiated a gas cavity with a known mass of TE gas. The energy of the proton as it exited the gas cavity was measured using a surface barrier detector. Thus, Glass and Samsky directly measured the energy loss in the gas cavity and related this to the path length in the gas cavity. Because of straggling, the proton edge is not perfectly sharp. The proton drop point, as defined by Glass and Samsky, is the point of inflection on the dose distribution curve. For site sizes with an equivalent diameter varying between $0.5 \mu \mathrm{m}$ and $10 \mu \mathrm{m}$, the proton drop point only varies between 90 and 103 $\mathrm{keV} / \mu \mathrm{m}$, as shown in Table A.2. The real problem with using the proton drop point for energy calibration is that good statistical accuracy requires high doses to obtain a reasonable estimate of the point of inflection.

A multichannel analyzer (MCA) is typically used to record the distribution of puise heights from a TEPC. Figure A.3 shows a typical spectrum as recorded by a TEPC operated with a $1-\mu \mathrm{m}$ equivalent diameter. The following describes how the data from the TEPC is analyzed for the energy calibration, as described above. More information about a computer program to perform the 
TABLE A.2. Relationship Between the Proton Drop Point Used

for Energy Calibration and the Site Size in a

Spherical Tissue Equivalent Proportional Counter

\begin{tabular}{|c|c|}
\hline $\begin{array}{c}\text { Equivalent Diameter, } \\
\mu \mathrm{m}\end{array}$ & $\begin{array}{c}\text { Energy Deposition, } \\
\mathrm{keV} / \mu \mathrm{m}\end{array}$ \\
\hline $\begin{array}{l}0.3 \\
0.5 \\
1.0 \\
2.0 \\
5.0\end{array}$ & $\begin{array}{r}104 \\
103 \\
101 \\
98 \\
90\end{array}$ \\
\hline
\end{tabular}

Source: Glass and Samsky 1967

necessary calculations is described in the report A Field Neutron Spectrometer for Health Physics Application: (Brackenbush et al. 1988). In this code, the counts per channel recorded by the MCA are multiplied by the chanrel number to obtain a distribution proportional to the dose distribution, which is shown in Figure A.3. A Fourier smoothing technique is used to smooth the data (Aubanen and 01dham 1985). A digital derivative filter is then applied to find the point of inflection on the dose curve, which is the proton drop point by definition. Knowing the dimensions of the counter and gas pressure allows the equivalent of a sphere of tissue of unit density to be calculated. This value can be used to determine the energy calibration in terms of keV per channel.

A problem experienced with some TEPCs is that the gas gain deteriorates over a period of several days to weeks. Small amounts of oxygen, water vapor, plasticizers, or other electronegative gases diffusing out of the TE plastic can cause a rapid deterioration in the counter gas. Different tests were made by placing a TEPC at a fixed distance from a ${ }^{252} \mathrm{Cf}$ neutron source and measuring the dose equivalent rate over a period of 3 weeks. When the counter was first filled, it underestimated the dose equivalent rate by about $4 \%$. After 3 weeks, the gain of the counter decreased by $50 \%$ and the resolution deteriorated. The same TEPC then overestimated the dose equivalent by $12 \%$ to $16 \%$. Much of the apparent increase coulu be attributed to the smoothing algorithm picking the value for the proton drop point. This points out the necessity for checking for gain shifts with time and temperature. 


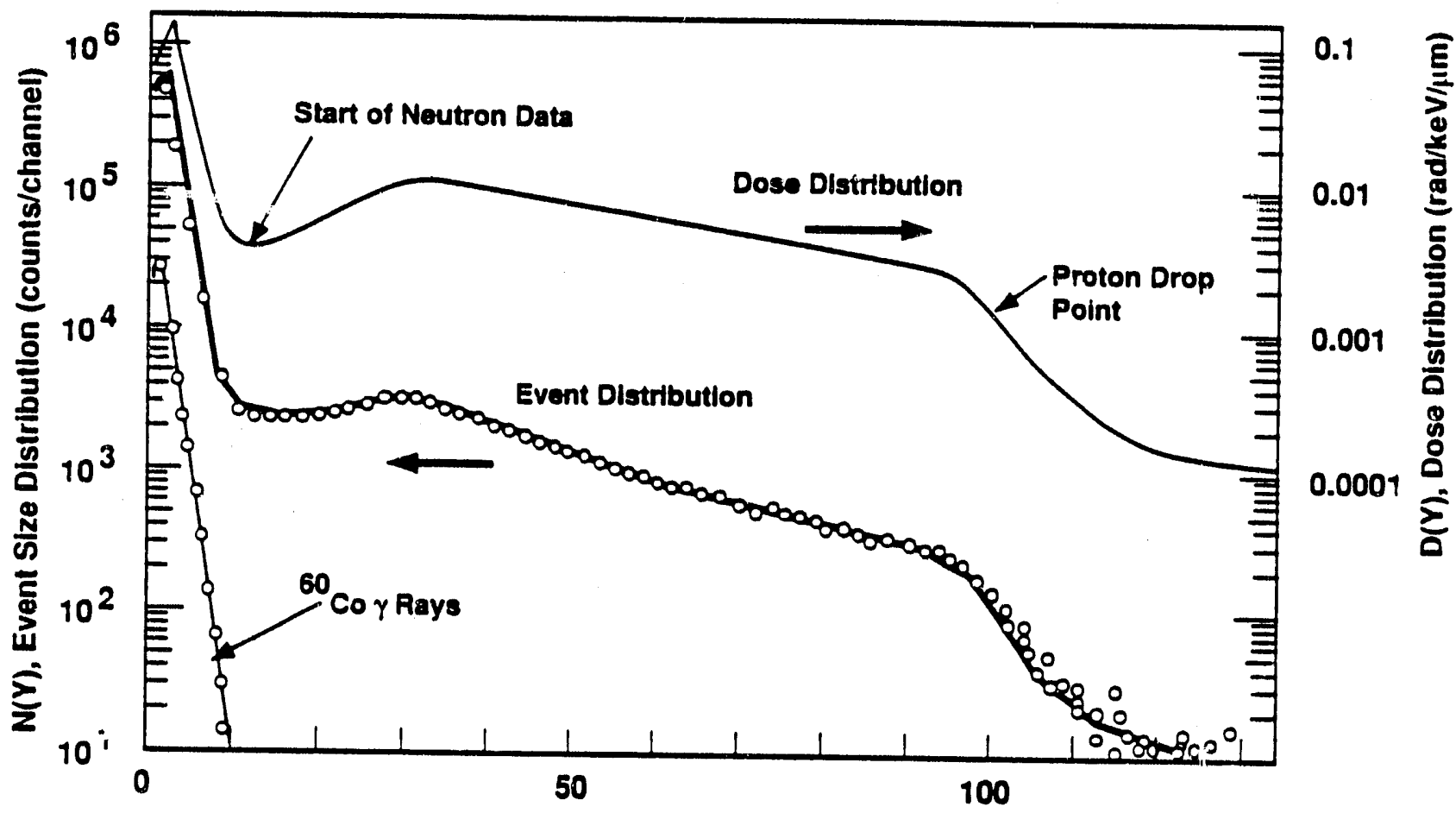

Channel Number or Event Size, (keV/ $/ \mu \mathrm{m})$

39101085.25

FIGURE A.3. A Typical Spectrum as Recorded by a TEPC Operated with a 1-um Equivalent Diameter

Many of the problems of changes in gas gain can be eliminated by careful manufacture of the proportional counters. In small instruments, it is often necessary to utilize cylindrical rather than spherical counters. Before the counter is made, it is necessary to pulverize the TE plastic and heat it to $100^{\circ} \mathrm{C}$ under a vacuum to 21 iminate the water vapor and dioctyl phthalate, which is usually added to the nylon as a plasticizer. Then, the TE plastic can be injection-molded into cylinders for the walls of the counter.

\section{A.4 DETERMINATION OF ABSORBED DOSE}

In mixed radiation fields of neutrons and gamma rays, it is possible to separate neutron and photon events recorded by a TEPC on the basis of lineal energy or puise height. Figure A.3 shows a plot of the absorbed dose distribution measured by a TEPC. The minimum shown in the figure at about $15 \mathrm{keV} / \mu \mathrm{m}$ is considered to separate neutron and gamina rays. Some overlap between the t::o types of events will occur, but the resultant error will be

$$
\text { A.8 }
$$


less than a few percent. The error is minimized for spherical counters, but will be larger for long cylindrical counters, where a gamma secondary travelling down the axis of the cylinder will deposit as much energy as a neutron secondary.

An alternative method of displaying the same data is shown in Figure A.4, in which the lineal energy times the absorbed dose is plotted as a function of the logarithm of the lineal energy. Figure A.4 shows the absorbed dose distribution measured for a ${ }^{252} \mathrm{Cf}$ source surrounded by $15 \mathrm{~cm}$ of deuterium oxide, which is used as the calibration standard for TLD-albedo dosimeters. In this plot, equal areas represent equal doses. This type of plot is preferred, because the separation between gamma ray and neutron induced events is more apparent, and the extrapolation of neutron and gamma events is easily accomplished. Also, it is easy to separate gamma events from electronic noise in the measurement system by using this type of plot.

Once the energy calibration and separation between neutron- and photoninduced events have been obtained, it is possible to determine the absorbed neutron dose, $D_{n}$, from the following formula:

$$
D_{n}=c / \zeta V \Sigma N(E) E
$$

where $E=$ the energy deposited expressed in terms of channel or energy bin number

$c=$ constant of proportionality relating the energy deposition to channel number (Rossi 1968) as determined in Section 1.3

$\zeta V=$ the product of gas density times cavity volume (or mass of gas in the cavity)

$N(E)=$ the number of events of energy $E$ as measured by the TEPC

The accuracy with which TEPCs can measure neutron absorbed dose is demonstrated in Figure A.5. Several different spherical TEPCs were exposed to nearly monoenergetic neutrons produced by Van de Graaff accelerators. The fluence was measured using a precision long counter (DePangher and Nichols 1966) or a fission counter. For these free-in-air exposures, the absorbed neutron dose in a small tissue site is closely approximated by the kerma. The 


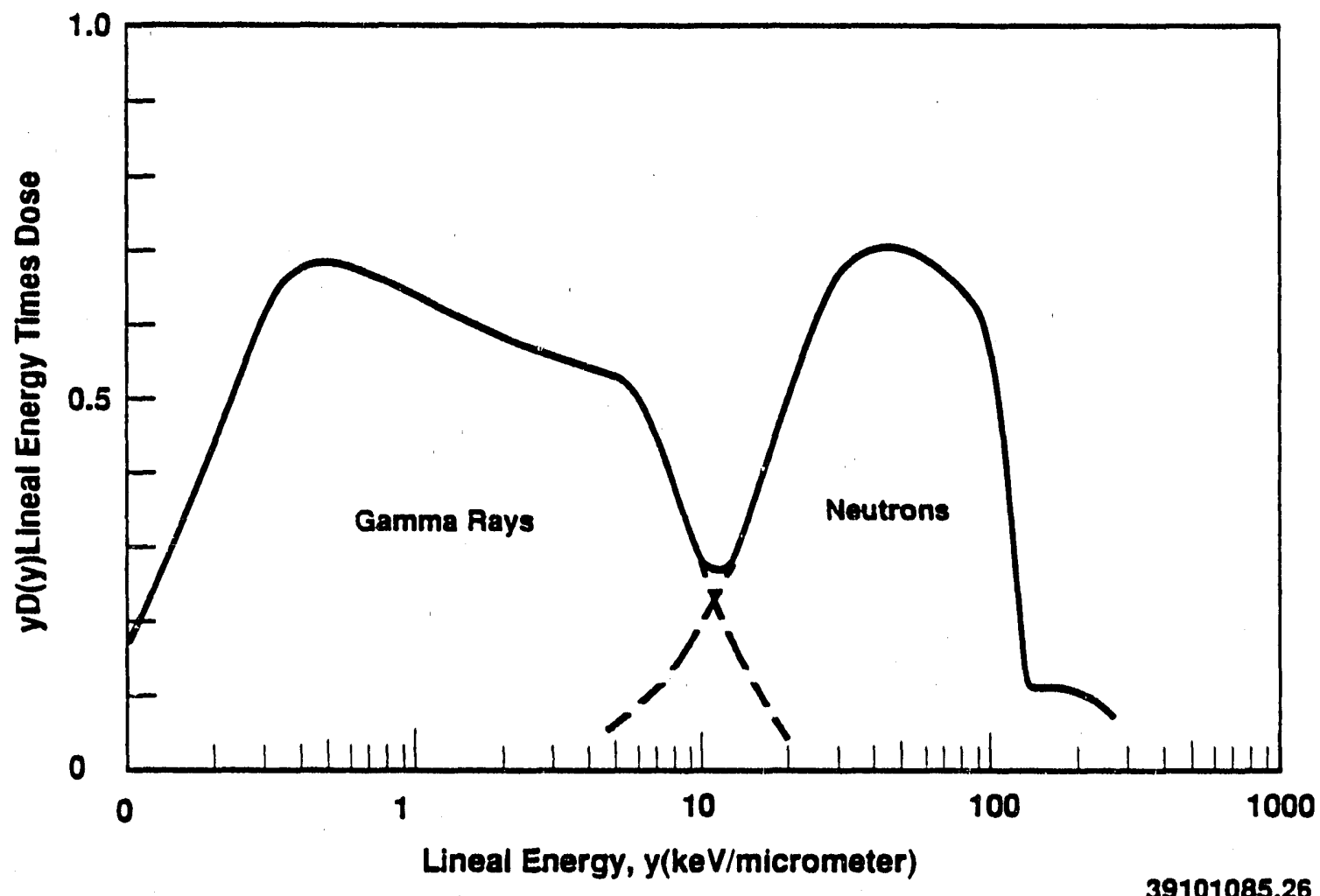

FIGURE A.4. Simultaneous Measurement of Absorbed Dose from Neutrons and Photons by a Tissue Equivalent Proportional CounterThe data have been grouped into logarithmic energy bins for clarity.

kermas were calculated using published conversion factors (Caswe11, Coyne, and Randolph 1980). On the average, the TEPC measurements agree within $3 \%$ with a standard deviation of $9 \%$ for neutron energies between $100 \mathrm{keV}$ and $7.5 \mathrm{MeV}$. The agreement may be better than indicated in Figure A.5 because of experimental difficulties. The fluence measurements may not be as accurate as the approximate kerma measurements made by the TEPCs because the long counters used for the fluence measurements were not uniformly illuminated (i.e., the neutron flux varied across the front face of the long counter because of angular yields from the accelerator targets). 


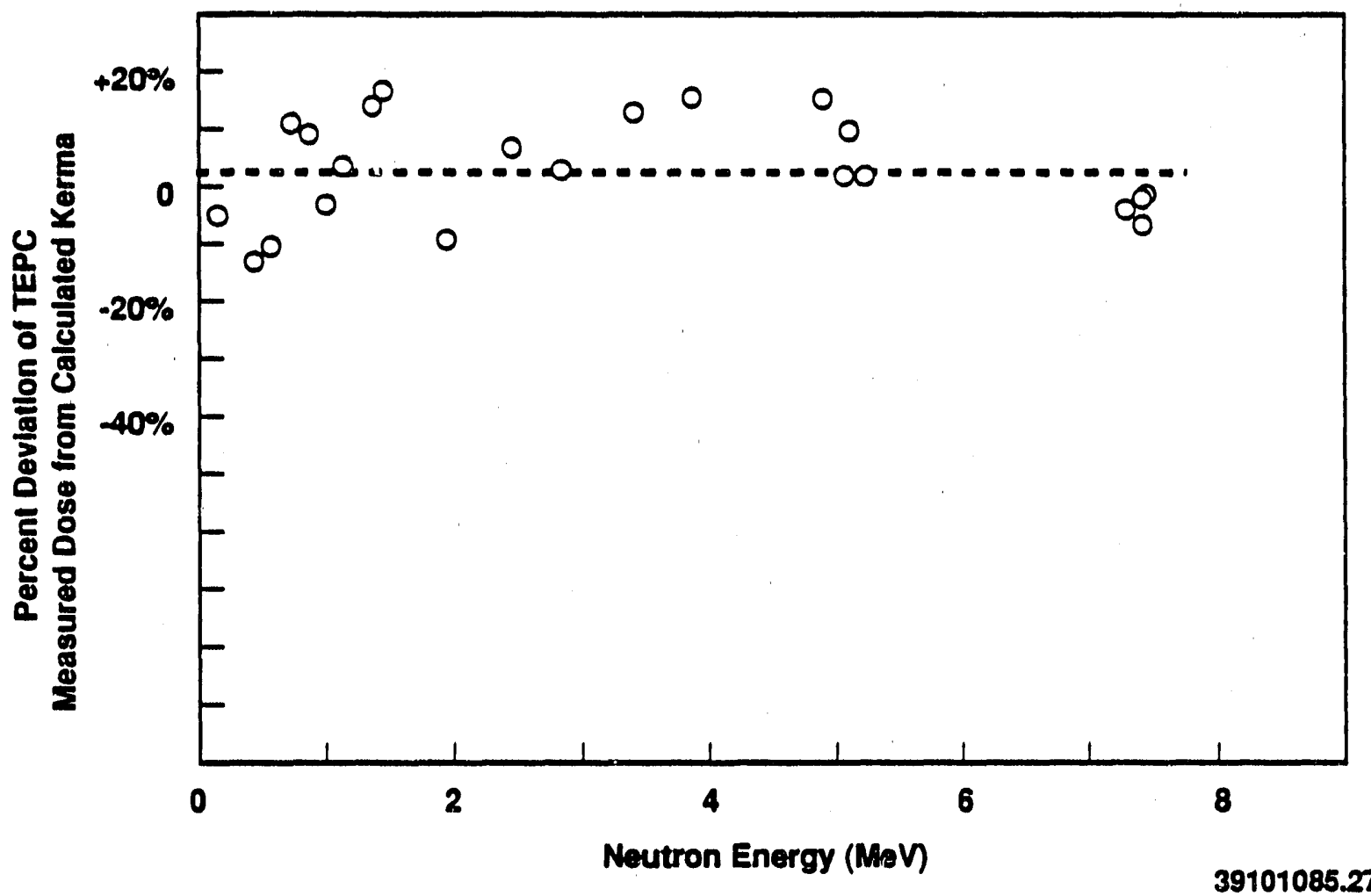

EIGURE A.5. Ratio of Neutron Dose Measured by TEPCs to the Kerma Calculated from Fluence Measurements

\section{A.5 DETERMINATION OF OUALITY FACTORS}

The most difficult problem in analyzing the data from a TEPC measurement is determining an appropriate quality factor, so that dose equivalent can be determined from the measured absorbed dose. At the present time, quality factors are defined as a function of linear energy transfer or LET (NCRP 1971a). The definition of this relationship is given in Table A.3. Quality factors are linearly interpolated from the values presented in Table A.3.

Tissue equivalent proportional counters measure dose distributions as a function of lineal energy, i.e., the energy deposited in the site divided by the mean chord length of the site. For a spherical proportional counter, the mean chord length is two-thirds of the diameter. Problems occur in attempting to convert from lineal energy distributions to LET, as discussed in 
IABLE A.3. Relationship Between Qual ity Factor and Linear Energy Transfer, LET

\section{Quality Factor LET, $\mathrm{keV} / \mathrm{um}$}

$\begin{array}{lr}1 & <3.5 \\ 2 & 7 \\ 5 & 23 \\ 10 & 53 \\ 20 & >175\end{array}$

Source: NCRP Report 39 (1971a), page 81.

Sections 4 and 5 of ICRU Report 36, Microdosimetry (ICRU 1983). A paper by Hartmann, Menzel, and Schuhmacher (1981) discusses various algorithms for determining quality factors from TEPC measurements. Additional information on determining mean quality factors from TEPC data is given on page 67 of ICRU Report 36 (ICRU 1983).

The theoretical basis for algorithms to relate lineal energy to LET was developed over 20 years ago by Albrecht Kellerer (1969). Equation 52 of Kellerer's paper relates LET and lineal energy by the equation

$$
\bar{y}_{D}=\left(\delta / \bar{L}_{D}\right)+\bar{L}_{D}\left(T_{2}\right) /(T)^{2}
$$

where $\bar{y}_{0}=$ the "dose mean" of the event spectrum measured by the TEPC (i.e., the average lineal energy or first moment of the dose distribution)

$\delta=$ the "energy mean" loss per collision given by Equation (43) of Kellerer (1969)

$T=$ the mean chord length in the cavity

$T_{2}=$ the mean of the square of the chord length distribution in the cavity

$\bar{L}_{D}=$ the dose mean linear energy transfer.

For practical purposes, the first term of Equation (A.2) can be ignored.

For cylindrical proportional counters, the mean chord length and square of the mean chord length can be determined from the data presented in Figure A.6, which is derived from Monte Carlo computer code calculations by Brackenbush, McDonald, Endres, and Quam (1985). 


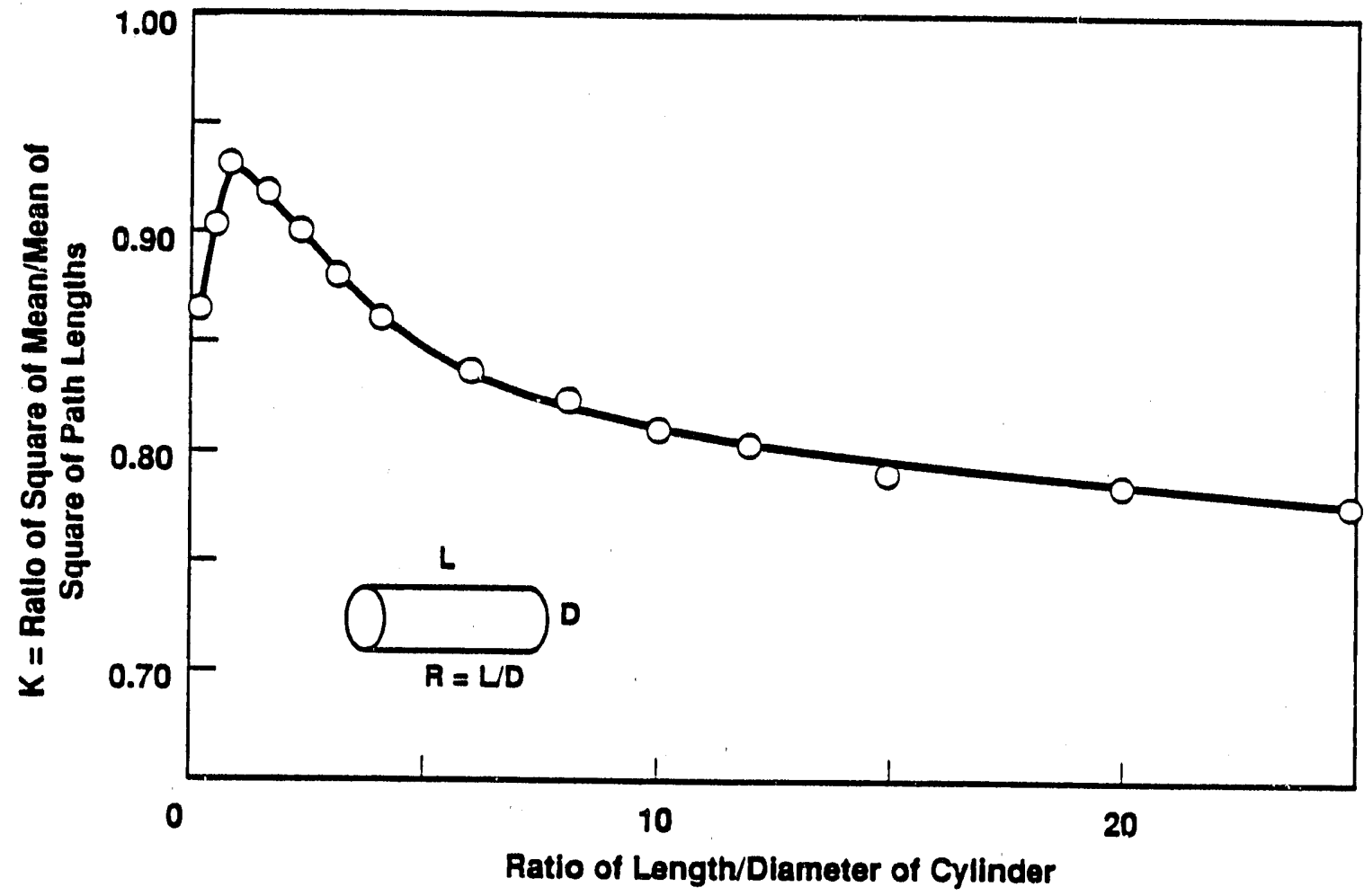

39101085.29

FIGURE A.6. Relation Between Quality Factor and the Mean Chord Length in a Cylinder as a Function of this Length/ Diameter Ratio

However, for a sphere, the mean chord length is two-thirds of the diameter, so Equation (A.3) reduces to

$$
\bar{y}_{D}=(9 / 8) \bar{L}_{0}
$$

Consider the case where a single LET value corresponding to a quality factor value is derived from Table A.3. In this case the quality factor can be found by

$$
\bar{L}_{0}=(8 / 9) \bar{y}_{0}
$$

Because of the linear and additive relationship, this process can be repeated for all values of $L_{D}$ to determine a dose weighted average quality factor, $Q$ : 


$$
\bar{Q}=(1 / D) \int Q(L) D(L) d L
$$

where $Q(L)=$ the quality factor interpolated from the data in Table A.3

$D(L)=$ the differential absorbed dose distribution as a function of linear energy transfer (derived by setting $L=(8 / 9) y$ )

$D=$ the total absorbed neutron dose.

Note that for cylinders the same formula can be applied using the relationships presented in Figure A.6. This formula works quite well for fast neutrons with moderate energies. However, errors can occur for neutrons with energies below about $200 \mathrm{keV}$ and for neutrons with energies in the range of 15-17 MeV, where there are resonances in the charged particle cross sections for carbon and oxygen.

There is a simple method of determining effective average quality factor using empirical relationships discovered by Brackenbush et al. (1985). Albrecht Kellerer (1969) predicted a linear relationship between the first moment of the dose distribution measured by the TEPC and the first moment of the dose distribution as a function of LET (ste Equation [A.5]). Because quality factors are defined as a function of LET, there should be a simple relationship between effective or average quality factors and the average lineal energy measured by the TEPC. Figure A.7 shows the average quality factors for neutrons plotted as a function of the average pulse height or the first moment of the lineal energy for TEPCs exposed to nearly monoenergetic neutrons produced at the Van de Graaff accelerator at the Pacific Northwest Laboratory (PNL). If the lineal energy is restricted to a range of about $15 \mathrm{keV} / \mu \mathrm{m}$ to $170 \mathrm{keV} / \mu \mathrm{m}$ (which correspond to proton recoils from fast neutron interactions), there is a simple linear relationship between the average or effective quality factors and the first moment of the dose distribution measured by the TEPC. Note that if all events (including alpha production. are included, this simple linear relationship is not valid. One reason for this is that the official quality factors listed in NCRP Report 38 (1971b) are calculated at 10, 14 and $20 \mathrm{MeV}$, and intermediate values are obtained by linear extrapolation. Unfortunately, there are resonances in the cross sections at these interpolated energies which are not properly accounted for. 
These resonances produce high values for the first moment of the dose distribution shown in Figure A.7.

Earlier studies (Brackenbush et al. 1985) have shown that the effective quality factor determined on the surface of the body (or on a phantom) is sufficiently close to the maximum values at various depths in the body that are currently used for radiation protection purposes. A problem exists for low neutron energies, where $2.2-\mathrm{MeV}$ gamma rays are produced by the absorption of neutrons by hydrogen. The TEPC measurement includes these activation gamma rays as part of the photon dose, but the official fluence-to-dose equivalent conversion factors include these as part of the neutron dose equivalent. If a gamma dosimeter is used, the 2.2-MeV gamma rays are in essence counted twice,

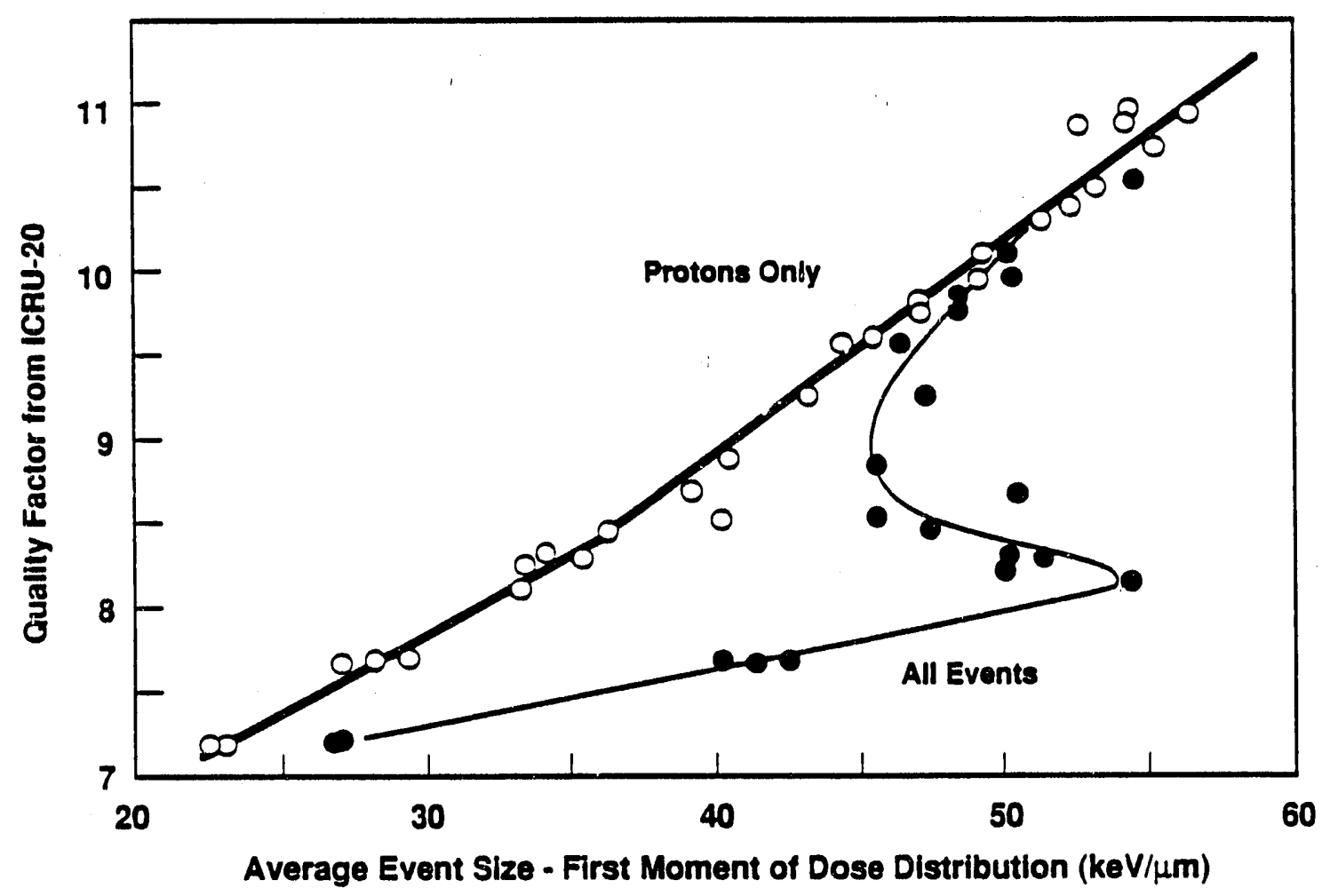

39101085.28

FIGURE A.7. Neutron Quality Factors Empirically Derived from the First Moment of the Absorbed Dose Distribution Measured by the Tissue Equivalent Proportional Counter 
which leads to overly conservative values using conventional fluence-to-dose equivalent calculations.

\section{A.6 PROPOSED CHANGES IN NEUTRON QUALITY FACTORS}

At the present time, apparently conflicting recommendations exist for changing both the values and methods used to determine quality factors and dose equivalent. In Publication 51, Data for Use in Protection Against External Radiation (ICRP 1987), the ICRP gives specific guidance on appropriate values for average or effective neutron quality factors. The recommended values are double existing values for fast neutrons. The NCRP has also recommended the doubling of neutron quality factors in Report No. 91, Recommendations on Limits for Exposure to lonizing Radiation (NCRP 1987).

However, simply doubling the existing values used for neutron quality factors may not be appropriate. The existing quality factors are based on Monte Carlo computer code calculations of Auxier, Snyder, Jones, and coworkers at Oak Ridge (Auxier, Snyder, and Jones 1968). For neutrons with energies below about $10 \mathrm{keV}$, a significant contribution to the quality factor originates from activation gamma rays produced by the absorption of slow neutrons by hydrogen. If existing quality factors for low energy neutrons are doubled, quality factors for these activation gamma rays are in essence doibled. Also, quality factors for all ionizing radiations are currently defined as a function of linear energy transfer using the relationships given in Table A.3. Simply doubling the values for average quality factors derived from the Oak Ridge calculations is inconsistent with the existing definition of quality factor as a function of LET. Obviously, there is a great deal of discussion concerning what neutron quality factors should be. To date, only Japan has formally adopted the recommendations of the ICRP to double quality factors for neutrons.

One recent recommendation is apparently consistent with doubling quality factors for fast neutrons. In ICRU Report 40 The Quality Factor in Radiation Protection (ICRU and ICRP 1986), a Joint Task Group composed of members of the ICRU and ICRP recommended defining a relationship between quality factor and

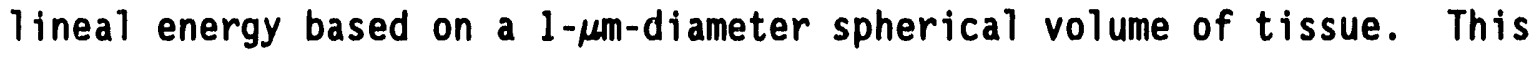
recommendation uses a procedure similar to that developed by Zaider and

$$
\text { A.16 }
$$


Brenner (1985). This relationship is shown in Figure A.8 and is given by the equation

$$
q(y)=\left(a_{1} / y\right)\left[1-\exp \left(-a_{2} y^{2}-a_{3} y^{3}\right)\right]
$$

with coefficients having the values of

$$
\begin{aligned}
& a_{1}=5510 \mathrm{keV} / \mu \mathrm{m} \\
& a_{2}=5 \times 10^{-5} \mu \mathrm{m}^{2} / \mathrm{keV}^{2} \\
& a_{3}=2 \times 10^{-7} \mu \mathrm{m}^{3} / \mathrm{keV}^{3} .
\end{aligned}
$$

Even an irradiation by monoenergetic radiation or particles with a constant LET will produce a distribution of lineal energies. Thus, it is necessary to define a dose-weighted average quality factor:

$$
\bar{q}=(1 / 0) \int d(y) q(y) d y
$$

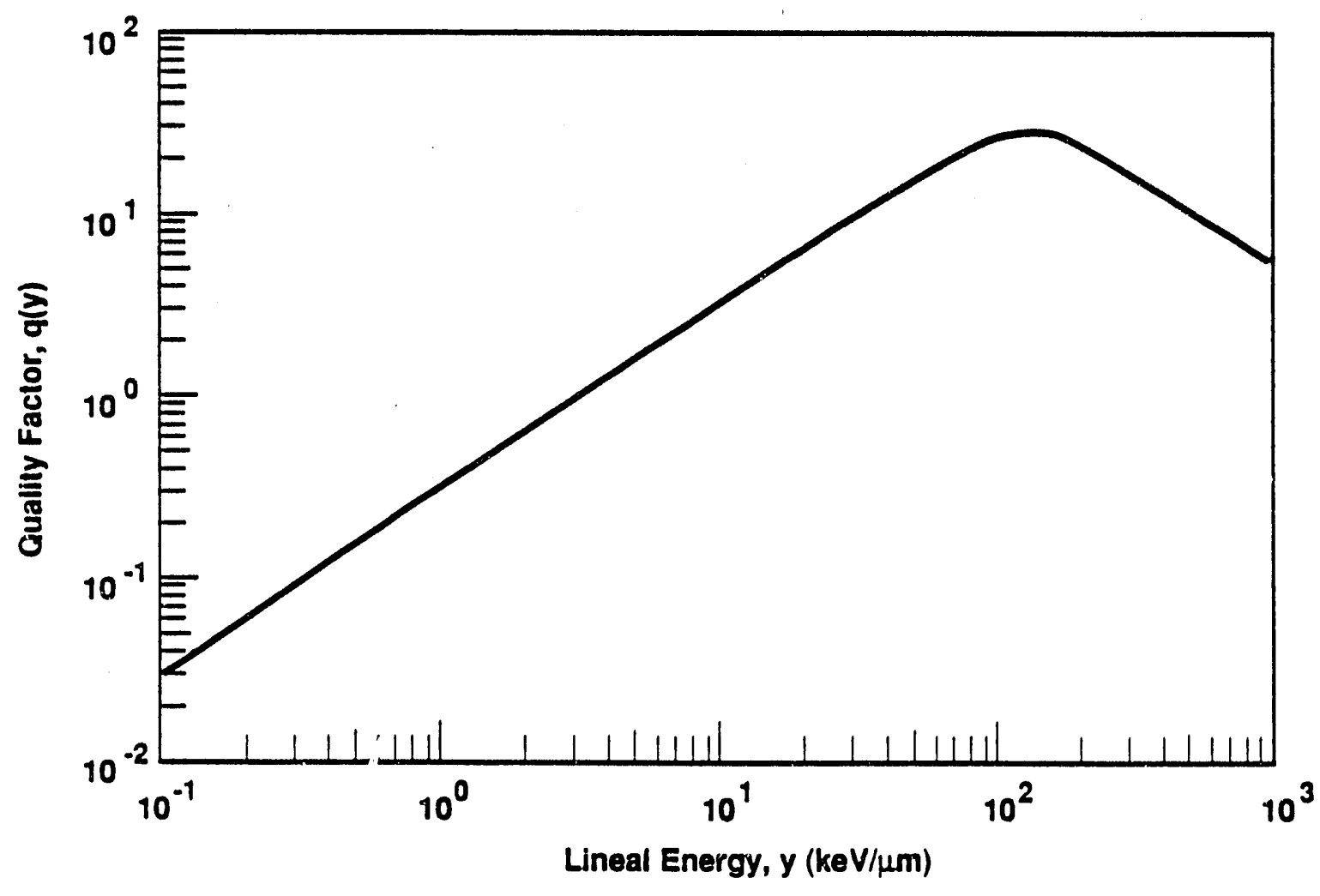

39101085.30

FIGURE A.8. Quality Factor Redefined as a Function of Lineal Energy

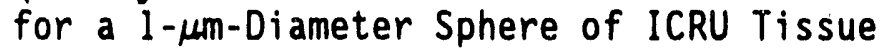

Source: ICRU and ICRP 1986, p. 10 
where $d(y)$ is the distribution of absorbed dose in lineal energy, $y$, and $g(y)$ is the quality factor defined in Equation (A.7). Once the dose-weighted average quality is determined, the dose equivalent can be determined by

$$
H=\bar{q} D
$$

The quantities defined in Equations (A.B) and (A.9) are determined by the energy spectrum at the point of interaction and not by the incident energy spectrum outside the body or phantom. Thus, these quality factors are not directly comparable to those used in existing regulations. Using the definition of quality factor from Equation (A.8), it is possible to determine dose-weighted average quality factors from Equation (A.9) for monoenergetic radiations. The dose-weighted effective quality factors, $q$, are given in Figure A.9 for monoenergetic neutrons (ICRU and ICRP 1986, p. 11).

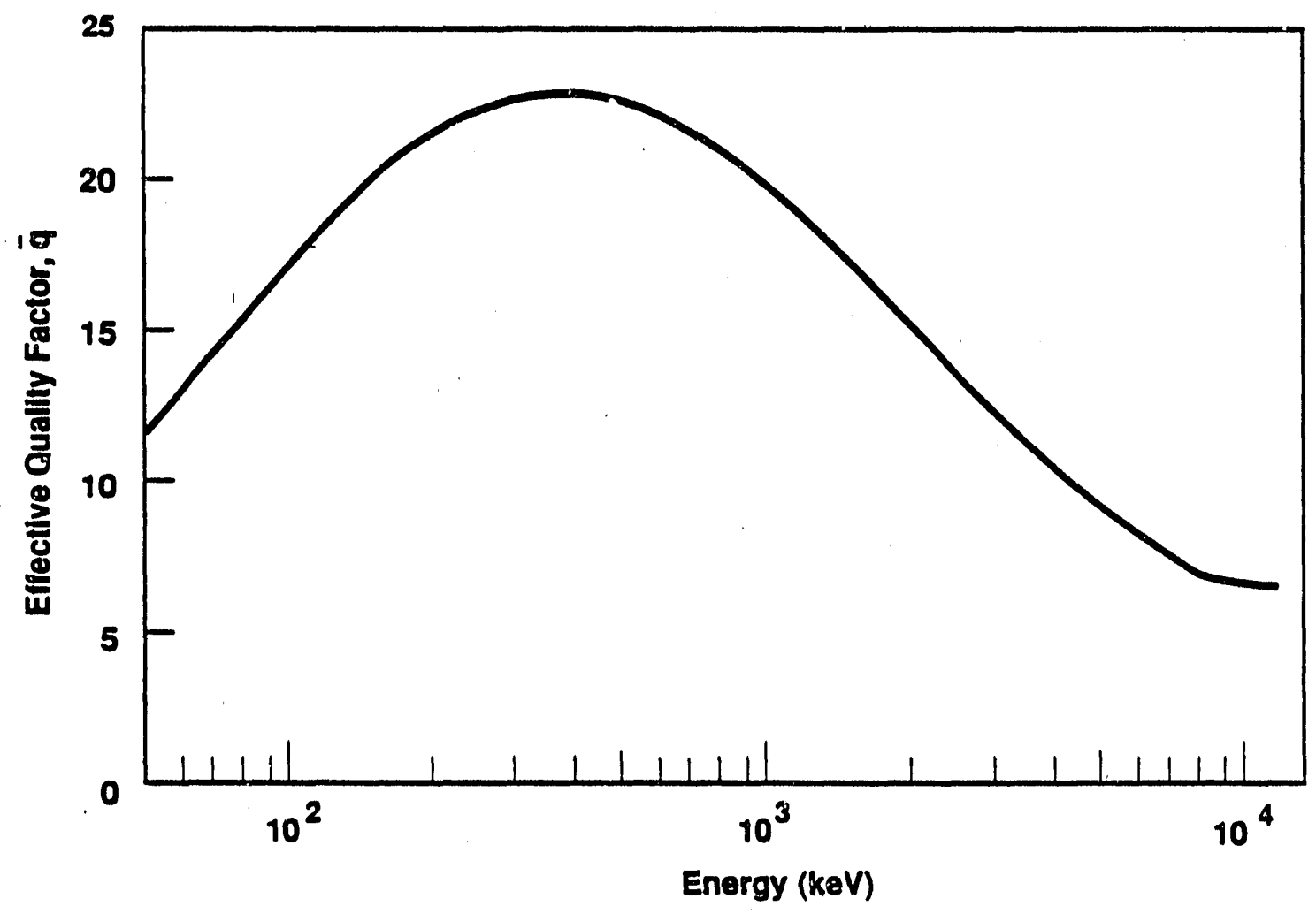

39101085.31

EIGURE A.9. Dose-Weighted Effective Quality Factor Calculated as a Function of Neutron Energy for Monoenergetic Neutrons

Source: ICRU and ICRP 1986, p. 11 
Redefining quality factors as a function of lineal energy results in adopting variable quality factors for all radiations, including photons. The value of the quality factor for photons varies between 0.5 and 1.5 using this definition. Differences in relative biological effectiveness (RBE) between soft $x$-rays and high energy gamma rays have been observed experimentally. However, the practical difficulties of measuring variable quality factors for photons may impede the acceptance of the recommendations in ICRU Report 40.

One advantage of adopting the recommendations of ICRU Report 40 (ICRU 1986) is that quality factors can be easily determined experimentally using TEPCs. The TEPC measures the absorbed dose distribution as a function of lineal energy. By redefining the quality factor in terms of lineal energy, the determination of dose-weighted average quality factors becomes almost trivial.

In conclusion, quality factors can be redefined in terms of lineal energy, which can be directiy measured by TEPCs. These quality factors are calculated at the tissue level and are consistent with proposals to double quality factors for fast neutrons. The quality factor values suggestad in ICRU Report 40 (ICRU and ICRP 1986) are consistent with relative biological effectiveness (RBE) experiments for low doses of fast neutrons on mammalian cells. However, adoption of this methodology will result in greatly increased complexity of calculations for whole-body weighted-dose equivalent.

\section{A.7 DETERMINATION OF DOSE EQUIVALENT FROM TEPCS}

A dose equivalent can be determined from TEPC measurements from the following equation

$$
H=\bar{Q} D
$$

where $Q$ is the average quality factor derived from Equation (A.6) (or Equation [A.8] if quality factors are redefined in terms of lineal energy) and the absorbed dose is determined by Equation (A.1). To be consistent with the Monte Carlo computer code calculations, the dose equivalent should be measured at some depth in the phantom or body.

How do the quality factors and dose equivalent determined by TEPC measurements for a small tissue site relate to the whole-body average quality 
factors and dose equivalents currently used in radiation protection? Over 20 years ago, Snyder, Auxier, Jones, and co-workers at Oak Ridge National Laboratory (ORNL) calculated average quality factors that were applicable for whole-body neutron irradiations (Auxier, Snyder, and Jones 1968). The human body was modeled as a cylinder of soft tissue, $30 \mathrm{~cm}$ in diameter. A parallel beam of monoenergetic neutrons was assumed to strike the cylinder normal to its axis. A Monte Carlo computer code was used to determine neutron transport and photon production in various small volumes inside the phantom. The Monte Carlo code calculated the production of charged particle secondaries and the LET disiribution of these secondary radiations.

From the definition of quality factor as a function of LET, it was possible to calculate the dose equivalent for each of the cylindrical shell volume elements in the cylindrical phantom using the simple equation

$$
H(L)=Q(L) D(L)
$$

where the dose equivalent and absorbed dose were calculated as a function of LET. All the contributions to dose equivalent and dose from neutron recoils, charged particle production, and activation gamma rays were summed together to determine a single dose equivalent or absorbed dose for a given volume element. For a given neutron energy, the Oak Ridge group selected the highest value of dose equivalent that occurred at any volume element in the cylinder. Following the conservative policy usually applied by health physicists, this maximum value represented the value for the whole body. Note that this procedure also provided average quality factors, which were calculated as the ratio $H / D$ (the dose equivalent divided by the absorbed dose) in the volume element with the highest value. A review of these calculations is given by Auxier, Snyder, and Jones (1968).

These values calculated for the cylindrical phantom are applicable to the whole body. They are the values used for fluence-to-dose equivalent conversion factors and average quality factors that are listed in NCRP Report 38, Protection Against Neutron Radiation (NCRP 1971) and used in DOE Orders. Several problems can occur when applying these calculated values. For polyenergetic neutron spectra, the fluence-to-dose equivalent conversion factors are added together for the various neutron energies. Because the 
maximum values of dose equivalent may occur at different depths in the phantom, this sum will always be conservative and not physically measurable. At low neutron energies, below about $10 \mathrm{keV}$, the primary mechanism for neutron interaction is the production of activation gamma from $H(n, \tau) D$ reactions. These activation gamma are included as part of the neutron dose equivalent, a)though a photon dosimeter on the surface of the body would measure some of these gamma and include them in gamma dose. Finally, no effects of irradiation genmetry are included in the conversion factors or average quality factors; all radiations are considered to be normal incident to the phantom. All of these effects result in conservative "cap" values for whole body dose equivalent and average quality factors. These values cannot be measured physically.

This conservatism is not reflected in TEPC measurements. The TEPC determines the quality factor at a depth corresponding to the thickness of the TE plastic walls, which is typically $1 / 8-i n$. thick for spherical counters available commercially. However, many algorithms for quality factor tend to slightly overestimate quality factors, so the TEPC measurements for fission energies are remarkably close to the values calculated from neutron energy spectra. Moreover, in a TEPC, it is not possible to distinguish between external gamma rays and gamma rays produced by neutron capture reaction in the body or phantom. Therefore, all gamma rays are excluded from analysis for neutron dose. For fission energies, this does not present a problem. However, for neutrons with energies below $10 \mathrm{keV}$, the major contributicn to neutron fluence-to-dose equivalent conversion factors originates from capture gamma rays from hydrogen. A more detailed discussion is given in an article by Brackenbush et a1. (1985).

The acceptance of TEPCs for health physics applications depends upon how well they match current regulatory requirements. The data presented in Table A.4 show that the dose equivalent calculated on the surface of the body is usually within about $20 \%$ of the maximum value calculated at depths of $3 \mathrm{~cm}$ to $6 \mathrm{~cm}$ below the surface, based on the Monte Carlo calculations of Auxier, Snyder, and Jones (1968). In a TEPC, the contributions from $H(n, \tau) D$ reactions cannot be distinguished from external photons, so the photon events are included as part of the photon dose, not as part of the neutron dose. Because 
IABLE A.4. Dose and Dose Equivalent Calculated on the Surface and at the Maximum Values in a Cylindrical Phantom

Maximum Vaiue in Phantom

Energy Dose ${ }^{(a)} \quad \begin{gathered}\text { Dose } \\ \text { Equivalent }\end{gathered}$

$0.025 \mathrm{eV}$

$1 \mathrm{eV}$

$10 \mathrm{eV}$

$100 \mathrm{eV}$

$1 \mathrm{keV}$

$10 \mathrm{keV}$

$100 \mathrm{keV}$

$500 \mathrm{keV}$

$1 \mathrm{MeV}$

$2.5 \mathrm{MeV}$

$5 \mathrm{MeV}$

$7 \mathrm{MeV}$

$10 \mathrm{MeV}$

$14 \mathrm{MeV}$
4.68

5.89

5.81

5.48

5.19

4.89

8.02

18.11

30.14

39.9

57.2

57.0

72.5

83.1
11.53

13.42

12.42

11,76

11.15

10.77

48.56

188.5

326.3

349.6

440.7

402.9

431.3

614.9
Value Calculated on Surface

Dose (b) Percent of Max. Equivalent $^{(b)}$ Dose Equivalent

$\begin{array}{lll}4.68 & 11.53 & 100\end{array}$

$\begin{array}{lll}5.89 & 13.42 & 100\end{array}$

$\begin{array}{lll}5.18 & 10 & 97\end{array}$

$\begin{array}{lll}4.45 & 10.05 & 85\end{array}$

$\begin{array}{lll}4.32 & 8.85 & 79\end{array}$

$\begin{array}{lll}4.33 & 9.92 & 92\end{array}$

$8.02 \quad 48.56 \quad 100$

$\begin{array}{lll}18.11 & 188.5 & 100\end{array}$

$30.14 \quad 326.3 \quad 100$

$\begin{array}{lll}39.9 & 349.6 & 100\end{array}$

$\begin{array}{lll}57.2 & 440.7 & 100\end{array}$

$\begin{array}{lll}57.0 & 402.9 & 100\end{array}$

$\begin{array}{lll}72.5 & 431.3 & 100\end{array}$

$\begin{array}{lll}83.1 & 614.9 & 100\end{array}$

\begin{tabular}{|c|c|c|c|c|c|}
\hline \multirow[b]{2}{*}{ Energy } & \multirow[b]{2}{*}{$\begin{array}{l}\text { Contribution } \\
\text { of } H(n, \tau) \text { to } \\
\text { Dose Equiv. } \\
\text { on Surface } \\
\text { of Phantom }(a) \\
\end{array}$} & \multirow[b]{2}{*}{$\begin{array}{l}\text { Contribution } \\
\text { of Charged } \\
\text { Particles to } \\
\text { Dose Equiv } \\
\text { on Surface }(b) \\
\end{array}$} & \multirow[b]{2}{*}{$\begin{array}{l}\text { Percent of } \\
\text { Total Dose } \\
\text { Equiv. from } \\
\text { Charged } \\
\text { Particles } \\
\text { on Surface }\end{array}$} & \multicolumn{2}{|c|}{$\begin{array}{c}\text { Effective Quality Factor, } \\
0=H / D\end{array}$} \\
\hline & & & & $\begin{array}{l}\text { Max. Value } \\
\text { of Dose } \\
\text { Equiv. } \\
\text { Including } \\
H(n, \tau) \\
\end{array}$ & $\begin{array}{l}\text { Calculated on } \\
\text { Surface } \\
\text { Including } \\
\text { Only Charged } \\
\text { Particles } \\
\end{array}$ \\
\hline $\begin{array}{c}0.025 \mathrm{eV} \\
1 \mathrm{eV} \\
10 \mathrm{eV} \\
100 \mathrm{eV} \\
1 \mathrm{keV} \\
10 \mathrm{keV} \\
100 \mathrm{keV} \\
500 \mathrm{keV} \\
1 \mathrm{MeV} \\
2.5 \mathrm{MeV} \\
5 \mathrm{MeV} \\
7 \mathrm{MeV} \\
10 \mathrm{MeV} \\
14 \mathrm{MeV}\end{array}$ & $\begin{array}{l}4.00 \\
5.14 \\
4.49 \\
3.89 \\
3.83 \\
3.42 \\
3.31 \\
2.80 \\
2.23 \\
1.84 \\
1.48 \\
1.68 \\
3.79 \\
7.21\end{array}$ & $\begin{array}{r}7.53 \\
8.27 \\
7.60 \\
6.17 \\
5.03 \\
6.50 \\
42.25 \\
185.7 \\
324.1 \\
347.8 \\
439.2 \\
401.2 \\
427.5 \\
607.7\end{array}$ & $\begin{array}{l}65 \\
62 \\
63 \\
61 \\
57 \\
65.5 \\
93 \\
98.5 \\
99.3 \\
99.5 \\
99.7 \\
99.6 \\
99.1 \\
98.8\end{array}$ & $\begin{array}{l}2.46 \\
2.28 \\
3 \\
4 \\
5 \\
2.22 \\
6.06 \\
10.41 \\
10.83 \\
8.76 \\
7.73 \\
7.0 \\
5.95 \\
7.40\end{array}$ & $\begin{array}{r}11.07 \\
11.07 \\
11.07 \\
10.99 \\
10.15 \\
7.08 \\
9.61 \\
13 \\
11.61 \\
9.14 \\
7.88 \\
7.25 \\
6.22 \\
8.01\end{array}$ \\
\hline
\end{tabular}

(a) Dose in $10^{-10} \mathrm{rad} \mathrm{n}^{-1} \mathrm{~cm}^{2}$.

(b) Dose equivalent in $10^{-10} \mathrm{rem} \mathrm{n}^{-1} \mathrm{~cm}^{2}$. 
the quality factor algorithm used to estimate neutron quality factors from TEPC data includes only charged particle events (i.e., protons from neutron recoils and heavy charged particle production), the quality factors estimated from TEPC data will always be larger than those calculated by Auxier et al. (1968). This is one of the reasons for the apparent failure of TEPCs to accurately predict whole body average quality factors for neutrons with energies below about $100 \mathrm{keV}$. A possible solution to this apparent dilemma is to determine an effective quality factor for the mixed radiation field and not attempt to determine neutron and photon dose equivalent separately (Brackenbush et al. 1985).

\section{REFERENCES}

Aubanen, A. A., and K. B. 01dham. 1985. "Fourier Smoothing "lithout Using the Fast Fourier Transform." Byte 11(2):207.

Auxier, J. A., W. S. Snyder, and T. D. Jones. 1968. "Neutron Interactions and Penetration in Tissue." In Radiation Dosimetry, vol. 1, eds. F. W. Attix and W. C. Roesch, pp.289-312. Academic Press, New York.

Brackenbush, L. W., J. C. McDonald, G. W. R. Endres, and W. Quam. 1985. "Mixed Field Dose Equivalent Measuring Instruments." Radiat. Protect. Dosim. $10(1-4): 307-318$.

Brackenbush, L. W., W. D. Reece, S. D. Miller, G. W. R. Endres, J. S. Durham, R. I. Scherpelz, and P. L. Tomeraasen. 1988. Personnel Neutron Dose Assessment Upgrade. Vol. 2: Field Neutron Spectrometer for Helath Physics Applications. PNL-6620, Pacific Northwest Laboratory, Richland, Washington.

Caswell, R. S., J. J. Coyne, and M. L. Randolph. 1980. "Kerma Factors for Neutron Energies Below $30 \mathrm{MeV} . "$ Radiat. Res. 83:217.

DePangher, J., and L. L. Nichols. 1966. A Precision and Long Counter for Measuring Fast Neutron Flux Density. BNWL-260, Battelle, Pacific Northwest Laboratories, Richland, Washington.

Glass, W. A., and D. N. Samsky. 1967. "Ionization in Thin Tissue-like Gas Layers by Monoenergetic Protons." Radiat. Res. 32:138-148.

Hartman, G., H. G. Menzel, and H. Schuhmacher. 1981. "Different Approaches to Determine Effective Quality Factors and Dose Equivalent Using the Rossi Counter." In Proceedings of the 4th Symposium on Neutron Dosimetry, p. 225. Office for Official Publications of the European Community, Luxembourg. 
International Commission on Radiological Protection (ICRP). 1987. Data for Use in Protection Against External Radiation. ICRP Publication 51, Pergamon Press, New York.

International Commission on Radiation Units and Measurements (ICRU). 1983. Microdosimetry. ICRU Report No. 36, ICRU Publications, Bethesda, Maryland.

International Commission on Radiation Units and Measurements (ICRU) and International Commission on Radiological Protection (ICRP), Joint Task Group. 1986. The Quality Factor in Radiation Protection. ICRU Report No. 40, ICRU Publications, Bethesda, Maryland.

Kellerer, A. M. 1969. "Analys is of Patterns of Energy Deposition." In Proceedings of the Second Symposium on Microdosimetry, Stresa, Italy, pp. 107-134. Office for Official Publications of the European Community, Luxembourg.

National Council on Radiation Protection and Measurements (NCRP). 1971a. Basic Radiation Protection Criteria. NCRP Report No. 39, NCRP, Bethesda, Maryland.

National Council on Radiation Protection and Measurements (NCRP). 1971b. Protection Against Neutron Radiation. NCRP Report No. 38, NCRP, Bethesda, Maryland.

National Council on Radiation Protection and Measurements (NCRP). 1987. Recommendations on Limits for Exposure to Ionizing Radiation. NCRP Report No. 91, NCRP, Bethesda, Maryland.

Zaider, M., and D. J. Brenner. 1986. "Evaluation of a Specific Quality Function for Mutation Induction in Human Fibroblasts." Radiat. Protect. Dosim. 15:79-82.

Ziegler, J. F. 1977. The Stopping and Ranges of Ions in Matter. Vol. 4: Helium. Pergamon Press, New York. 
APPENDIX B

MULTISPHERE SPECTROMETER 


\section{APPENDIX B}

\section{MULTISPHERE SPECTROMETER}

This section describes the multisphere or Bonner sphere spectrometer used in the measurements at the Plutonium Finishing Plant. The multisphere spectrometer consists of a set of five polyethylene spheres of various sizes, a ${ }^{6} \mathrm{LII}(E U)$ scintillator to measure slow neutrons at the center of the spheres and a cadmium cover. Measurements are made with the scintillator detector positioned at the center of the five spheres and with both a bare and a cadmium-covered scintillator detector.

From the ratio of the count rates, it is possible to "unfold" the neutron energy spectrum, given certain restrictions, such as non-negative fluxes and continuous flux distributions. Unfortunately, there are an infinite number of mathematically correct solutions possible, so no unique solution is possible. In addition, the multisphere spectrometer has very poor energy resolution. However, the multisphere spectrometer is the only type of spectrometer that can function over a wide range of energies, from thermal to over $20 \mathrm{MeV}$.

Section B.1 describes the theory of operation of the multisphere spectrometer and includes details of the mathematical algorithms used to "unfold" the neutron energy spectrum. These algorithms were used in a computer code called SPUNIT (Brackenbush [1983]), which was used to derive the neutron flux as a function of energy. Once the flux distribution is known, it is possible to apply flux-to-dose equivalent rate conversion factors to obtain the dose equivalent rate. In this case, the conversion factors given in National Council of Radiation Protection and Measurements (NCRP) Report 38, Protection Against Neutron Radiation, (NCRP 1971) were used. Section B.2 describes the construction of the multisphere set, the type of scintillator detector used, and the necessary electronic equipment. 


\section{B.1 THEORY OF OPERATION FOR THE MULTISPHERE SPECTROMETER}

In the multisphere or Bonner sphere spectrometer, a thermal neutron detector is positioned at the center of moderating spheres of various sizes. The larger spheres moderate fast neutrons to thermal energies, where they are readily detected. Slow neutrons are absorbed before they penetrate to the center of the large spheres. In the smaller spheres, slow neutrons are thermalized and easily detected by the thermal neutron detector. There is not sufficient moderator in the small spheres to thermalize fast neutrons. Thus, various count rates will be recorded by each moderator configuration, depending on the energy of the incident neutrons. With the appropriate mathematical algorithm, the incident neutron energy spectrum can be determined from the measured count rates from each moderator configuration. Once the neutron flux is determined, the dose equivalent rate can be calculated from published fluxto-dose equivalent rate conversion factors.

The advantages of the Bonner sphere spectrometer are its simplicity and usefulness over a wide range of energies, typically from thermal to $20 \mathrm{MeV}$ (or $100 \mathrm{MeV}$ if larger sphere sizes are used). The electronics needed to operate this type of spectrometer are quite simple. However, as will be discussed later, the spectra derived from Bonner spheres are not unique and are prone to errors. The differential spectra are not always accurate, especially in the intermediate energy regions. But the integral flux and dose equivalent derived from the differential spectra are usually accurate enough for health physics purposes.

The Bonner or multisphere spectrometer was originally developed by Bramblett, Ewing, and Bonner (1960). Their spectrometer consisted of a ${ }^{6} \mathrm{Lil}(E U)$ scintillator positioned at the center of polyethylene spheres with diameters of $2,3,5,8$, and $12 \mathrm{in}$. The response of each detector/moderator was determined experimentally using approximately monoenergetic neutrons with energies from thermal to $15 \mathrm{MeV}$. Others added additional sphere sizes and extended the energy range.

The Pacific Northwest Laboratory (PNL) version of the multisphere spectrometer is patterned after spectrometers developed by Griffith and coworkers at Lawrence Livermore National Laboratory (LLNL). In the PNL version, a 
1/2-in. diameter by $1 / 2-i n$. long cylindrical ${ }^{6} \mathrm{LII}(\mathrm{EU})$ scintillator optically coupled to a photomultiplier is used as the detector. The detector is al ternately covered with a 0.030 -in. thick cadmium cover, 3-in., 5-in., 8-in., 10-in. and 12-in. diameter polyethylene spheres. Details of the exact dimensions of the moderators are given in the next section. To use the spectrometer, one simply records the number of counts produced in the peak produced by slow neutrons in the ${ }^{6} \mathrm{LiI}(\mathrm{Eu})$ detector with the various detector/ moderator configurations. Because the scintillator crystal is also sensitive to gamma rays, the user must subtract a gamma continuum from the peak, as shown in Figure B.1. Experience has shown that an exponential background subtraction results in more accurate net counts in the neutron peak and, hence, more accurate neutron energy spectra. The computer code subroutine LIAREA developed by the author automatically subtracts out the gamma background, providing the user enters the resolution of the neutron peak.

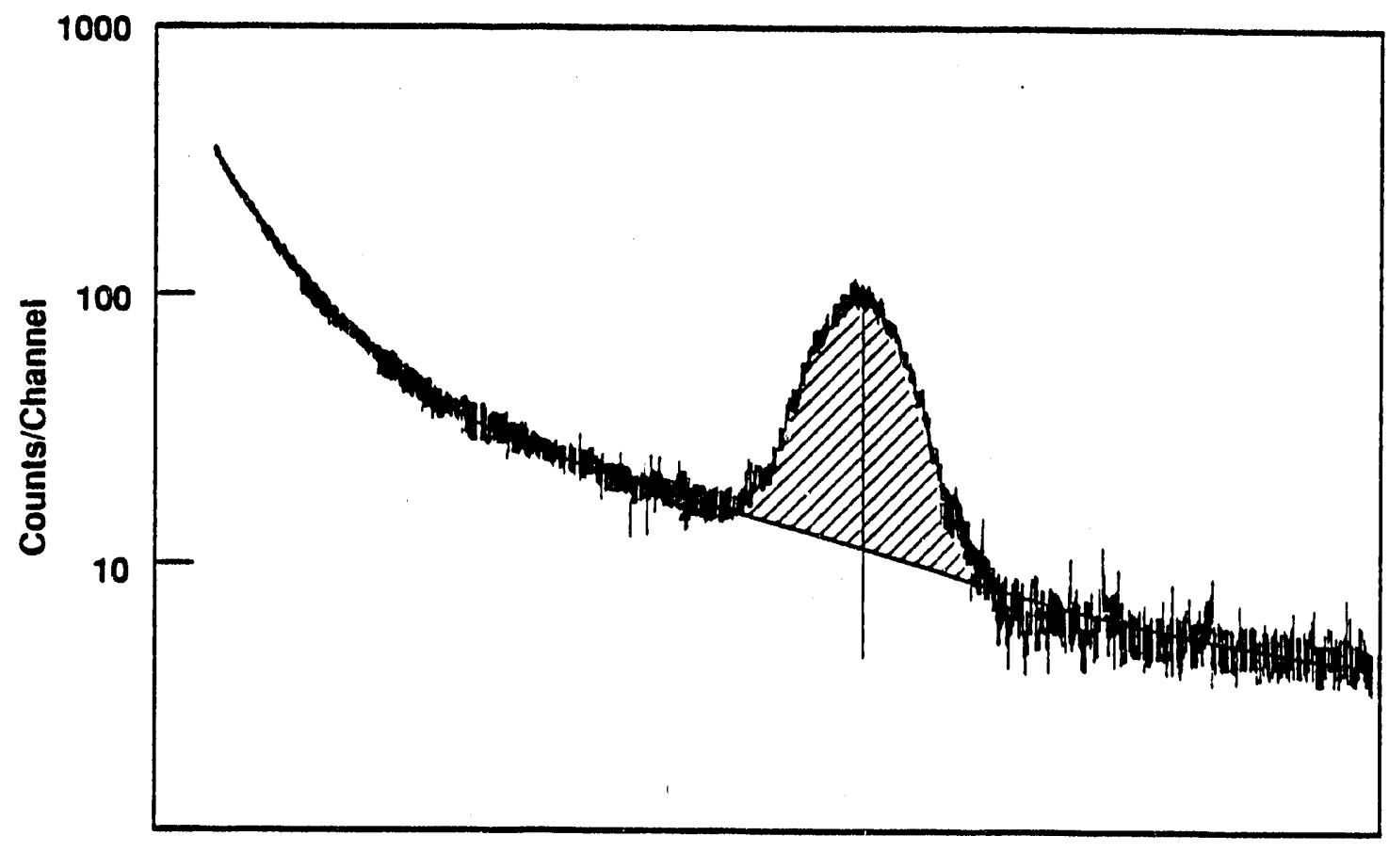

Channel Number

39101085.32

FIGURE B.1. Typical Spectrum Measured by the ${ }^{6} \mathrm{LiI}(E \mathrm{E})$ Scintillator Showing the Slow Neutron Peak and Gamma Continuum 


\section{B.1.1 Mathematical Techniques for Unfolding Energy Spectra}

One of the major problems in using the multisphere spectrometer is how to derive the incident neutron energy spectrum from the counts recorded by the various detector/moderator configurations. There are a number of techniques that have been successfully applied. A paper by C. A. Oster (1977) reviews the various mathematical techniques and representative computer codes using these techniques. There are four principal methods of unfolding spectra: Monte Carlo techniques, parametric representation, derivative methods, and quadrature methods. Most of the codes used for multisphere unfolding use quadrature methods, such as linear estimation and least squares, iterative adjustment methods, and mathematical programming methods. See papers by C. A. Oster (1977) and W. H. Miller and W. Meyer (1983) for a further discussion of the available techniques.

In the PNL system, there are seven detector/moderator configurations. The count rate in the ${ }^{6} \mathrm{LII}(E u)$ scintillator depends on the spectral shape of the neutron flux density and the size of the polyethylene sphere used for the moderator. The count rate, $C(r)$, can be calculated if the response of the system, $R(r, E)$, is known as a function of the size of the sphere and the incident energy, and if the neutron flux density, $\phi(E)$, is known as a function of incident neutron energy. This can be written mathematically as:

$$
C(r)=\int R(r, E) F(E) d E
$$

However, because we cannot continuously change the radius of the sphere or the energy, we must rewrite this equation in terms of a series of summations rather than integrals:

$$
C_{k}=\sum_{i=1}^{n} F_{i} \quad R_{i k}
$$

where $C_{k}=$ the count rate for the $k$ th detector/moderator configuration

$F_{1}=$ the neutron flux density in the ith energy bin

$R_{i k}=$ the response function value relating the $k$ th detector/moderator to the flux density in the ith energy bin. 
In the problem presented here, there are seven detector/moderator configurations, so $k$ ranges from 1 to 7 ; and there are 26 energy bins arranged logarithmically, so $i$ ranges from 1 to 26 . This group of seven equations is known as the discrete version of the Fredholm integral equation of the first kind. The unfolding problem is to use the seven measured count rates and the $7 \times 26$ response matrices to find the 26 flux values. Because there are only 7 known values and 26 values to solve for, this is mathematically an underdefined problem with an infinite number of mathematically correct solutions. our problem is to pick the physically correct solution (i.e., positive and nonzero fluxes) from the infinite number of possible solutions.

There are a great number of codes available to solve Equation (B.2), including Monte Carlo techniques used in the code SWIFT (Sanna and O'Brian 1971), least squares techniques (Zaider, Martin, and Edwards 1978), and iterative nonlinear techniques in the codes TWOGO (Hajnal 1981) and LOUHI (Routi and Sandberg 1978). Iterative recursion techniques are employed in the codes BON (Sanna 1976), YOGI (Johnson and Gorbics 1981), BUNKI (Lowery and Johnson 1984), and SPUNIT (Brackenbush and Scherpelz 1983).

A new mathematical method for solving the unfolding problem for Fredholm integral equations of the first kind was suggested by members of the U.S.S.R. Institute of Biophysics in Moscow (Doroshenko et a1. 1977). This method has been incorporated into the codes SPUNIT and BUNKI. The Soviet authors stated that their method was based on the principals of mathematical physics and information theory, as explained by Doroshenko et al. (1977).

To unfold the spectra, we used the method for minimizing the directed divergence. This method uses the statistical nature of all functions in [Equation B.1], allowing one to use the methods of mathematical statistics and information theory for its solution. Actually, an unknown neutron spectrum, $F(E)$, can be considered as a probability density distribution of an occurrence of the neutron with the energy $E$, with $N_{1}$ and $\sigma_{f}(E)$ as the probability density distribution, $N(U)$, and conventional probability density $\sigma(U, E)$, with an infinite increase of the number of detectors (where $U$ is a variable). Therefore, in the general case of two persistent variables $E$ and $U$, [Equation B.1] can be presented as

$$
N(U)=\int_{a}^{b} \phi(E) \sigma(U, E) d E .
$$


All functions in [Equation B.3] possess known characteristics of density probability, i.e.,

$$
\begin{aligned}
& \int_{a}^{b} \phi(E) d E=1, \quad \phi(E) \geq 0 \\
& \int_{c}^{d} \sigma(U, E) d U=1, \quad \sigma(U, E) \geq 0 \\
& \int_{c}^{d} N(U) d U=1, \quad N(U) \geq 0
\end{aligned}
$$

The name of this method is based on the use of the information measure,.....

$$
\begin{aligned}
& J\left\{N(U)\left[\int_{a}^{b} \phi(E) \sigma(U, E) d E\right]\right\}= \\
& \int_{c}^{d} N(U) \ln \frac{N(U)}{\int_{a}^{b} \phi(E) \sigma(U, E) d E} d U
\end{aligned}
$$

(which has the meaning of directed divergence in the probability space) as a disagreement measure between the left and right sides of [Equation B.3]. Such a functional is always positive and becomes zero only if the left and right sides of [Equation B.3] are equal. Minimization of such a functional according to its statistical meaning is equivalent to the use of the maximum probability principle for determining the disagreement between these two parts. To find the minimum of the functional [Equation B.5], according to the Byess theorem, the following iteration process can be built. If the reverse conventional probability density is $L(E, U)$, it can be used for obtaining the unknown function as:

$$
\phi(E)=\int_{c}^{d} L(E, U) N(U) d U
$$

Substituting into it an approximate value of $L_{n}(E, U)$ obtained by the Byess theorem according to the given a priori probability density, $\phi_{n}(E)$,

$$
L_{n}(E, U)=\frac{\sigma(U, E) \phi_{n}(E)}{\int_{a}^{b} \sigma(U, E) \phi_{n}(E) d E}
$$

we obtain a recurrent formula for the following approximately of the unknown function $\phi_{n+1}(E)$ : 


$$
\phi_{n+1}=\left[\phi_{n}(E) \int_{c}^{d} \sigma(U, E) \frac{N(U)}{\int_{a}^{b} \sigma\left(U, E^{\prime}\right) \phi_{n}\left(E^{\prime}\right) d E^{\prime}} d U\right.
$$

Passing to [Equation B.1] and making the necessary standardization to meet the conditions of [Equation B.4], we obtain the calculated aigorithm as

$$
\phi_{n+1}(E)=\frac{\phi_{n}(E)}{\sum_{j=1}^{m} \sigma_{j}(E)} \sum_{i=1}^{n} \sigma_{i}(E) \frac{N_{i}^{P}}{N_{i}^{n}}
$$

where

$$
\begin{aligned}
& N_{1}^{0}=\text { initial detector readings } \\
& N_{1}^{n}=\text { caiculated detector readings after } \underline{n} \text { iterations. }
\end{aligned}
$$

Irrespective of the form of $\sigma_{i}(E)$, the iteration process [see Equation B.8] always converges to a non-negative function satisfying [Equation B.1] in the best way with respect to the directed divergence. This method provides a good approximation to the unknown solution, since it does not require smoothness of the spectrum and allows one to use any number of energy points and a sufficiently great number of detectors....

The methodology of Doroshenko et al. was incorporated into the computer code SPUNIT by using the following algorithm:

$$
\phi_{i, 1+1}=\frac{\phi_{i, 1}}{\sum_{j=1}^{m} R_{i j}} \sum_{k=1}^{m} R_{i k} \frac{C_{k}}{N_{k, 1}}
$$

where $\phi_{i, 1}=$ the neutron flux density for energy bin $i$ calculated during the lth iteration

$m=$ the number of detector/moderator configurations

$n=$ the number of energy bins (26 in current scheme)

$C_{k}=$ the measured count data for each of the seven configurations

$N_{k, 1}=$ the recalculated count rates, found by: 


$$
N_{k, 1}=\sum_{i=1}^{n} F_{i+1} R_{i k}
$$

In SPUNIT, Equation (B,9) is solved for all energy bins; then, Equation (B.10) is solved for all detector/moderator configurations. A new iteration is then begun using the $F$ and $N$ values calculated in the previous iteration. The iterations continue until a convergence criterion is met.

The code SPUNIT uses two convergence criteria for ending the iterations. One criterion is based on the number of iterations and, hence, the running time of the code. The present default value is 500 iterations, which require less than 30 seconds on a personal computer with a math coprocessor. The second criterion is the deviation of the recalculated detector counts. This aeviation is described by:

$$
e=\left(\sum_{k=1}^{7}\left(\frac{N_{k, 1}-C_{k} 2}{C_{k}}\right)^{1 / 2} \times 100 \%\right.
$$

for the lth iteration. The current default value in the code is $3 \%$. When SPUNIT reaches either criterion, it terminates the iterations and uses the calculated flux to derive the average energy from

$$
\bar{E}=\frac{\sum_{i=1}^{26} E_{i} \phi_{1}}{\sum_{j=1}^{26} \phi_{i}}
$$

where $i$ is the index for the energy bins, $E_{i}$ is the energy of the $i$ th bin, and $F_{i}$ is the neutron flux density in the $i$ th bin. SPUNIT then calculates the dose equivalent rate using the flux-to-dose equivalent conversion factors given in ANSI/ANS-6.1.1 (ANSI 1977). 
As mentioned previously, there are an infinite number of mathematically correct, physically possible solutions. The problem is how to select the "correct" solution. It has been demonstrated that a trial solution can be provided to the iterative code, and the code will converge on a solution that minimizes the differences between the calculated and measured count rates for the various detector/moderator configurations. In the SPUNIT code, the user can select no initial guess (which is equivalent to all fluxes being the same for the initial guess) or the user can specify an initial guess for the solution. For the version of SPUNIT used in the field neutron spectrometer, the cocie uses an initial guess of a fission spectrum with a $1 / E$ tail (i.e., the spectrum with energies below the Maxwellian distribution of the fission spectrum is invers? neutrons is estimated from the ratio of responses from the bare and cadmiumcovered scintillators. This is usually a good initial guess in most DOE facilities, because most neutron sources are moderated fission sources.

SPUNIT has been thoroughly tested in comparisons with the codes LOUHI (Routi 1978) and YOGI (Johnson and Gorbics 1981), and the results have been quite favorable. The advantage of SPUNIT is that the code converges to a solution much faster than almost any other code, thus minimizing the time necessary to obtain a result. T. Johnson has adapted part of the SPUNIT code into an improved version called BUNKI (Lowery and Johnson 1984), which allows the user to select a variety of initial guesses for increased accuracy.

\section{B.1.2 Response Functions for Multisphere Spectrometers}

Although most computer codes give approximately the same unfolded fluxes, the values are highly dependent on the response function selected by the user. A number of response functions are available, but all have some problems associated with using them. To save calculational time on the computer, most response functions are calculated using a one-dimensional model with spherical symmetry. This is quite adequate for larger size spheres, but not entirely satisfactory for small spheres. Consider the case of a 2-in.diameter sphere with a 11/16-in.-diameter hole drilled in it for the 1/2-in.diameter ${ }^{6} \mathrm{LiI}(\mathrm{Eu})$ scintillator crystal. This presents a large "hole" for slow neutrons to leak into the center of the polyethylene sphere, which is not adequately modeled in a one-dimensional calculation. The authors have also 
found thut the 4-mm diameter by 4-mm high scintillator crystals manufactured by Harshaw Chemical Company are lot adequately modeled by published response functions.

After extensive testing, the authors have verified that the response function data published by Sanna (1976) is an accurate representation of the response of the 1/2-in. diameter ${ }^{6} \mathrm{LiI}(E \mathrm{E})$ scintillator detector manufactured by Harshaw Chemical Company, which is used in the field neutron spectrometer. This detector is patterned after an LLNL design and has been thoroughly tested at LLNL and PNL.

A commercially available Bonner sphere set is manufactured by Ludlum Measurements, Inc., Sweetwater, Texas. Recently, Hertel and Davidson (1984) have modeled a response for this detector, which uses a much larger (2-in.diameter) photomultiplier tube and light pipe. The calculations of Hertel and Davidson should be much more accurate for the Ludlum instruments than the Sanna calculations used here for the Harshaw detector. As explained in Section 2, particular care should be exercised in the selection of the multisphere set and detectors used. The response functions used should correspond to a specific multisphere set if accurate results are expected.

\section{B.2 EQUIPMENT USED FOR THE MULTISPHERE SPECTROMETER}

This section describes the fabrication of the necessary equipment used for the multisphere or Bonner sphere spectrometer. This includes details of the spherical moderators used for the multisphere detectors, the ${ }^{6} \mathrm{LII}(\mathrm{Eu})$ scintillator detector, and the necessary electronics.

\section{B.2.1 Moderators Used in the Multisphere Set}

The Bonner sphere or multisphere spectrometer consists of a set of poiyethylene spheres with a hole drilled to the center; a slow neutron detector is inserted into the hole and positioned at the center of the spherical moderator.

The PNL multisphere set consists of five spheres of pclyethylene and a cadmium cover for the scintillator detector. The cadmium cover consists of a cylinder of cadmium $0.030-\mathrm{in} .(0.76-\mathrm{mm})$ thick with one end covered with cadmium. The cadmium cover can be readily fabricated from cadmium sheets.

B. 10 
Because cadmium metal is soft and malleable, the cover can be cut out by using scissors.

The spheres are fabricated from high-density linear polyethylene. Ordinary low density polyethylene can be used, but it tends to flow and distort at high temperatures. It is important to fabricate the spheres from the same type of material for uniform composition. The five spheres are 3.0, 5.0, 8.0, 10.0, and $12.0 \mathrm{in}$. in diameter; the 3-in. and 5-in. diameter spheres are covered with $0.030 \mathrm{in}$. $(0.75 \mathrm{~mm})$ of cadmium. The cadmium covers can be made from hemispheres using hydroforming techniques. They can be fabricated from cadmium sheet cut into segments and pressed onto the polyethylene spheres, or they can be made by metal spinning techniques. Hydroforming seems to provide the most uniform thickness for hemispherical covers. The spheres have 11/16in.-diameter holes drilled to the center for the insertion of the ${ }^{6} \mathrm{LII}(\mathrm{EU})$ scintillator detector. The holes are drilled an extra $3 / 8 \mathrm{in} .(9.5 \mathrm{~mm})$ deep beyond the center of the sphere so that the center of the $1 / 2-i n$. scintillator will be at the geometric center of the moderator. Note that the scintillator housing is only 6-in. long, so that an additional $3 / 8 \mathrm{in}$. of moderator must be removed from the surface of the 12-in. diameter sphere for the scintillator crystal to be centered in the sphere. The spheres can be made at a local machine shop, or they can be ordered from a commercial supplier. The PNL sphere set used in the Plutonium Finishing Plant measurements was made on-site at the 300 Area machine shop. Details of the PNL sphere set are contained in Table B.1.

IABLE B.1. Dimensions of PNL Bonner Sphere Set

$\begin{array}{ccc}\text { Diameter (in.) } & \text { Depth of Hole (in.) } & \text { Weight of Sphere (g) } \\ 3.0+C d & 2-5 / 8 & 213 \\ 5.0+C d & 2-5 / 8 & 989 \\ 8.0 & 4-3 / 8 & 4130 \\ 10.0 & 5-3 / 8 & 7814 \\ 12.0 & 6-3 / 8 & 14063\end{array}$




\section{B.2.2 Scintillator Detector}

The scintillator detector used at PNL is similar to one developed at LLNL and is available commercially. This ${ }^{6} \mathrm{LiI}(\mathrm{Eu})$ scintillator detector contains a 1/2-in.-diameter by 1/2-in.-high crystal mounted on a light pipe connected to a 1/2-in.-diameter Hamamatsu R647 photomultiplier. A diagram of the exterior dimensions of the scintillator detector, including a photomultiplier tube and voltage divider, is shown in Figure B.2. The detector also includes a signal splitter circuit used to block the high-voltage supplied to the photomultiplier from reaching the input to the preamplifier.

\section{B.2.3 Electronics for the Multisphere Spectrometer}

The electronic circuits necessary for the multisphere spectrometer include the ${ }^{6} \mathrm{LII}(\mathrm{EU})$ scintillator detector, a high-voltage power supply capable of supplying $+1000 \vee D C$, a preamplifier, an amplifier, and the necessary cables. The electronics can be made from circuits described in Section 7.4.2 of PNL-6620, Vol. 2 (Brackenbush et al. 1988) with certain modifications. A high-gain preamplifier is not required for the circuit, and the circuit should be modified to include a voltage driver circuit to allow the amplifier to drive a 100-ft-long coaxial signal cable. The high-voltage circuit described in Brackenbush et al. (1988) cannot supply enough current to operate the photomultiplier voltage divider, but a number of suitable high voltage power supplies with continuously adjustable voltages up to $+1000 \mathrm{~V} D C$ are available from commercial sources.

The electronic components can also be obtained from commercial sources using NIM bin modules. An example of a system in use at PNL is provided in Table B.2. There are a number of manufacturers who can provide the necessary electronics, and the components listed in Table B.I are merely examples. Mention of a specific product does not imply endorsement by PNL or the U.S. Department of Energy. The electronics set listed in Table B.2 was used for the measurements at the Plutonium Finishing Plant.

Typically, the ${ }^{6} \mathrm{LiI}$ scintillator detector is connected to the signal splitter box. The signal is routed to the preamplifier using a 2-ft-long $93 \Omega$ coaxial signal cable with male BNC connectors on each end. If an Ortec Model 113 scintillation preamplifier is used, the input capacitance is set to 


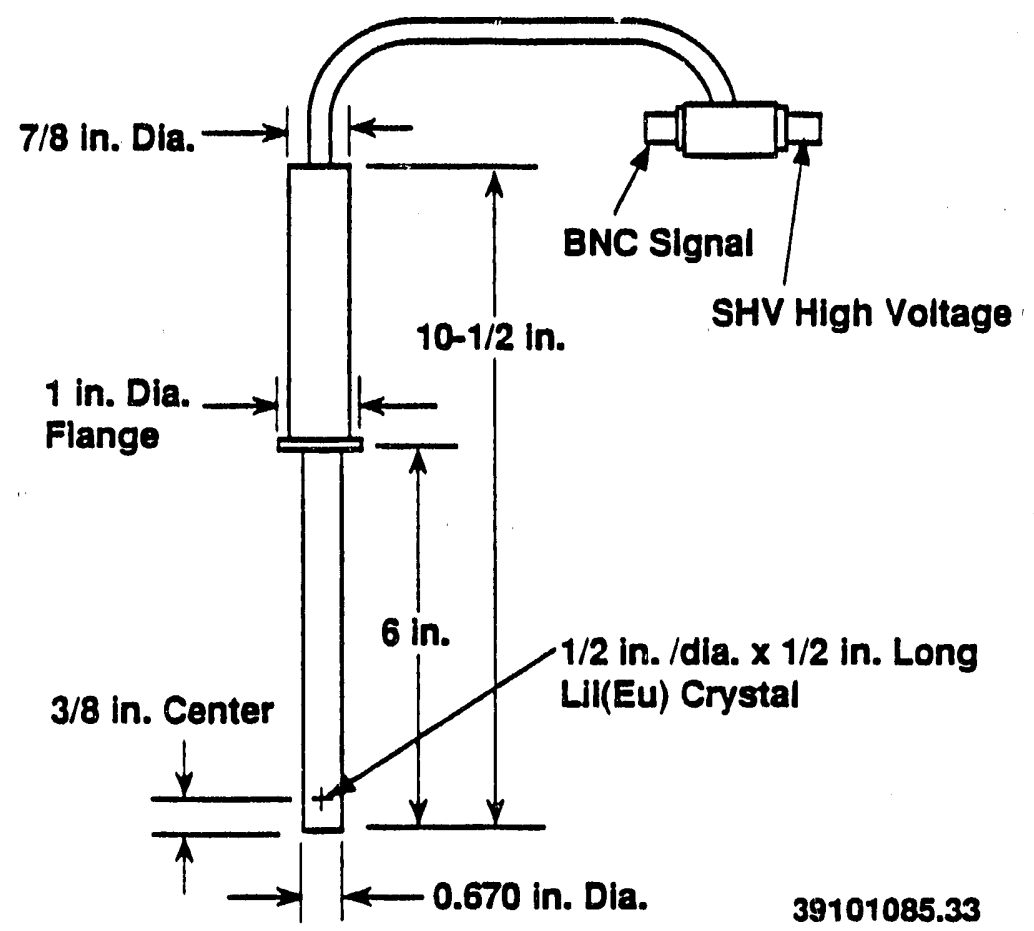

FIGURE B.2. Diagram of the Scintillator Detector

$0 \mathrm{pF}$. The signal from the back side of the Ortec Model 113 preamplifier is then routed to the amplifier in the NIM Bin using a $50-$ or $100-\mathrm{ft}$ long $93 \Omega$ coaxial signal cable with male BNC connectors on both ends. Power is supplied to the preamplifier from the amplifier using 50- or 100-ft long standord NIM power cables with nine-pin "D" connectors on each end. The end connected to the preamplifier has a female connector; the end connected to the amplifier has a male connector. High voltage is supplied from a high voltage supply in the NIM bin to the voltage splitter using a 50 - or 100-ft long coaxial cable with male SHV connectors on both ends. The high voltage supply is typically operated at $+700 V$ to $+800 \mathrm{~V}$. The shaping time constants on the amplifier are typirally set to $2 \mu \mathrm{sec}$, and the gain of the amplifier is adjusted to provide a thermal neutron peak in channels 300 to 400 of the multichannel analyzer used in the field neutron spectrometer. Signals from the amplifier are routed to the input of Port 4 of the field neutron spectrometer. Specific instructions on how to set up the field neutron spectrometer and operate the software 
IABLE B.2. NIM Bin Electronic Components Used to Provide Signals from the Multisphere Detector to the Spectrometer ${ }^{(a)}$

\begin{tabular}{|c|c|c|}
\hline Quantity & Component & Manufacturer \\
\hline 1 & NIM Bin and power supply & $\begin{array}{l}\text { Berkeley Nucleonics Corp. } \\
\text { Model AP-2 or AP-3 } \\
\text { or equivalent }\end{array}$ \\
\hline 1 & $\begin{array}{l}\text { High voltage power supply } \\
0-5000 \text { volts }\end{array}$ & $\begin{array}{l}\text { EG\&G Ortec } \\
\text { Mode1 } 456 \text { or equivalent }\end{array}$ \\
\hline 1 & Signal amplifier & $\begin{array}{l}\text { EG\&G Ortec } \\
\text { Model } 572 \text { or } 575 \mathrm{~A} \\
\text { or equivalent }\end{array}$ \\
\hline 1 & Scintillation preamplifier & $\begin{array}{l}\text { EG\&G Ortec } \\
\text { Model } 113 \text { or equivalent }\end{array}$ \\
\hline 1 & $\begin{array}{l}{ }^{6} \mathrm{LII}(E \mathrm{EU}) \text { detector and } \\
\text { photomultiplier }\end{array}$ & $\begin{array}{l}\text { Harshaw Chemical Co. } \\
\text { Mode1 2PA2-Q-1/2-X }\end{array}$ \\
\hline 1 & $\begin{array}{l}\text { Signal splitter box with } \\
\text { female SHV connector. and } \\
\text { female BNC connector }\end{array}$ & Tektronix Inc. \\
\hline 1 & $\begin{array}{l}\text { Coaxial signal cable } \\
2-\mathrm{ft}-1 \text { ong, } 93 \Omega \text {, } \\
\text { male BNC to male SHV }\end{array}$ & $\begin{array}{l}\text { Canberra Industries or } \\
\text { EG\&G Ortec or equivalent }\end{array}$ \\
\hline 1 & $\begin{array}{l}\text { Coaxial signal cable } \\
6-f t-7 \text { ong, } 93 \Omega \text {, } \\
\text { male BNC to BNC }\end{array}$ & $\begin{array}{l}\text { Canberra Industries or } \\
\text { EG\&G Ortec or equivalent }\end{array}$ \\
\hline 1 & $\begin{array}{l}\text { Coaxial signal cable } \\
50 \text { or } 100-\mathrm{ft}-1 \text { ong, } 93 \Omega \text {, } \\
\text { male BNC to BNC }\end{array}$ & $\begin{array}{l}\text { Canberra Industries or } \\
\text { EG\&G Ortec or equivalent }\end{array}$ \\
\hline 1 & $\begin{array}{l}\text { Preamplifier power cable } \\
50 \text { or } 100 \text {-ft-long } \\
\text { NIM Bin standard 9-pin } \\
\text { "D" connectors }\end{array}$ & $\begin{array}{l}\text { Canberra Industries or } \\
\text { EGGG Ortec or equivalent }\end{array}$ \\
\hline
\end{tabular}

(a) See PNL-6620, Vol. 3 (Brackenbush and Scherpelz 1990) for additional information. 
are provided in the document PNL-6620 Vo1. 3, Personnel Neutron Dose Assessment Uparade, Volume 3: Field Neutron Spectrometer with Mult isphere Detectors (Brackenbush et al. 1990).

A support stand is used to accurately position the multispheres at a fixed location. The support stand uses a series of concentric rings to ensure that the center of each sphere is located at the same position within $1 \mathrm{~mm}$. It also is used to accurately position the bare scintillator detector, and the detector with a cylindrical cadmium cover over the scintillator and light pipe. The support stand can be placed on top of a video camera tripod using a 1/4-20 screw thread tapped into the bottom of the support stand.

To use the support stand, place all of the rings into the plate on top. Position the 3-in. diameter sphere in the first ring, and insert the scintillator detector into the hole in the 3-in. diameter sphere. Then, snap the scintillator detector into the holder and begin the count. To use progressively larger spheres, remove a ring and repeat the process. The measurements for bare and cadmium-covered scintillator detectors can be made by placing the detector into the holder bracket provided. Use of this support stand considerably simplifies the multisphere measurement process because the user does not have to measure the distance and reposition the detector for each measurement.

\section{REFERENCES}

American National Standards Institute (ANSI). 1977. American National Standard Neutron and Gamma-Ray Flux-to-Dose-Rate Factors. ANSI/ANS-6.1.1, American Nuclear Society, LaGrange Park, Illinois.

Brackenbush, L. W., W. D. Reece, S. D. Miller, G. W. R. Endres, J. S. Durham, R. I. Scherpelz, and P. L. Tomeraasen. 1988. Personnel Neutron Dose Assessment Upgrade Volume 2: Field Neutron Spectrometer for Health Physics Applications. PNL-6620 Vol. 2, Pacific Northwest Laboratory, Richland, Washington.

Brackenbush, L. W., and R. I. Scherpelz. 1983. SPUNIT, A Computer Code for Multisphere Unfolding. PNL-SA-11645, Pacific Northwest Laboratory, Richland, Washington. 
Brackenbush, L.W., and R. I. Scherpelz. 1990. Personnel Neutron Dose Assessment Upgrade. Vol. 3: Field Neutron Spectrometer with Multisphere Detectors. PNL-6620, Vol. 3, Pacific Northwest Laboratory, Richland, Washington.

Bramblett, R. L., R. I. Ewing, and T. W. Bonner. 1960. "A New Type of Neutron Spectrometer." Nuclear Instruments and Methods 9:1-12.

Doroshenko, J. J., S. N. Kraitor, T. V. Kuznetsova, K. K. Kushnereva, and E. S. Lonov. 1977. "New Methods for Measuring Neutron Spectra with Energy from $0.4 \mathrm{eV}$ to $10 \mathrm{MeV}$ by Track and Activation Detectors." Nuclear Technology $33: 296-304$.

Hajna1, F. 1981. An Iterative Nonlinear Unfolding Code: TWOGO. DOE/EML-391, Environmental Measurements Laboratory, New York.

Herte1, N. E., and J. W. Davidson. 1984. "The Response of Bonner Spheres to Neutrons from Thermal Energies to $17.3 \mathrm{MeV} . "$ Nuclear Instruments and Methods in Physics Research A238:509-516.

Johnson, T. L., and S. G. Gorbics: 1981. "An Iterative Perturbation Method for Unfolding Neutron Spectra from Bonner Sphere Data." Health Physics $41(6): 859$.

Lowery, K. A., and T. L. Johnson. 1984. Modifications to Iterative Recursion Unfolding Algorithms and computer Codes to Find More Appropriate Neutron Spectra. NRL-5340, Nava7 Research Laboratory, Washington, D.C.

Miller, W. H., and W. Meyer. 1983. "Standardization of Neutron Spectrum Unfolding Codes: Tests Using Idealized, Calculated Response Functions." Nuclear Instruments and Methods 205:185-195.

National Council on Radiation Protection and Measurements (NCRP). 1971. Protection Against Neutron Radiation. NCRP Report No. 38, NCRP, Bethesda, Maryland.

Oster, C. A. 1977. Review of Unfolding Methods Used in the U. S. and The ir Standardization for Dosimetry. BNWL-SA-6503, Battelle, Pacific Northwest Laboratories, Richland, Washington.

Routi, J. T., and J. V. Sandberg. 1978. General Purpose Unfolding Program LOUH178 with Linear and Non-Linear Reqularization. Report TKK-/A359, Helsinki University of Technology, Department of Technical Physics, Otaniemi, Finland.

Sanna, R. S., and K. O'Brian. 1971. "Monte Carlo Unfolding of Neutron Spectra." Nuclear Instruments and Methods 91:573-576.

Sanna, R. S. 1976. Modification of an Iterative Code for Unfolding Neutron Spectra from Multisphere Data. HASL-311, Health and Safety Laboratory, Energy Research and Development Administration, New York, New York. 
Zaidins, C. S., J. B. Martin, and F. M. Edwards. 1978. "A Least-Squares

Technique for Extracting Neutron Spectra from Bonner Sphere Data." Medical Physics 5(1):42-47. 
4

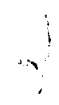

APPENDIX C

RAW DATA FROM TLD-ALBEDO DOSIMETERS 
APPENDIX C

RAW DATA FROM TLD-ALBEDO DOSIMETERS

This appendix includes the raw and analyzed data from the Hanford Multipurpose and Mound Laboratory TLD-albedo dosimeters, as well as the data from the electrochemically etched CR-39 track-etch dosimeters (TEDs). The data are included so that other algorithms for determining dose equivalent or effective dose can be tested. Also, it may be possible to evaluate past dosimeter algorithms using these data.

Each page includes information about the exposure (the neutron source, the irradiation geometry, time of irradiation, etc.) at the top of the page. The Hanford Multipurpose dosimeter results are then displayed, including the TLD reader counts for each of the five TLD chips. The reader counts corrected for gamma background are listed, as well as the ratio of TLD chip 3/chip 4 . The last three columns give the shallow and deep photon dose and the neutron dose equivalent in mrem.

The Mound badge results are given in the center of each page. This includes the TLD chip readings at each filter position and the dose equivalent evaluated in mrem for "shallow" and "deep" photons and the fast neutrons.

Finally, the results from the CR-39 track etch dosimeters (TEDs) are included at the bottom of the page. Three dosimeters are exposed at each position, and the average track density corrected for background is given in the third column. The dose equivalent for each dosimeter is given in column 4 and the average for the three TEDs is given in column 5 along with one standard deviation from counting statistics in column 6 . The coefficient of variation in percent is given in column 7 .

C. 1 
Californium Source 318-167

Bare at $50 \mathrm{~cm}$ for 2.73 Minutes

500.5 mrem Neutron Exposure

Ident. Seq. Adlusted Chio Counts

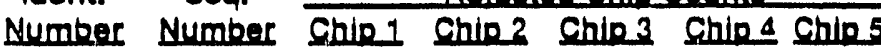

ED420 $\quad 14777 \quad 74 \quad 70$

ED421 $14776 \quad 70 \quad 72$

ED422 $14775 \quad 71 \quad 65$

ED423 $14829 \quad 72 \quad 78$

ED425 $11817 \quad 70$

ED429 $14824 \quad 80 \quad 70$

ED617 $14822 \quad 76$

ED618 $14790 \quad 74 \quad 79$

ED619 $14806 \quad 83 \quad 98$

ED620 $14807 \quad 76$

ED621 $14787 \quad 69$

$818 \quad 64$

$\begin{array}{lllllll}70 & 850 & 775 & 67 & 783 & 708 & 1.106\end{array}$

$\begin{array}{llllll}910 & 821 & 70 & 840 & 751 & 1.119\end{array}$

$812 \quad 859 \quad 61 \quad 751$ 1004 939 939 959

838 849 932 1037 893

$\begin{array}{ll}259 & 61 \\ 906 & 69\end{array}$

$821 \quad 66$

$860 \quad 68$

$785 \quad 68$

$757 \quad 64$

$864 \quad 74$

$824 \quad 67$

Average
935

873

891

770

785

858

970

829

844 $\begin{array}{ll}798 & 0.941\end{array}$

$837 \quad 1.117$

$755 \quad 1.156$

$792 \quad 1.125$

$717 \quad 1.074$

$693 \quad 1.133$

$790 \quad 1.086$

$757 \quad 1.281$

$754 \quad 1.099$

$759 \quad 1.112$
Badiation Dose in mrem

Shallow Deen Neutron

$30 \quad 30 \quad 310$

$30 \quad 30 \quad 330$

$30 \quad 30 \quad 350$

$40.40 \quad 370$

$30 \quad 30 \quad 330$

$40 \quad 30 \quad 350$

$30 \quad 30 \quad 310$

$30 \quad 30 \quad 300$

$50 \quad 50 \quad 350$

$30 \quad 30 \quad 330$

$30 \quad 30 \quad 330$

333

Mound Badae Resulte

$\begin{array}{lllllllllllll}\text { ED298 } & 14781 & 64 & 57 & 401 & 800 & 58 & 343 & 742 & 0.462 & 30 & 30 & 320 \\ \text { ED304 } & 14790 & 65 & 67 & 398 & 751 & 60 & 338 & 691 & 0.489 & 30 & 30 & 300 \\ \text { ED308 } & 14828 & 65 & 62 & 405 & 840 & 63 & 342 & 777 & 0.440 & 30 & 30 & 340 \\ \text { ED309 } & 14779 & 58 & 60 & 399 & 759 & 56 & 343 & 703 & 0.488 & 30 & 30 & 310 \\ \text { ED419 } & 14778 & 79 & 74 & 430 & 913 & 68 & 362 & 845 & 0.428 & 40 & 40 & 370 \\ & & & & & & \text { Average } & 346 & 752 & 0.461 & & 328\end{array}$

Cr-39 Besults

\begin{tabular}{|c|c|c|c|c|c|c|}
\hline DESCR & $\begin{array}{c}\text { Not } \\
\text { Irk/em }\end{array}$ & $\begin{array}{l}\text { Ave Net } \\
\text { Irk/am }\end{array}$ & mrem & $\begin{array}{c}\text { Average } \\
\text { mrem }\end{array}$ & $\begin{array}{c}\text { Standard } \\
\text { Dey }\end{array}$ & $\mathrm{cV}(\%)$ \\
\hline 2 & 2286 & & 406 & & & \\
\hline 2 & 2386 & & 423 & & & \\
\hline 2 & 2496 & 2388 & 443 & 424 & 18.5 & 4.4 \\
\hline 8 & 2731 & & 485 & & & \\
\hline 8 & 2355 & & 418 & & & \\
\hline 8 & 2618 & 2464 & 465 & 456 & 34.4 & 7.5 \\
\hline 9 & 2906 & & 516 & & & \\
\hline 9 & 2871 & & 510 & & & \\
\hline \multirow[t]{2}{*}{9} & 2984 & 2920 & 530 & 519 & 10.3 & 2.0 \\
\hline & Average & 2590 & & 466 & 46.3 & 9.90 \\
\hline
\end{tabular}

39105051.1

C.2 
Californium Source 318-167

$1.27 \mathrm{~cm}$ of $\mathrm{PL}^{*}$ at $50 \mathrm{~cm}$ for 6.45 Minutes

1017 mrem Neutron Exposure

Ident. Seq. Adlusted Chip Counts

ED165 $9139 \quad 154 \quad 130$

$\begin{array}{lllll}\text { ED166 } & 9138 & 131 & 119 & 2896\end{array}$

$\begin{array}{lllll}E 0203 & 9136 & 124 & 137 & 2536\end{array}$

ED204 $9131 \quad 129 \quad 112 \quad 2667$

$\begin{array}{lllll}\text { ED205 } & 9130 & 135 & 125 & 2803\end{array}$

$\begin{array}{lllll}\text { ED206 } & 9129 & 138 & 126 & 2838\end{array}$

$\begin{array}{lllll}\text { ED208 } & 9128 & 131 & 127 & 2540\end{array}$

$\begin{array}{lllll}\text { ED210 } & 9132 & 132 & 152 & 2336\end{array}$

$\begin{array}{lllll}E D 212 & 9133 & 127 & 128 & 2768\end{array}$

$\begin{array}{lllll}\text { ED229 } & 9134 & 132 & 127 & 2854\end{array}$

ED231
Number Number Chind Chin2 Chin3 Chios Chin 5
9135
$124 \quad 116 \quad 2648$

\section{$2757 \quad 127$}

$2502 \quad 127$

$2246 \quad 121$

$2513 \quad 128$

$2421 \quad 126$

$2257 \quad 132$

$2271 \quad 127$

$2138 \quad 121$

$2388 \quad 124$

$2324 \quad 126$

$2281 \quad 118$

Average
B3-85

2461

2769

2415

2539

2677

2706

2413

22

264

272

2530

2554
B4-R5 B3/R4

$2630 \quad 0.936$

23751.166

$2125 \quad 1.136$

$2385 \quad 1.065$

$2295 \quad 1.166$

$2125 \quad 1.273$

$2244 \quad 1.075$

$2017 \quad 1.098$

$2264 \quad 1.168$

$2198 \quad 1.241$

$2163 \quad 1.170$

$2256 \quad 1.136$
Badiation Dose in mrem

Shallow Deen Neutron

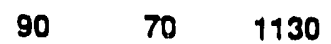

$80 \quad 70 \quad 1040$

$80 \quad 80 \quad 930$

$80 \quad 70 \quad 1040$

$80 \quad 70 \quad 1000$

$80 \quad 70 \quad 930$

$70 \quad 70 \quad 930$

$80 \quad 80 \quad 880$

$70 \quad 70 \quad 990$

$70 \quad 70 \quad 960$

$70 \quad 60 \quad 940$

979

Mound Badae Besults

$\begin{array}{lllllllllllll}\text { ED414 } & 9144 & 132 & 114 & 1078 & 1888 & 113 & 965 & 1775 & 0.544 & 80 & 70 & 770 \\ \text { ED142 } & 9143 & 124 & 116 & 1139 & 2401 & 126 & 1013 & 2275 & 0.445 & 70 & 70 & 990 \\ \text { ED143 } & 9142 & 119 & 110 & 1180 & 2327 & 117 & 1063 & 2210 & 0.481 & 70 & 70 & 960 \\ \text { ED154 } & 9141 & 129 & 125 & 1173 & 2412 & 119 & 1054 & 2293 & 0.460 & 70 & 70 & 990 \\ \text { ED160 } & 9140 & 122 & 118 & 1210 & 2361 & 120 & 1090 & 2241 & 0.449 & 70 & 70 & 970 \\ & & & & & & \text { Average } & 1037 & 2159 & 0.476 & & & 936\end{array}$

Cr-39 Results

\begin{tabular}{|c|c|c|c|c|c|c|}
\hline DESCB & $\begin{array}{c}\text { Net } \\
\text { Irk/em }\end{array}$ & $\begin{array}{l}\text { Average } \\
\text { Irk/am }\end{array}$ & mrem & $\begin{array}{c}\text { Average } \\
\text { mrem }\end{array}$ & $\begin{array}{c}\text { Standard } \\
\text { Deve } \\
\end{array}$ & CV (\%) \\
\hline F6 & 2603 & & 1041 & & & \\
\hline F6 & 2498 & & 999 & & & \\
\hline F6 & 2593 & 2564 & 1037 & 1026 & 23.0 & 2.3 \\
\hline $\boldsymbol{F}$ & 2413 & & 965 & & & \\
\hline$F$ & 2360 & & 944 & & & \\
\hline$F$ & 2118 & 2297 & 847 & 919 & 63.0 & 6.9 \\
\hline F8 & 2333 & & 993 & & & \\
\hline F8 & 2488 & & 995 & & & \\
\hline F8 & 2210 & 2337 & 884 & 935 & 63.5 & 6.6 \\
\hline $\mathbf{F g}$ & 2605 & & 1042 & & & \\
\hline F9 & 2243 & & 897 & & & \\
\hline \multirow[t]{2}{*}{ F9 } & 2385 & 2411 & 954 & 964 & & \\
\hline & liverage & 2402 & & 967 & 64.2 & 6.7 \\
\hline
\end{tabular}

"Where PL is Acrylic Plastic 
Californium Source 318-167

$2.54 \mathrm{~cm}$ of PL" at $50 \mathrm{~cm}$ for 7.04 Minutes 996 mrem Neutron Exposure

\begin{tabular}{|c|c|c|c|c|c|c|c|c|c|c|c|c|}
\hline \multirow{2}{*}{$\begin{array}{l}\text { Ident. } \\
\text { Number }\end{array}$} & \multirow{2}{*}{$\begin{array}{l}\text { Seq. } \\
\text { Number }\end{array}$} & \multicolumn{5}{|c|}{ Adlusted Chio Counts } & \multirow[b]{2}{*}{$\mathrm{B} 3 \cdot \mathrm{RS}$} & \multirow[b]{2}{*}{ B4-B5 } & \multirow[b]{2}{*}{ B3/B4 } & \multicolumn{3}{|c|}{ Badiatlon Doge in mrem } \\
\hline & & Chion & Chio2 & Chio3 & Chin 4 & Chio 5 & & & & Shallow & Deen & Neutron \\
\hline ED232 & 9127 & 136 & 121 & 3820 & 3284 & 131 & 3689 & 3133 & 1.177 & 80 & 70 & 1370 \\
\hline ED233 & 9126 & 142 & 139 & 3803 & 3165 & 132 & 3671 & 3033 & 1210 & 80 & 80 & 1330 \\
\hline ED235 & 9125 & 143 & 131 & 4352 & 3623 & 132 & 4220 & 3491 & 1.209 & 80 & 70 & 1530 \\
\hline ED236 & 9124 & 148 & 146 & 3524 & 2900 & 143 & 3381 & 2757 & 1226 & 80 & 80 & 1210 \\
\hline ED237 & 9123 & 159 & 123 & 3568 & 3118 & 138 & 3430 & 2980 & 1.151 & 100 & 80 & 1300 \\
\hline ED238 & 9121 & 139 & 128 & 4282 & 3679 & 133 & 4149 & 3546 & 1.170 & 80 & 70 & 1550 \\
\hline ED239 & 9120 & 136 & 128 & 4276 & 3498 & 138 & 4038 & 3355 & 1.204 & 80 & 80 & 1470 \\
\hline ED241 & 9119 & 137 & 171 & 3492 & $30 \pi$ & 131 & 3361 & 2946 & 1.141 & 100 & 100 & 1280 \\
\hline ED255 & 9113 & 134 & 129 & 3654 & 3004 & 133 & 3521 & 2963 & 1.188 & 80 & 70 & 1290 \\
\hline ED256 & 9112 & 141 & 124 & 3704 & 3152 & 128 & 3576 & 3024 & 1.983 & 80 & 70 & 1320 \\
\hline \multirow[t]{2}{*}{ ED257 } & 9111 & 128 & 119 & 3753 & 2887 & 124 & 3629 & 2763 & 1.313 & 70 & 70 & 1210 \\
\hline & \multicolumn{6}{|r|}{ Average } & 3697 & 3090 & 1.196 & & & 1351 \\
\hline \multicolumn{13}{|c|}{ Mound Badoe Beaulte } \\
\hline ED243 & 9118 & 148 & 132 & 1715 & 3100 & 134 & 1581 & 2969 & 0.533 & 80 & 70 & 1290 \\
\hline ED244 & 9117 & 153 & 145 & 1826 & 3287 & 146 & 1680 & 3441 & 0.535 & 90 & 80 & 1360 \\
\hline ED245 & 9116 & 136 & 131 & 1828 & 3010 & 133 & 1695 & 2877 & 0.589 & 80 & 70 & 1250 \\
\hline ED251 & 9115 & 145 & 133 & 1847 & 3601 & 136 & 1681 & 3465 & 0.485 & 80 & 80 & 1500 \\
\hline \multirow[t]{2}{*}{ ED254 } & 9114 & 134 & 127 & 1721 & 2785 & 135 & 1586 & 2650 & 0.598 & 80 & 80 & 1150 \\
\hline & \multicolumn{6}{|r|}{ Average } & 1645 & 3020 & 0.548 & & & 1310 \\
\hline
\end{tabular}

\section{Cr-39 Results}

\begin{tabular}{|c|c|c|c|c|c|c|}
\hline DESCB & $\begin{array}{c}\text { Not } \\
\text { Int } / \mathrm{em}^{2}\end{array}$ & $\begin{array}{l}\text { Aversge } \\
\text { Irk/am }^{2}\end{array}$ & mrem & $\begin{array}{c}\text { Average } \\
\text { mram }\end{array}$ & $\begin{array}{c}\text { Standard } \\
\text { Dey }\end{array}$ & $\operatorname{cr}(\%)$ \\
\hline F10 & 2150 & & 860 & & & \\
\hline F10 & 2240 & & 896 & & & \\
\hline F10 & 2040 & 2143 & 816 & 857 & 40.1 & 4.7 \\
\hline F11 & 2028 & & 811 & & & \\
\hline F11 & 2350 & & 940 & & & \\
\hline F11 & 2338 & 2237 & 933 & 895 & 72.5 & 8.1 \\
\hline $\mathrm{F} 12$ & 2493 & & 997 & & & \\
\hline F12 & 2260 & & 904 & & & \\
\hline F12 & 2373 & 2375 & 949 & 950 & 46.5 & 4.9 \\
\hline F13 & 2358 & & 943 & & & \\
\hline F13 & 2248 & & 899 & & & \\
\hline \multirow[t]{2}{*}{$F_{13}$} & 2080 & 2228 & 832 & 891 & 55.9 & 6.3 \\
\hline & Average & 2246 & & 898 & 58.4 & 6.5 \\
\hline
\end{tabular}

"Where PL is Acrylic Plastic

Adiustent Chip Count

hion Chins Chind Chios$$
1645
$$

Badiation Doge in mrem

1330

300

1550

40

290

1320

210

39105051.3 
Californium Source 318-167

$5.08 \mathrm{~cm}$ of PL* at $50 \mathrm{~cm}$ for 4.55 Minutes

529 mrem Neutron Exposure

Ident. Seq. Adiusted Chip Counts

Number Number Chip 1 Chip2 Chip 3 Chips Chip

$\begin{array}{lllllll}\text { ED552 } & 14798 & 92 & 86 & 3062 & 2521 & 82\end{array}$

$\begin{array}{lllllll}E D 553 & 14789 & 85 & 83 & 3166 & 2249 & 81\end{array}$

$\begin{array}{lllllll}E D 627 & 14784 & 108 & 106 & 3766 & 2466 & 93\end{array}$

$\begin{array}{lllllll}\text { ED628 } & 14823 & 101 & 97 & 4316 & 2568 & 95\end{array}$

$\begin{array}{llllllll}E D 629 & 14785 & 108 & 99 & 3595 & 2336 & 97\end{array}$

$\begin{array}{lllllll}E D 630 & 14805 & 101 & 99 & 3916 & 2505 & 96\end{array}$

$\begin{array}{lllllll}\text { ED631 } & 14804 & 103 & 109 & 4074 & 2805 & 101\end{array}$

$\begin{array}{lllllll}E D 632 & 14803 & 109 & 117 & 4482 & 3211 & 95\end{array}$

$\begin{array}{lllllll}\text { ED633 } & 14802 & 106 & 405 & 3331 & 2783 & 92\end{array}$

$\begin{array}{lllllll}E D 634 & 14800 & 116 & 116 & 3970 & 2730 & 112\end{array}$

ED635
3657
B3-B5 B4-R5 B3/R4

$2980 \quad 2439 \quad 1.222$

$\begin{array}{lll}3085 & 2168 & 1.423\end{array}$

$\begin{array}{lll}3673 & 2374 & 1.548\end{array}$

$4221 \quad 2473 \quad 1.707$

$3498 \quad 2239 \quad 1.562$

$\begin{array}{lll}3820 & 2409 \quad 1.586\end{array}$

$\begin{array}{lll}3974 & 2704 & 1.497\end{array}$

$4387 \quad 3116 \quad 1.408$

$\begin{array}{lll}3239 & 2691 & 1206\end{array}$

$\begin{array}{lll}3858 & 2618 & 1.474\end{array}$

$\begin{array}{lll}3553 & 2449 & 1.451\end{array}$
Radiation Dose in mrem

Shallow Deep Neutron

$40 \quad 40 \quad 1070$

$40 \quad 40 \quad 960$

$50 \quad 50 \quad 1050$

$50 \quad 50 \quad 1110$

$50 \quad 50 \quad 1000$

$50 \quad 50 \quad 1070$

$50 \quad 50 \quad 1200$

$60 \quad 60 \quad 1380$

50 so 1180

$60 \quad 60 \quad 1160$

$90.90 \quad 1080$

$$
\begin{array}{llll}
\text { Average } 3663 \quad 2516 & 1.462
\end{array}
$$

Mound Badge Results

\begin{tabular}{|c|c|c|c|c|c|c|}
\hline DESCR & $\begin{array}{c}\text { Not } \\
\text { Irk/em² }\end{array}$ & $\begin{array}{l}\text { Average } \\
\text { Ink/ } \mathrm{cm}^{2}\end{array}$ & mrem & $\begin{array}{c}\text { Average } \\
\text { mrem }\end{array}$ & $\begin{array}{c}\text { Standard } \\
\text { Dey }\end{array}$ & Siv $(\%)$ \\
\hline 3 & 2666 & & 474 & & & \\
\hline 3 & 2491 & & 442 & & & \\
\hline 3 & 2498 & 2552 & 444 & 453 & 18.5 & 4.1 \\
\hline 6 & 2731 & & 485 & & & \\
\hline 6 & 2944 & & 523 & & & \\
\hline 6 & 2856 & 2844 & 507 & 505 & 19.1 & 3.8 \\
\hline 7 & 2573 & & 457 & & & \\
\hline 7 & 2786 & & 495 & & & \\
\hline \multirow[t]{2}{*}{7} & 2421 & 2593 & 430 & 461 & 32.7 & 7.0 \\
\hline & Average & 2663 & & 473 & 32.0 & 6.8 \\
\hline
\end{tabular}

$\begin{array}{rrrrrrrrrrrrr}\text { ED622 } & 14830 & 100 & 97 & 1860 & 2514 & 98 & 1762 & 2416 & 0.729 & 50 & 50 & 1050 \\ \text { ED623 } & 14790 & 109 & 99 & 2300 & 2779 & 101 & 2199 & 2678 & 0.821 & 50 & 50 & 1170 \\ \text { ED624 } & 14788 & 107 & 103 & 1838 & 2588 & 97 & 1741 & 2491 & 0.699 & 50 & 50 & 1080 \\ \text { ED625 } & 14810 & 106 & 113 & 2188 & 2622 & 103 & 2085 & 2519 & 0.828 & 50 & 50 & 1100 \\ \text { ED626 } & 14797 & 108 & 101 & 1763 & 2310 & 99 & 1664 & 2211 & 0.753 & 50 & 50 & 960 \\ & & & & & & \text { Average } & 1890 & 2463 & 0.766 & & 1072\end{array}$

\section{Cr-39Results}

Where PL is Acrylic Plastlc
39105051.4 
Californium Source 318-167

$10.16 \mathrm{~cm} \mathrm{PL*}$ at $50 \mathrm{~cm}$ for 7.44 Minutes

448 mrem Neutron Exposure

Ident. Seq. Adiusted Chip Counts

Number Number Chip1 Chip2 Chip3 Chip4 Chip5 B3-R5 B4-R5 B3/R4

$\begin{array}{llllllllll}\text { ED533 } & 17519 & 101 & 100 & 4238 & 2484 & 99 & 4139 & 2385 & 1.735\end{array}$

$\begin{array}{llllllllll}\text { ED534 } & 17518 & 116 & 114 & 4529 & 2796 & 96 & 4433 & 2700 & 1.642\end{array}$

$\begin{array}{lllllll}\text { ED535 } & 17517 & 118 & 117 & 4283 & 2961 & 111\end{array}$

$\begin{array}{lllllll}\text { ED544 } & 17507 & 111 & 105 & 4739 & 2866 & 103\end{array}$

$\begin{array}{lllllll}\text { ED545 } & 17506 & 119 & 123 & 4889 & 2869 & 110\end{array}$

ED546 $17505 \quad 116 \quad 110$

ED547 $\quad 17504 \quad 110 \quad 106$

ED548 $17503 \quad 104 \quad 104$

ED549 $17502 \quad 110 \quad 166$

ED550 $17501 \quad 113 \quad 112$

ED551 $17500 \quad 104 \quad 103$

$5262 \quad 3288 \quad 118$

$\begin{array}{lll}4710 & 2457 \quad 99\end{array}$

$\begin{array}{lll}4179 & 2492 \quad 97\end{array}$

$4374 \quad 2614 \quad 106$

$4601 \quad 2714 \quad 107$.

4360

$2621 \quad 97$
$41822850 \quad i . ₹ 67$

$\begin{array}{lll}4636 & 2763 \quad 1.678\end{array}$

$4779 \quad 2759 \quad 1.732$

$5144 \quad 3170 \quad 1.623$

$4611 \quad 2358 \quad 1.355$

$4082 \quad 2395 \quad 1.704$

$\begin{array}{lll}4268 & 2608 \quad 1.637\end{array}$

$4494 \quad 2607 \quad 1.724$

$\begin{array}{llll}4263^{\circ} & 2524 & 1.689\end{array}$
Badiation Dose in mrem

Shallow Deen Neutron

$50 \quad 50 \quad 1070$

$50 \quad 50 \quad 1200$

$60 \quad 60 \quad 1260$

$50 \quad 50 \quad 1230$

$60 \quad 60 \quad 1240$

$60 \quad 60 \quad 1410$

$50 \quad 50 \quad 1060$

$50 \quad 50 \quad 1070$

$90 \quad 90 \quad 1120$

$50 \quad 50 \quad 1170$

$50 \quad 50 \quad 1130$

$44572647 \quad 1.690$

\section{Mound Badge Results}

$\begin{array}{lllllllllllll}\text { ED532 } & 17520 & 111 & 117 & 2544 & 2764 & 117 & 2527 & 2647 & 0.955 & 60 & 60 & 1150 \\ \text { ED557 } & 17524 & 130 & 124 & 2398 & 2507 & 119 & 2279 & 2398 & 0.950 & 60 & 60 & 1040 \\ \text { ED571 } & 17523 & 132 & 129 & 2518 & 2902 & 114 & 2404 & 2788 & 0.862 & 60 & 60 & 1210 \\ \text { ED572 } & 17522 & 116 & 113 & 2693 & 2938 & 105 & 2588 & 2833 & 0.914 & 60 & 50 & 1230 \\ \text { ED573 } & 17521 & 112 & 120 & 2576 & 2637 & 113 & 2463 & 2524 & 0.976 & 60 & 60 & 1100 \\ & & & & & & \text { Average } & 2452 & 2638 & 0.931 & & & 1146\end{array}$

Cr-39 Results

\begin{tabular}{|c|c|c|c|c|c|c|}
\hline DESCR & $\begin{array}{c}\text { Net } \\
\text { Irk/cm }\end{array}$ & $\begin{array}{l}\text { Ave Net } \\
\text { Irk/em }\end{array}$ & mrem & $\begin{array}{c}\text { Average } \\
\text { mrem }\end{array}$ & $\begin{array}{c}\text { Standard } \\
\text { Dev }\end{array}$ & $\mathrm{CV}(\%)$ \\
\hline 20 & 2369 & & 421 & & & \\
\hline 20 & 2169 & & 385 & & & \\
\hline 20 & 2576 & 2371 & 458 & 421 & 36.5 & 8.7 \\
\hline
\end{tabular}


Californium Source 318-167

$15.24 \mathrm{~cm}$ of $\mathrm{PL}^{*}$ at $50 \mathrm{~cm}$ for 27.3 Minutes

774 mrem Neutron Exposure

\begin{tabular}{|c|c|c|c|c|c|c|c|c|c|c|c|c|}
\hline \multirow{2}{*}{$\begin{array}{l}\text { Ident. } \\
\text { Numbar }\end{array}$} & \multirow{2}{*}{$\begin{array}{c}\text { Seq. } \\
\text { Number }\end{array}$} & \multicolumn{5}{|c|}{ Adiusted Chin Counts } & \multirow[b]{2}{*}{$B 3-85$} & \multirow[b]{2}{*}{$B 4-B 5$} & \multirow[b]{2}{*}{ B3/BA 4} & \multicolumn{3}{|c|}{ Badiation Dose in mrem } \\
\hline & & Chio 1 & Chip 2 & Chin 3 & Chip 4 & Chip 5 & & & & Shallow & Deeg & Neutron \\
\hline ED560 & 14818 & 342 & 335 & $1: 319$ & 6891 & 326 & 10993 & 6566 & 1.674 & 200 & 200 & 2920 \\
\hline ED361 & 14819 & 320 & 315 & 11113 & 5890 & 306 & 10808 & 5585 & 1.935 & 190 & 180 & 2520 \\
\hline ED561 & 14820 & 308 & 326 & 19182 & 6427 & 310 & 10872 & 6117 & $1.7 \pi 7$ & 190 & 190 & 2750 \\
\hline ED563 & 14821 & 321 & 308 & 11284 & 6793 & 301 & 10983 & 6492 & 1.692 & 190 & 180 & 2930 \\
\hline ED564 & 14813 & 330 & 322 & 11284 & 7042 & 318 & 10966 & 6724 & 1.631 & 190 & 190 & 3030 \\
\hline ED565 & 14814 & 350 & 331 & 11271 & 7416 & 330 & 10941 & 7086 & 1.544 & 210 & 190 & 3170 \\
\hline ED566 & 14815 & 335 & 316 & 11243 & 7175 & 307 & 10936 & 6866 & 1.592 & 200 & 180 & 3080 \\
\hline ED567 & 14808 & 314 & 304 & 11151 & 6192 & 329 & 10822 & 5863 & 1.846 & 190 & 190 & 2640 \\
\hline ED568 & 14811 & 357 & 304 & 11098 & 6038 & 322 & 10776 & 5716 & 1.875 & 220 & 190 & 2570 \\
\hline ED569 & 14812 & 334 & 488 & 11081 & 6159 & 306 & 10775 & 5853 & 1.841 & 280 & 280 & 2630 \\
\hline 0570 & 14809 & 336 & 314 & 9905 & 4614 & 312 & 9593 & 4302 & 2.230 & 200 & 180 & 1960 \\
\hline & & & & & & Average & 10770 & 6107 & 1.785 & & & 2745 \\
\hline
\end{tabular}

Mound Badae Results

$\begin{array}{lllllllllllll}\text { ED554 } & 14795 & 301 & 297 & 5798 & 5431 & 276 & 5522 & 4855 & 1.138 & 170 & 170 & 2250 \\ \text { ED555 } & 14794 & 329 & 316 & 6608 & 5493 & 304 & 6304 & 5189 & 1.215 & 190 & 180 & 2280 \\ \text { ED556 } & 14793 & 322 & 320 & 5672 & 5521 & 297 & 5375 & 5224 & 1.029 & 190 & 190 & 2280 \\ \text { ED558 } & 14792 & 367 & 376 & 8391 & 7627 & 346 & 8045 & 7281 & 1.105 & 220 & 220 & 3180 \\ \text { ED559 } & 14791 & 357 & 369 & 6510 & 5906 & 340 & 6170 & 5566 & 1.109 & 220 & 220 & 2430 \\ & & & & & & \text { Average } & 6283 & 5623 & 1.119 & & & 2484\end{array}$

Cr-39 Results

\begin{tabular}{|c|c|c|c|c|c|c|}
\hline DESCB & $\begin{array}{c}\text { Net } \\
\text { Ink/em }\end{array}$ & $\begin{array}{l}\text { Average } \\
\text { Irk/am }\end{array}$ & mrem & $\begin{array}{c}\text { Average } \\
\text { mrem }\end{array}$ & $\begin{array}{c}\text { Standard } \\
\text { Dev } \\
\end{array}$ & CV $(\%)$ \\
\hline 1 & 3416 & & 607 & & & \\
\hline 1 & 3446 & & 612 & & & \\
\hline 1 & 3458 & 3440 & 614 & 611 & 3.6 & 0.6 \\
\hline 10 & 3043 & & 540 & & & \\
\hline 10 & 3556 & & 632 & & & \\
\hline 10 & 3393 & 3331 & 603 & 592 & 47.0 & 8.0 \\
\hline 11 & 2958 & & 525 & & & \\
\hline 11 & 2776 & & 493 & & & \\
\hline \multirow[t]{2}{*}{11} & 3693 & 3142 & 656 & 558 & 86.4 & 15.5 \\
\hline & Average & 3311 & & 587 & 54.4 & 9.3 \\
\hline
\end{tabular}

"Where PL is Acrylic Plastic 
Californium Source 318-167

D20 Moderated at $50 \mathrm{~cm}$ for 24.31 Minutes

1000 mrem Neutron Exposure

\begin{tabular}{|c|c|c|c|c|c|c|c|c|c|c|c|c|}
\hline \multirow{2}{*}{$\begin{array}{l}\text { Ident. } \\
\text { Number }\end{array}$} & \multirow{2}{*}{$\begin{array}{l}\text { Seq. } \\
\text { Number }\end{array}$} & \multicolumn{5}{|c|}{ Adiusted Chin Counts } & \multicolumn{6}{|c|}{ Badlation Dose in mrem } \\
\hline & & Chip 1 & Chin 2 & Chin 3 & Chio 4 & Chin 5 & $\mathrm{B3}-\mathrm{B5}$ & B4-85 & B3/R4 & Shallow & Deen & Neutron \\
\hline ED121 & 9163 & 277 & 300 & 11125 & 11010 & 322 & 10830 & 10688 & 1.011 & 200 & 200 & 4260 \\
\hline ED122 & 9164 & 318 & 322 & 11405 & 11261 & 337 & 11068 & 10924 & 1.013 & 210 & 210 & 5340 \\
\hline ED123 & 9154 & 373 & 310 & 11276 & 11155 & 334 & 10942 & 10821 & 1.011 & 200 & 200 & 4880 \\
\hline ED124 & 9153 & 303 & 302 & 11311 & 11291 & 337 & 10974 & 10954 & 1.002 & 210 & 210 & 5450 \\
\hline ED128 & 9151 & 326 & 326 & 11350 & 11250 & 378 & 10972 & 10872 & 1.009 & 230 & 230 & 5270 \\
\hline ED130 & 9150 & 322 & 329 & 11326 & 11220 & 342 & 10984 & 10878 & 1.010 & 210 & 210 & 5160 \\
\hline ED133 & 9149 & 309 & 310 & 11289 & 17204 & 331 & $4 n 958$ & 10874 & 1.008 & 200 & 200 & 5090 \\
\hline ED135 & 9148 & $3: 6$ & 471 & 11392 & 11260 & 353 & 11039 & 10907 & 1.012 & 280 & 280 & 5330 \\
\hline ED136 & 9147 & 335 & 339 & 11234 & 11145 & 358 & 10876 & 10787 & 1.008 & 220 & 220 & 4820 \\
\hline ED137 & 9146 & 320 & 333 & 11335 & 11163 & 345 & 10990 & 10818 & 1.016 & 210 & 210 & 4920 \\
\hline ED139 & 9145 & 297 & 309 & 11170 & 11062 & 323 & 10847 & 10739 & 1.010 & 200 & 200 & 4480 \\
\hline & & & & & & Average & 10950 & 10842 & 1.010 & & & 5000 \\
\hline
\end{tabular}

Mound Badge Results

$\begin{array}{lllllllllllll}\text { ED112 } & 9155 & 331 & 322 & 5645 & 11013 & 362 & 5283 & 10651 & 0.496 & 220 & 220 & 4230 \\ \text { ED114 } & 9156 & 339 & 349 & 6176 & 11307 & 386 & 5790 & 10921 & 0.530 & 240 & 240 & 5500 \\ \text { ED115 } & 9160 & 331 & 332 & 6337 & 11172 & 376 & 5961 & 10796 & 0.552 & 230 & 230 & 4920 \\ \text { ED118 } & 9161 & 329 & 342 & 6339 & 11227 & 361 & 5978 & 10866 & 0.550 & 220 & 220 & 5160 \\ \text { ED120 } & 9162 & 327 & 324 & 6426 & 11180 & 346 & 6080 & 10834 & 0.561 & 210 & 210 & 4960 \\ & & & & & & \text { Average } & 5818 & 10814 & 0.538 & & 4954\end{array}$

Cr-39 Results

\begin{tabular}{|c|c|c|c|c|c|c|}
\hline DESCR & $\begin{array}{c}\text { Net } \\
\text { Irk/am }\end{array}$ & $\begin{array}{l}\text { Average } \\
\text { Irk/em² }\end{array}$ & mrem & $\begin{array}{c}\text { Average } \\
\text { mrem }\end{array}$ & $\begin{array}{c}\text { Standard } \\
\text { Dev }\end{array}$ & $\operatorname{cV}(\%)$ \\
\hline$F 1$ & 2218 & & 887 & & & \\
\hline $\mathbf{F 1}$ & 2268 & & 907 & & & \\
\hline$F 1$ & 2348 & 2278 & 939 & 911 & 26.2 & 2.9 \\
\hline$F 2$ & 2140 & & 856 & & & \\
\hline F2 & 2315 & & 926 & & & \\
\hline F2 & 2203 & 2219 & 881 & 888 & 35.5 & 4.0 \\
\hline F3 & 2483 & & 993 & & & \\
\hline F3 & 2525 & & 1010 & & & \\
\hline F3 & 2610 & 2539 & 1044 & 1016 & 25.0 & 2.6 \\
\hline$F 4$ & 2570 & & 1028 & & & \\
\hline$F 4$ & 2380 & & 952 & & & \\
\hline \multirow[t]{2}{*}{ F4 } & 2488 & 2479 & 995 & 992 & 38.1 & 3.8 \\
\hline & Average & 2379 & & 952 & 62.15 & 6.5 \\
\hline
\end{tabular}


Plutonium Fiuoride Source

Bare at $50 \mathrm{~cm}$ for 76.04 Hours

1683 mrem Neutron Exposure

\begin{tabular}{|c|c|c|c|c|c|c|c|c|c|c|c|c|}
\hline Ident. & Seq. & & Adiuss & ad Chip & Sounts & & & & & Badiatio & Dose & in mrem \\
\hline Number & Number & Chip 1 & Chip 2 & Chin 3 & Chip 4 & Chin 5 & B3-R5 & B4-A5 & $\mathrm{B} 3 / \mathrm{R4}$ & Shallow & Deep & Neutron \\
\hline ED238 & 1815 & 447 & 399 & 3275 & 3013 & 266 & 3009 & 2747 & 1.095 & 260 & 240 & 1200 \\
\hline ED239 & 1817 & 439 & 399 & 3476 & 3101 & 289 & 3187 & 2812 & 1.133 & 250 & 240 & 1230 \\
\hline ED240 & 1819 & 446 & 427 & 4115 & 3565 & 292 & 3823 & 3272 & 1.168 & 260 & 260 & 1430 \\
\hline ED241 & 1827 & 460 & 425 & 3100 & 2803 & 274 & 2826 & 2529 & 1.117 & 260 & 250 & 1100 \\
\hline ED243 & 1828 & 415 & 377 & 2882 & 2579 & 258 & 2624 & 2321 & 1.131 & 230 & 220 & 1010 \\
\hline ED292 & 1807 & 401 & 384 & 3303 & 2938 & 265 & 3038 & 2673 & 1.137 & 230 & 230 & 1170 \\
\hline ED450 & 1811 & 493 & 469 & 4341 & 3655 & 341 & 4000 & 3292 & 1.215 & 290 & 290 & 1450 \\
\hline ED451 & 1813 & 454 & 496 & 3669 & 3497 & 313 & 3356 & 3184 & 1.054 & 300 & 300 & 1380 \\
\hline ED536 & 1816 & 402 & 389 & 3324 & 2760 & 256 & 3068 & 2504 & 1.225 & 230 & 230 & 1100 \\
\hline ED537 & 1818 & 388 & 389 & 3203 & 2648 & 254 & 2949 & 2394 & 1.232 & 230 & 230 & 1050 \\
\hline ED538 & 1826 & 367 & 367 & 2800 & 2431 & 240 & 2560 & 2190 & 1.169 & 220 & 220 & 960 \\
\hline & & & & & & Average & 3131 & 2720 & 1.152 & & & 1189 \\
\hline
\end{tabular}

Mound Badoe Results

$\begin{array}{lllllllllllll}\text { ED532 } & 1812 & 450 & 421 & 1496 & 2919 & 304 & 1192 & 2615 & 0.456 & 260 & 260 & 1130 \\ \text { ED533 } & 1810 & 432 & 402 & 1451 & 2987 & 285 & 1166 & 2702 & 0.432 & 250 & 240 & 1170 \\ \text { ED534 } & 1806 & 432 & 408 & 1306 & 2694 & 274 & 1032 & 2420 & 0.426 & 250 & 250 & 1050 \\ \text { ED535 } & 1814 & 447 & 413 & 1320 & 2933 & 280 & 1040 & 2653 & 0.392 & 260 & 250 & 1150 \\ & & & & & & \text { Average } & 1108 & 2598 & 0.427 & & & 1125\end{array}$

Cr-39 Results

\begin{tabular}{|c|c|c|c|c|c|c|}
\hline DESCR & $\begin{array}{c}\text { Net } \\
I n k / \mathrm{em}^{2}\end{array}$ & $\begin{array}{l}\text { Ave Net } \\
\text { Irk/am }\end{array}$ & mrem & $\begin{array}{c}\text { Average } \\
\text { mrem }\end{array}$ & $\begin{array}{c}\text { Standard } \\
\text { Dev }\end{array}$ & cv $(\%)$ \\
\hline A9 & 4274 & & 1716 & & & \\
\hline A9 & 4084 & & 1640 & & & \\
\hline A9 & 4114 & 4157 & 1652 & 1670 & 40.9 & 2.5 \\
\hline A10 & 4094 & & 1644 & & & \\
\hline A10 & 4434 & & 1781 & & & \\
\hline A10 & 4309 & 4279 & 1731 & 4718 & 69.3 & 4.0 \\
\hline A11 & 3986 & & 1601 & & & \\
\hline A11 & 4297 & & 1726 & & & \\
\hline A11 & 4222 & 4168 & 1695 & 1674 & 65.1 & 3.9 \\
\hline A12 & 3724 & & 1496 & & & \\
\hline A12 & 3959 & & 1590 & & & \\
\hline \multirow[t]{2}{*}{ A12 } & 4397 & 4027 & 1766 & 1617 & 137 & 8.5 \\
\hline & Average & 4158 & & 1670 & 82.3 & 4.9 \\
\hline
\end{tabular}

39105051.8

C.9 
Plutonium Fluoride Source

$2.54 \mathrm{~cm} \mathrm{PL*}$ at $50 \mathrm{~cm}$ for 72.43 Hours

1108 mrem Neutron Exposure

\begin{tabular}{|c|c|c|c|c|c|c|c|c|c|c|c|c|}
\hline \multirow{2}{*}{$\begin{array}{l}\text { Ident. } \\
\text { Number }\end{array}$} & \multirow{2}{*}{$\begin{array}{c}\text { Seq. } \\
\text { Number }\end{array}$} & \multicolumn{5}{|c|}{ Adjusted Chip Counts } & \multirow[b]{2}{*}{ R3-R5 } & \multirow[b]{2}{*}{ B4-R5 } & \multirow[b]{2}{*}{ R3/R4 } & \multicolumn{3}{|c|}{ Badiation Dose in mrem } \\
\hline & & Chin 1 & Chipe & Chip 3 & Chin 4 & Chip 5 & & & & Shallow & Deen & Neutren \\
\hline ED165 & 1784 & 408 & 356 & 4695 & 4677 & 245 & 4450 & 4432 & 1.004 & 240 & 220 & 1920 \\
\hline ED166 & 1778 & 401 & 367 & 5622 & 4584 & 271 & 5351 & 4313 & 1.241 & 230 & 220 & 1890 \\
\hline ED202 & 1793 & 403 & 374 & 6353 & 4911 & 265 & 6088 & 4646 & 1.310 & 230 & 230 & 2040 \\
\hline ED203 & 1790 & 413 & 376 & 5031 & 4179 & 247 & 4784 & 3932 & 1.217 & 230 & 230 & 1720 \\
\hline ED204 & 1804 & 360 & 333 & 4619 & 3952 & 230 & 4389 & 3722 & 1.179 & 200 & 200 & 1620 \\
\hline ED205 & 1799 & 368 & 358 & 5299 & 4154 & 232 & 5067 & 3922 & 1.292 & 220 & 220 & 1720 \\
\hline ED206 & 1774 & 385 & 354 & 5465 & 4052 & 240 & 5212 & 3812 & 1.367 & 220 & 210 & 1680 \\
\hline ED208 & 1770 & 390 & 417 & 5308 & 4304 & 243 & 5065 & 4061 & 1.247 & 250 & 250 & 1780 \\
\hline ED233 & 1795 & 392 & 375 & 5389 & 4239 & 261 & 5128 & 3978 & 1.289 & 230 & 230 & 1740 \\
\hline D234 & 1785 & 388 & 364 & 6520 & 4679 & 254 & 6266 & 4425 & 1.416 & 220 & 220 & 1950 \\
\hline D235 & 1780 & 363 & 353 & 5627 & 4502 & 242 & 5385 & 4260 & 1.264 & 210 & 210 & 1870 \\
\hline & & & & & & Average & 5199 & 4137 & 1.257 & & & 1812 \\
\hline
\end{tabular}

Mound Badge Resulis

$\begin{array}{lllllllllllll}\text { ED210 } & 1800 & 421 & 390 & 2576 & 4327 & 275 & 2301 & 4052 & 0.568 & 240 & 230 & 1760 \\ \text { ED212 } & 1775 & 430 & 415 & 2779 & 4868 & 294 & 2485 & 4574 & 0.543 & 250 & 250 & 1980 \\ \text { ED229 } & 1771 & 413 & 402 & 2612 & 4249 & 271 & 2341 & 3978 & 0.589 & 250 & 250 & 1780 \\ \text { ED231 } & 1791 & 397 & 365 & 2576 & 4294 & 275 & 2301 & 4019 & 0.573 & 230 & 220 & 1740 \\ \text { ED232 } & 1805 & 431 & 405 & 2582 & 4736 & 295 & 2387 & 4441 & 0.538 & 240 & 240 & 1930 \\ & & & & & & \text { Average } & 4213 & 2413 & 0.562 & & & 1838\end{array}$

Cr-39 Results

\begin{tabular}{|c|c|c|c|c|c|c|}
\hline DESCB & $\begin{array}{c}\text { Net } \\
\text { Irk/em }\end{array}$ & $\begin{array}{l}\text { Ave Net } \\
\text { Irk/cm }\end{array}$ & mrem & $\begin{array}{c}\text { Average } \\
\text { mrem }\end{array}$ & $\begin{array}{c}\text { Standard } \\
\text { Dev } \\
\end{array}$ & $\operatorname{cv}(\%)$ \\
\hline A5 & 3014 & & 1210 & & & \\
\hline A5 & 3014 & & 1210 & & & \\
\hline A5 & 2797 & 2942 & 1123 & 1181 & 50.2 & 4.3 \\
\hline A6 & 3047 & & 1223 & & & \\
\hline A6 & 3177 & & 1276 & & & \\
\hline A6 & 3057 & 3093 & 1228 & 1242 & 29.3 & 2.4 \\
\hline A7 & 3089 & & 1241 & & & \\
\hline A7 & 3147 & & 1264 & & & \\
\hline A7 & 2949 & 3062 & 1184 & 1230 & 41.2 & 3.4 \\
\hline A8 & 3386 & & 1360 & & & \\
\hline A8 & 3154 & & 1267 & & & \\
\hline \multirow[t]{2}{*}{$A 8$} & 3164 & 3235 & 1271 & 1299 & 52.6 & 4.1 \\
\hline & Average & 3085 & & 1238 & 58.0 & 4.7 \\
\hline
\end{tabular}


Plutonium Fluoride Source

$5.08 \mathrm{~cm}$ PL* at $50 \mathrm{~cm}$ for 70.03 Hours 693 mrem Neutron Exposure

\begin{tabular}{|c|c|c|c|c|c|c|c|c|c|c|c|c|}
\hline \multirow{2}{*}{$\begin{array}{l}\text { ldent. } \\
\text { Number }\end{array}$} & \multirow{2}{*}{$\begin{array}{l}\text { Seq. } \\
\text { Number }\end{array}$} & \multicolumn{5}{|c|}{ Adjusted Chip Counts } & \multirow[b]{2}{*}{$B 3-B 5$} & \multirow[b]{2}{*}{$\mathrm{B} 4-\mathrm{R} 5$} & \multirow[b]{2}{*}{ B3/R4 } & \multicolumn{3}{|c|}{ Badiation Dose in mrem } \\
\hline & & Chip 1 & Chip 2 & Chip 3 & Chip 4 & Chip 5 & & & & Shallow & Deep & Neutron \\
\hline ED244 & 1769 & 490 & 552 & 8698 & 5872 & 328 & 8370 & 5544 & 1.510 & 320 & 320 & 2450 \\
\hline ED245 & 1798 & 442 & 414 & 8003 & 5125 & 285 & 7718 & 4840 & 1.595 & 240 & 240 & 2150 \\
\hline ED251 & 1782 & 430 & 426 & 8728 & 6342 & 297 & 8431 & 6045 & 1.395 & 250 & 250 & 2660 \\
\hline ED252 & 1796 & 483 & 454 & 9932 & 6914 & 345 & 9587 & 6569 & 1.459 & 270 & 270 & 2900 \\
\hline ED256 & 1773 & 494 & 442 & 8922 & 6249 & 309 & 8613 & 5940 & 1.450 & 280 & 260 & 2620 \\
\hline ED257 & 1797 & 487 & 447 & 9105 & 5853 & 306 & 8799 & 5547 & 1.586 & 270 & 260 & 2460 \\
\hline ED261 & 1787 & 474 & 458 & 11008 & 6872 & 328 & 10680 & 6544 & 1.632 & 270 & 270 & 2890 \\
\hline ED300 & 1788 & 503 & 455 & 11114 & 7211 & 341 & 10773 & 6870 & 1.568 & 290 & 270 & 3050 \\
\hline ED310 & 1803 & 445 & 418 & 11095 & 6142 & 305 & 10790 & 5837 & 1.849 & 250 & 250 & 2610 \\
\hline ED329 & 1789 & 463 & 428 & 91056 & 7190 & 313 & 10743 & 6877 & 1.562 & 260 & 250 & 3040 \\
\hline ED330 & 1783 & 463 & 420 & 11012 & 7109 & 310 & 10702 & 6799 & 1.574 & 260 & 250 & 3000 \\
\hline & & & & & & Average & 9564 & 6128 & 1.562 & & & 2712 \\
\hline
\end{tabular}

Mound Badoe Results

$\begin{array}{lllllllllllll}\text { ED254 } & 1801 & 513 & 485 & 4882 & 6014 & 358 & 4524 & 5656 & 0.800 & 290 & 290 & 2450 \\ \text { ED255 } & 1777 & 496 & 484 & 4770 & 6688 & 358 & 4412 & 6330 & 0.697 & 290 & 290 & 2740 \\ \text { ED262 } & 1792 & 464 & 446 & 4812 & 6132 & 347 & 4465 & 5785 & 0.772 & 260 & 260 & 2510 \\ \text { ED263 } & 1802 & 506 & 475 & 4757 & 6213 & 366 & 4391 & 5847 & 0.751 & 290 & 280 & 2530 \\ \text { ED266 } & 1768 & 489 & 468 & 5391 & 7113 & 350 & 5049 & 6763 & 0.745 & 280 & 280 & 2930 \\ & & & & & & \text { Average } & 4567 & 6072 & 0.753 & & & 2632\end{array}$

Cr-39 Resulks

\begin{tabular}{|c|c|c|c|c|c|c|}
\hline DESCR & $\begin{array}{c}\text { Net } \\
\text { Irk/em }\end{array}$ & $\begin{array}{l}\text { Ave Net } \\
\text { Irk/am }\end{array}$ & mrem & $\begin{array}{c}\text { Average } \\
\text { mrem }\end{array}$ & $\begin{array}{l}\text { Standard } \\
\text { Dev }\end{array}$ & CV $(\%)$ \\
\hline A1 & 2469 & & 992 & & & \\
\hline A1 & 2524 & & 1008 & & & \\
\hline A1 & 2537 & 2510 & 1019 & 964 & 13.6 & 1.4 \\
\hline A2 & 2362 & & 948 & & & \\
\hline A2 & 2504 & & 1006 & & & \\
\hline A2 & 2339 & 2402 & 939 & 964 & 36.4 & 3.8 \\
\hline$A 3$ & 2757 & & 1107 & & & \\
\hline A3 & 2892 & & 1161 & & & \\
\hline A3 & 2739 & 2796 & 1100 & 1123 & 33 & 3.0 \\
\hline A4 & 2059 & & 827 & & & \\
\hline A4 & 2577 & & 1035 & & & \\
\hline \multirow[t]{2}{*}{ A4 } & 2292 & 2309 & 920 & 927 & 104.2 & 11.2 \\
\hline & Average & 2504 & & 1005 & 91.2 & 9.1 \\
\hline
\end{tabular}

C.11 
Plutonium Metal anode $4981508 \mathrm{~g}$

Bare at $50 \mathrm{~cm}$ for 234.87 Hours

146 mrem Neutron Exposure

Ident. Seq. Adiustext Chip Count

Number Number Chin1 Chin2 Chin3 Chind Chins B3-R5 B4-R5 B3/R4

ED592

ED594

ED597

ED598

ED599

ED600

ED601

ED602

ED603

ED604

ED605
64417

$\begin{array}{llll}64415 & 822 & 767 & 737\end{array}$

64411784

$64410 \quad 87$

64409

64408

64406

64405

64404

64403 $\begin{array}{llll}64412 & 801 & 756 & 744\end{array}$
744

792767

807

821

843

622

631

634

\section{3}

666382

681381

$633 \quad 381$

$657 \quad 404$

$739 \quad 418$

$663 \quad 401$

527

$524 \quad 315$

$499 \quad 293$

Average
$694 \quad 386$

\section{7}

355

363

307

381

378

360

317

343

347

365

351
$279 \quad 1.244$

$270 \quad 1.315$

$300 \quad 1.210$

$252 \quad 1218$

$308 \quad 1.237$

$253 \quad 1.494$

$233 \quad 1.472$

$209 \quad 1.660$

$206 \quad 1.772$

$263 \quad 1.359$
$321 \quad 1.121$

2621210
Badiation Dose in mrem

Shallow Deep Neutron

$460 \quad 400 \quad 120$

$440 \quad 420 \quad 120$

$430 \quad 410 \quad 130$

$420 \quad 410 \quad 110$

\begin{tabular}{l}
$470 \quad 430 \quad 130$ \\
\hline
\end{tabular}

$500 \quad 440 \quad 110$

$510 \quad 450 \quad 140$

$510 \quad 460 \quad 110$

$370 \quad 370 \quad 100$

$370 \quad 370 \quad 90$

$380 \quad 380 \quad 90$

Mound Badge Results

$\begin{array}{lllllllllllll}\text { ED606 } & 64402 & 520 & 486 & 442 & 593 & 299 & 143 & 294 & 0.486 & 290 & 290 & 130 \\ \text { ED607 } & 64401 & 737 & 714 & 517 & 687 & 382 & 135 & 305 & 0.443 & 430 & 430 & 130 \\ \text { ED608 } & 64400 & 761 & 720 & 520 & 667 & 392 & 128 & 275 & 0.465 & 410 & 400 & 120 \\ \text { ED609 } & 64399 & 787 & 754 & 535 & 743 & 413 & 122 & 330 & 0.370 & 450 & 450 & 140 \\ \text { ED610 } & 64398 & 804 & 749 & 521 & 677 & 401 & 120 & 276 & 0.435 & 440 & 410 & 120 \\ & & & & & & \text { Average } & 130 & 296 & 0.440 & & 128\end{array}$

Cr-39Results

\begin{tabular}{|c|c|c|c|c|c|c|}
\hline DESCR & $\begin{array}{c}\text { Not } \\
\text { Irk/am }\end{array}$ & $\begin{array}{l}\text { Average } \\
\text { Irk/em }^{2}\end{array}$ & mrem & $\begin{array}{c}\text { Average } \\
\text { mrem }\end{array}$ & $\begin{array}{l}\text { Standard } \\
\text { Dev }\end{array}$ & CV $(\%)$ \\
\hline D1 & 387 & & 154 & & & \\
\hline D1 & 345 & & 137 & & & \\
\hline D1 & 357 & 366 & 146 & 146 & 8.5 & 5.8 \\
\hline D2 & 322 & & 128 & & & \\
\hline D2 & 305 & & 121 & & & \\
\hline D2 & 362 & 330 & 144 & 131 & 11.8 & 9.0 \\
\hline D3 & 295 & & 117 & & & \\
\hline D3 & 342 & & 137 & & & \\
\hline D3 & 332 & 323 & 128 & 127 & 10.0 & 7.9 \\
\hline D4 & 435 & & 173 & & & \\
\hline D4 & 340 & & 135 & & & \\
\hline \multirow[t]{2}{*}{ D4 } & 310 & 362 & 123 & 144 & 26.1 & 18.2 \\
\hline & Average & 345 & & 137 & 15.8 & 11.5 \\
\hline
\end{tabular}


Plutonium Oxide Source ID ARF-102-90-01 846.6 g Pu

Bare at $50 \mathrm{~cm}$ for 187.83 Hours

81.0 mrem Neutron Exposure

\begin{tabular}{|c|c|c|c|c|c|c|c|c|c|c|c|c|}
\hline \multirow{2}{*}{$\begin{array}{l}\text { Ident. } \\
\text { Number }\end{array}$} & \multirow{2}{*}{$\begin{array}{l}\text { Seq. } \\
\text { Number }\end{array}$} & \multicolumn{5}{|c|}{ Adiusted Chio Counts } & \multirow[b]{2}{*}{$\mathrm{B} 3 \cdot \mathrm{B5}$} & \multirow[b]{2}{*}{ B4-R5 } & \multirow[b]{2}{*}{ B3/B4 } & \multicolumn{3}{|c|}{ Radiation Dose in mrem } \\
\hline & & Chio 1 & Chin 2 & Chin 3 & Chip 4 & Chin 5 & & & & Shallow & Deep & Neutron \\
\hline ED298 & 64395 & 551 & 467 & 533 & 507 & 341 & 192 & 166 & 1.160 & 320 & 280 & 70 \\
\hline ED304 & 64394 & 546 & 486 & 546 & 500 & 349 & 197 & 151 & 1.300 & 320 & 290 & 70 \\
\hline ED308 & 64393 & 533 & 495 & 567 & 533 & 350 & 217 & 183 & 1.190 & 300 & 300 & 80 \\
\hline ED309 & 64391 & 514 & 478 & 531 & 476 & 341 & 190 & 135 & 1.410 & 290 & 290 & 60 \\
\hline ED419 & 64390 & 553 & 487 & 549 & 541 & 354 & 195 & 187 & 1.040 & 320 & 290 & 80 \\
\hline ED457 & 64389 & 578 & 510 & 555 & 519 & 366 & 189 & 153 & 1.240 & 330 & 310 & 70 \\
\hline ED460 & 64388 & 606 & 533 & 528 & 506 & 357 & 171 & 149 & 1.150 & 350 & 320 & 60 \\
\hline ED463 & 64387 & 597 & 530 & 565 & 525 & 364 & 201 & 161 & 1.250 & 340 & 320 & 70 \\
\hline & & & & & & Average & 194 & 161 & 1.359 & & & 70 \\
\hline
\end{tabular}

Mound Badge Results

Lost Results-Badges Fell on Floor

Cr-32Results

\begin{tabular}{|c|c|c|c|c|c|c|}
\hline DESCB & $\begin{array}{c}\text { Not } \\
\text { Irk/em }\end{array}$ & $\begin{array}{l}\text { Average } \\
\text { Ink/am² }\end{array}$ & mrem & $\begin{array}{c}\text { Average } \\
\text { mrem }\end{array}$ & $\begin{array}{c}\text { Standard } \\
\text { Dey }\end{array}$ & cV $(\%)$ \\
\hline B7 & 206 & & 80 & & & \\
\hline B7 & 181 & & 70 & & & \\
\hline B7 & 191 & 193 & 74 & 75 & 5.0 & 6.7 \\
\hline B8 & 173 & & 68 & & & \\
\hline 88 & 171 & & 67 & & & \\
\hline \multirow[t]{2}{*}{ B8 } & 214 & 186 & 83 & 73 & 9.0 & 12.3 \\
\hline & Average & 189.5 & & 74 & 6.6 & 9.0 \\
\hline
\end{tabular}

C.13 
Background Measurement -234-5 Bldg Rm 179C

Exposure 336 Hours 29.1 mrem Neutron Exposure

Ident. Seq.

Adiusted Chio Counts Number Number Chip1 Chin2 Chip3 Chip4 Chins B3-B5 B4-B5 B3/R4

Badiation Dose in mrem 156

80

200

146

$196 \quad 150$

ED136

$\begin{array}{lll}92151 & 167 & 138\end{array}$

ED137

$92150 \quad 163 \quad 138$

$188 \quad 135$

ED205

$92149 \quad 163 \quad 137$

$201 \quad 143$

$177 \quad 143$

$216 \quad 169$

ED206

92148

92147

$165 \quad 152$

ED235

92146

$174 \quad 136$

$207 \quad 150$

$246 \quad 193$

$217 \quad 163$

$234 \quad 194$

$212 \quad 17$

ED399

92145

$182 \quad 152$

92144

$259 \quad 166$

212

174
159

52
49
44
42
53
42
50
51
45
51
44
Average

148

147

144

149

163

165

196

166

189

161

94

$94 \quad 1.57$

Sellow Neutron

ED411

$92141 \quad 210 \quad 138$

Average

184

$91 \quad 1.58$

$101 \quad 1.48$

$116 \quad 1.41$

$108 \quad 1.53$

$143 \quad 1.37$

$112 \quad 1.48$

$149 \quad 1.27$

$123 \quad 1.31$

1.31
1.60

1.60

Mound Badoe Results

$\begin{array}{lllllllllllll}\text { ED412 } & 92140 & 173 & 152 & 141 & 175 & 64 & 77 & 111 & 0.69 & 80 & 70 & 50 \\ \text { ED413 } & 92139 & 126 & 102 & 122 & 155 & 47 & 75 & 108 & 0.69 & 60 & 50 & 50 \\ \text { ED416 } & 92138 & 109 & 88 & 130 & 154 & 40 & 90 & 114 & 0.79 & 50 & 40 & 50 \\ \text { ED451 } & 92137 & 124 & 118 & 165 & 208 & 50 & 115 & 158 & 0.73 & 60 & 50 & 70 \\ \text { ED454 } & 92136 & 176 & 144 & 158 & 183 & 56 & 102 & 127 & 0.80 & 90 & 70 & 50 \\ & & & & & & \text { Average } & 92 & 124 & 0.74 & & & 54\end{array}$

\section{Cr-39Results}

\begin{tabular}{|c|c|c|c|c|c|c|c|}
\hline DESCB & $\begin{array}{c}\text { Net } \\
\text { Ink/am }\end{array}$ & $\begin{array}{l}\text { Average } \\
\text { Irk/cm }^{2}\end{array}$ & mrem & $\begin{array}{c}\text { Average } \\
\text { mrem }\end{array}$ & $\begin{array}{c}\text { Standard } \\
\text { Dey }\end{array}$ & CV $(\%)$ & \\
\hline M0001 & 56 & & 9 & & & & \\
\hline Mo001 & 40 & & 7 & & & & \\
\hline Mo004 & 105 & 67 & 17 & 11 & 5.3 & 48.2 & \\
\hline M0002 & 72 & & 12 & & & & \\
\hline MO002 & 105 & & 17 & & & & \\
\hline MO002 & 40 & 72 & 7 & 12 & 5.0 & 41.7 & \\
\hline M0003 & 72 & & 12 & & & & \\
\hline M0003 & 72 & & 12 & & & & \\
\hline M0003 & 89 & 78 & 15 & 13 & 1.7 & 13.3 & \\
\hline M0004 & 105 & & 17 & & & & \\
\hline M0004 & 56 & & 9 & & & & \\
\hline M0004 & 89 & 83 & 15 & 14 & 4.2 & 30.4 & \\
\hline M0005 & 89 & & 15 & & & & \\
\hline M0005 & 56 & & 9 & & & & \\
\hline MoOOE: & 56 & 67 & 9 & 11 & 3.5 & 31.5 & \\
\hline MOOOE & 40 & & 7 & & & & \\
\hline M0006 & 56 & & 9 & & & & \\
\hline M0006 & 56 & 51 & 9 & 8 & 1.2 & 13.9 & ' \\
\hline & Average & 69.7 & & 11.5 & 3.7 & 31.7 & 39105051.13 \\
\hline
\end{tabular}




\section{DISTRIBUTION}

No. of

Copies

\section{OFFSITE}

12 Office of Scientific and Technical Information

\section{R. Brake}

Los Alamos National Laboratory P.0. Box 1663

Mail Stop $\mathrm{K} 483$

Los Alamos, NM 87544

J. C. Clark

Lawrence Livermore National Laboratory

P.0. Box L-383

Livermore, CA 94550

S. Clow

U.S. Department of Energy

Albuquerque Field office

P.0. Box 5400

Albuquerque, NM 87115

J. Cortes

Los Alamos National Laboratory

P.0. Box 1663

Los Alamos, NM 87544

L. Coulson

SSC Laboratory

2550 Beckleymeade Ave.

Suite 125, MS-1071

Dallas, TX 75237

K. W. Crase

Health Protection Department

Savannah River Site

Bldg. 735-11A

P.0. Box 616

Aiken, SC 29802

S. W. Crositin

Oak Ridge National Laboratory

P.0. Box 2008

Oak Ridge, TN 37831-6105
No. of

Copies

R. Cummings

U.S. Department of Energy

Radiological \& Environmental

Sciences Lab CF690

785 DOE Place

Idaho Falls, ID 83402-4149

R. T. Devine

Los Alamos National Laboratory

P.0. Box 1663

Mail Stop 808

Los Alamos, NM 87544

R. B. Falk

EG\&G Rocky Flats

Rocky Flats Plant

P.0. Box 464

Golden, CO 80402-0464

J. D. Foulke

Office of Health (EH-411)

U.S. Department of Energy

Washington, DC 20555

P. Fulmer

U.S. Department of Energy

Albuquerque Field office

P. 0. Box 5400

Albuquerque, NM 87115

R. Gooley

Los Alamos National Laboratory

P.0. Box 1663

Los Alamos, NM 87544

R. E. Halliburton

Oak Ridge National Laboratory

P. 0. Box 2008

Bldg 2007, MS-6042

Oak Ridge, TN 37831-6105 
No. of

Copies

W. Harvey

Los Alamos National Laboratory

P.0. Box 1663

Mail Stop K483

Los Alamos, NM 87544

$R$. Jones

Reynolds Electric \&

Engineering $\mathrm{C}_{0}$. , Inc.

P.0. Box 98521

Las Vegas, NV 89192-8521.

P. N. Koch

Reynolds Electric \&

Engineering $\mathrm{C}_{0}$. , Inc.

P.0. Box 98521

Las Vegas, NV 89192-8521

D. G. Linkenheil

Radiological Engineering

EG\&G Rocky Flats

P.0. Box 464

Golden, CO 80402-0464

J. C. Liu

Stanford Linear Accelerator Center

SLAC BIN-48

P.0. Box 4349

Stanford, CA 94309

R. M. Loesch

Office of Health (EH-40)

U.S. Department of Energy

Washington, DC 20545

Lt. Col. Edward Maher

USAF AL/OEBS Brooks AFB

San Antonio, TX 78235

K. L. McMahan

Oak Ridge National Laboratory

Mart in Mariette Energy

Systems, Inc.

P.0. Box 2008

Oak Ridge, TN 37831-6105
No. of

Coptes

W. M. Quam

EG\&G Energy Measurements

P.0. BoX 98

Goleta, CA 93116-0098

J. Rabovsky

Office of Health (EH-40)

U.S. Department of Energy

Washington, DC 20555

C. S. Sims

Oak Ridge National Laboratory

P.0. Box 2008

Oak Ridge, TN 37831-6379

L. S. Sygitowicz

Reynolds Electric \&

Engineering $\mathrm{C}_{0} .$, Inc.

P.0. Box 98521

Las Vegas, NV 89192-8521

M. L. Souleyrette

Martin Marietta Energy Systems

$Y-12$ Plant

Oak Ridge, TN 37830

D. J. Thompson

Organization 3313

Sandia National Laboratory

Albuquerque, NM 87185

D. G. Vasilik

Los Alamos National Laboratory

P.0. Box 1663

Los Alamos, NM 87545

I. J. Wells

Reynolds Electric \& Engineering $\mathrm{C}_{0} .$, Inc.

P.0. Box 98521

Las Vegas, NV 89192-8521

M. K. Winegardner

EG\&G Mound Applied Technologies

Bldg. 91

P.0. Box 3000

Miamisburg, $\mathrm{OH}$ 45343-3000

Distr.2 
No. of

Copies

FOREIGN

$$
\begin{aligned}
& \text { J. L. Chartier } \\
& \text { CEA-IPSN/DPHD-SDOS } \\
& \text { B. P. No. } 6 \text { F }-92265 \\
& \text { Fonteay-aux-Roses, Cedex } \\
& \text { France }
\end{aligned}
$$

R. V. Griffith

Department of Nuclear

IAEA

Energy and Safety

P.0. Box $200 \cdot A-1000$

Vienna, Austria

H. G. Menzel

Commission of the European Communities

$D G X I I / D / 3$

Rue de la Loi 200

B-1049 Brussels

Belgium

S. Guldbakke

Physikal isch-Technische Bundesanstalt

Labor 7.21

Bundesa7lee $100 \mathrm{~W}-3300$

Braunscheweig

Federal Republic of Germany
No. of

Coptes

H. Schuhmacher

Phys ikal isch-Technische Bundesaristalt

Labor 7.52

Bundesallee $100 \mathrm{~W}-3300$

Braunscheweig

Federal Republic of Germany

L. Tommasino

ENEA/DISP

Via Vitaliano Brancati

48 I-00144 Rome

Italy

\section{ONSITE}

4 U.S. Department of Energy Richland Field office

P. K. Clark

D. T. Evans

R. A. Holton

J. R. Yesberger

Kaiser Engineers Hanford

D. J. Foust 
No. of

Copies

8 Westinghouse Hanford Company

D. S. Cunningham

F. D. Fischer

W. A. Decker, Jr. (3)

R. E. Heineman

T. J. Kelly

J. A. Schur

48 Pacific Northwest Laboratory

W. J. Bair

W. V. Baumgartner (5)

L. W. Brackenbush (5)

G. L. Carter

A. W. Endres

G.W.R. Endres

L. G. Faust

J. J. Fix (5)

D. M. Fleming

T. J. Forelich

D. J. Hanley

D. F. Higby
No. of

Copies

C. D. Hooker

J. R. Houston

J. R. Johnson

J. A. Leonowich

M. Lyon

J. C. McDonald

L. L. Nichols

C. L. Oxley

M. A. Parkhurst

J. D. Peters

S. R. Reese

R. I. Scherpelz

J. M. Selby

K. L. Soldat

E. E. Stapleton

J. E. Tanner

Health Physics Library

External nosimetry Historical Fields (c/o V. L. Brerdt)

Publication Coordination

Technical Publications (5) 

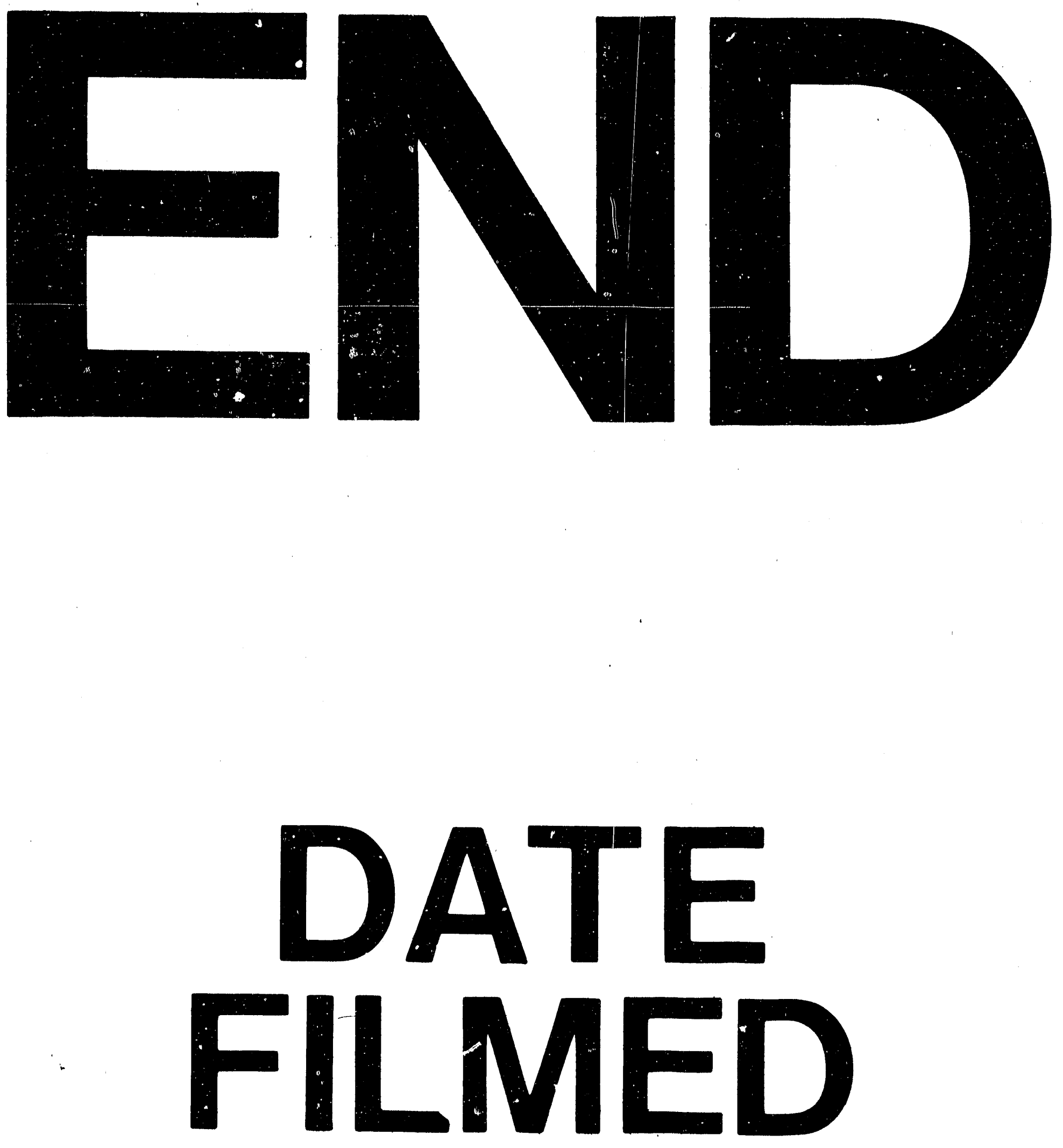

$\bar{t}$

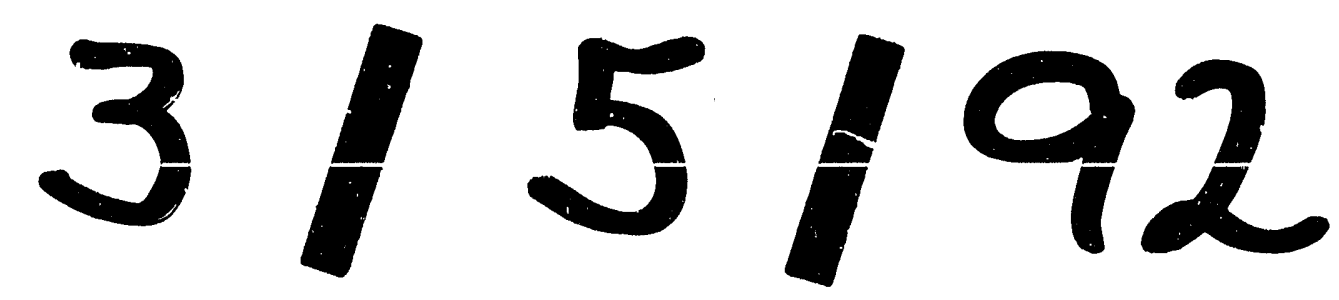


